\title{
NCCARF
}

National

Climate Change Adaptation

Research Facility

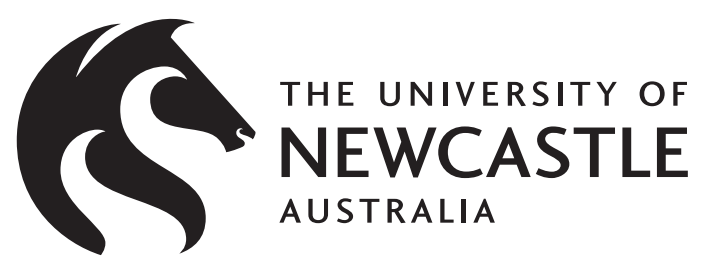

\section{Climate change adaptation and the rental sector}

Final Report

Lesley Instone, Kathleen Mee, Jane Palmer,

Miriam Williams and Nicola Vaughan 



\title{
CLIMATE CHANGE ADAPTATION AND THE RENTAL SECTOR
}

Rental housing, climate change and adaptive capacity: A case study of Newcastle, NSW

\section{Centre for Urban and Regional Studies University of Newcastle}

\author{
AUTHORS \\ Lesley Instone \\ Kathleen Mee \\ Jane Palmer \\ Miriam Williams \\ Nicola Vaughan
}

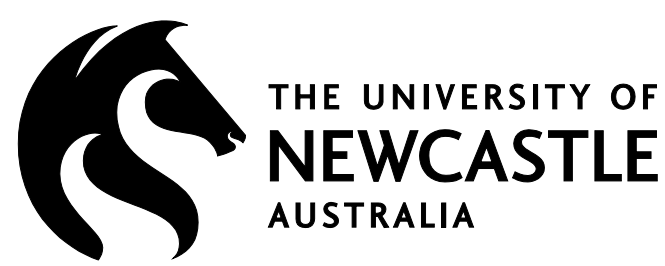




\section{Published by the National Climate Change Adaptation Research Facility 2013}

ISBN: 978-1-925039-11-5 NCCARF Publication 40/13

Australian copyright law applies. For permission to reproduce any part of this document, please approach the authors.

\section{Please cite this report as:}

Instone, L, Mee, K, Palmer, J, Williams, M \& Vaughan, N 2013, Climate change adaptation and the rental sector, National Climate Change Adaptation Research Facility, Gold Coast, 200 pp.

\section{Acknowledgement}

This work was carried out with financial support from the Australian Government (Department of Climate Change and Energy Efficiency) and the National Climate Change Adaptation Research Facility (NCCARF).

The role of NCCARF is to lead the research community in a national interdisciplinary effort to generate the information needed by decision-makers in government, business and in vulnerable sectors and communities to manage the risk of climate change impacts.

We wish to acknowledge the major contribution made to this research by those tenants and property managers who agreed to be interviewed and who participated in the Focus Groups and in the production of video clips for YouTube.

We also acknowledge the valuable contribution of the members of our project Steering Committee, who provided expert advice and guidance throughout the project:

- Mr Peter Dormand - Manager, Environment and Climate Change Services, Newcastle City Council, NSW

- Professor Robyn Dowling - Department of Environment and Geography, Faculty of Science, Macquarie University NSW

- Dr Geoff Evans - Environmental Security Coordinator, Sustainability Department, Lake Macquarie City Council, NSW

- Mr Ross Fallins - Assistant Manager, Asset Supply, Department of Finance and Services, Newcastle, NSW

- Mr Wayne Stewart - Past President, Real Estate Institute of NSW, Newcastle NSW.

\section{Disclaimer}

The views expressed herein are not necessarily the views of the Commonwealth or NCCARF, and neither the Commonwealth nor NCCARF accept responsibility for information or advice contained herein.

Cover image/s 'Rental Life' (c) 2013 Peter Lankas 


\section{TABLE OF CONTENTS}

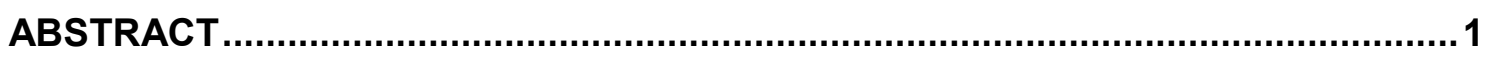

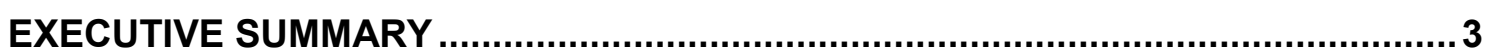

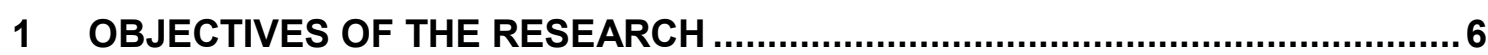

1.1 Background: The reason for undertaking this research ................................. 6

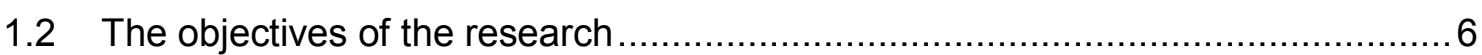

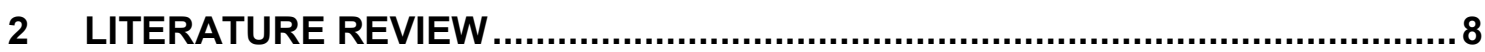

2.1 Introduction: Themes of the literature review ….......................................... 8

2.2 Asset-Based Community Development..................................................... 8

2.3 Pro-poor Asset-based Climate Change Adaptation......................................... 10

2.4 Combining asset based and pro-poor approaches...................................... 11

2.5 Vulnerability, resilience and adaptation: A climate justice approach................... 12

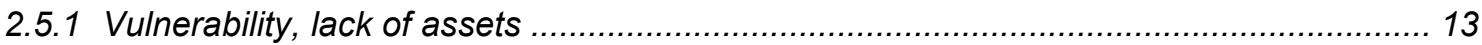

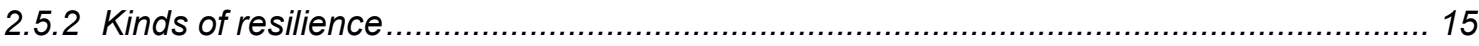

2.5.3 Multistranded approaches: More-than-adaptation ...................................................... 15

2.6 The role of the housing manager ............................................................. 17

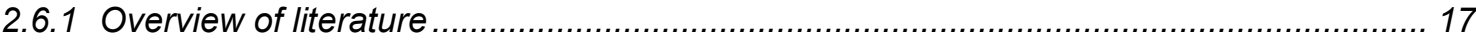

2.6.2 The work of housing managers/ housing management............................................. 19

2.6.3 Managing and influencing tenants, landlords, and relationships ................................. 21

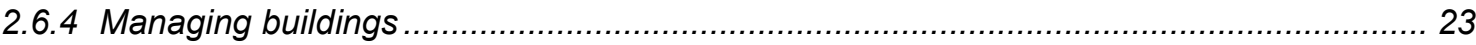

2.7 Tenants and theories of everyday practice and homemaking …...................... 25

3 RESEARCH ACTIVITIES AND METHODS .................................................... 27

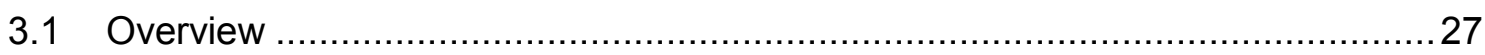

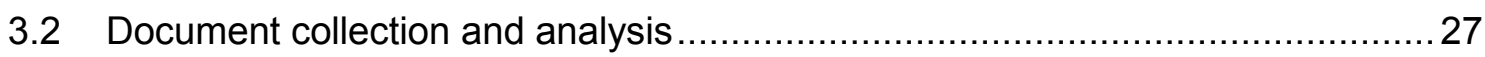

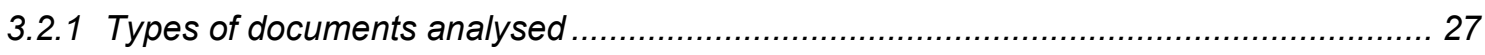

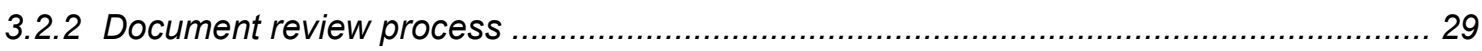

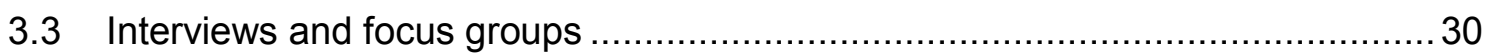



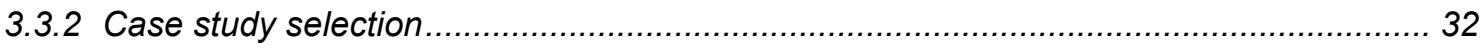

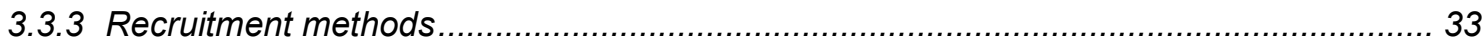

3.3.4 Recruitment

3.4 Conducting the interviews and focus groups............................................. 35

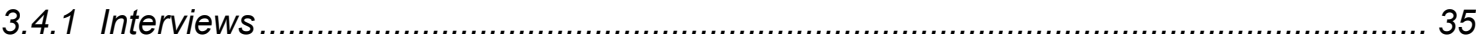

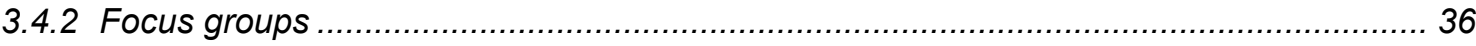




3.6 Enhancing adaptive capacities: Development of public resources ....................37

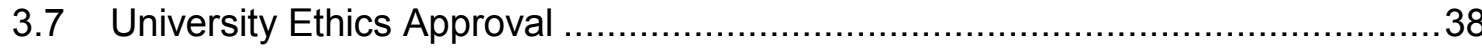

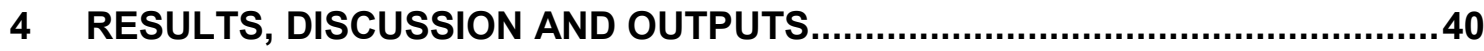

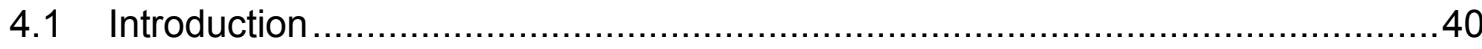

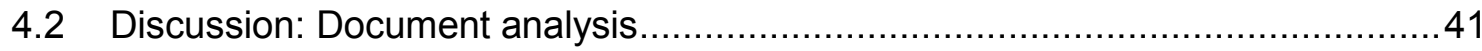

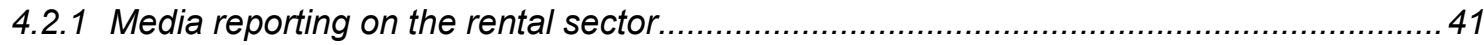

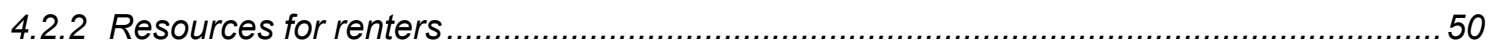

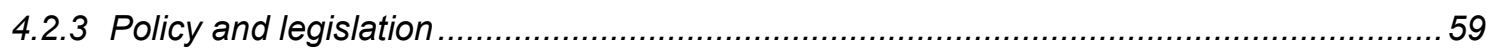

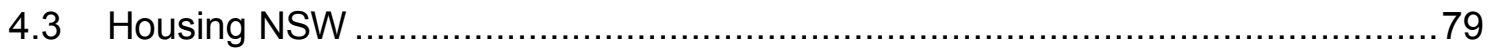

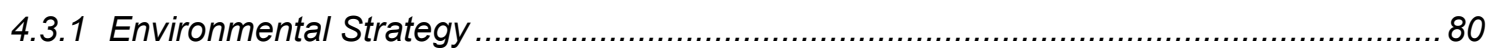

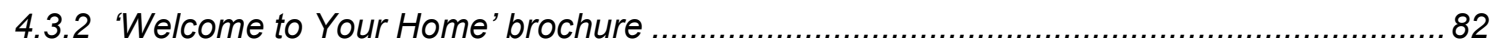

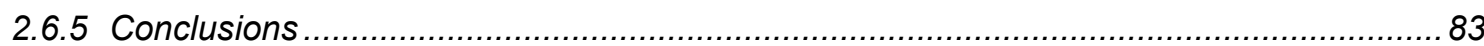

4.4 Climate change adaptation and rental housing in Newcastle: analysis of

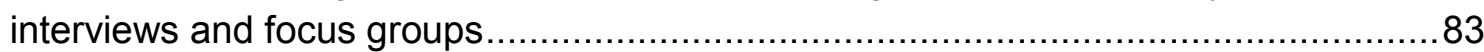

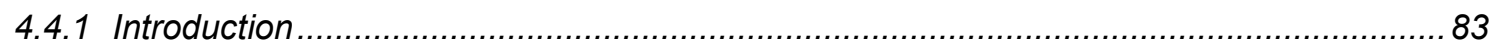

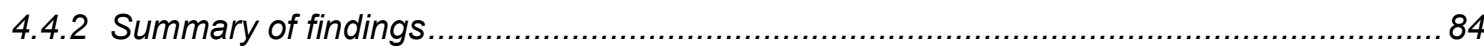

4.4.3 Assets: Tenants' understanding and commitment to sustainability and climate change



4.4.4 Assets: Property managers' understanding and commitment to sustainability and climate

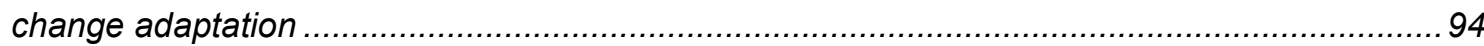

4.4.5 Assets: Action by tenants on climate change and sustainability ................................... 95

4.4.6 Assets: Action on climate change and sustainability by property managers ....................98

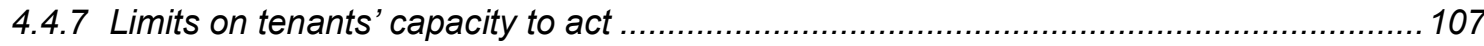

4.4.8 Limits on housing managers' and landlords' capacity to act ...................................... 117

4.4.9 'Unmaking unsustainability' in the rental sector: the roles of tenants, landlords, housing



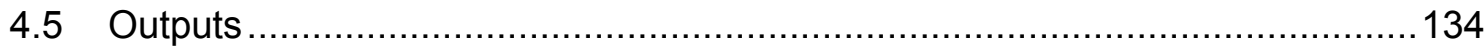

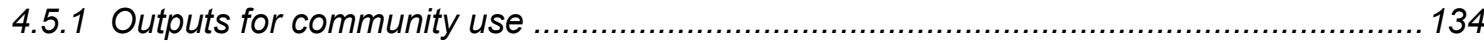

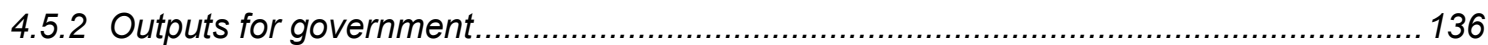



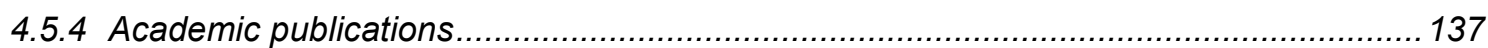

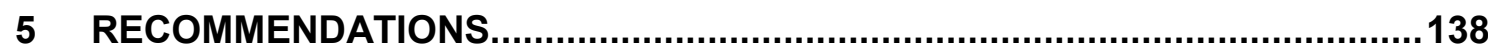

6 GAPS AND FUTURE RESEARCH DIRECTIONS .........................................142

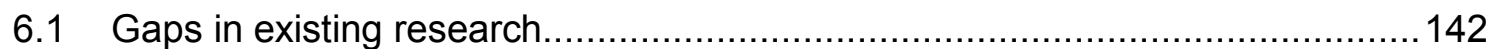

6.2 Future research directions .................................................................. 142

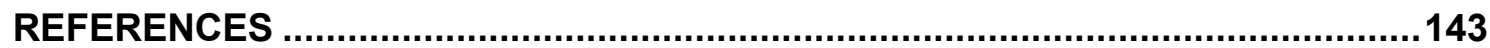

APPENDIX 1: LIST OF TENANT RESOURCE DOCUMENTS ANALYSED ............166

ii Climate change adaptation and the rental sector 
APPENDIX 2: LIST OF MEDIA DOCUMENTS ANALYSED . 168 APPENDIX 3: LIST OF LEGISLATIVE AND POLICY DOCUMENTS ANALYSED.. 172 APPENDIX 4: PRIVATE HOUSING MANAGER INTERVIEW SCHEDULES. 172 APPENDIX 5: PUBLIC HOUSING MANAGER INTERVIEW SCHEDULES .............. 193 APPENDIX 6: TENANT INTERVIEW SCHEDULES ........................................... 195 APPENDIX 7: FOCUS GROUP SCHEDULES .................................................... 198 APPENDIX 8: LIST OF COMMUNITY GROUPS CONTACTED TO RECRUIT TENANTS

\section{LIST OF TABLES}

Table 1: Document collection

Table 2: Interview and Focus Group participants

Table 3: Sustainability Practices... 47

Table 4: Suggested Tenant Practices. 55

Table 5: Housing NSW Sustainability Programs... 81 


\section{ABSTRACT}

The research employed an asset-based approach to understanding the capacities, assets and skills which tenants, landlords and housing managers bring to climate change adaptation. The project also took a pro-poor approach focusing on the adaptive capacity of low-income renters in the public and private sectors, addressing the equity dimensions of vulnerability and adaptation.

In addition to analysing a range of secondary sources such as media articles, 'green' guides and policy documents, the research analysed primary data from interviews and focus groups, focusing on:

1. The assets of the rental sector in adaptation

2. Barriers which limit the capacity of individuals and organisations to exercise these assets

3. The relationships between the stakeholders - tenants, landlords and property managers - which underlie both assets and barriers to adaptation.

We found that the tenants we interviewed were motivated by concern about the impact of human activity on the environment, and exercised this concern through everyday sustainable household practices, as well as through engagement with community or political organisations. They believed however that their capacity to act in the home was inhibited by a lack of care from some landlords and property managers about the sustainability of rental housing.

Public housing managers who were interviewed positioned the public housing sector as policy leaders in sustainability and adaptation, but as constrained by a lack of resources (human and financial) and the busy reactive nature of their work. Busyness and lack of resources was also seen as a constraint on private property managers' capacity to advocate or arrange for sustainability modifications to the properties they managed. Property managers emerged as crucial 'knowledge brokers' mediating between landlords and tenants, but expressed a need for more information and training.

Both tenants and property managers acknowledged that the current shortage of rental housing in many areas was one of the most important constraints on tenants' ability to influence the market through preference for more adaptive and sustainable housing.

The interviews and focus groups with tenants and property managers mapped out a strong asset base in the rental sector including: tenants' strong visions for the future; property managers' understandings of the tenant/landlord/property manager relationships, legislation, costing and procurement processes; organisational and community networks; and existing adaptive capacity already evident in the everyday practices.

The research report makes recommendations in the following areas:

- increased support for an enhanced role for property managers as advocates and knowledge brokers for sustainability and adaptation 
- incentives and education for landlords to see investment properties as 'ethical investments' to enable tenants to adapt to climate change

- increased overall supply of rental housing, particularly affordable rental housing

- increased assets for tenants to enable investments of time and money in a secure 'home'

- changes to tenancy conditions and better communication with landlords

- government action on regulatory change to support the above changes, including action on housing supply and a review of rental building sustainability standards. 


\section{EXECUTIVE SUMMARY}

Housing tenants, especially low-income tenants, are often forgotten when it comes to strategies that seek to lessen the impact of climate change on households. Rental housing comprises $27 \%$ of housing in Australia, is currently poorly adapted to climate change, incorporates the lowest quality housing which is over represented by lowincome earners and is the most vulnerable to climate change.

This research project sought to understand the adaptive capacity of rental housing, including potential adaptions by tenants, landlords and housing managers by asking:

- What adaptation strategies are tenants, housing managers and landlords currently undertaking?

- What assets do tenants, housing managers and landlords bring to adaptation?

- What are some of the barriers to adaptation?

- How might landlords, property managers, tenants, governments and NGOs work together to strengthen the adaptive capacity of rental housing in Australia?

The project resulted in the development of widely accessible resources such as YouTube clips, as well as a community implementation plan that included a bestpractice guide that supports the rental sector in acting on climate change.

The project employed an asset-based approach to understanding the capacities, assets and skills which tenants, landlords and housing managers bring to climate change adaptation. The project also took a pro-poor approach focusing on the adaptive capacity of low-income renters in the public and private sectors, and addresses equity dimensions of vulnerability and adaptation.

The research involved literature review of asset-based and pro-poor approaches to adaptation, the role of property managers in the rental sector and the role of everyday household practices in adaptation. Data analysed included secondary sources such as recent media articles on sustainability in the rental sector, sustainability resources already available for tenants, and policy and legislation affecting adaptation in the rental sector. Primary data sources included interviews and focus groups conducted with tenants and housing managers in the public and private rental sectors. The analysis focused on the following aspects of adaptation:

1. The assets of the rental sector in adapting to climate change, including existing everyday practices by tenants and property managers, existing capacities and commitments of individuals and organisations to sustainability and climate change adaptation

2. Barriers which limit the capacity of individuals and organisations to exercise these assets, including quality, availability and affordability of housing stock, attitudes of stakeholders to climate change adaptation, lack of resources (particularly financial resources), public perceptions of tenancy, and regulatory constraints

3. The relationships between the stakeholders - tenants, landlords and property managers - which underlie both assets and barriers to adaptation. 
The tenants we interviewed were motivated by concern about the impact of human activity on the environment, and exercised this concern through everyday sustainable household practices, as well as through engagement with community or political organisations. They believed however that their capacity to act in the home was inhibited by a lack of care from some landlords and property managers about the sustainability of rental housing.

Public housing managers positioned the public housing sector as policy leaders in sustainability and adaptation, but as constrained by a lack of resources (human and financial) and the busy reactive nature of their work. Busyness and lack of resources was also seen as a constraint on private property managers' capacity to advocate or arrange for sustainability modifications to the properties they managed. Property managers emerged as crucial 'knowledge brokers' mediating between landlords and tenants, but expressed a need for more information and training in order to be able to advocate effectively to landlords and influence tenant practices.

Both tenants and property managers acknowledged that the current shortage of rental housing in many areas, including the Newcastle area, was one of the most important constraints on tenants' ability to influence the market through preference for more adaptive and sustainable housing. The research identified a desire for more opportunities for tenants, housing managers and landlords to work together to address climate change in a way that would benefit all these groups and the environment.

The interviews with tenants and property managers mapped out a strong asset base in the rental sector which could be used in the sector's adaptation to climate change.

These assets included:

- tenants' strong visions of the future and understandings of what would make climate change adaptation more possible

- property managers' deep understanding of the possibilities of the tenant/landlord/property manager relationship, tenancy legislation and contracts, costing and procurement processes for maintenance and improvements to houses

- existing capacity on the part of both tenants and property managers to act on adaptation through everyday practices, despite structural, material or resource limitations

- networks which could be mobilised to support climate change adaptation. For tenants these networks included neighbourhood, community and political networks. For property managers these networks included networks within their institutions, professional training and information networks, and their role as 'knowledge brokers' for both landlords and tenants.

The research report makes recommendations in the following areas:

- increased support for an enhanced role for property managers as advocates and knowledge brokers for sustainability and adaptation in the rental sector

- incentives and education for landlords to see investment properties as 'ethical investments' which provide opportunities for tenants to practice sustainability and adapt to climate change 
- increased overall supply of rental housing, particularly affordable rental housing. Low vacancy rates and the fear of eviction inhibit adaptation in the rental sector

- increased assets for tenants to enable investments of time and money in a secure 'home' through short-term lease of installations such as solar panels or water tanks

- changes to tenancy conditions and better communication with landlords to enable, rather than inhibit, adaptive modifications by tenants such as gardens and water tank

- government action on regulatory change to support the above changes;

- government consideration of the Housing Supply Bonds proposal recently released by AHURI (Lawson et al. 2012), and different more sustainable housing models

- government review of rental building sustainability standards

- such changes need to be implemented with care and consultation with representatives of landlord, tenant and property manager groups. Investment in rental property sits alongside other potential investment strategies for landlords. When regulatory impositions appear too onerous landlords may choose to sell rental properties, and these may be lost to the sector. The loss of rental properties would inhibit adaptation in the rental sector. 


\section{OBJECTIVES OF THE RESEARCH}

\subsection{Background: The reason for undertaking this research}

Throughout the world, low-income groups are the most at risk from extreme weather events and other negative impacts of climate change (Moser 2011; Stanley 2009). In Australia, housing tenants, particularly low income tenants, are often forgotten when it comes to strategies that seek to lessen the impact of climate change on households. Rental housing comprises $27 \%$ of housing in Australia and is associated with low household income: "While in 2005-06 less than a quarter (23\%) of high income households were renting, around one-half (49\%) of households in the bottom quintile were renting" (Gabriel et al. 2010b: 22). The 'non-house' net worth of rental households in Australia is on average only one third that of homeowners (Gabriel et al. 2010a: 25, Table 5). Because of this wealth discrepancy, and the 'split incentive' which is an obstacle to landlord investment in upgrading buildings, rental housing is generally poorly adapted to climate change, incorporates the lowest quality housing and is the most vulnerable to climate change.

Rental housing therefore represents a high priority for intervention, but there are disincentives which impede climate change adaptation measures being adopted by landlords and advocated by property managers. The large and disparate nature of the sector and long lead times in making changes to housing stock and landlord-tenant cultures, mean that there is an urgent need for research to identify ways of overcoming barriers to adaptation in the rental sector.

This research project sought to understand the adaptive capacity of public and private tenants by asking:

- What adaptation strategies are tenants, housing managers and landlords currently undertaking?

- What assets do tenants, housing managers and landlords bring to adaptation?

- What are some of the barriers to adaptation?

- How might landlords, property managers, tenants, governments and NGOs work together to strengthen the adaptive capacity of rental housing in Australia?

These questions frame public and private housing tenants, landlords and housing managers as active agents (Mee 2009) with the capacities, skills and assets that can assist in their ability to adapt to climate change. By including a focus on the adaptive capacity of tenants, the project reflects both an asset based and pro-poor approach to climate change adaptation.

\subsection{The objectives of the research}

The objectives of the research were:

1. To employ an asset-based approach to climate change resilience in the rental housing sector in Newcastle, NSW

2. To identify the adaptive capacity of tenants to respond to climate change 
3. To identify the adaptive capacity of housing managers (private and public) and landlords to respond to the challenge of climate change in the rental housing sector

4. To link the capacities of tenants and housing managers/landlords to adapt to climate change

5. To identify productive entry-points for interventions which enhance adaptation responses in the rental housing sector.

The project encompassed the development of resources such as YouTube clips, and best-practice guides to support people acting on climate change in the rental sector. This report will inform housing management practices across Australia in adapting to climate change, and will be helpful to advocacy organisations such as Shelter, ACOSS and peak tenancy organisations. It will also be a useful resource for peak property bodies, such as the Real Estate Institute of Australia, and for local government including Newcastle and Lake Macquarie City Council. 


\section{LITERATURE REVIEW}

\subsection{Introduction: Themes of the literature review}

This section reviews theoretical literatures used to frame research in the project. The review examines those factors which enhance or are barriers to adaptive capacity, and hence focuses on the following key areas of interest:

- Asset-based community development (section 2.2)

- Pro-poor development (section 2.3)

- Combining an asset-based and pro-poor approach (section 2.4)

- Theories of vulnerability, adaptation and resilience and climate justice (section 2.5)

- The role of property managers in adaptation in the rental sector (section 2.6)

- Everyday practices of residents and homemaking (section 2.7).

\subsection{Asset-Based Community Development}

A 2006 OECD paper on 'Key Adaptation Concepts and Terms' (Levina and Tirpak 2006) included a widely accepted definition of adaptive capacity as "[t]he ability of a system to adjust to climate change..., to moderate potential damages, to take advantage of opportunities, or to cope with the consequences". It also defined 'capacity' as "[a] combination of all the strengths and resources available within a community, society or organisation that can reduce the level of risk, or the effects of a disaster" (2006: 8). The OECD paper pointed out that there is very little distinction in the literature between 'adaptive capacity' and 'coping capacity'(Levina and Tirpak 2006: 12), and concludes with a statement that points to the potential circularities in defining adaptive capacity, vulnerability and resilience:

It is important to clearly define the relationship between 'resilience', 'vulnerability', 'adaptive capacity', 'coping capacity' and 'coping range'. In the IPCC definition of resilience, this term seems to be closely related to 'coping range', since the emphasis of the definition is on the amount of change that the system can tolerate. Other definitions emphasise the 'ability' of a system,... [as] its 'coping and/or adaptive capacity' to tolerate change. 'Vulnerability' seems to largely[to] imply an inability to cope and 'resilience' seems to broadly imply an ability to cope. They may be viewed as two ends of a spectrum (Levina and Tirpak 2006: 15).

In an asset based approach to adaptive capacity, the focus is on 'capacity' - that "combination of all the strengths and resources available within a community" (Levina and Tirpak 2006: 8)- and supporting those community assets which enable adaptation, increase resilience and reduce vulnerability. It takes as a first principle that the more assets a community has, the greater its adaptive capacity and resilience, and the less vulnerable it is to the ill-effects of climate change (see Moser 2011).

Assets are the "natural, physical, social, financial and human capital" (Moser 2011: 6) that enable people to act and meet their needs. Assets grant people the "power to act 
and to reproduce, challenge or change the rules that govern the control, use and transformation of resources" (Bebbington 1999: 2022).

Asset-based Community Development (ABCD) is a community development theory, model and practice developed by Kretzmann and McKnight (1993) in the United States. $A B C D$ aims to enable people to identify their own assets and envisage ways they can use them to meet their own needs and the needs of their community (Haines and Green 2012). ABCD facilitates the creation of new stories that help communities recognise their strengths, challenging problematic constructions of places (or groups of people) as deficient (Ennis and West 2010; see also Bankoff 2001). ABCD is based on an understanding that "every single person has capacities, abilities and gifts" (Kretzmann and McKnight 1993: 13). The key principles of ABCD are:

...change must come from within the community; development must build upon the capacities and assets which exist within the community; change should be relationship driven, and change should be oriented towards sustainable community growth (Ennis and West 2010: 405).

Often in community development there is a focus on finding help from outside experts (Gibson-Graham 2006; Kretzmann and McKnight 1993). This has the potential to create a cycle of dependency on these experts and further disadvantage communities (Kretzmann and McKnight 1993). It is particularly unhelpful when the process of seeking expert help reinforces the stereotype of particular places or groups as being needy or disadvantaged (Cameron and Gibson 2005). The ABCD model seeks to prevent people from becoming dependent, so that they seek help from experts as an (informed) second step rather than as an immediate course of action (Gibson-Graham 2006).

While $A B C D$ is described by its founders as both an approach to community development and a community development strategy (Kretzmann and McKnight 1996: 27 ), it is also used as a methodology. For example the Canadian NGO SOPAR (Society for Partnership), in its ABCD Methodology Manual (SOPAR undated), describes the way in which the ABCD 'approach' can be used as a methodology in much the way we do in this project:

There is no "blueprint" for carrying out an $A B C D$ approach, but the principle behind the methodology is that communities that recognize their assets and opportunities are more likely to be motivated to take initiative to mobilize and strengthen their asset base. Guided by this, the NGO has to decide which combination of tools and methods are appropriate for helping communities organize themselves to identify, link, and mobilize their assets (SOPAR undated: 27)

The SOPAR Manual outlines a number of tools and methods (such as asset mapping) to be used as part of the ABCD methodology (SOPAR undated: 27-28).

In a similar way, our project built on $A B C D$ in order to explore the assets and capacities already present in the rental sector and provide ways for such assets to be enhanced. Rather than position the research team as experts, the research positions tenants and 
housing managers as experts on the current state of climate change adaptation and collected their stories of what is happening in the sector in the contemporary period and their visions for how the rental sector could become more sustainable. The interviews and focus groups conducted as part of this project were aimed at gaining this kind of inventory of assets from tenants, housing managers and landlords.

This information was supplemented with a review of secondary sources, such as existing tenant resources to encourage climate change and media articles about green renting. For more details about the methods used in the project see Chapter 3 of this report. This report, and other project outputs such as YouTube clips and a best practice guide will become assets to adaptation in the rental sector in the future.

\subsection{Pro-poor Asset-based Climate Change Adaptation}

Pro-poor Asset-based Climate Change Adaptation (PACCA) has been applied most commonly in developing countries, but is applicable to any context where marginalised groups are encountering the challenges posed by climate change. Like ABCD, PACCA (Moser 2011; Prowse and Scott 2008; Moser and Satterthwaite 2008) focuses on people's capacities: the assets of individuals and groups that can enable them to adapt to climate change.

The term pro-poor encapsulates the emphasis of this framework on those more vulnerable to climate change impacts. Vulnerability can be defined in Folke's (2006) sense as lowered resilience, which in turn implies loss of adaptability. Poor socioeconomic conditions, and social responses to gender, ethnicity or age, can lead to reduced resilience and hence reduced adaptive capacity (Moser and Satterthwaite 2008). A consequence of these conditions is a lack of assets:

One of the most important factors shaping the adaptive capacity of individuals, households and communities is their access to and control over natural, human, social, physical, and financial resources (CARE International 2009: 5, citing the IPCC Working Group 2, 2001. Third Assessment Report, Annex B: Glossary of Terms).

People who have minimal access to the resources they need to prevent, prepare for, and recover from severe weather events and rising costs associated with mitigation strategies are the most vulnerable. This is shown in the literature, highlighting past and future challenges faced by low-income groups:

Studies of Hurricane Mitch in Honduras showed that the hurricane exacerbated asset inequalities as the poor lost a greater share of assets in the disaster and recovered at a slower rate than the non-poor (Heltberg et al. 2009: 90).

Particular barriers for low-income renters include lower quality housing, with less effective heating and cooling, disincentives for either landlords or tenants to make significant improvements to housing, and lack of insurance (Sullivan 2007: 1).

A PACCA framework involves understanding vulnerabilities as well as assets (Moser 2011). This is particularly important in contexts where institutions and governments are 
unwilling or unable to assist poor communities in their efforts to adapt (Prowse and Scott 2008). Thus the research investigated the ways in which tenants are vulnerable to climate change and how vulnerability limits their potential adaptations to climate change. This approach enabled the development of more nuanced recommendations for actions to address climate change.

PACCA is guided by the principle of climate justice, a principle explored in the next section.

\subsection{Combining asset based and pro-poor approaches}

ABCD has been criticised for not taking broad scale forms of injustice such as class, ethnicity, gender and age into account when seeking to mobilise assets and understand reasons for local disadvantage (Ennis and West 2010). Ennis and West (2010) argue that ABCD fails to challenge structural or macro-level injustices and needs to address these broader structural issues in order to fully mobilise the strengths and assets of a community.

The argument for taking account not only the diversity of local responses to climate change adaptation but of broader policy intervention and possibilities, has been made by Kates and Wilbanks (2003):

...residents can alter the emissions emanating from their homes but only within a small range governed by who built the structure and how and when they did so...[R]enters in multifamily dwellings have little influence over such issues as insulation. On the other hand, even such external decisions as a distant utility office's choice of location for an electricity generating plant may have been influenced by local desires for economic development or by local demand (Kates and Wilbanks 2003: 18).

It is important to acknowledge the context-specific and multiple ways injustice can occur, particularly when it comes to the implementation of government policy frameworks, or the absence of frameworks that could potentially assist tenants or lowincome groups meet their needs. The structural issues affecting low-income tenants, their assets and networks are context-specific, but affected by regional, state and national frameworks and connections. Utilising a pro-poor framework helps to identify the broader structural issues that cause climate injustice and inhibit the ability of tenants and managers to adapt to climate change. It also requires adaptation responses which benefit rather than further disadvantage, low income tenants (Prowse and Scott 2008).

Both the pro-poor and $A B C D$ frameworks highlight the importance of participation in decision-making as key to successful development. As Bankoff (2001) argues, integral to the process of identifying and resolving multistranded vulnerability is "the positive and intelligent participation of those most at risk" (Bankoff 2001: 30). It is those most at risk who are best able to describe multistranded disadvantage in their lives and communities, "the outcomes we wish to avoid" (Ribot 2010: 60), and potential solutions. The limited literature on adaptive capacity in the rental sector tends to position tenants as passive, bound by the regulations of their tenancies and their 
meagre financial capacity (Toohey and Fritze 2009; Gurran et al. 2008). However renters can be repositioned as active (Mee 2009) rather than passive in adaptation. Housing managers also have critical roles to play in adaptation (Brown and Bhatti 2003, Priemus 2005). Thus it is crucial that any measures to adapt to climate change should involve key stakeholders and knowledge-brokers, such as tenants, housing managers and landlords from their development to implementation. For this reason our research explores the ways in which key stake-holders were involved in past attempts to enhance the sustainability of rental property to explore the lessons that can be learnt for future adaptive measures.

Adaptive capacity is thus viewed throughout this research project in terms of the assets that enable the rental sector to adapt to climate change, and the barriers that prevent adaptation responses. Combining the ABCD and PACCA frameworks allows us to address a broad spectrum of issues connected to these two aspects of adaptive capacity in the rental sector.

\subsection{Vulnerability, resilience and adaptation: A climate justice approach}

Within the climate change adaptation literature, fairness is an important principle. Fairness is a component of the four climate change justice principles proposed by Adger et al (2006):

1. Avoiding dangerous climate change, that is, mitigation rather than adaptation

2. Forward looking responsibility, where those responsible for emissions compensate others

3. Putting the most vulnerable first

4. Fair participation for all - participation by those most vulnerable to and affected by decision making about adaptation (see Hill 2008 for a discussion of these principles).

A pro-poor approach to adaptation is founded on the principle that, as climate change is mostly the result of the actions of the rich, poor people should not be further disadvantaged by climate change. Instead poor people ought to benefit more from climate adaptation practices and policies than the rich (Prowse and Scott 2008). As Ribot argues:

The inability to manage stresses does not fall from the sky. It is produced by onthe-ground social inequality; unequal access to resources; poverty; poor infrastructure; lack of representation; and inadequate systems of social security, early warning, and planning. These factors translate climate vagaries into suffering and loss (Ribot 2010: 49).

More broadly, climate justice frameworks raise the question of who should be held responsible for compensating those at risk from the ill effects of climate change. Discussions of climate justice often focus on retrospective compensation (Vanderheiden 2009). For example climate justice frameworks that focus on adaptation address the question of who should compensate whom for the harm caused by climate change. How should the people who have played a minimal role in causing climate 
change be compensated for the harm they experience because of the actions of others (Vanderheiden 2009)? On the other hand, mitigation approaches focus more on how to distribute resources fairly and justly (Vanderheiden 2009).

Action on mitigation and adaptation originate in different arenas:

...mitigation can be driven as a national agenda, promoted by international agreement, whereas effective adaptation needs to be locally driven, in part because adaptation measures must be rooted in the particulars of each local economic, social, political and ecological context (Moser and Satterthwaite 2008: 5).

Focusing on equity means that reducing vulnerability and increasing resilience becomes a broader project than simply enabling recovery from an adverse event. It enables assessments of vulnerability to examine not only individual or household 'susceptibility' but broader structures and relationships which influence the outcomes for people confronting climate change.

\subsubsection{Vulnerability, lack of assets}

Vulnerability is a concept often criticised as disempowering and encouraging "a sense of societies and people as weak, passive and pathetic" (Bankoff 2001: 29). It is therefore important to define it clearly for the purposes of this project. Vulnerability has an inverse relationship with a person's ability to cope or ability to adapt to adverse events, and has been defined as "a function of exposure, sensitivity and adaptive capacity of a system" (Moser et al. 2010). CARE International, for example, defines vulnerability as:

The degree to which a system is susceptible to, or unable to cope with, adverse effects of climate change, including climate variability and extremes (CARE International 2009: 5, citing the IPCC Working Group 2, 2001. Third Assessment Report, Annex B: Glossary of Terms).

Vulnerability is influenced by conditions or 'variables' such as "age, class, occupation, gender, ethnicity and disability" (Morioka 2012: vi). However these conditions, like 'adverse events' or 'natural hazards', only produce adverse consequences when framed by larger social, economic, political and institutional structures which produce differential outcomes for different groups. Vulnerability, rather than endemic to a particular region, population or group (such as renters), is a product of these structures which manifest as poverty, marginalization and depleted resources in particular places or groups (Bankoff 2010; Howitt et al. 2010).

There is, as noted above, a link between vulnerability and a lack of assets. However identifying this link does not identify the deeper causes of a lack of assets and hence of vulnerability. Vulnerability arises at many levels and over time:

[V]ulnerability is signified by historical processes that deprive people of the means of coping with hazard[s] without incurring damaging losses that leave them physically weak, economically impoverished, socially dependent, humiliated 
and psychologically harmed... the simple identification of the poor as vulnerable fails to explain how people at the same income level do not suffer equally from disaster (Bankoff 2001: 25).

It is only in analysing the causes of poverty or marginalization at a deeper level that vulnerability can be properly described and addressed. Such analysis helps to resolve the deeper causes of vulnerability rather than trying to fix outcomes afterwards (Ribot 2010: 59). Assets required to enable action may be both tangible and intangible, including "the material resources of individuals, their social relations, the state of governance, the role of freedoms and choices, and the state of equity" (Millennium Ecosystem Assessment 2003: 156). Other adaptation theorists have noted the importance of difficult-to-measure qualities such as trust, social networks and social memory, leadership and vision (Folke 2006: 262). These assets of a community are rarely included in a "decision making calculus" (Adger et al. 2009: 348-349) but are critical to consider and nurture in response to climate change.

\subsubsection{Assets and losses}

The corollary of identifying causes of vulnerability or lack of assets is identifying those existing assets which are vulnerable (Moser and Satterthwaite 2008: 33). In some cases, asset losses need to be mapped. Historical, cultural and symbolic losses can reduce a community's capacity to adapt (Adger et al. 2009: 349). For low-income housing tenants, marginalisation, long-term unemployment and economic or housing stress may contribute to what has been described as the "hidden limits to adaptation" (Adger et al. 2009: 340).

An example of the consequences of a loss of social networks or good governance is the absence in particular communities of coordinated planning for future disaster. ActionAid reported on several such cities in which, for example, there has been a lack of community preparation to limit flooding:

Effective community-based pre-disaster measures to limit damage require levels of trust and cohesion - community social capital - that are often not present (Moser and Satterthwaite 2008: 11).

In addition to historical loss or increasing vulnerability of social and cultural assets, there may be a failure to recognise already available assets, such as the specialised knowledge of marginalised populations who are not invited to participate in planning and decision-making:

...problematic is the failure to recognize women's individual and collective capacities for recovery and reconstruction as community leaders, neighbourhood networkers, producers, gardeners, rainwater harvesters, and monitors of floodprone rivers. This means that their resources, capacities, assets and hard-won knowledge about how to make life safer for their families and live with risk are all ignored (Moser and Satterthwaite 2008: 12).

Vulnerability is closely tied to the concept of resilience, and has been defined as a lack of resilience combined with "insecurity in ... wellbeing" (Moser and Satterthwaite 2008: 
5-6). The issues of recognising and supporting assets in marginalised populations in order to increase resilience are discussed in the following section.

\subsubsection{Kinds of resilience}

Just as analysing 'vulnerability' requires critical analysis of a wide range of structures and influences, so too does analysis of its apparent obverse, resilience. Deborah Bird Rose (2004) distinguishes three kinds of human activities affecting resilience:

1. Anti-resilience activities such as dam-building which "actively oppose and seek to suppress Nature's own resilience"

2. Engineered resilience activities such as preventing fires in national parks, which attempt to "force Nature to behave as humans would like nature to behave"

3. Resilience facilitation, which supports the conditions in which Nature' resilience can flourish, which may sometimes mean doing nothing (Rose 2004: 48).

These distinctions can be mirrored in the kinds of actions which influence economic resilience (Roelvink and Gibson-Graham 2009), where anti-resilience actions might include the imposition of taxes on subsistence livelihoods or appropriation of land, engineered resilience might include the co-option of 'social capital' for micro-finance schemes, and resilience facilitation would support more community-based economic practices such as "gifting, sharing, reciprocity and cooperation" (Roelvink and GibsonGraham 2009: 148).

As noted in 2.4 above, the asset-based approach to climate change adaptation which is used in this project is based on:

- identifying and mobilising existing assets to increase the adaptive capacity of a community

- a pro-poor approach that also takes a critical look at the wider structural factors which may weaken or ignore these existing assets in the service of policy or economic objectives.

\subsubsection{Multistranded approaches: More-than-adaptation}

Pro-poor and climate justice proponents argue that improving conditions for the disadvantaged should be a goal of adaptation strategies. Fundamental to this expanded approach to reducing vulnerability is the belief that, for many, "everyday conditions are unacceptable even in the absence of climate stress" (Ribot 2010: 50). Many such lives, suggests Bankoff, are already a "permanent emergency" (Bankoff 2001: 25). Climate justice proponents argue for adaptation approaches which go beyond resilience defined simply as asset protection or 'recovery' and, instead, seek to improve the long-term conditions of those who are most vulnerable (Prowse and Scott 2008: 43).

Climate justice advocates call for poverty alleviation and livelihood security as a right or entitlement, where entitlements are "utilities...over which social actors have legitimate effective command and which are instrumental in achieving well-being" (Ribot 2010: 56). Within an entitlements framework, vulnerability to climate change is defined as "a 
lack of sufficient means to protect or sustain oneself in the face of climate events" (Ribot 2010: 53). Similarly, a rights-based approach focuses on the vulnerable as those who have yet to obtain "the minimum conditions for living with dignity (i.e. ...their human rights)" (CARE International 2009: 8).

Entitlements and rights-based approaches thus seek adaptation strategies which address the causes of vulnerability. These causes contrast with a first response to reducing vulnerability to climate change and increasing resilience such as 'fixing' the physical capital of a community and developing preparedness by:

- installing protective infrastructure and complementary risk-reduction measures;

- supporting better-quality buildings

- assisting those who live in the most dangerous sites to move to safer sites (adapted from Moser and Satterthwaite 2008: 29-30).

Another example of a 'first response' is advice provided to coastal communities to maintain spaces for emergency access and shelter, to plan ahead for evacuation, develop transport and communication strategies, and ensure that infrastructure can withstand an emergency (Gurran et al. 2008: 32).

It has been claimed that Asset-based approaches without Pro-poor principles fail to challenge those structural and macro-level injustices (Ennis and West 2010) which not only increase vulnerability to the impacts of climate change but present obstacles to reducing more general disadvantage. Heltberg et al suggest instead that:

...addressing human vulnerability to risks associated with climate change may offer opportunities for development and poverty alleviation through no-regrets pro-poor adaptation interventions (2009: 89).

However even at the level of material assets, improvements can address multiple disadvantage:

For instance, better-quality housing, infrastructure and services greatly reduce a range of hazards - including exposure to many disease-causing agents (pathogens)... (Moser and Satterthwaite 2008: 9).

In pro-poor adaptation strategies there is an opportunity to re-negotiate the conditions and entitlements of the vulnerable in a range of mutually reinforcing areas which produce more-than-adaptation. In adopting a pro-poor approach to climate change adaptation, this project examines the relationships between renters and other key actors, as well as regulatory and policy constraints, and develop proposals which, in supporting community assets and adaptive capacity, "go far beyond reducing risk with respect to climate events" (Ribot 2010: 64).

Bringing these strands together is what we term a "more-than-adaptation" approach. It involves thinking about climate-change assets and adaptive capacity in a range of ways, and positioning even vulnerable groups as capable of change, albeit in limited circumstances. A more-than-adaptation approach is consistent with Moser et al's call for 'asset accumulation' rather than simply asset protection, and the interconnected 
citizen rights, institutional accountability and governance required to support such accumulation and strengthen resilience (Moser and Satterthwaite 2008: 8). It is also consistent with the idea of 'facilitated resilience' which supports and mobilises the existing assets of a community to enhance adaptive capacity.

\subsection{The role of the housing manager}

\subsubsection{Overview of literature}

In order to develop an understanding of 'more-than-adaptation' in the rental sector, we need to be attentive to the experiences of different actors. In particular, this approach recognises the important role of housing managers in working with tenants and landlords to strengthen the adaptive capacity of the rental sector. Priemus (2005) recognises that the "the environmental impacts of residential properties also depend on the behaviour of management agents, property owners, and occupants" (2005: 12). In this section, we outline how the role of the housing public and private housing manager has been understood in the literature and explore how the different roles, responsibilities, challenges and areas of influence of housing managers have been positioned. We also review literature that examines the role of housing managers in enhancing sustainability more specifically, including literature on sustainable housing that incorporates references to housing managers, and work on property managers that engages with attempts to 'green' the commercial sector ${ }^{1}$.

This section reviews the assets and capacities which housing managers bring to adaptation, including the extent to which housing managers' skills have been harnessed in measures to render dwellings more sustainable. We also point to 'gaps' in existing research, identifying areas where our focus on the relationships between property managers, landlords, and tenants goes some way to address these gaps. It describes different spheres of influence on housing managers and considers the role of housing managers in managing residents, managing buildings and managing relationships. We do this by briefly describing each of these spheres of management, and, where possible, noting how they are evident in research on sustainable housing.

There has been little attention in academic work on conceptualising sustainable housing (Priemus 2005; Winston 2009) and even less on sustainable housing in the rental sector. Brown and Bhatti (2003), in their review of environmental issues in housing studies make reference to the role of housing practitioners (or managers) in connecting environmental concerns with housing, asserting that:

... the assumption during these heady 'green' times was that housing practitioners, policy makers and academics could simply incorporate environmental issues into traditional housing concerns, and there would be progress. From a policy and practice perspective this has been relatively successful (although more could be done); but from a theoretical perspective it has been a failure (Brown and Bhatti 2003: 507-508).

\footnotetext{
${ }^{1}$ While the term 'housing manager' is more common in Australia in the public housing sector, and the term 'property manager' is more commonly used in the private rental sector, throughout this report these two terms are used interchangeably.
} 
While policy and practice may exist around increasing sustainable housing for climate change in the rental sector, in the Australian context, housing practitioners, and housing managers in particular, have not experienced significant exposure to policies and practices that seek to enhance the adaptive capacity of the rental sector. Unsurprisingly then, the role of housing managers in this area has also been undertheorised in housing studies literature.

Because of the limited research in this area in Australia, international research provides valuable context for exploring the capacities and assets that housing managers can bring to adaptation. There are, however, key empirical differences between international research and our study that are important to note. Firstly, some work offers examinations of sustainable housing in a particular locale and in pursuit of untangling some of the murkiness of defining sustainable housing, such as Priemus's (2005) consideration of the Dutch sustainable housing policy. Other work considers sustainable housing through the lens of particular urban processes, such as Winston's consideration of sustainable housing in urban regeneration (Winston 2009), and Stenberg et al's consideration of housing regeneration in Sweden (Stenberg et al. 2009). Much of the remainder of the literature emerges from two types of case studies: those which consider social housing, retrofitting and energy efficiency in European countries (Smid and Nieboer 2008; Femenías and van Hal 2009), and work which considers the role of housing managers in reducing energy consumption of apartment buildings in Helsinki (Kyrö et al. 2011; Kyrö et al. 2012).

Work which examines social housing (Smid and Nieboer 2008; Femenías and van Hal 2009 ) is based in countries with a markedly different social housing sector to Australia, both in terms of the proportion of rental stock constituted by social housing and in the way this is administered. In the Netherlands and Sweden, where there is a significant amount of research into retrofitting social housing, social housing constitutes a much larger proportion of rental stock than Australia. Furthermore, while social housing in Australia is administered through state agencies, housing associations and municipal housing companies are much more heavily involved in the provision and management of social housing throughout Europe.

Another point of distinction is the function of the 'housing manager'. In Finland, housing companies can employ professional housing managers to act as CEOs of the housing companies they manage (Kyrö et al. 2012: 204). Housing companies themselves are constituted by the homeowners, who become share-holders in the housing company that manages and maintains the buildings. In this, they are not unlike strata management in the Australian context.

Despite these differences, there are important synergies with our research that help us to further theorise the role of the housing manager. In particular, we note that research has pointed to the leadership role of housing associations and housing managers in facilitating environmental change in the housing sector. For example Femenias and van Hal (2009) focus on housing associations as "drivers for change" and note the importance of both "their behavioural predisposing 'culture' in the permanent organisation and ... their behavioural response to innovation in a project situation" (Femenías and van Hal 2009, s.2.2), while Christudason recognises Singapore 
property managers as "catalyst[s] for change" (2002: 252). On the other hand, Kyrö et al (2011) suggest that "managers seem to lack the willingness to become forerunners in environmental and energy related practices" (2011: 509).

Nonetheless, common to both these views is a recognition of the important role of the housing manager and their capacity to influence adaptation. The remainder of this section reviews the work of housing managers, and areas that housing managers influence: tenants and landlords, relationships, and buildings.

\subsubsection{The work of housing managers/ housing management}

Housing managers draw on a diverse array of influences in their everyday practices, including policy directives and personal beliefs. Housing managers are not passive conduits through which policy, legislation, or directives pass between dwellings/ residents/ landlords, but are actively involved in translating, and sometimes, resisting institutional aims and programs, and negotiating contradictory and complex organisations and environments. This section explores the work of housing managers.

Research into the role of housing management in social housing has had a particularly strong focus on how policy changes influence the tasks of the housing manager. For instance, much research into neoliberal influences on housing management identify a (re)construction in the role of the social housing manager in their practical relationships with tenants (for example Manzi and Smith Bowers 2004). Broader policy changes potentially (re)shape the role of the housing manager. Our research also shows that policy and program changes at the federal, state, and organisational levels can influence the day to day activities of housing managers.

There is certainly evidence of policy directives in energy efficiency and sustainable housing influencing social housing management in an international context. Research into sustainability and housing management draws out the role of legislation in steering housing managers' practice to incorporate specific environmental concerns and features. Smid and Nieboer (2008) consider how energy efficiency can be incorporated into the asset management of Dutch social housing landlords in response to an EU Environmental Performance Building Directive (EPBD) policy directives. Broader legislative changes can therefore be considered as potential drivers in the way housing management incorporates issues surrounding sustainability and climate change in terms of how the physical stock is managed, and how this information is communicated to tenants. Smid and Nieboer note the importance of legislation in influencing the actions of landlords in this respect:

... professional landlords can significantly contribute to governmental policies by improving the energy performance of their housing stock...energy conservation should be integrated in all phases of the strategic asset management processes. With professional landlords facing tightening energy performance requirements, the EPBD legislation could be considered as an opportunity and, at the same time, a means for professional landlords to incorporate energy conservation in their strategic asset management (2008: 31). 
However housing managers can translate and enact policy and programs in diverse ways and cannot be thought of as passive receptors of policy. Saugeres (1999), in her work on social housing managers' perceptions of tenants, emphasises the agency of managers, noting that:

... even though frontline staff have to operate within policies, procedures and definitions that limit their discretionary powers, they still interact with tenants and interpret their situations according to their own subjectivities... it is argued that staff are not passive recipients of organizational rules and socialization, but both reproduce and resist dominant ideologies through everyday discourse and practice (1999: 1403).

Elsewhere, research has framed housing managers in relation to shifts in organisational practices and cultures, and the housing management styles of practitioners. These observations therefore offer insights into housing managers' individual practices and motivations for driving change, as well as the importance of sector and organisation wide capacities for driving change in relation to rendering housing more sustainable. We examine this research with an eye to how it enhances our understandings of the role of housing managers, the assets and capacities that they may draw on, and barriers to adaptation in the rental sector.

Research that theorises the role of social housing managers emphasises the importance of an individual practitioner's subjectivities and perspectives in enacting change. This is also evident in research focused on the challenges of implementing sustainability into buildings and building management. Kyrö et al's $(2011 ; 2012)$ work on the role of housing managers in their buildings' environmental performance paid particular attention to the style of housing management. They saw housing managers as well-placed to address energy performance of buildings because they have the financial information, consumption data, and professional expertise to reduce building energy consumption.

Kyrö et al (2011) categorised attitudes of housing managers as 'caring', and 'professional' and 'uninformed'. The 'caring' category was used for housing managers who expressed a strong concern about the environmental impacts of buildings, their maintenance and management, and about the ability of managers to influence this impact through their own actions. The most common category in the study, 'professional', applied to housing managers who "generally felt environmental issues should be considered, but only to the extent financially and socially reasonable" (Kyrö et al. 2011: 206). The authors noted that these managers held perspectives such as believing that the payback time of improvements was too long, and felt constrained by finances and time (an attitude that also emerged in our interviewee responses as we discuss in the results section of the report). Finally, the 'uninformed' management style included ignorance and aversion to incorporating energy-efficiency improvements into buildings and management practices. The authors' quantitative analysis of building performance suggested a positive relationship between the perspective of the housing manager and environmental performance. They argue that "the results suggest a combination of technical solutions and managerial practices is likely to lead to best results" (Kyrö et al. 2012: 209). Individual perspectives can influence the management 
style of housing managers, something that, the authors suggest, is important in mobilising environmentally friendly management practices.

Multiple aims, cultures, and practices co-exist within the one organisation, and must be actively negotiated by housing managers. Priemus (2005: 15) observes that housing associations, which may have both construction and management activities, can have contradictory goals and aims, another point that chimes with themes emerging from our research. Further, he points to contradictions within government policies that can impede or undermine sustainability in other ways.

Priemus cites the Dutch government's co-existing aims to enhance the sustainability of housing while at the same time pushing up housing consumption through market led developments. He points to examples such as financial support for homeowners and tenants that can stimulate housing consumption while "considerably reduc[ing] the sustainability of housing" (2005: 12). While these contradictions may not directly be experienced by housing managers, they inform the environment they operate in. Moreover, our analysis suggests that the financial 'bottom line' was/is a major constraint to adaptation in the rental sector, and in broad strokes, at least, we can see similarities here with the focus on a market economy and increased consumption competing against sustainability, a factor that Priemus sees as some of the key policy contradictions surrounding sustainability and housing.

\subsubsection{Managing and influencing tenants, landlords, and relationships}

Housing managers, particularly in social housing, are understood as managing tenants. Indeed, literature on social housing management is one of the most prominent areas of housing research that explicitly explores the role of the housing manager (see for example Clapham et al. 2000; Priemus et al. 1999; Saugeres 2000; Saugeres 1999; Saugeres and Clapham 1999; Franklin 2000; Manzi and Smith Bowers 2004), and its influence, both directly and implicitly, on tenants. For this reason, this literature is one of the most useful sources for looking at how the housing manager has been conceived as an active agent in the housing sector. While this literature is most directly relevant to understanding the role of social housing managers in our research, many of the themes may also be relevant to private housing managers.

The literature on the role of the social housing manager observes a consistent focus in on guiding and shaping the tenant. For instance, the Octavia Hill method of social housing management in early 20th Century Britain had a strong emphasis on managing tenants to instil residents with middle class values and behaviours. Similarly, neoliberal housing management strategies have sought to make tenants 'participative', 'work force ready' and appropriate 'neoliberal citizens', which would occur in part through housing management (Ravetz 2001; Flint 2004; Grayson 1997). Efforts to explore the capacity of housing managers to work with tenants to improve the sustainability of the rental sector must take care to avoid using similar assumptions about housing managers as somehow 'improving' tenants.

There is remarkably little research on the role of the housing manager in the private rental sector, especially in terms of mediating and managing the relationship between landlords and tenants. It is particularly notable that most research on relationships in 
the private rental sector focuses directly on the landlord and tenant, or conflates landlords and property managers (see for example Lister 2004; Lister 2005; Bierre et al. 2010; Grineski and Hernández 2010). Nonetheless, this work is relevant to understanding how tenants may experience housing managers and landlords. What is most striking about this work is the power the landlord is perceived to wield over tenants. Lister's $(2004 ; 2005)$ work examined the challenges faced by young people when first entering the rental sector, and their experiences of being 'monitored' by landlords as landlords seek to control both tenants and the property. Grineski and Hernández (2010) explored environmental injustices of the private rental sector in Arizona. They argued that the poor quality of housing stock, and the failure of landlords to improve it, contributed to the ongoing health problems of tenants; tenants were placed in an unequal relationship with their landlords and were ignored when they sought improvements to their dwellings. Such examples suggest the constraints on tenants and the potential for dire consequences as a result of landlord and housing manager inaction.

Nonetheless, both this research and other works note the potential for improvements and interventions for these relationships. In particular, personal connections are fundamental in reshaping such relationships, so that landlords, and housing managers, can more positively interact with tenants:

Lister (2007) argued that acknowledgement of this personal relationship and the associated informal rules and understandings associated may hold the key to better outcomes for landlords and tenants (Bierre et al. 2010: 23).

Elsewhere, work in the private sector (for example Rasila 2010) observes the importance of trust and commitment in positive landlord-tenant relations in the commercial sector. There is therefore scope for a greater recognition of emotional and informal relationships and connections to be drawn upon in improving the adaptive capacity of the rental sector.

There is limited literature on how housing managers have sought to engage with tenant practice to enhance the sustainability of dwellings. This is general recognition that technical changes through retrofit and renewal programs rely for their effectiveness at least in part on human interactions with technical systems, and on the relationships and communications between different actors. Stenberg et al's (2009) work on the enhanced sustainability of housing projects evaluated efforts made to change tenant practice. The authors point to waste as one area where housing companies have had (moderate) success in altering 'behaviour patterns', as some residents adapted to sorting recyclables. There needs to be a note of caution in considering the role that housing managers can play in relation to tenant practices; especially when framed, as in Stenberg et al's paper, in terms of "inspir[ing] more people to change their behaviour" (Stenberg et al. 2009: 550); such practices can risk echoing some of the more paternalistic themes evident in the Octavia Hill management style, where housing managers are tasked with improving the behaviours of tenants.

Another way in which housing managers are seen as having the capacity to encourage a change in tenant practice is via labelling systems that provide information about the energy efficiency of housing stock. Smid and Nieboer (2008) consider enrolling 
labelling in this capacity as part of their focus on integrating energy conservation into the maintenance and renovation practices of housing managers. They suggest this as part of an attempt to develop a methodology for Dutch Social Housing Landlords that draws on the Energy Performance of Buildings Directive (EPBD). The EPBD requires the use of energy certificates that outline the current energy performance of the building and possibilities for improving its energy performance, supplied at each transition when a building is new or sold (Smid and Nieboer 2008: 19). The

Netherlands requires these certificates be paired with an energy label that classifies the energy performance of a dwelling. Such certificates, the authors suggest, are a means for housing management to communicate "with its stakeholders and tenants about energy performance and conservation measures" (Smid and Nieboer 2008: 22) In this way housing managers could be positioned as critical knowledge brokers, supplying knowledge that could help tenants adapt to climate change. EPBD labels are a potential means of communicating a building's energy credentials with prospective tenants which "can raise their awareness about energy consumption and influence their behaviour regarding energy consumption, but it does not improve the energy efficiency of housing stock" (Smid and Nieboer 2008: 32). The authors also note that in tight rental markets, properties are in demand regardless of energy efficiency.

It can be seen in these studies that both the housing manager and the tenant have the capacity to contribute to the energy performance of the building. Moreover, in both the examples discussed here, influencing tenant behaviour is not independent but is interconnected with legislative or technical changes.

\subsubsection{Managing buildings}

Finally, we can examine the role of housing managers in terms of their capacity to manage and influence particular dwellings. The following examples are drawn primarily from Scandinavian social housing examples.

Housing managers are able to manage the buildings and the technical systems integrated in the buildings to generate particular outcomes. Smid and Nieboer (2008) focused on the integration of energy conservation into professional landlords' maintenance and renovation practices, using the example of Dutch Social Landlords. They note a willingness to improve the energy efficiency of their stock despite the financial cost, pointing to motivations such as increasing the market value of energy efficient stock, decreasing living costs of social housing residents and enhancing the living comfort of the homes generated through energy measurements such as insulation (Smid and Nieboer 2008: 20). In proposing a methodology that professional landlords could use to implement such changes, they suggest a recognition of the capacities for professional landlords (albeit at an institutional level) and the role they can play in adapting buildings in particular ways.

Another body of work that considers the capacity of housing managers to reduce greenhouse emissions, primarily through their capacity to reduce the emissions of the buildings they manage, is Kyrö et al's $(2011 ; 2012)$ research on the role of professional housing managers and energy efficiency in existing housing. Their work is primarily informed by an interest in housing management styles and practices and their influence on building performance, but is mentioned here because it recognises the capacity of 
the housing manager to intervene at the scale of the building through, for instance, maintenance practices, rather than through interactions with residents. The authors also point to the importance of the building characteristics and the capacities of different types of buildings for adaptation. Other work in this area also emphasises the potential for housing managers to enhance the environmental performance of buildings through their capacity to intervene at the material level of the building. Christudason (2002) observes that attempts to generate sustainable housing can be let down by the failure of building maintenance to retain environmental standards.

Stenberg et al (2009) take a different approach. Their work evaluates social and environmental regeneration programs carried out in Sweden across ten housing projects (9 municipal housing companies and one a partly tenant owned association). They note that there are benefits to technical systems implemented by housing associations, especially as they remain in place after the regeneration program has finished. However, their evaluation suggests that there may have been over reliance on technical systems and interventions in attempts to change residents' energy use, without appropriate consultation and communication with tenants. They argue:

In most cases, energy and water solutions were treated as a matter for housing company experts. Consequently, the tenants' influence with regard to these topics was less than their influence over, e.g. the function and design of the external environment. However, there were examples where employees stressed the importance of communicating with tenants concerning technical issues. In one project, the property manager followed the tenants' energy and water use through a remote supervision system. When the use was higher than usual, the manager spoke directly with the tenant to discover the reason and gave the tenant a chance to change their behaviour. This case shows how a technical system can support learning and save energy. However, typically, technical systems supported top-down control and inhibited tenants' control over the learning process, individually and as a group (Stenberg et al. 2009: 549).

This research suggests that a focus on retrofitting the dwelling alone for sustainability and climate change is insufficient, as it overlooks the way tenants interact with their residences. The relationship between residents, housing managers, their dwellings, and newly retrofitted technical systems can be even more complex in the case of multidwelling buildings. For example, new laundry and rubbish disposal systems had varying measures of success dependent on a range of factors including: the extent to which changes were communicated to residents; the extent to which the changes enhanced residents comfort and enjoyment of their dwelling; and the ways technical changes could be integrated into existing habits of tenants. Implicit in this work is the idea that the reliance on technical systems is limited by the relationships through which these changes were introduced and maintained.

These insights into the role of housing managers in implementing sustainable practices have informed our study of climate change adaptation in the rental sector. 


\subsection{Tenants and theories of everyday practice and homemaking}

Everyday practice and home making are crucial to understanding the assets and capacities that tenants bring to the rental sector. There is a dearth of research into the everyday practices of renters and their experiences of sustainability and climate change adaptation. There is however a significant, and growing, body of literature on material practices of household sustainability in Australia and elsewhere (Lane and Gorman-Murray 2011), and literature concerned with environmental behaviour change at the scale of the household (Evans 2011; Reid et al. 2010). We can consider this research as broadly concerned with home as a site of 'resource management' as householders "develop homemaking practices with fewer ecological impacts" (Mee and Vaughan 2012: 149). Because we are interested in exploring tenants as active agents in adaptation, theories of everyday practice and sustainable home making have helped us to conceptualise and explore the potential of everyday adaptive actions of tenants.

Practice, understood as "...routinized activity which involves connected elements of or nexuses between bodily and mental activities, objects/materials and shared competencies (knowledge, skills)" (Horne et al. 2011: 90) is a useful entry point for considering what people do in their everyday lives and the messiness of everyday practice, and how these are bound up in the day-to-day goings on where environmental concerns intersect with experience of dwelling (Mee and Vaughan 2012). Furthermore, we can, to some extent, differentiate practice from behaviour change in order to more fully explore how tenants' daily routines are connected with home making, in recognition of the importance of routine and repetition in the performance of home. Moloney et al (2010) distinguish behaviour change strategies and practice as follows:

The use of the concept 'practices' in socio-technical analysis, as opposed to behaviours, indicates a rejection of the emphasis on individually focused behaviour change but rather begins with the collective or social context shaping and framing our daily actions. Practices are embedded in a range of sociotechnical systems which constitute a diversity of institutions, regulations, infrastructures and technologies. They are also framed and shaped by the norms and values of the societies and contexts in which they take place (Moloney et al. 2010: 7618).

Such understandings of practice may be useful in overcoming some of the challenges posed by the historical emphasis on managing tenants' behaviours through housing management (see previous section). These theorisations of sustainable home making practice point to a more collaborative approach where tenants' everyday practices are valued in part because of their connection to home, but also where the everyday practices of housing managers are open to an enhanced appreciation of renter's connection to their home.

Finally, this theorisation of practice is helpful for exploring the everyday experiences of tenants because it is attentive to the embeddedness of sustainable practice in the routines of householders, most especially when these routines intersect with other ways of making home. For instance, we learn from this research some of the diverse ways that sustainability is bound up with 'making home', such as the ways in which 
renovators incorporate sustainability concerns into household improvements and home renovations (Maller et al. 2012; Maller and Horne 2011), how recycled and reused goods are acquired and used to re-make the materiality of home (Horne et al. 2011; Watson and Lane 2011), the diverse factors affecting uptake of sustainable water technologies (Allon and Sofoulis 2006), and sustainable consumption (Gibson et al. 2011). Similarly, work on motivations for everyday sustainable consumption observes the intersections that permeate everyday routines. Sustainability "can both complement and challenge other social practices such as being a parent, being healthy, being a good consumer, and being an ecological citizen" (Evans 2011: 110). In light of our concern to make renters more visible in discussions of climate change adaptation, theories of everyday home making practice and sustainability allow us to explore how tenants can carry out adaptation through their everyday practices, as well as the challenges that hinder their everyday practices and experiences of home. 


\section{RESEARCH ACTIVITIES AND METHODS}

\subsection{Overview}

Within an Asset-Based methodology, the project adopted the following methods for mapping assets and identifying existing adaptation strategies and barriers to adaptation:

- A review of secondary sources which revealed existing practices and assets and the potential of the rental sector to adapt to climate change. Secondary sources analysed include resources produced to encourage adaptation by tenants, media reports about "green renting" and sources which document the legislative and policy framework for rental housing and enhancing sustainability

- Interviews with key actors, specifically tenants and property managers in the public and private rental sectors

- Focus groups which brought these key actors together to generate ideas for building capacity and devising more effective strategies for adaptation

- Analysis of these stories, ideas and sources to reveal key themes about climate change adaptation in the rental sector.

These activities are described below, beginning with the collection of secondary sources and then moving to primary data collection.

The project was run with reference to a project steering committee that provided advice about the conduct of the project in all stages of the project's development. Steering committee members also provided key contacts and suggestions about the recruitment of participants for the research. In addition to the research team (Dr Lesley Instone, Dr Kathy Mee, Dr Jane Palmer (Post-Doctoral Researcher), Miriam Williams (Senior Research Assistant) and Nicola Vaughan (Senior Research Assistant), the members of the steering committee were:

- Professor Robyn Dowling, Macquarie University

- Wayne Stewart, Real Estate Institute of NSW

- Ross Fallins, Housing NSW

- Dr Geoff Evans, Lake Macquarie Council

- Peter Dormand, Newcastle City Council.

\subsection{Document collection and analysis}

\subsubsection{Types of documents analysed}

To analyse the resources currently available to renters, a search was conducted for sustainability resources targeting households and rental households in particular. This search produced around 12 'green living' guides from State and local governments, non-government organisations and property managers, as well as 5 review articles. The guides included web-based material targeting renters specifically, and more general guides for the community on sustainable living or on the impacts of climate change. 
To examine media constructions of climate change adaptation in the rental sector, a web-based search collected media based reports. These included 46 newspaper articles, 1 radio program, 2 magazine articles, and 5 online news webpages. Newspaper articles were obtained through a search of an online newspaper database-Newsbank from January 2011 to July 2012. Articles were identified using specific search words to target current issues facing the rental sector. Searches included such topics as changes to the Residential Tenancy Act in NSW; the effects of the introduction of the carbon tax on public housing; along with other more general themes on sustainability in the home, going "green" and the rental sector. In total 54 articles were found that reflected these themes. A particular author was identified as writing a regular column on the rental sector and their work was sought out via Google searches. We also analysed a radio program on ABC Radio National called This Rental Life which was aired June-July 2012.Topics covered by the media reports included housing shortages, the impact of changes to tenancy legislation on the landlord/tenant relationship, the impact of the Commonwealth Government's 'carbon tax', and case studies of 'green' tenants and landlords.

To analyse the legislative and policy context of climate change adaptation in the rental sector, the research team conducted a web-based search yielded almost 200 sources, including reports by government and non-government organisations and consultants, legislative statutes, and organisational websites. These documents covered the areas of ecologically sustainable development, land use planning, responses to climate change, tenancy regulation, housing provision and housing standards, access to infrastructure, and sustainability education, guidelines and incentives. The review of State and local government policy and legislation focused mainly on NSW and on the Newcastle and Lake Macquarie areas which are the focus of this research project.

Table 1 summarises the documents collected for these reviews. 
Table 1: Document collection

\begin{tabular}{|c|c|}
\hline \multicolumn{2}{|l|}{ RESOURCES FOR RENTERS } \\
\hline Document type & Number of documents \\
\hline Booklet (State Government) & 1 \\
\hline Online guides (State Government) & 2 \\
\hline Online guides (Local Government) & 3 \\
\hline Online guides (non-government) & 6 \\
\hline Total & 12 \\
\hline \multicolumn{2}{|l|}{ MEDIA CONTEXT } \\
\hline Document type & Number of documents \\
\hline Newspaper articles & 46 \\
\hline Magazine articles & 2 \\
\hline Online news & 5 \\
\hline Radio programs & 1 \\
\hline Total & 54 \\
\hline \multicolumn{2}{|l|}{ LEGISLATIVE AND POLICY CONTEXT } \\
\hline Document type & Number of documents \\
\hline Statutes & 12 \\
\hline Commonwealth Government reports/guides & 42 \\
\hline Commonwealth Government websites & 30 \\
\hline State Government reports/guides & 30 \\
\hline State Government websites & 43 \\
\hline Local Government reports/guides & 18 \\
\hline Local Government websites & 9 \\
\hline Tenant organisation reports and fact sheets & 7 \\
\hline International reports & 1 \\
\hline Total & 192 \\
\hline
\end{tabular}

\subsubsection{Document review process}

Documents were analysed to reveal key themes about adaptation in the rental sector. Important aspects of this analysis concerned the positioning of key stakeholders as playing certain roles in the sector (in particular tenants, housing managers and landlords but also other actors such as policy makers), the types of adaptation that were already occurring, types of adaptation that could happen in the future, relationships that were crucial in the sector and the barriers to adaptation. 
The critical review and analysis of each document collection made a valuable contribution to the research in a number of ways:

1. In undertaking the reviews, the researchers made a number of useful findings about the current state of climate change adaptation in the rental sector

2. Each review provided a context for examining the qualitative primary data of the interviews and focus groups

3. The primary field data in turn cast a new light on this context, for example by illuminating the impact on everyday experience of government policies or media discourse

4. The document analysis contributes to the findings and recommendations in this report.

\subsection{Interviews and focus groups}

\subsubsection{Interviews and focus groups methods}

Assets are key in facilitating adaptation. Thus a main focus of the research is to reveal individual and sector assets. To understand assets we needed to understand current practices in the sector and the perceptions of key stakeholders about the barriers to adaptation. Semi-structured interviews and focus groups with tenants and housing managers were used to map assets and understand everyday adaptations.

Research has pointed to the difficulty people have in relating what seems to be a very distant or abstract concept like climate change, to their everyday lives and everyday practices. Barr (2011) argues that:

... the complexity of climate change necessitates reductions in socioeconomically pervasive gases such as methane, carbon or sulphur dioxide. For most people, their relationship with these gases is unconscious and embedded in the practice and materialities of everyday life (Barr 2011: 16; 1979 (updated July 2012)).

Moreover, according to Hobson and Niemeyer (2011) people are not always aware of the reasons and motivations for adaptive action. Selecting appropriate methods for exploring climate change adaptation is therefore a challenging and important task. As Hobson and Niemeyer explain:

...questions of how to stimulate and sustain an array of positive collective and individual responses [to climate change] remain contentious and challenging (2011: 958).

In this project we discussed adaptation with participants through the lens of the more commonly used term sustainability. By discussing practice through sustainability (although still an abstract term), we are open to the diversity of responses around why, for example, people are adopting energy efficiency or water saving practices and what meaning participants place on these practices in regards to climate change.

Semi-structured interviews and focus groups are a very common methods used in geographical enquiry because they provide a rich and detailed account of participants' 
reflections on their practices. They are appropriate for this research because they are an effective means of collecting stories about everyday practices, adaptations and barriers to adaptation. Interviews and focus groups provide a way for tenants and housing managers to discuss their sustainability practices and identify assets through connecting these to their motivations and understandings.

Therefore we devised interview and focus group questions that gave room for participants to talk about their practices and motives, information sources and barriers to adaptation, thus providing space for the messiness of everyday adaptations to be revealed. They leave room for tenants and housing managers to make connections between practice and climate change (see further details below and Appendices 4, 5 and 6).

The tenant interviews were semi-structured, and questions begin by focusing on and using the terminology of sustainability practices and environmentally-friendly practices, in order to allow for a broad spectrum of initial responses. We recognised the power of language to close down and open up possible responses to climate change and thus made space for more general responses to questions around sustainability practices before asking specific questions on climate change. This allowed people to make sense of climate change in their own way and show how they are doing this in their responses to the interview questions.

Topics covered in interviews with public and private housing managers were different from those for tenants, in order to develop a picture of the broader roles of institutions and organisations in manager approaches to tenant adaptations. Interviews with public housing managers additionally focused on the organisation's sustainability program, and its approach to sustainability practices and infrastructure assets along with information networks. Interviews with public housing managers discussed barriers to change within the institution and the major opportunities for further facilitating the adaptation of public housing tenants.

Interviews with private housing managers focused on the private rental sector, and assets and issues that affect sustainability in this sector more specifically. In interviews with public and private housing managers' terms such as environmentally positive, sustainability, environmentally-friendly habits etc. we used to capture the diversity of practices and approaches to adaptation rather than framing the discussion solely around adaptation and mitigation. People do not necessarily make distinction between mitigation and adaptation when they reflect on their everyday sustainability practice. Our focus was on understanding the capacities (assets) alongside the barriers forging connections between housing managers/landlords and tenants. Focus groups provided this space of connection as these two groups had the opportunity to identify the assets and possibilities together. As Goss and Leinbach (1996) argue:

Focus group discussions are social events and, typically, the range of personalities and perspectives involved, and the dynamic rhythm that develops under the direction of a skilled moderator, generally sustains participation more effectively than the in-depth interview (1996: 117). 
Focus groups are sites of co-learning and participation that have most commonly been used in market research and psychotherapy studies (Crang and Cook 2007: 90). Members of the groups discuss a particular topic and learn from the experience and input of others. It is important that "...focus groups should be viewed as a performance by all concerned, with participants and researcher all positioning themselves through the group discussions" (Smithson 2000: 116). Focus groups are particularly appropriate for identifying assets and the potential for adaptation as the discussion between group members can open up consideration of potential futures.

We conducted tenant-only focus groups and mixed groups comprising housing managers and tenants. Some tenants were not comfortable attending a focus group with their housing manager and so offering a different possibility was an ethical option. Much of the literature on focus groups points to the importance of keeping the groups as homogenous as possible in order to ensure participants are able to speak freely (Cameron 2005; Goss and Leinbach 1996; Smithson 2000; Smithson 2008). Focus groups comprised only of tenants remove potential power imbalances or inhibitions that might occur between tenants and housing managers. However the mixed groups offered the important opportunity of opening dialogue between the groups about possibilities for change. As Cameron (2005) argues:

The interactive aspect of focus groups also provides an opportunity for people to explore different points of view, and formulate and reconsider their own ideas and understandings (2005: 159).

Given the importance of relationships in the sector to enhancing climate change adaptation such occasions for encounter are critical. Approaching focus groups as potentially transformative research engagements which can change assumptions, ideas and opinions, is consistent with our methodological approach of exploring assets. Participants can challenge and question the views of other participants, providing an opportunity for people to encounter diverse opinions and ideas (Cameron 2005).

In the next section we discuss the processes of case study selection, recruitment, describe the conduct of the interviews and focus group and discuss the analysis of the empirical generated by the interviews.

\subsubsection{Case study selection}

The research was conducted in two sites in Newcastle, NSW, a coastal location expected to confront significant problems caused by sea-level rise and increased storm and flood activity due to climate change. The urban locality of Newcastle, based on the Local Government Areas of Newcastle and Lake Macquarie, has a population of nearly 300,000 people and over 20,000 public and private rental properties (ABS 2006). It is sufficiently large to contain a range of tenancy types and relationships comparable to other Australian cities, while remaining a manageable research site. The two case study sites selected represent two important aspects of the adaptive vulnerability of Newcastle housing. Inner-Urban Newcastle contains a significant amount of lowincome, medium-density rental properties potentially under flood risk due to climate change. The Toronto district of Lake Macquarie contains low income, low-density housing properties in the vicinity of the lake. The physical assets represented by the 
housing stock of these two locations - houses, terraces and flats - are indicative of most housing assets in Australian cities. These case studies therefore allowed insights into the possibilities for adaptation elsewhere in Australia.

Tenants and housing managers in the private and public sector were recruited for interviews and focus groups for the research. The next section discusses the recruitment of participants.

\subsubsection{Recruitment methods}

Renters and housing managers were recruited in the private and public rental sectors using a variety of methods.

Private renters were contacted in the following ways:

1. Public notices: via posters/fliers placed in real estate agencies, cafes, public notice boards, libraries, and other public venues in the two research sites. These notices invited potential participants to contact the researchers, and to attend an information session held in each of the research sites. For public tenants, permission was sought from the Director-General of Housing NSW to also display fliers on estate noticeboards, and include items in tenant newsletters or other avenues used by Housing NSW to communicate with tenants

2. Through community organisations: Community Groups were approached to include an invitation to participate in their Newsletter or email communications with their members. Community groups were selected which had an interest in the environment, sustainability, climate change in particular, or had a connection with tenancy and housing issues. A list of these community groups and area of relevance to the project is at Appendix 8 . Members of the community groups who were renters were invited to contact the researchers and to attend an information session at either of the research sites

3. Information sessions: The information sessions were intended to inform potential participants about the study and provided them with information regarding climate change adaptation.

Renters were recruited when they responded to a public notice or newsletter, contacted the researchers, received an Information Statement and returned a signed consent form. In the Information Statement they were invited to opt for an interview and/or participation in a focus group. Renters who opted for a focus group were given the choice of participating in either a focus group comprised exclusively of renters, or one that included both renters and housing managers (private and public see discussion in the previous section).

Private rental housing managers and real estate agents were selected from the Yellow Pages on the basis of the area they serviced with rental accommodation. An information statement was sent to the person in charge of rental properties at the agency, with an invitation to participate in the project. They were asked to participate in both an interview and a focus group. Housing managers were recruited when they signed a consent form. 
To recruit Housing NSW staff, permission was received from the Director-General of Housing NSW to approach relevant housing officers in the Northern Region Housing NSW Office. Researchers liaised with Northern Region Housing NSW Officer to identify key housing managers. Housing managers involved in both tenant management and asset management were approached for interviews. In addition the Environmental Sustainability Officer of Housing NSW was interviewed for the project. An Information Statement was sent to nominated staff inviting them to participate in both an interview and a focus group. Housing NSW staff members were recruited when they return a signed consent form.

At the conclusion of interviews (with both renters and housing managers) selected respondents were invited to participate in creating YouTube clips which detail a range of examples of climate change adaptation. Renters and managers were selected to provide a range of different types of adaptations in the YouTube clips. Those who were willing were given an Information Statement regarding the videos and a suitable time was arranged for filming. Participants were recruited when they return a signed consent form.

\subsubsection{Recruitment}

Despite the wide distribution of recruitment material, and conducting four public information sessions, recruitment of renters was lower than hoped. A total of 19 private housing tenants and 3 public housing tenants were interviewed. Despite comprehensive recruitment activities in the Toronto, Lake Macquarie area, only one tenant from that area participated in an interview.

The recruitment process encouraged participation by tenants with a particular interest in sustainability and/or climate change adaptation. While the project was in part motivated by concern for the climate adaptation needs of low-income households which are disproportionately represented in rental housing, our focus in recruitment was not on the socioeconomic status of interviewees but on mapping those assets and adaptive practices already present in the rental sector.

In the case of public housing tenants, delays in recruitment and the low response rates meant it was not possible to organise a focus group for these tenants. However 12 private housing tenants participated in focus groups.

Recruitment of public and private housing managers was more successful, and a total of 7 Housing NSW managers, 1 community liaison officer with a community housing organisation, and 9 private property managers were interviewed. Three of the private property managers also participated in focus groups. We were also unable to recruit any private property managers in the Lake Macquarie area, but several public housing managers in this area agreed to be interviewed.

A summary of those interviewed and those who participated in Focus Groups is shown in Table 2 below. 
Table 2: Interview and Focus Group participants

\begin{tabular}{|l|l|l|}
\hline $\begin{array}{l}\text { Interviewee } \\
\text { category }\end{array}$ & $\begin{array}{l}\text { Number } \\
\text { interviewed }\end{array}$ & $\begin{array}{l}\text { Number } \\
\text { participating in } \\
\text { Focus Groups }\end{array}$ \\
\hline $\begin{array}{l}\text { Tenants } \\
\text { (public housing) }\end{array}$ & 3 & 0 \\
\hline $\begin{array}{l}\text { Tenants } \\
\text { (private housing) }\end{array}$ & 19 & 12 \\
\hline $\begin{array}{l}\text { Housing managers } \\
\text { (social housing) }\end{array}$ & 8 & 0 \\
\hline $\begin{array}{l}\text { Housing managers } \\
\text { (private sector) }\end{array}$ & 9 & 3 \\
\hline Total & $\mathbf{3 9}$ & $\mathbf{1 5}$ \\
\hline
\end{tabular}

\subsection{Conducting the interviews and focus groups}

\subsubsection{Interviews}

Interviews were generally conducted by two members of the research team in the tenant's own home or a housing manager's office. Interviews were generally one hour in length.

The semi-structured interview schedule (see Appendices 4 and 5) introduced a discussion about sustainability then focused more specifically on climate change. It allowed time for tenants and property managers to expand on areas of particular concern to them, but was designed to cover at least the following areas:

\subsubsection{For tenants:}

- a description of their home in their own words, including the features they liked best and least about it, and including environmental features of the home

- everyday sustainability practices by the tenants to conserve water, energy, grow food, reduce waste or consumption

- motivations for acting sustainability

- information assets and networks which supported their sustainability practices

- understanding of climate change and its impact upon themselves

- barriers to living sustainably or adapting to climate change

- changes they would like to be made to their home to make it more sustainable and adaptive to climate change

- their view of the role of housing managers and landlords in improving sustainability of rental housing and adaptation to climate change. 


\subsubsection{For housing managers}

Semi-structured interviews with private property managers included questions in the following areas:

- size and type of housing management portfolio

- perceived shifts towards sustainability in rental housing

- recent water efficiency legislation for rental housing

- impact of climate change on their work

- housing maintenance and sustainability

- experience with retrofitting properties for sustainability

- training and information networks or resources about sustainability and climate change

- barriers to improving the sustainability of rental housing

- engagement with landlords and tenants about sustainability of rental properties

- motivations to take action on sustainability and climate change adaptation

- additional training which would be useful

- changes needed to improve climate change adaptation and sustainability in the rental sector.

Interviews with NSW public housing managers also included specific questions on organisational approaches to sustainability and the implications of recent changes to administration which split asset management from tenancy management.

\subsubsection{Focus groups}

All participants in the Focus Groups had been previously interviewed individually as part of the research project, and all had agreed to participate either in a group which included both tenants and property managers (Focus Groups 1 and 2) or a group of tenants only (Focus Group 3), or either.

A facilitator and an assistant conducted the focus groups and scribed the main points of the discussion to butchers paper. The discussions were also audio-recorded.

The discussion was semi-structured around the following activities:

- a preamble by the facilitator about the purpose of the project, the asset-based approach, and the activities proposed for the focus group

- mapping of personal assets (done in pairs): gifts, talents, dreams, hopes, knowledge, fears

- mapping of sector assets (done in pairs): physical assets, associations, economy, institutions, individuals

- uncovering additional assets (in small groups or the whole group): what has been successful in the participant's home, business, workplace, what are their motivations to act

- areas for building capacity: what would a sustainable rental sector look like, how do we get there, what other building blocks are required to address climate 
change, how can the assets identified be used to make a more sustainable rental sector, who needs to be involved

- recommendations (small groups or the whole group): 3 key recommendations arising from the discussion, recommendations responding to climate change, who needs to be informed.

\subsection{Coding and analysis of primary data}

The interviews and focus groups yielded high quality data. The interviews were transcribed in full and the text coded using the qualitative data analysis program NVivo. This program supported the analysis process in two ways:

1. By enabling the researchers to identify emerging themes and sub-themes through clustering related comments across the participant groups

2. By providing immediate access to the words of tenants and property managers on these themes during the research writing stage.

The issues and recommendations arising from Focus Group discussions were recorded by a scribe and analysed alongside the interview transcripts for similarities and differences. Analytic focus was placed on identifying assets and capabilities that could enhance responses to climate change in the rental sector.

The main themes (which each had many sub-themes) emerging across the participants were:

- barriers and constraints to adaptation

- connections to place

- everyday practices of sustainability

- examples of modifications and adaptations

- ideas for change

- knowledge and networks to support sustainability

- motivations for sustainability

- relationships (tenant/landlord/property manager)

- responses to climate change.

Analysis of the transcripts of interviews and Focus Group records was used to reflect upon the theoretical work and the document analysis undertaken earlier in the project, and to identify entry-points for intervention which could inform on-going action elsewhere in Australia.

\subsection{Enhancing adaptive capacities: Development of public resources}

The research outputs of this project are intended to continue the work of enhancing the adaptive capacity of tenants and the rental sector more broadly. This has been done in two ways. 
1. With the help of the Steering committee a community implementation plan has been developed from the responses of tenants and housing managers during interviews and focus groups. This plan has four components:

a) the development of a best practice information guide for housing managers, landlords and tenants. The guide contains sustainability checklists for property managers, landlords and tenants; an overview of resources for renters; listing of our YouTube clips; a checklist fact sheet on gardening and chickens in rental housing; and a project overview. As part of our community implementation plan, it is intended that this guide be distributed to landlords and tenants via property managers as part of the leasing process. This guide will be available on the CURS website and be distributed to community groups

b) a workshop for property managers will be held in Newcastle, NSW, to disseminate the best-practice guide, overview the key findings of the project and provide an opportunity to enhance the role of property managers as sustainability 'knowledge brokers' by creating an knowledge-sharing environment for property managers

c) a launch of the 'sustaining rental life' YouTube clips targeted at tenants and the general public will be held in order to share knowledge and awareness of the project and resources that have been created to assist people in adapting to climate change

d) the dissemination of a postcard that publicises the research project in order to direct people to the resources created including our website, YouTube channel and Facebook sites.

2. YouTube clips have been produced that showcase innovative tenant adaptations and the role of housing managers in responding to climate change. These clips will reach a broad audience, and add significantly to the small number of YouTube clips made in Australia which show what tenants can do to be more sustainable in their homes.

The clips were made in the homes of the tenants who agreed to participate and the offices of housing managers. They are also accessible via the CURS website and this link has been disseminated to participants and interested community groups, NGOs and other interested parties. The steering committee for the project has provided many suggestions of fruitful dissemination avenues for the YouTube clips.

\subsection{University Ethics Approval}

The research was subject to the University of Newcastle Human Research Ethics approval process with an initial application submitted in December 2011. The ethics application engaged with issues of participant confidentiality, informed consent and detailed our tenant and housing manager recruitment processes. Final approval was not received until 27 March 2012, resulting in delayed recruitment of tenants and property managers for interviews and focus groups. We had originally hoped to complete recruitment by the end of March.

Moreover, our initial contact with the public housing organisation, Housing NSW, in accordance with our ethics process resulted in a requirement that we interview a senior management representative in the Sydney central office before contacting other Housing NSW staff or public housing tenants. 
These processes, along with other internal delays, restricted the time available for recruitment of public housing tenants in particular. Despite distributing over 2000 recruitment postcards to hundreds of cafés and libraries in the inner Newcastle, Toronto and west Lake Macquarie areas and contacting numerous community groups (see Appendix 8), our response rate for both public and private tenants and housing managers in the Lake Macquarie area was poor. 


\section{RESULTS, DISCUSSION AND OUTPUTS}

\subsection{Introduction}

This chapter examines firstly the way climate change adaptation in the rental sector is already framed, by analysing relevant media articles, existing sustainability resources for renters, and legislative and policy documents. It then uses this analysis, and the literature review above, to examine the primary data from interviews and focus groups. The conclusions at the end of each section inform the recommendations made in the following chapter.

The main themes which emerge from this chapter are:

- tenants are variously positioned in the media, in the targeting of sustainability and adaptation guides, and by property managers, as passive or active in adapting to climate change

- the rental sector remains marginalized in the development of policy and legislation in ways which have an impact on its capacity to adapt to climate change

- the tight rental market and lack of affordable housing in general is one of the greatest barriers to enhancing tenants' capacity to adapt to climate change

- tenants bring a range of strong assets to adaptation, including concern about sustainability and climate change, an array of adaptive household practices already embedded in their everyday lives, a desire to modify their homes to support these practices, engagement with the wider community on sustainability issues, and a range of information networks

- for tenants, in addition to housing shortages, the main barriers to adaptation are restrictive tenancy laws and a lack of communication between tenants, property managers and landlords, which limit tenants' capacity to adapt their homes to climate change. A lack of public transport or pedestrian/bicycle paths is also an issue for tenants wishing to act sustainably and adaptively, and rising energy costs is increasingly becoming an issue for low income tenants

- property managers bring strong assets to adaption in the sector including organisational systems to arrange maintenance and improvement of physical housing stock, a critical 'knowledge broker' role for both tenants and landlords, disaster preparedness systems (in some cases), and experience in implementing legislated changes

- for property managers, barriers to adaptation include a lack of leadership (in the private sector) on climate change issues, limited time and resources, some scepticism about the need for adaptation, and some negative experiences with implementing legislative changes, including the implications these processes can have for their relationship with landlords and/or tenants

- the public and private rental management sectors each have a different focus, the former tenant-focused and the latter more investment-focused, but for both sectors a shortage of resources is a major obstacle to improving the physical building stock to adapt to climate change. 
We commence our discussion of results with the secondary sources, media articles, tenant resources, policy and legislation before turning to our primary material.

\subsection{Discussion: Document analysis}

\subsubsection{Media reporting on the rental sector}

Media reports play an important role in constructing information about climate change (Anderson 2009; Slocum 2004; Carvalho 2010; Carvalho 2007). How climate change and the rental sector are framed through media reporting is of particular interest in this research project which is seeking to enhance the adaptive capacity of the rental sector. Media reporting can involve struggles over defining meaning and constructing public responses to policy by framing problems and using specific news narratives in order to shape how stories are interpreted (Mee 2004). As a politically charged issue, reporting on climate change is variable and inherently political (Anderson 2009; Slocum 2004; Carvalho 2010; Carvalho 2007). Communicating about climate change can be particularly difficult because of how distant the problem can seem from everyday life (Slocum 2004: 413). Media reporting also plays a significant role in constructing perceptions of the rental sector, including framing public housing policy responses and debates (Mee 2004).

The articles/media focus on four main themes: the rental market; carbon tax impacts; information on tenancy law changes; and sustainability. In each of these areas we identify the key focus of the articles and the ways in which the authors position the issues discussed. The discussion provides an overview of some of the discourses circulating in the Australian print, radio and online media on climate change, sustainability and rental housing. These discourses influence and inform the everyday practices of tenants and housing managers.

\subsubsection{Shortages of affordable housing}

Housing markets are framed in particular ways through media reports (Mee 2004). One framing of the rental sector throughout the media reports studied is a lack of affordable housing. In some areas the shortage is positioned as a crisis. The rental market of the Hunter region is positioned in this way. Canberra, Sydney, Melbourne and Newcastle are each highlighted as suffering from a shortage in affordable rental housing and as being negatively affected by rising rents (ABC 2012a; Anderson 2012; Dolan 2012b; Raimondo 2012; Dolan 2011a; Wade and Irvine 2012).

For example an article written for the Sydney Morning Herald explains:

Canberra's rental affordability crisis has been labelled the worst for any city in the country after a property snapshot found there was 'virtually no affordable housing' available for low-income earners in the ACT. Fewer than 140 listed properties suitable for a variety of low-income earners were recorded for the Canberra and Queanbeyan area in Anglicare Australia's annual Rental Affordability Snapshot, issued today (Anderson 2012). 
Renters across Australia are said to be experiencing "housing stress" with "[n]ationally, just over 60 per cent of the poorest 10 per cent of households... considered to be overstretched" (Cullen 2012). According to Dolan (2012b) and Raimondo (2012), in Victoria housing shortages are most pronounced in the lower-end of the housing market with more people entering the rental market, and less affordable houses being available to rent. Whilst in Sydney, Wade and Irvine (2012) argue that it is becoming increasingly difficult for people to buy homes, resulting in more competition for rental housing.

In the Hunter region, the latest census figures revealed that the price of rent is increasing, resulting in a housing crisis (ABC 2012a). Public housing in the Newcastle region is particularly seen as being in short supply with the "Hunter experiencing chronic public housing shortage" (ABC 2012b). Governments are positioned as being responsible for addressing the issue of housing affordability and such actions are clearly seen as out of the hands of tenants (ABC 2012a; Cullen 2012; ABC 2012b). Images of renters and the rental market more broadly are varied as the next sections discuss.

\subsubsection{Renters in the market}

Media reporting on renters, and the rental market more broadly, is varied, particularly when it comes to story-telling about life in rental housing. Of specific interest to our research is how renters are framed as either active or passive, bound by the regulations of their tenancies and their assumed meagre financial capacity (Toohey and Fritze 2009; Gurran et al. 2008). Renters appear in a variety of ways in these articles.

An example of general information provided to tenants is the advice for Melbourne tenants that appears in a semi-regular column by Kath Dolan who writes for The Age. The contentious relationship between landlords and tenants is regularly highlighted by Dolan. This relationship could be considered as narrated through the "problem frame" (Mee 2004: 121), a way of constructing people and relationships as inherently and intractably problematic. Dolan has articles on a variety of topics including the lack of affordable housing generally (Dolan 2011a) as well as the difficulty tenants have finding sustainable rental properties (Dolan 2012a). In an article on Green Moves, Dolan (2012a) interviews the founder, Dani King, who explains that there are not many sustainable rental properties available.

Dolan also writes information on particular aspects of Victorian tenancy law such as enabling tenants fee-free ways to pay their rent (Dolan 2011d). In these articles Dolan reports on events, rental legislation, changes in rental vacancies and general rental issues such as the length of leases and rising rents. Renters are constructed as passive in some situations, for example, tenants cannot always successfully encourage landlords to repair the property without incurring increased rent (Dolan 2011c). In other articles Dolan moves beyond the problem framing highlighting the importance of the landlord-tenant relationship, reporting that "the key to improving even a poorly performing rental property is a good relationship with your landlord" (Dolan 2012d). In 
this article tenants are positioned as actively able to change their everyday practices and relationships in order to live more sustainably.

Another mode of reporting that moves beyond the problem framing of rental housing is the story-telling mode adopted by a recent $A B C$ Radio National program called 'This Rental Life'. This series documented the life of a number of different renters, interviewing specific people on topics including renting and gardening; pets and renting; renovating and renting; housing cooperatives as a utopian form of renting; and renting in boarding houses (ABC Radio National 2012a). The series highlighted some of the problems facing tenants and landlords while also discussing some of the innovative practices of tenants and potential possibilities for improving rental life.

A discussion board on the topics covered in the program was provided after each episode on the website to continue the conversation. In these discussions both active and passive constructions of tenants were mobilised in and out of the problem frame. This website became a temporary moment for people to share more ideas and make comments such as:

... grab some larger plastic pots or even cheap buckets with some holes drilled into the base, fill them up with a premium potting mix, add some seeds and keep them watered, plonk the pots on the back patio or balcony and enjoy you're portable edible garden. This is a great way for renters to still grow their own vegetables at home (Patrick Johnstone 18th August at ABC Radio National 2012b).

A key issue of direct relevance to climate change adaptation that emerged in 2012 was a series of discussions of the impacts of the carbon tax on the rental sector.

\subsubsection{Carbon tax impacts}

Tenants will need to adapt not only to climate change, but to mitigation measures such as the carbon tax. The carbon tax was introduced in July 2012. The introduction of the carbon tax has an active role to play in the rental sector and may affect the economic assets of tenants and the way they behave in their home due to increased energy costs.

In the months preceding the introduction of the carbon tax in Australia, State governments in New South Wales, Queensland and Western Australia released information indicating they would increase public housing rents in response to the carbon tax. Fifteen of the 58 articles deal specifically with concerns over the effect rising rents will have on public housing tenants, and specifically on pensioners. Articles written around this time focused on the moves made by the NSW State government to raise the rents of public housing tenants in response to Federal government compensation for cost-of-living increases resulting from the tax (Caldwell and Helbig 2012; The Daily Examiner 2012; Tovey 2012; Wood 2012; Coorey and Wroe 2012; Harrison 2012; Martins 2012; Clement 2012; Drape and Bennett 2012). Headlines such as "O'Farrell accused of carbon tax compo raid" (Coorey and Wroe 2012), and "O'Farrell accused of 'grab' at pensioner carbon rebate" (Tovey 2012) surfaced after announcements were made that NSW public housing rents will be increased to take 
account of the increased "income" given to tenants to compensate them for the increased costs incurred from the carbon tax. An example of this was published in The Daily Examiner (2012) which argues that:

About 1400 public housing tenants in the region will be slugged with a hike in rent after the NSW Government announced that rents would increase from March 2013 when the state includes carbon tax compensation payments in people's income.

The emotive language evoked here was echoed in similar sentiments by other commentators in QLD who claim that:

Carbon tax pain looks set to deepen, with the State Government expecting to claw back compensation payments and hike public housing rents for some of Queensland's poorest families (Caldwell and Helbig 2012).

In WA:

The West Australian government has back flipped after saying it would take a quarter of carbon tax compensation payments from pensioners who live in public housing (Australian Associated Press 2012).

In each of the articles local government ministers, state housing ministers and the federal minister for housing are quoted as 'experts' justifying decisions or calling each other to account. In one article published in the Daily Telegraph, confusion about the effect of the carbon tax on public housing rents was evident:

Alison Peters, director of the NSW Council of Social Services said she was 'bemused' about the decision, particularly after being told in a post-budget briefing on Tuesday that the carbon compensation would not be counted as personal income. 'At that briefing a pensioner's group raised this exact issue, and was told (carbon tax compensation) would not be taken into account,' Ms Peters said. 'To hear today that there's been a change in position is a bit of a surprise. We are hoping to talk to the state government about what they are doing and why they appear to have changed their policy' (Wood 2012).

Each of these articles raises issues of climate justice and further disadvantage to vulnerable tenants. These articles are framed in terms of an issue - that carbon tax compensation is being taken by the State government from the public housing tenants or pensioners (depending on the article) - and this action is seen as unjust.

Public housing tenants are mentioned in these articles only as pensioners who are victims of the various governments' cash grab. The power is solely positioned with the governments or decision-makers who have decided to tax federal compensation measures. Two out of 15 articles inform people about a petition being run by NSW Labor MPs to challenge the "pension rent gouge" (AAP 2012). For example, Clement (2012) lets readers know that:

If you oppose the government's move to increase public housing rents, sign the petition at the office of your local Labor MP. 
Whilst governments are seen as powerful decision-makers, tenants are represented move in these two articles as still able to actively challenge this problematic policy. However, the majority of the articles written about the carbon tax "comp raid" (Coorey and Wroe 2012) position tenants as passive victims.

\subsubsection{Information on tenancy law changes}

The changes that have been made to the tenancy law in NSW by previous governments are reported on in a different way from the carbon tax reports. To canvas media response to recent changes made to the tenancy laws in NSW, we targeted both media articles that responded to shifts and discussions on tenancy laws more broadly. In NSW, new laws came into effect on the $31^{\text {st }}$ January 2011 . Articles written around that time highlighted the important changes for both landlords and tenants such as:

... changes to arrangements for rent payments, early termination by tenants, alterations by tenants, no grounds evictions, rent arrears, shared housing, subletting, security and tenancy database (Tarala 2011).

The overviews are brief and include information about how "tenants have at least one fee-free way to pay their rent" and "landlords gain clear right to show premises to prospective tenants or buyers at least twice a week" (Dickson 2011).

Some articles expose the tensions evident in the landlord-tenant relationship and document ideas about who benefits most from the changes made to the Act. For example it was reported that "[u]pdating 20-year old tenancy laws, the changes aim to level the balance of power between tenants and landlords" in the favour of the tenants (Dickson 2011). The Manly Daily published two pieces on the changes made to the Act that raised concerns about landlords being disadvantaged by the changes. For example, Nicastri (2011) interviews a local landlord and housing manager and reports that:

... the new Act attempts to balance the rights of landlords and tenants, and reduce disputes by making the law clearer and up to date with modern practices. But some landlords and real estate agents said some parts of the Act had made things less clear.

The new Act is implicitly criticised for disadvantaging landlords.

Fears about renters who damage property and threaten to undermine the investment of landlords are also presented. For example, Pike (2011) wrote a piece on "reckless renters", who "can leave landlords with a financial headache which could include lost rent and a long list of repairs". He goes on to say that "changes to the Act, which came into effect on January 31 this year, made some residential investors nervous" (Pike 2011). In this case the relationship between tenant and landlord is constructed as one that is tension-filled and the tenant as problem.

These problematic messages are present alongside more hopeful accounts of the tenant-landlord relationship. An article published in the Newcastle Herald written by Mathew Kelly (2011) reveals a more positive take on the changes. He reported that: 
... millions of litres of water will be saved in the Hunter each year thanks to new legislation requiring landlords to ensure their rental properties are water efficient (Kelly 2011).

Kelly (2011) interviewed a local tenant and reported on her first positive shower experience with the new water-saving shower head. These positive framings of tenants (and their enhanced experience following a change made by a landlord) are further expressed in connections made in the media between tenants and sustainability.

A few of the articles highlighted some potential difficulties in the implementation of the new legislation. For example Dickson (2011) explains that "there is some concern that the new legislation may deter people from entering the investment property market". Nicastri (2011) highlights a concern about tenants being able "to carry out 'reasonable' renovations". This concern in particular highlights perceived problems about how subjective terms in the Act will be interpreted. These articles point to the differences between policy intentions and implementation. This is critical because implementation is imperative to a policy intention being translated into a potential asset for, or barrier to, adaptation to climate change.

\subsubsection{Sustainability}

Media articles on renters and sustainability have been published in conjunction with specific events that connect ideas of sustainability with the rental sector or housing more broadly. These articles are framed in a positive way, showcasing particular events or practices that landlords and tenants are involved in. They therefore highlight the active roles of landlords, housing managers and tenants in moving towards making rental properties more sustainable.

Although the relationship between media reporting and changes to everyday practice is ambiguous, media reporting on sustainability practices can be seen as another important avenue through which people may be exposed to various adaptation practices (Anderson 2009: 166). Table 3 provides a summary of the types of changes to the everyday practices of tenants or landlords that are contained in four articles on sustainability. These articles make suggestions to landlords and tenants or showcase particular sustainability practices in contrast to other articles that have different purposes. 
Table 3: Sustainability Practices

\begin{tabular}{|l|l|}
\hline Sustainability Practice & Actor \\
\hline Use grey water & Tenant \\
\hline Don't place hot items in the fridge, and don't open the fridge door too often & Tenant \\
\hline Hang heavy, lined curtains & Tenant \\
\hline Use timer switches on heating and cooling systems. & Tenant \\
\hline $\begin{array}{l}\text { Stop draughts with door snakes or self-adhesive seals around windows } \\
\text { and doors }\end{array}$ & Tenant \\
\hline Turn appliances off at the power point when not in use & Tenant \\
\hline Invest in a portable rainwater tank & Tenant \\
\hline Switch to green power & Tenant \\
\hline Ensure fridge seals worked properly & Tenant \\
\hline Draught-proof with door snakes or rugs & Tenant \\
\hline Utilise passive solar design principles & Landlord \\
\hline Install insulation & Landlord \\
\hline Install heavy curtains and pelmets & Landlord \\
\hline Draught-proof property & Landlord \\
\hline Use gas appliances and heating & Landlord \\
\hline Turning off non-essential lights & Landlord \\
\hline Raise tenant awareness & Landlord \\
\hline Install solar & Landlord \\
\hline Use energy efficient appliances & Both \\
\hline Use AAA-rated shower heads & Both \\
\hline Install motion-sensor lighting & Landlord \\
\hline Install energy-saving devices, such as timers & Landlord \\
\hline Switch the property's electricity to Gold Standard Green Power & Landlord \\
\hline Provide recycling facilities and services for tenants & Landlord \\
\hline Install rainwater tanks for watering gardens and lawns & Landlord \\
\hline Tell your tenants about Earth Hour & Landlord \\
\hline Sour: & $2012 c)$ \\
\hline
\end{tabular}

(Sources: Lacey 2012; Melbourne Times Weekly 2012; Dolan 2011b; Dolan 2012c)

The types of sustainability, mitigation and adaptation practices for rental housing conveyed in media reporting differ slightly from sustainability practice guides targeted at tenants (see next section of this report). In sustainability guides landlords are positioned as able to play an active role in encouraging the sustainable practices of tenants by altering the physical fabric of the home through the installation of sustainable technologies (Dolan 2012c). Stories are told of what some "green" landlords have done to make their rental properties sustainable (Dolan 2011b).

A number of these stories of more sustainable practice come from an article by Dolan (2011b) titled "light-bulb moment for landlords". Dolan (2011b) captures the active role 
of landlords in improving the sustainability of properties by focusing on the annual 'Sustainable House Day':

Sustainable House Day offers inspiration to landlords to make improvements that add value and help retain good tenants (Dolan 2011b).

In this article Dolan interviews a 'green' landlord who discusses the benefits of sustainable housing for himself and the tenants:

Having happy, long-term tenants looking after a place means less spent on advertising for new tenants, fewer periods of no rental income and potentially less spent on damages and repairs (Dolan 2011b).

Sustainable House Day is seen as an opportunity to showcase the possibility of positive tenant-landlord relationships.

A similar event to the Sustainable House Day is Earth Hour. Earth Hour was used in one article to promote conversations between landlords and tenants around sustainability practices (Dolan 2012c). The article reports that in 2011 landlords were targeted by the organisers of Earth Hour to engage with their tenants and other landlords in order to encourage them to make more sustainable lifestyle choices:

'We're encouraging landlords to take an active engagement in Earth Hour', $\mathrm{Dr}$ Llewellyn says. 'We've got materials on the website- posters and flyers-so they can raise awareness with their tenants. It would be great if landlords want to host an event-sign up, bring your tenants together for a conversation about sustainability' (Dolan 2012c).

Other articles highlight the changes that renters can make to their homes. An example of this is an article by Lacey (2012) who reflects on his own renting experience and the expertise of Chris Ward from Green Renters who discusses greening rental properties:

Until recently, renters who wished to create a sustainable home didn't have many options. But all that is changing thanks to a swag of state and federal government programs (Lacey 2012).

This article raises awareness of the context of sustainability and the rental sector and provides a set of tips for renters to follow if they want to green their homes. Tips have been sourced from the Alternative Technology Association Renters Guide and include suggestions such as: "hang heavy, lined curtains.", "invest in a portable rainwater tank" and "switch to green power" (Lacey 2012). Other similar articles feature workshops that are held at local councils or with specific green groups such as 'Just Change', and the Moreland Energy Foundation (The Standard 2012; Dolan 2012d). There are articles on people living sustainable lives, who just happen to be tenants, such as the article by O'Dwyer (2011) called "Greener at the grassroots-Sustainable Sydney special report-Sustainable Homes" which showcases a couple living in Enmore:

In the front yard, the mulberry tree is heavy with dark berries and there are waisthigh clumps of green beans and fennel. Brussels sprouts, rhubarb and kale are ready to pick (O'Dwyer 2011). 
These articles share sustainable rental stories in a relatively positive light and serve to inspire readers to make changes. Such stories of positive landlord-tenant relationships and of active tenants and landlords are assets for encouraging climate change adaptation. Such stories work against the passive or necessarily problematic framing of the landlord tenant relationship to offer a different vision of how the sector could operate.

\subsubsection{Conclusions}

Media reporting contains a diverse array of tools to communicate climate change adaptation and policy responses as has been shown here. The articles reviewed portray tenants and landlords as both active and passive. There are a number of key themes emerging from the articles reviewed:

Firstly, some of the media articles raise key concerns about issues affecting the rental sector such as the lack of affordable housing and a housing shortage affecting the sector in particular localities. As we discuss below, rental housing shortage is a barrier to climate change adaptation in the short and long term. Governments are seen as needing to play a key role in addressing these concerns.

Secondly, and evident in the review of media on the carbon tax, the government is seen as having a responsibility to not further disadvantage poor people, in this case public housing tenants, through climate change mitigation measures. This is shown in the critique of the New South Wales and Queensland State governments and their raising of public housing rents. Here tenants are constructed as passive victims in critiques aimed at governments, and focusing on government responsibility to help public housing tenants.

Thirdly, the discourses circulating around the landlord-tenant relationship utilise a number of problem frames focusing on tensions, fears and stereotypes. However accounts of the possibilities for positive relationships between tenants, housing managers and landlords are also emerging. These are simultaneously playing out in print media and revealed on online discussion forums. They construct both tenants and landlords as responsible and active.

Finally the media items focused on sustainability and connected to particular events or groups highlighted the possibilities for action on the part of both tenants and landlords. Instead of drawing out the tensions in the relationship, these articles focused on the possibility for positive relationships between landlords and tenants to be fostered.

These articles played an awareness-raising role in providing information to tenants and landlords about potential sustainability practices by providing tips or stories of particular sustainability practices.

Overall the media items reviewed for this report simultaneously perpetuated and challenged existing discourses about the landlord-tenant relationship and the possibility of rental housing to be a site for sustainable practices and climate change adaptation. In general sustainability and sustainable practices are positioned in a positive light. There were some instances where tenants and landlords are constructed as playing an active role in practicing sustainability. However, from the media reviewed it is clear that 
very little connection is made between sustainability practices and climate change adaptation in the rental sector, revealing an important gap that remains to be filled.

\subsubsection{Resources for renters}

This section scopes the resources available to tenants about how they can make their homes more sustainable. It examines the kind of information already available and provides useful context for how best to target the resources for tenants developed as part of this research project. Crucially, it is a response to the question: Is there already enough information available to tenants about how they can make their homes more sustainable and how they can better adapt to climate change?

We begin by providing an overview of the different information sources available to tenants, including background on the different organisations that produce these resources. We then discuss examples of resources that seek to help mediate the tenant-landlord/housing manager relationship. We explore the suggestions provided to tenants about how they can change their own everyday practices, looking at more general guides and those that attempt to target particular groups of tenants, or tailor information to users. We conclude this analysis by reflecting on general trends in these documents and offering some observations about the role of specifically tailored information for tenants in enhancing the adaptive capacity of the rental sector.

\subsubsection{Sources of information}

The information made available to tenants comes in the form of information guides or websites, or as more general information on sustainable living from local government. Sustainable renters' guides are most often produced by local and state government departments or NGOs that have a specific goal of reducing environmental impacts and focus on mitigation, such as the Nature Conservation Council of NSW. Recently, one of Australia's largest real estate agents, LJ Hooker, has launched a sustainability website and also produced a guide for renters, showing how private companies are engaging with sustainability and beginning to produce their own resources (LJ Hooker 2012a). We explore these sources of information and how they construct tenants in terms of their assumed passivity or activity below. Each of these guides include collections of tips and practices for renters that sketch out what activities require landlord permission, and what they can do without permission.

In Australia, state-government legislation such as the NSW Residential Tenancies ACT 2010 regulates what tenants are able to do in their homes in that most minor changes that tenants make need to be approved by their landlord (NCC NSW 2012). The laws affecting tenancies are a significant focus of sustainability information that is made available to tenants. Because of the role of housing managers and landlords in regulating what changes can be made to the physical asset of rental housing, it is quite common to find resources that focus on everyday practices and habits that explicitly state they do not require permission from landlords (for example NCC NSW 2012; McCann 2010; Environment Victoria 2012). For example, in NSW tenants need their landlord's permission to install a water-saving shower head or build a vegetable garden. In the Nature Conservation Council of NSW (2012) guide there is a section specifically addressing the ambiguity of the Residential Tenancies Act (2010 (updated 
January 2012)) in relation to what classes as a "minor alteration" and what tenants need to ask permission to do. The suggestion in this guide is to approach housing managers or landlords "... about what could be considered minor alterations such as beginning a vegetable garden..." (NCC NSW 2012: 4). In NSW tenants can access information on what they can and cannot do during their tenancy through the NSW Fair Trading website which provides a number of guides based on the Act (NSW Department of Fair Trading 2011b; NSW Department of Fair Trading 2012a; NSW Department of Fair Trading 2012b).

Websites are an important source of information and there are an increasing number of sites that specifically address the sustainability practices of tenants. Information for renters appears in new websites such as the Liveability website of LJ Hooker (LJ Hooker 2012a). This site "is an initiative that supports people to make the sustainability choices that are right for them" (LJ Hooker 2012a). The website contains information for both home owners and renters on how to improve energy and water efficiency along with information on government rebates. Recently, the company has produced a "Rent Smart" guide in conjunction with the Alternative Technology Association, Kildonan Uniting Care and the SustainAbility Advice team (LJ Hooker 2012a). According to this guide,

You don't have to own your own property to reduce your environmental impact, save money and increase your comfort at home. Renters too can find many simple, inexpensive ways to reduce a rental home's energy and water use ( $\mathrm{LJ}$ Hooker 2012b).

Here, renters are positioned as being able to make significant changes to their everyday practices, a theme echoed in other resources including particular organisations directly targeting renters.

A number of renter-specific organisations have emerged over the last few years that focus on encouraging sustainable practice. Green Renters, provides information to tenants through providing workshops specifically on topics such as sustainable rental living, eco-crafting, preserving and green cleaning (Green Renters 2012). Green Renters is

... a not-for-profit organisation providing sustainability advice specifically for those living in rental accommodation. Renters are a growing part of the community and we believe their involvement is vital and possible (Green Renters 2012).

Another organisation that targets renters is Just Change,

... a not for profit organisation founded by six friends in Victoria who saw a gap in the current approach to energy efficiency and climate change action in Australia. We seek to fill that gap through an innovative program that gives renters, property managers and landlords the tools they need to access the many energy efficiency schemes available in Victoria (Just Change 2012).

This organisation is unique in its specific focus on climate change and the effects on rental households including a focus on property managers. Just Change provides 
training sessions for property managers about aspects of rental housing such as improving energy efficiency and issues affecting low-income tenants in particular (Just Change 2012). Interestingly both of these organisations are not-for-profits based in Victoria that have identified renters as a key target audience.

Another source of information that is web-based is the information provided by local governments. Local government websites often provide more general information on sustainable living, rather than information specifically targeted at tenants. For example in Newcastle, the Newcastle City Council (NCC) website provides general information on topics such as composting, grey water re-use, worm farming and provides general links to other sites (The City of Newcastle 2011). More recently, NCC has begun running workshops on keeping backyard chickens, solar power and conducting energy assessments (The City of Newcastle 2012). Lake Macquarie City Council (LMCC), provides brochures and workshops on sustainable living such as information about green cleaning, sustainable eating, saving water/energy/waste and sustainable transportation (Lake Macquarie City Council 2012d; Lake Macquarie City Council 2012e). They have also developed their own sustainable living guide, but this guide does not mention renters as a specific group. These resources are, however, available to renters as members of a carbon conscious community. In the next section we turn to our analysis of these resources, exploring how tenants are resourced in their relationships with landlords/housing managers.

\subsubsection{Relationships with housing managers/landlords}

The relationships between tenants and landlords/housing managers is one that is specifically addressed in many of the information resources due to the central role these actors play in the shaping the physical dwelling. Resources on sustainability acknowledge that there are changes that are solely reliant on the actions of landlords/housing managers such as those involving alterations to the physical asset of the home. Physical adaptations and changes to the rental property such as installing solar panels, installing insulation, fixing water leaks, installing fly screens and allowing tenants to install/modify/use garden beds require permission and action from landlords/housing managers. The relationship between landlords/housing managers and tenants is particularly important because of the legislative context and practices of landlords/housing managers in governing and shaping the physical fabric of the home and therefore influencing tenant's everyday practice.

Tenant guides have particular sections that address the landlord/housing manager and tenant relationship, usually by indicating which everyday practices can be undertaken without or with landlord/housing manager approval. In particular, the NSW Sustainable Renting Guide breaks up each potential way tenants can green their home into distinct headings within each section: 'what to look for', 'once you've moved in' and 'ask your landlord' (NCC NSW 2012). For example under water efficiency, this guide suggests to "ask your landlord for permission to install low-flow fixtures..." (NCC NSW 2012: 16). Other guides have specific icons that indicate practices reliant on landlord/housing manager involvement (LJ Hooker 2012b; Alternative Technology Association 2009). Here tenants are positioned as having the ability to ask for changes to be made to improve their physical dwelling. 
Interestingly though on a legislative note, the installation of water efficient household technologies in rental properties is required under legislation in NSW and QLD (and a review in Tasmania made a similar recommendation). The legislation makes the installation of water-saving shower heads and aerators/flow restrictors on taps mandatory for all rental properties where the tenant is charged for water. Other changes that landlords are responsible for such as installing curtains or water tanks are not mandatory but are encouraged as potential contributors to making rental properties more comfortable to dwell in and making it easier for renters to adapt to climate change. The role of legislation and the law is highlighted in resource guides which equip tenants with knowledge about their rights and responsibilities and what they can and cannot do in relation to their home under the law as tenants.

Because of this, some information resources provided to tenants contain information on how to approach your landlord or housing manager to ask for changes to be made (NCC NSW 2012; LJ Hooker 2012b; Environment Victoria and Tenants Union of Victoria Ltd 2010). For example, in the Liveability Rent Smart guide tenants are encouraged to "work with your landlord or property investment manager to achieve the best possible results" (LJ Hooker 2012b: 20). Both this guide and the Alternative Technology Association guide provide a template letter for tenants to customise in order to contact their housing manager or landlord about making changes (Alternative Technology Association 2009; LJ Hooker 2012b). The Liveability guide suggests,

Before contacting your property investment manager or landlord it is a good idea to research state and federal government tax deductions and rebates for improvements/upgrades that will reduce the environmental impact and ongoing running costs of rental properties (LJ Hooker 2012b: 20).

This guide suggests tenants do research into state and federal government rebates or tax deductions that may be available if improvements are made (LJ Hooker 2012b: 20). Other guides suggest that tenants "tell them it's a good investment" or "tell them it's tax deductable" in order to persuade landlords to make the changes (Environment Victoria and Tenants Union of Victoria Ltd 2010). Tenants are positioned as having the capacity to work effectively with housing managers and landlords to get a favourable sustainability outcomes (LJ Hooker 2012b: 20). However, the majority of practices listed in these resources do not require landlord/housing manager involvement, rather, they aim to shift the everyday practices of tenants.

\subsubsection{Tenant practices}

The information provided to tenants aims to shift tenant everyday practices to make them more sustainable. Tenants are positioned as active most clearly in guides that outline the changes they can make to their habits and everyday practices. We know from Moloney et al. (2010: 7616) that "information can be an important first step in prompting people to change their behaviour. However, information alone is unlikely to motivate changes as a matter of course". In this section we firstly discuss the use of checklists, tips and suggestions and explore the way in which more general guides communicate to tenants. Secondly we analyse a new resource that has been produced by Housing NSW (the NSW government body responsible for the provision of public housing) called "Welcome to your home", which provides information about how public 
housing tenants can save energy and water and is the first of its kind in Australia (NSW Department of Family and Community Services 2012). We use this brochure as an example of a new practice of Australia's biggest residential landlord, and one that may be the forerunner to developments elsewhere in Australia as a sustainability guide targeted at a particular community of tenants. And finally we explore examples of resources, such as carbon/ecological footprint calculators and web-based forums, that shift beyond the positioning of the individual as a tenant and attempt to interactively engage individuals/households as members of a carbon-concerned public in an effort to enhance sustainability outcomes more broadly.

\section{General guides}

The majority of the practices listed in guides on sustainable living require changes in everyday practices, habits and routines more than monetary capital, ownership of property or additional knowledge and specific skills. These practices can be adopted without consulting or obtaining permission from landlords and arguably owneroccupiers could also engage in these practices in order to reduce their environmental impact. It is argued that by adopting the suggested new practices or altering existing practices, tenants will reduce the environmental impact of their lifestyles. At the same time these practices would also reduce the amount of money that the tenants spends on water, energy and food, potentially enhancing the adaptive capacity of tenants. However these resources have been produced specifically for tenants and the targeting of that audience is important perhaps to counter prevailing understandings of the passivity of tenants (Mee 2009). As the Nature Conservation Council of NSW chief Executive officer explains:

[W]hile renting can have some impact-after all you do not have complete control over the physical structure of your home and finances may be limited-it does not have to be a barrier to living sustainably (NCC NSW 2012: 3).

A tenant's understanding of themselves as unable to make changes in their housing could potentially be a barrier to climate change adaptation. We are particularly interested in how this information is presented.

Resource guides targeted at tenants mostly contain tips and suggestions of possible everyday practices, materials and habits tenants can adopt. Sustainability practices are grouped under particular themes, based on rooms such as kitchen and bathroom, or more general areas such as: energy saving practices, water saving practices, food/consumption/waste practices, transport practices and gardening practices. Information is provided on specific practices coupled with facts on what happens when you change your practice as shown in Table 4. 
Table 4: Suggested Tenant Practices

\begin{tabular}{|l|l|l|l|}
\hline $\begin{array}{l}\text { Type of } \\
\text { Practice }\end{array}$ & $\begin{array}{l}\text { Suggested } \\
\text { practice/ } \\
\text { question }\end{array}$ & Excerpt of Explanation & Source \\
\hline $\begin{array}{l}\text { Energy } \\
\text { saving }\end{array}$ & $\begin{array}{l}\text { Leave the } \\
\text { fridge 20\% } \\
\text { empty }\end{array}$ & $\begin{array}{l}\text { "Fridges work best when not too } \\
\text { full or too empty as it allows the } \\
\text { cool air to circulate" }\end{array}$ & (NCC NSW 2012: 12) \\
\hline $\begin{array}{l}\text { Water } \\
\text { saving }\end{array}$ & $\begin{array}{l}\text { Mulch } \\
\text { Garden Beds }\end{array}$ & $\begin{array}{l}\text { "Mulch on garden beds and pots } \\
\text { can help reduce water evaporation } \\
\text { by up to 70\%." }\end{array}$ & (LJ Hooker 2012b: 15) \\
\hline Food & $\begin{array}{l}\text { Do you grow } \\
\text { your own } \\
\text { food? }\end{array}$ & $\begin{array}{l}\text { "If you're feeling keen, one of the } \\
\text { most sustainable ways of getting } \\
\text { food is to grow a few veggies on } \\
\text { the balcony or some herbs on the } \\
\text { window sill." }\end{array}$ & $\begin{array}{l}\text { (Environment Victoria } \\
\text { and Tenants Union of } \\
\text { Victoria Ltd 2010: 12) }\end{array}$ \\
\hline Outdoor & Use a broom & $\begin{array}{l}\text { "Clean down paths and driveways } \\
\text { with a broom or rake rather than a } \\
\text { leaf blower or hose" }\end{array}$ & $\begin{array}{l}\text { (Alternative } \\
\text { Technology } \\
\text { Association 2009: 13) }\end{array}$ \\
\hline
\end{tabular}

Source: (Alternative Technology Association 2009; NCC NSW 2012; LJ Hooker 2012b)

The Victorian Green Renter's Guide structures its guide around posing particular questions, providing multiple choice responses (like a survey) and explaining facts and resources on why a particular practice is preferable (Environment Victoria and Tenants Union of Victoria Ltd 2010). This is a more interactive way to structure a resource guide than providing a long checklist of practices with their additional facts and figures.

Because various sustainability measures that are suggested by these guides are dependent upon housing location (for example, access to public transport) some develop checklists to help tenants make informed decisions about which property to rent (see NCC NSW 2012). Other checklists have been designed to help tenants assess the physical assets of a rental property, for example, whether or not it has a vegetable garden, solar hot water, or curtains etc. (Environment Victoria and Tenants Union of Victoria Ltd 2010).

More broadly, critiques of information provision claims this practice suffers from being overly generic: it fails to attend to diverse audiences, and presumes that energy and resource use are imbricated in everyday household practices in largely similar ways in all households (Strengers and Maller 2011; Waitt et al. 2012; Whitmarsh et al. 2011). At times resources overplay what tenants can realistically achieve, for example the Rent Start brochure suggests that "if possible, use gas for cooking" (LJ Hooker 2012b: 11 ), assuming that tenants have the choice. Or they can overlook the complexity of the suggestion, for example if the tenant purchased $100 \%$ green power it may be more sustainable to cook with an electric rather than a gas stove. Further, they can overlook the difficulty of accessing rental accommodation close to public transport in already tight rental markets. 


\section{Specific guides}

We turn now to an example of a resource guide that is particularly targeted at a specific group of tenants-public housing tenants. We then examine ecological footprint calculators as interactive tools that are potentially attempting to address some of the problems of providing generic information to tenants and members of the carbon conscious community.

Carbon or ecological footprint calculators are more dynamic information tools that seeks to generate information tailored to set responses. Although carbon and ecological footprint calculators are not tailored specifically at tenants, these interactive and dynamic tools are another way that organisations and governments provide information on sustainability and climate change that attempts to move beyond the 'one size fits all' approach. Carbon footprint or ecological footprint calculators are interactive tools that assist individuals calculate their personal and household environmental impacts (Bottrill 2007; Franz and Papyrakis 2011). They are most often directed at encouraging people to engage in mitigation measures such as decreasing energy consumption. Carbon calculators are often produced by NGOs in conjunction with governments or business. Bottrill (2007: 2) explains that:

Carbon calculators have been developed primarily to increase awareness of the connection between fossil fuel use and carbon emissions and/or to enable people to invest in carbon saving projects to offset their emissions.

Carbon calculators are interactive, posing questions about specific consumption choices (e.g. choice of local food, transport options) and living arrangements (how many people live in the dwelling, do they buy green power etc.) and then making suggestions about how to reduce emissions through changes in lifestyle. One example of an ecological footprint calculator is provided on the Lake Macquarie City Council (LMCC) website (Lake Macquarie City Council 2010). The calculator available on the LMCC website features an animation and a series of questions that calculate the number of planet earths needed to sustain a person's current lifestyle, the amount of land needed to support them, and suggestions for reducing their ecological footprint (Lake Macquarie City Council 2010). Users are then able to make changes to their calculations and pledge to change particular lifestyles in order to reduce their impacts. They have been critiqued by Franz and Papyrakis (2011) for not providing a way for people to "...fully offset one's environmental impacts..." or change their lifestyles to such an extent as to prevent environmental destruction (Franz and Papyrakis 2011: 392). Yet they do tailor suggestions to the answers given by participants, and as such may speak to renters as members of a carbon concerned public.

Another example of a more targeted guide is the "Welcome to your Home" brochure produced in June 2012 by the NSW government body responsible for the provision and management of public housing-Housing NSW. This booklet has been produced for a targeted group of tenants-public housing tenants-and provides suggestions about how to save energy and water. The first of its kind in Australia, this booklet contains a range of information for public housing tenants structured around how to reduce energy use, how to reduce consumption, how to reduce water use, how to reduce waste and how to buy seasonally (NSW Department of Family and Community Services 2012). 
Other State Housing Authorities offer information on sustainability (for example the Office of Housing Victoria, You and Your Home guide includes sustainability information, however this is the first targeted guide).

Whilst much of the information mirrors that already discussed, some of the tips for tenants provided in this guide do not appear in other resource guides. For example, in the 'Family and Kitchen' (NSW Department of Family and Community Services 2012) section tenants are told that it is better to "thaw frozen foods on the bottom shelf of the fridge before cooking" (NSW Department of Family and Community Services 2012: 7). In the sub-section on "Children and Family" suggestions are made about how to save money at the same time as being environmentally sustainable such as using cloth nappies, buying pre-loved clothes and making use of toy libraries instead of purchasing new toys (NSW Department of Family and Community Services 2012: 6).

This guide is comprehensive and has clearly been targeted to a group of low-income tenants. The Housing NSW 'Welcome to Your Home' booklet represents an attempt to produce information specifically targeted at public housing residents, including implicit references to public housing tenure in enabling adaptation. For instance, the guide refers to the role of gardens which are easier for public housing tenants with long term tenure to cultivate than for tenants in the private sector. The document also encourages renters to report leaky taps to maintenance, alerting them to the role of the landlord in maintaining their property in a sustainable way. The guide provides a link to the 'NILS' (No Income Loan Schemes), available in some areas to assist low income households purchase essential household items (that could include energy efficient appliances). This information could be viewed as endeavouring to tailor information appropriate for a specific group rather than producing a generic resource. In this way, it diverges somewhat from one of the common critiques of information as a strategy to encourage change, which is that it fails to recognise diverse audiences (Strengers and Maller 2011; Waitt et al. 2012; Whitmarsh et al. 2011) .

At the same time, the information provided reveals assumptions about the mobility and livelihoods of public housing tenants most obviously seen in the section on "summer cooling" where a suggestion is made that "If your home is too hot, go somewhere cool like a library, shopping centre or the movies" (NSW Department of Family and Community Services 2012: 4). Whilst this suggestion seems logical for those of us with the means to travel, we know that some tenants (and home owners) may be unable to leave home due to lack of mobility, or caring responsibilities for a child, sick or elderly person. In Strengers and Maller's work on cooling practices, where 'travelling' is especially associated with vulnerable groups:

[t]his would require understanding, embracing and supporting the diversity of practices amongst specific vulnerable population groups (e.g. low-income households, young children and those with mental ill-health), in addition to attempting to change elements of practices and encourage new forms of circulation within these groups. In particular, encouraging cooling practices and their carriers to 'travel' (to shopping centres, libraries, pools and cinemas) and therefore to integrate with other practices (such as shopping, reading, swimming or seeing a film) may be an appropriate policy response in the short term or 
where providing air-conditioning and/or retrofitting more thermally efficient homes is unfeasible (Strengers and Maller 2011: 165).

What this example shows is the complexity of providing targeted information to diverse groups in the form of a paper guide or resource that is unable to account for the particular circumstances of all tenants.

\subsubsection{Interactive forums}

Online forums are a growing practice targeting tenants that we wish to briefly highlight. Online forums potentially assist people make changes through collaborative knowledge sharing. They potentially provide people with a digital space to grapple with and discuss the complexities of what it means for them to adapt to climate change and live sustainably, because answers can be tailored to individual challenges. For example, the 'Reduce your footprint' site, which is a collaboration between three local governments in the Eastern suburbs of Sydney, contains blog posts on particular topics, question and answer discussion forums, event/workshop listings and other projects (Reduce your footprint 2012). A resource such as this specifically targeted at sharing tenant-knowledge might assist tenants to develop context-specific responses that address their needs and weigh up the complex ethical and practice-based decisions that are made every day.

\subsubsection{Conclusions}

The types of information available to tenants along with a list of practices that are reliant upon the actions of landlords, and those changes to practice that can be undertaken by tenants alone have been reviewed here. Many of these resources are constructing tenants as active, yet problematically, very little literature on tenants reflects this active positioning of tenants (Mee 2009). It is clear from the preceding discussion that the practices of tenants that are reliant on the approval of landlords are only a small percentage of the overall changes that tenants can make to improve their adaptive capacity and sustainable living practices. Moreover, there is a messiness and overlap in the fields of adaptation, mitigation and sustainability, particularly when it comes to providing resources for tenants. Most sustainability resources for tenants do not specifically address climate change adaptation. Yet the everyday practices listed in resources on sustainable renting will potentially assist tenants to mitigate and adapt to climate change. Creating resources for tenants on adaptation strategies may not require additional work in identifying what constitutes adaptation versus sustainability. However the relative absence of resources that specifically focus on adaptation moves us to question what other adaptation practices tenants will need to adopt in the context of climate change that are specific to their location and subjectivity as a tenant? How might regulations and legislation help facilitate adaptation in ways that adopting more sustainable living practices cannot? Moreover, are tenants adopting the practices suggested in the guides reviewed?

The types of resources listed here reveal the importance of contextually appropriate guides and materials that are not 'one size fits all'. This information needs to be provided in a way that moves beyond a generic approach to encourage collaborative knowledge sharing that takes account of the nuanced complexities of what it means for 
tenants to adapt to climate change and live sustainably. The types of resources reviewed here show the emergence of more interactive resources that are attempting to elicit changes to tenant practice. Information targeted specifically at tenants is important. Indeed, this is increasingly recognised with the guides reviewed being published by both public and private housing managers. Including the household rental sector as a distinct yet diverse node with distinct adaptation requirements will be imperative for developing situated climate responses.

\subsubsection{Policy and legislation}

\subsubsection{Introduction}

The review below shows the ways in which policy and legislation, not only in tenancy law but across a wide range of areas, affects the sustainability practices and adaptive capacity of the rental sector, in particular for those on low incomes. It discusses the roles of Commonwealth, State and local government in provision of housing, infrastructure (transport, electricity, water) and information and education about sustainability and adaptation. In these areas, the actions at each level of government, and the ways in which costs and responsibilities are shifted between them, will have an impact on access by tenants to affordable and sustainable housing, public transport, pedestrian and bicycle paths, affordable and sustainable energy and water; it will also have an impact on the capacity of communities to respond to disasters.

Ecologically Sustainable Development is a critical component of government policy in a number of areas. In this report, and in accordance with the pro-poor approach adopted in our study, it is discussed with a focus on the principle of equity, which requires policies and legislation with environmental impacts to also take account of social or equity impacts. This has particular relevance for policy affecting climate change adaptation in the rental sector, where low-income households are disproportionately represented.

This discussion of policy and legislation finds that the current marginalisation of the rental sector in the design and implementation of policy is an important equity issue. For example, the development of new legislation on building standards, of development controls in flood-prone areas, of electricity and water pricing mechanisms, does not explicitly include an assessment of their impact on sustainability and adaptive capacity in the rental sector. Many of the government guides for householders on adapting to climate change recommend actions which are not options for those in rental housing.

This review concludes that, as a significant contributor to climate change adaptation, and a significant area of impact for adaptation policies and legislation, the rental sector needs to shift from the margins to occupy, alongside home-owners, a central position in policy development and evaluation.

\subsubsection{ESD, equity and climate change in policy and legislation}

The first formal commitment by the Commonwealth Government to ESD occurred around the time of the 1992 Rio Declaration on the Environment and Development by 
the United Nations (UN Conference on Environment and Development 1992), and was consistent with key principles of Sustainable Development in the Declaration, namely:

- Principle 3: the right to development must be fulfilled so as to equitably meet developmental and environmental needs of present and future generations

- Principle 4: in order to achieve sustainable development, environmental protection shall constitute an integral part of the development process and cannot be considered in isolation from it

- Principle 15: in order to protect the environment, the precautionary approach shall be widely applied by States according to their capabilities. Where there are threats of serious or irreversible damage, lack of full scientific certainty shall not be used as a reason for postponing cost-effective measures to prevent environmental degradation

- Principle 16: national authorities should endeavour to promote the internalisation of environmental costs and the use of economic instruments, taking into account the approach that the polluter should, in principle, bear the cost of pollution, with due regard to the public interest and without distorting international trade and investment (UN Conference on Environment and Development 1992).

The National Strategy for Ecologically Sustainable Development (1992) (DSEWPC 1992) thus defined ecologically sustainable development as:

... using, conserving and enhancing the community's resources so that ecological processes, on which life depends, are maintained, and the total quality of life, now and in the future, can be increased.

The Strategy also stated that its core objectives were

- to enhance individual and community well-being and welfare by following a path of economic development that safeguards the welfare of future generations

- to provide for equity within and between generations

- to protect biological diversity and maintain essential ecological processes and life-support systems (DSEWPC 1992).

The 1992 Intergovernmental Agreement on the Environment was endorsed by Commonwealth State and Territory Governments, and by the Australian Local Government Association. It stated that:

The parties consider that the adoption of sound environmental practices and procedures, as a basis for ecologically sustainable development, will benefit both the Australian people and environment, and the international community and environment. This requires the effective integration of economic and environmental considerations in decision-making processes, in order to improve community well-being and to benefit future generations (DSEWPC 2010).

The goal of ecologically sustainable development (ESD) is thus the integration of positive social, environmental and economic outcomes, providing for equity within and between generations. 
ESD, or objectives which include social, environmental and economic outcomes, are included in many State, regional and city strategies and plans, including the NSW Protection of the Environment Administration Act (1991 (updated Feb 2012)), the NSW Government's Green Paper on A New Planning System for NSW (DoP 2012), the NSW 2021 strategic plan (DPC 2011), the NSW Local Government Act (1993) (LGSA undated, s.402), the Newcastle Local Environment Plan (2003 (updated June 2011)), the Newcastle City Centre Local Environment Plan (2008), the Newcastle Community Strategic Plan, Newcastle 2030 (NCC 2011b), and the Lake Macquarie Local Environment Plan (2004 (updated July 2012)), the Lake Macquarie Community Plan 2008-2018 (LMCC 2012) and Environmental Sustainability Action Plan (LMCC 2011c).

Community plans and local environment plans developed by Councils generally incorporate ESD principles in accordance with State and Commonwealth agreements. The NSW Local Government Act (1993) states that ecologically sustainable development requires the effective integration of economic and environmental considerations in planning (LGSA undated, s.402).

There has been a series of Commonwealth Government responses to 'greenhouse' and climate change issues since the early 1990s. The 1992 Intergovernmental Agreement on the Environment (DSEWPC 2010) for example endorsed emission reductions of $20 \%$ by 2005 , as the basis for a National Greenhouse Response Strategy (this Strategy is no longer in circulation but is cited, for example, in Wilkenfeld et al. 1995). The Agreement also acknowledged the importance of social equity in implementing a greenhouse strategy and that this would require "coordinated and effective action by all levels of government and the community" (DSEWPC 2010).

The National Greenhouse Response Strategy was superseded by the 1998 National Greenhouse Strategy (quoted in NSW EDO 2008) which had the following objectives:

- To limit net greenhouse gas emissions, and to meet Australia's international commitments

- To foster knowledge and understanding of greenhouse issues

- To lay the foundations for adaptation to climate change (NSW EDO 2008: 1516).

The 1998 Strategy has effectively also been superseded by a number of other Commonwealth documents, including the Government's Position Paper on Adapting to Climate Change (DCC 2010), COAG's National Strategy on Energy Efficiency discussed below (COAG 2010), and the Government's 2011 Climate Change Plan (Australian Government 2011a) which accompanied the 2011 Clean Energy and carbon pricing legislation. Emissions reduction targets have been upgraded to reduce emissions by at least 5\% compared with 2000 levels by 2020, with a long-term reduction of $80 \%$ by 2050 (Australian Government 2011a).

Equity principles have been considered in the Commonwealth Government's climate change response; its 'Position Paper on Adapting to Climate Change' (DCC 2010: 9) notes that a "strong safety net will be essential" for more vulnerable groups, to be provided through the existing social welfare system. 
However there are significant ways in which the social equity aspects of environmental policy can lose traction, affecting particularly lower income groups, or those groups such as tenants who are marginalised in Australian discourses of material aspiration and home ownership. Environmental economics, for example, can apply a reductive approach to ESD, so that the 'polluter pays' principle results in social and environmental impacts of development being valued primarily in economic terms. Sharon Beder (2000) suggests that this approach may discount economic impacts in poorer areas, where reductions in land values or income losses will be less than in wealthy areas; it may assume that protection of environmental and social interests should be market-based or penalty-based decisions by business rather than decisions by the community or its government.

The assumption that human-made assets can replace environmental assets "takes a public resource and turns it into something that can be traded as if it were property" (Beder 2000 citing Richard Ayres, chair of the US National Clean Air Coalition). The use of terms like "land use trade-offs based on social, economic and environmental factors" (see for example the NSW Government's Green Paper on planning regulation DoP 2012) could be seen as reflecting this view. Tenants particularly can be limited in their influence in this kind of 'trade-off' between economic, environmental and social values, because of the currently tight rental market in Australia; this means that their relocation options are limited and their influence as potential clients in the 'sustainable and affordable housing' market is reduced.

\subsubsection{ESD and social and environmental outcomes: a case study of the National Electricity Market}

Issues of sustainable and equitable access to resources and services can become lost in policies driven by economic efficiency, to the detriment of both. A review of the performance of the National Electricity Market (Ison et al. 2011) pointed out that social and environmental objectives have been excluded from the National Electricity Objective (NEO) of the National Electricity Law. The National Electricity Law states that its objective is:

... to promote efficient investment in, and efficient operation and use of, electricity services for the long term interests of consumers of electricity with respect to-

(a) price, quality, safety, reliability and security of supply of electricity

(b) the reliability, safety and security of the national electricity system (Ison et al. 2011: v).

As part of the review of the NEM, a survey of Australian consumer organisations, which found that these organisations saw the long term interests of consumers as including "environmental performance, protection of vulnerable consumers, energy efficiency and demand management" (Ison et al. 2011: vii). In the UK electricity market, the interests of electricity consumers are taken to include "their interests in the reduction of greenhouse gases" and in Canada, these interests are "[i]nclusive of all Canadians and refers to a balance of economic, environmental and social considerations that changes as society's values and preferences evolve over time" 
(Ison et al. 2011: 26). The report notes that protecting the environment and vulnerable consumers are the subject of separate legislative and policy frameworks, with vulnerable consumers often becoming a responsibility of State Governments (Ison et al. 2011). In the Commonwealth Government's suite of Clean Energy legislation, pricing of energy is legislatively separate from compensation for medium and low income householders.

However integrating rather than separating social, economic and environmental factors in policy and legislation enables a more critical assessment of electricity pricing, such as that provided by the Australian Council on Social Service (ACOSS) (2012). ACOSS (along with the NSW retail price regulator for electricity, IPART (Brakey 2012)) noted the negative impact on consumers of infrastructure investment which is approved within the framework of the NEM in order to meet peak load for short periods. A consideration of the value of infrastructure capacity along with the value of equitable and sustainable access to energy, might produce alternative approaches such as reducing demand at peak periods. (Energy authorities have recently released reports on proposals for differential pricing, smart metering and reduction of peak loads to reduce pressure on infrastructure and provide consumers with usage options (Australian Energy Regulator 2012; Australian Energy Market Commission 2012)).

\subsubsection{Clean energy, ESD and equity}

The Commonwealth Government's Clean Energy Plan and legislation (Australian Government 2011b; 2011b), and the NSW Government's recent commitment to renewable energy investment, also have the potential to affect the standard of living of those on lower incomes, where tenants are disproportionately represented. The Commonwealth Government's suite of Clean Energy legislation provides rebates to middle and low income earners to compensate for foreseeable increases in energy costs arising from the 'carbon tax' (Australian Government 2011a).

However as noted in the discussion on media coverage above, for tenants in NSW public housing the State Government is effectively 'clawing back' most of the Commonwealth rebate through increased rents. Community organisations have responded strongly to the clawback, criticising it for rendering the carbon rebate ineffective in reducing the impact of the carbon tax on low income households (see for example NCOSS 2012).

The consequences of separating social or equity objectives from environmental and economic objectives can be seen in the separate Clean Energy (Household Assistance Amendments) Act (2011a), which provides household assistance in a form able to be clawed back by State public housing authorities. Moreover, while the Commonwealth provides compensation to middle and low income earners for rises in energy costs, its national climate change plan Securing a Clean Energy Future (Australian Government 2011a) also supports improved household energy efficiency to assist residents in saving money as well as reducing emissions. This latter component of the plan reductions in energy consumption - will apply differentially across poorer and more affluent households. 
The NSW Government has also stated as part of its recent commitment to investment in renewable energy that it will 'contain customer costs' by focusing on energy efficiency, including customers' energy efficiency (NSW Government 2012b) ${ }^{2}$. There has been no indication from the Government that it will financially recompense low income residents for future energy cost increases arising from this initiative. Any increase in energy costs is likely to make these residents more dependent on increasing their 'energy efficiency' than more affluent residents.

A focus on 'household energy efficiency' as a way to contain energy costs therefore increases the discrepancy between low and high income households, because the latter are more able to absorb costs. Tenants in particular also have fewer options than owner-occupiers for pursuing energy efficiency through modifications to their home (see the discussion on tenancy legislation below).

As well as advising tenants on reducing energy consumption, addressing these equity implications requires provision of housing which meets sustainability standards, and provision of information to tenants about the environmental performance of their homes. These issues are discussed further below.

\subsubsection{Other infrastructure: equity and ESD}

\section{Water and equity}

A 2010 review of regional water quality and security (Miles et al. 2010) also argues that the economic issues of water pricing should be separated from, rather than integrated with, equity and environmental issues, which should be addressed in separate instruments. The review argues that it would be more efficient if the price of water were set to reflect costs of supply, and adverse impacts on vulnerable consumers were addressed through compensating payments via the welfare system. The review cites water economist Professor Mike Young:

Unfortunately, governments tend to use water pricing regimes to achieve equity, environmental, revenue and economic efficiency objectives simultaneously. This approach violates a golden rule in policy development, to avoid conflicts - use a separate instrument to achieve every objective and, once an instrument is assigned to one objective, don't try to use it to achieve another objective (Miles et al. 2010: 37 quoting Young et al 2007).

The review suggests that compensation for low income water users should cover the fixed access charge, "while still exposing all water users to the variable element of the bill that reflects the actual amount of water used" (Miles et al. 2010: 37).

\section{Transport and equity}

The 1992 National Strategy for ESD aims to "optimise the modal mix of transport to achieve greater economic, environmental and social benefits” (DSEWPC 1992). Transport policy and strategy at both Commonwealth and State levels has retained a

\footnotetext{
${ }^{2}$ In any case the government is proposing that a large part of this investment be funded by the Commonwealth's Clean Energy Finance Corporation.
} 
focus on the equity principle of ESD, although this has not always been achieved. COAG's Reform Council has stated that social inclusion still needs to be addressed by integrating transport planning into land use decisions (COAG Reform Council 2011).

The NSW Government's draft Long Term Transport Master Plan acknowledges that better public transport and integrated modes of transport is one aspect of addressing 'social disadvantage' as well as environmental sustainability (NSW Government 2012a). The NSW Government's Affordable Rental Housing State Environmental Planning Policy (AHSEPP) addresses the issue of proximity to public transport in Sydney, and includes a requirement that regional affordable housing developments be within 400 metres of a local centre.

These policies, combined with plans for improving pedestrian and bicycle networks (for example the NSW draft Long Term Transport Master Plan (NSW Government 2012a), local Pedestrian Access and Mobility Plans and Bike Plans (DoTRMS 2012), the NSW Roads and Maritime Services funding program for Councils (RTA 2009) the National Cycling Strategy (Australian Bicycle Council 2011)), have the potential not only to assist low income residents by providing better access to employment and town centres, but also to reduce carbon emissions by encouraging higher patronage of public transport, more cost efficient public transport, and greater use of 'non-motorised' transport (walking and cycling).

\subsubsection{Sustainability and affordability: supporting housing choice in the rental sector}

The 2009 National Affordable Housing Agreement (COAG Reform Council 2012) and the 2008-2010 National Rental Affordability Scheme (FaHCSIA 2012) were intended to address the lack of affordable rental housing. However in 2012 the COAG Reform Council (2012) noted that housing affordability and social inclusion had not yet been adequately addressed in the strategic planning of Australian cities. The Reform Council found that rental affordability had worsened, especially for those with the lowest incomes. The rate of rental stress in Australia had jumped from $49.2 \%$ in $2007-08$ to $60.8 \%$ in 2009-10. It also found that NSW had a higher proportion of low income households living in rental stress than the national average.

Homes have also become less affordable for buyers, which has implications for the numbers of people seeking rental accommodation and the number of homeowners buying investment properties for rental. One reason for reduced affordability for low and moderate income households was cited as the increases in interest rates during 2009-2011 (COAG Reform Council 2012).

Australians for Affordable Housing, a coalition of national housing, welfare and community sector organisations, commissioned a study from the National Centre for Social and Economic Modelling (NATSEM) on housing stress in Australia. Based on Australian Bureau of Statistics Household Income and Income Distribution, Australia, 2009-10, it defined those in housing stress as those who are in the lowest 40 per cent of household incomes and who spend more than 30 per cent of their income on housing costs. The report concluded that around 180,000 renters in NSW were in housing stress, or $27 \%$ of all renters (Australians for Affordable Housing undated). It 
also found that NSW had a higher proportion of low income households living in rental stress than the national average. COAG noted in its response to the Reform Council's report that interest rate and market fluctuations are not within its control. In the case of affordable housing, it could be concluded that 'the market' is currently unable to meet some of the basic needs of the community.

However the Commonwealth's Urban Design Protocol, with its five pillars of "productivity, sustainability, liveability, leadership and design excellence" (DIT 2012) is one response to some of these issues. It is intended for use by decision makers and professionals, and aims to "cultivate healthy, cohesive and inclusive communities" and "foster environmental responsibility" (DIT 2012: 7). The Commonwealth has stated that its contribution to city infrastructure funding depends on State Governments' developing strategic planning systems for their cities (Albanese 2011).

The Australian Housing and Urban Research Institute (AHURI) has developed a detailed proposal (Lawson et al. 2012) for housing supply bonds to fund affordable rental housing, for consideration by the Commonwealth Government. The model is based on a successful scheme in Austria. AHURI noted that the 5-yearly review of the National Affordable Housing Agreement

... represents a critical window of opportunity to establish an enhanced, more comprehensive and long-term national policy framework for achieving public and private investment in affordable housing supply at sufficient scale to address current and predicted housing needs (Lawson et al. 2012: 76).

The NSW Government has recently announced a program of asset sales to increase available funding for social housing, although this is also likely to involve displacement of existing social housing tenants (Allen and Morton 2012; Allen 2012).

The Lower Hunter Regional Strategy, re-endorsed by the NSW Government in 2010, focuses on sustainable growth, and includes specific elements such as monitoring the supply of dwellings and enabling the release of up to 69,000 greenfield lots and better neighbourhood design and infrastructure (DoP 2006). These would help to address both supply and quality of housing, and potentially increase options for tenants in the tight rental market of the Lower Hunter ${ }^{3}$.

The NSW Government's State Environmental Planning Policy (SEPP) on Affordable Housing will soon be replaced by a new 'Affordable Housing Choice' SEPP (DoPI 2011), which is intended to apply only until local Councils develop their own 'Local Affordable Housing Choice Strategies' (DoPI 2011). This raises a recurring issue in the implementation of Commonwealth and State initiatives at local government level, which is the argument that Councils need access to adequate resources to support such strategies and meet their duties of care to residents. This issue is discussed in the following section.

\footnotetext{
${ }^{3}$ There have been recent media claims however that housing construction is slowing in the Hunter region rather than increasing (see for example Kelly 2012).
} 


\subsubsection{Duties of care: Local government resources and climate change adaptation}

While the 1992 Intergovernmental Agreement on the Environment was endorsed by the Australian Local Government Association, it did not bind Councils to observe its terms. However the NSW Land and Environment Court has stated that "a proper exercise of the powers of local government authorities would mean that they would apply the ESD policy unless there were cogent reasons to depart from it" (Biscoe 2007: 16).

However ensuring ESD planning principles are implemented, and that necessary infrastructure and services are provided equitably for all residents, requires adequate resourcing at local government level. Funding from the Federal Government occurs through the Federal Local Government (Financial Assistance) Act (1995), which provides funds to State-based Local Government Grants Commissions (Hyder Consulting 2011: 21). A 1974 Commonwealth referendum to allow the Australian Government to directly fund local government rather than having to pass the funds through state and territory governments, was defeated (Hyder Consulting 2011: 19).

The NSW Environmental Defenders Office has noted that a Council's legal duty of care to address climate change risks, for example in assessing development applications, depends among other factors on its resources:

It is important to note that under the Civil Liability Act 2003 the resources of councils will be taken into account when determining whether a duty of care has been breached. Therefore, financially strapped councils will likely be subject to a lesser expected response in meeting their duty of care (NSW EDO 2008: 31).

In a review of the role of local government and ESD, Darren McKay and Ray Rauscher (2005) noted that while the 1992 National Strategy for ESD was intended to support all levels of government in implementing ESD programs, during the 1990s the NSW State Government put increasing pressure on local government to adopt plans which met State ESD objectives; these included for example urban consolidation, biodiversity conservation, and design guidelines for residential flats. Implementing these policies became the responsibility of Councils through development consent processes.

In McKay and Rauscher's view, both Commonwealth and State governments failed to provide supporting infrastructure and inter-governmental, inter-departmental coordination for innovative local government ESD programs. A 2002 review of local government responsibilities for public health by the National Public Health Partnership ${ }^{4}$, also commented on local government resources:

...almost all submissions received during consultation identified the same issuea lack of resources both financial and staffing to perform the tasks required of local government, including regulatory functions. In other words, it is one thing for

\footnotetext{
4 The National Public Health Partnership operated under a Memorandum of Understanding signed by all Australian Health Ministers in 1996. As of 30 June 2006 the National Public Health Partnership was replaced with the Australian Health Protection Committee and the Australian Population Health Development Principal Committee (NPHP 2010).
} 
local government to have regulatory responsibilities, the capacity to carry them out effectively is another (NPHP 2002: 5).

This review noted that local government's role in making the regulations concerning public health was diminishing as legislation and standards were more often established by State and Commonwealth governments (NPHP 2002). As with ESD, it appears that local government has limited influence over legislation and policy but a large responsibility for its implementation.

Moreover there are other pressures on Councils in mining regions, such as the Hunter Valley where our project is located, to maximise economic benefits while also leading climate change mitigation initiatives (Pillora 2010). Other resource pressures on local governments include:

- the loss of Federal funding for the Cities for Climate Protection program, which provided an agreed framework for 238 Councils to measure emissionsreduction milestones

- issues related to the often generic results produced by the Commonwealth Local Adaptation Pathway Program, which funded Councils for climate change risk assessments by consultants

- a need for local governments to receive more specialised and localised information in order to respond effectively to climate change (Pillora 2010).

There may be a role for the Local Government and Shires Association (LGSA undated), which formerly coordinated the Urban Sustainability Support Alliance (NSW Environmental Trust 2010) in meeting some of these needs.

However all of these pressures are also pressures on Councils' capacity to apply ESD principles in reducing carbon emissions and adapting to climate change. They will have an impact on the provision of affordable housing, pedestrian and bicycle networks, environmental monitoring and disaster planning and prevention. This last issue in particular is one where Councils' 'duty of care' is likely to tested as cities adapt to climate change.

\subsubsection{Disaster planning and the rental sector}

The Newcastle City Council and Lake Macquarie City Council comply with the local Disaster Plan (DISPLAN) developed under the NSW State Emergency and Rescue Management Act 1989. The DISPLAN is concerned primarily with clarifying roles and chains of command among emergency agencies in the event of an emergency (NCC 2012b; LMCC 2011d). The plans include arrangements for evacuation and care in emergency shelters.

Newcastle City Council provides online advice to all residents on preparing for a bush fire (NCC 2010), a list of 'safer' places in the event of a fire (NCC 2011a), contacts in the event of flooding (NCC 2012a), and refers residents to the 'storm safety' awareness program conducted by the NSW State Emergency Service (NCC 2011c). 
Lake Macquarie City Council has developed detailed online community guides for responses to climate change impacts such as heat stress and increased frequency of extreme weather events (Lake Macquarie City Council 2012b; Lake Macquarie City Council 2012c; Lake Macquarie City Council 2012a). The Emergency Ready Lake Macquarie web pages on the Council's website includes advice applicable to all residents, such as preparing a home emergency plan, and creating an emergency kit. However it also refers to the Bushfire Survival Plan of the NSW Rural Fire Service (RFS), which includes advice on 'preparing your home', such as replacement of damaged roof tiles, use of fireproof materials for fencing, installation of fly screening etc. It may be useful if this RFS guide included a section targeting tenants specifically, with advice on how to approach their property manager/landlord if the tenant believes their home is at risk.

Lake Macquarie City Council is a sponsor of the Australian Early Warning Network through which all residents of the city are able to receive free alerts via email, SMS and landline (where requested) about severe weather events, including storms, hail, bushfire weather and heat stress. Residents have indicated in Council evaluations of the service that these alerts have forewarned them to secure furniture and other objects around their houses, put cars under shelter, and change planned activities to reduce their exposure to risk.

Lake Macquarie City Council's Be Ready Be Safe community engagement campaign includes climate change adaptation elements including promoting natural disaster and heat wave preparedness. A major focus of the campaign is working through a network of Sustainable Neighbourhood groups throughout the city that seek to build community support networks, self-help and resilience to deal with local issues. A wide range of local residents are members of the Sustainable Neighbourhood groups, including tenants.

A private company in Queensland has produced a disaster management best practice guide for property managers (Real Estate Excellence Academy 2013). This guide as well as the Fact Sheet on natural disasters (flood and storm) prepared by the Real Estate Institute of Queensland (2011) for property managers, and the Fact Sheet produced by the Residential Tenancies Authority in Queensland (2011) address the needs of both tenants and landlords.

There are several fact sheets available for NSW tenants which offer advice on their contractual rights and obligations in the event of their home becoming completely, or partially, uninhabitable as a result of a natural disaster (NSW Department of Fair Trading 2011a; TenantsNSW 2013a; TenantsNSW 2013b).

Under the NSW Government Flood Policy (DEH 2011), the management of flood liable land is the responsibility of Local Government. The State Government subsidises flood mitigation works to alleviate existing problems and provides some specialist technical advice to assist councils in the discharge of their floodplain management responsibilities (WMAwater 2011a).

The flood management strategies of Councils are designed to protect people's safety and to protect property from inundation particularly using planning regulations such as 
minimum floor level heights, but also community education and engagement, and in some circumstances flood modification measures such as levees to protect vulnerable areas (See for example the Newcastle City Council's draft Floodplain Risk Management Plan (BMT WBM 2012), and two Lake Macquarie City Council studies: a Waterway Flood Study (WMAwater 2011b) and a Waterway Flood Risk Management Study (WMAwater 2011a). These were prepared in accordance with the NSW Government's Floodplain Development Manual (DEH 2011) and Flood Risk Management Guide (DECCW 2010)).

The situation of renters requiring relocation after a natural disaster will be exacerbated if there is a continued severe shortage of affordable housing. Moreover as particular areas are assessed as vulnerable to sea level rise or flooding for example, it is likely that the wealthy will retreat and vulnerable areas will house a greater proportion of those on low incomes. This could result in a disproportionately high number of tenants among those at risk or affected by any natural disaster. Rental housing is already higher than average in those suburbs of Newcastle which were inundated in the 2007 flood (for example Carrington, a low-lying inner suburb of Newcastle consists of almost $50 \%$ rental housing (Australian Bureau of Statistics 2008)). The consequent lack of security of tenure for renters would only be increased by re-zoning of areas as nonresidential, or by implementation of a proposal by the NSW Government for 'time limited' leases on developments at risk (DoP 2010).

The issue of Councils' duty of care to residents in this regard has been analysed by the Environmental Defenders Office (EDO 2009). The EDO suggests that landowners may be owed a duty of care based on several criteria including the following:

- Control - Where one of the parties is in a position of control and has the power to control the situation that brought about harm

- Knowledge - Where one of the parties knew, or ought to have known, of an existing risk of harm to the plaintiff, or a specific class of persons who included the plaintiff (rather than the general public)

- Vulnerability - Where the claimant is in a position of vulnerability in that he or she could not reasonably take action to safeguard herself or himself (NSW EDO 2008: 25).

Landowners may also be able to make claims against Councils for the impacts of sea level rise for example under 'nuisance' legislation, which concerns interference with a neighbour's property or enjoyment of their property (NSW EDO 2008: 34).

In the analysis by the EDO, both 'duty of care' and 'nuisance' are related to property rather than residents. However the criteria for duty of care - including control, knowledge, vulnerability - suggest it would be useful to assess whether a similar duty is owed to tenants of buildings affected by sea level rise. The State legislative requirement to apply the equity principles of ESD in Council decisions suggests that tenants' interests at least need to be taken into account in the development of policies concerning the impacts of sea level rise on land and buildings.

Lake Macquarie City Council's statement on sea level rise notes that any major changes will involve community collaboration in the development of local Area 
Adaptation Plans (LMCC 2011e). Whether tenants as well as landowners are included in this consultation process is yet to be determined. However the proposed sea level rise response by Lake Macquarie City Council includes not only planning guidelines for new development and certification of affected properties, but also adaptation assessments for infrastructure and services such as drainage, sewer, water, communications, and emergency services (LMCC 2011b). These plans address the needs of all residents rather than only property owners and reveal a distinction between the focus of planning legislation and the focus of disaster response legislation (Lake Macquarie City Council 2012b; Lake Macquarie City Council 2012c; Lake Macquarie City Council 2012a).

The disaster management best practice guide for property managers produced by LJ Hooker (unpublished), the Fact Sheet on natural disasters prepared by the Real Estate Institute of Queensland (2011) and the Fact Sheet produced by the Residential Tenancies Authority in Queensland (2011) all address the needs of both tenants and landlords (NSW Department of Fair Trading 2011a; TenantsNSW 2013a; TenantsNSW 2013b).

\subsubsection{Tenant access to information: Residential Building Mandatory Disclosure (RBMD)}

The NSW Residential Tenancies Act stipulates that a landlord "must not induce a tenant to enter into a residential tenancy agreement by any statement, representation or promise that the landlord or agent knows to be false, misleading or deceptive" (2010 (updated January 2012) s.26). This clause requires provision of information to tenants about, for example, potential for flooding, but not poor energy performance. A national Residential Building Mandatory Disclosure scheme proposed as part of the National Strategy on Energy Efficiency (COAG 2010) would address this gap, particularly if it formed a part of the standard rental contract.

The RBMD scheme currently under consideration by the Commonwealth Government for house sales and leases, would assist both buyers and renters in making sustainable choices (The Allen Consulting Group 2011). Even in a tight rental market the availability of information on building performance has the potential to produce a 'point of difference' for houses which are more sustainable.. The Regulation Impact Statement notes that one argument for an RBMD is that "residential properties are large, one-off or low frequency investments where the purchasers cannot rely on significant previous personal experience" (The Allen Consulting Group 2011: 9). It could also be argued that for both owner-occupiers and renters, making a 'home' and the burden of moving house are large investments which warrant the provision of clear information about building performance in advance of entering either a rental or a purchase contract.

Analysis in the Regulatory Impact Statement of social costs and benefits excluded the benefit of increased property values for the owners of sustainable properties. It argued this was simply a transfer of wealth from first-home buyers to existing home owners (The Allen Consulting Group 2011: 39-40). The social costs of this transfer of wealth could also include an increase in the number of renters in an already limited market, 
and hence a further reduction in renters' options and capacity to influence the quality of their housing.

\subsubsection{RBMD and social housing tenants}

Full implementation of a recently released Environmental Sustainability Strategy of Housing NSW (DFS 2011) ${ }^{5}$ will assist climate change adaptation by social housing tenants who, like all tenants, are restricted in the modifications they can make to their homes to make them more sustainable and to save energy and water. In the case of social housing tenants, these restrictions are generally further exacerbated by low incomes.

However the RBMD Regulation Impact Statement argues on the basis of these factors that social housing tenants have limited choices and capacity to influence the quality of their housing, and therefore should not receive a building performance assessment (The Allen Consulting Group 2011). This withholding of information about the buildings occupied by social housing tenants could be seen as discriminatory and a disempowerment of social housing tenants. It would leave social housing tenants as the only group for whom advice on climate change adaptation is framed solely in terms of their own behaviour change. Knowledge about their buildings has the potential to increase the capacity of social housing tenants to argue for improvements to assist them in adapting to climate change.

\subsubsection{Advice on buildings and development: 'Your Home'}

The Commonwealth Government has sponsored a number of resources aimed at home buyers, home renovators and developers which provide valuable information on master planning, building design and materials.

However much of this information could also be useful (and empowering) for renters. One of these resources for example, is the 'Your Home' online guide (Reardon et al. 2010b; Reardon et al. 2010a). It contains information on 'living in your new home', garden design, maintenance and selection of appliances which would be valuable for tenants as well as renovators and home builders. The 'Your Home' guidelines for buyers would (in a less tight rental market) also be useful for renters in selecting a location close to public transport, a house with good orientation to the sun, and with insulation and other energy saving features.

Equitable access to expert advice could also include making available to tenants such services as that offered by Newcastle Council's Sustainable Building Advisor Service, which could potentially provide a 'score card' to tenants on the sustainability features of their homes. This service however appears already to be overloaded with requests from home-owners for environmental design advice (NCC 2012d). The 'Your Home' site provides a comprehensive overview of 'rating' tools, and how to apply them, which could form the basis for training of property managers, landlords or tenants in evaluating the performance of a building. It also offers advice on assessing the sustainability of an existing home (Reardon et al. 2010a) which includes water and

\footnotetext{
${ }^{5}$ The sustainability initiatives of Housing NSW are discussed further at the end of this chapter.
} 
energy use by occupants. This information could usefully be made available to tenants as well as home owners.

Another website, 'Your Development' (CSIRO and DEWHA 2008), is published by CSIRO and the Commonwealth Government. It cites market benefits of applying ESD principles to development projects which would apply to all residents, whether renters or owner-occupiers:

- lower insurance premiums

- avoid the need for repair or retrofit

- lower energy costs

- avoid the risk of disruptions of utilities, communications or other infrastructure (Bengtsson 2008).

Including the rental sector in these publications as a matter of course, as target audience and in impact descriptions, would enhance both the capacity and the profile of the rental sector in climate change adaptation and sustainability.

\subsubsection{Climate change adaptation and sustainability: education and awareness}

The Commonwealth Government's 1992 National Greenhouse Response Strategy included measures for "ensuring that the community understands the need for early action on measures to reduce greenhouse gas emissions" (DSEWPC 2010).

The Government's National Action Plan for sustainability education (DEWHA 2009) aims 'to equip all Australians with the knowledge and skills required to live sustainably', and to help to achieve 'national sustainability objectives'. The education plan is also part of Australia's participation in the United Nations 'Decade of Education for Sustainable Development, 2005-2014' (DEWHA 2009). The strategies outlined in the plan include:

- equipping people to understand connections between environmental, economic, social and political systems

- participation is critical

- improve communication and networks between different sectors of society

- harnessing community spirit to act (DEWHA 2009: 5).

The Commonwealth provides grants for community education projects, development of sustainability education best practice guides, use of the media and 'ambassadors' to communicate sustainability concepts to the public, and the funding of research and surveys to identify the most effective education approaches (DEWHA 2009).

At State level, the programs of the NSW Council on Environmental Education are aimed at "[e]ffective and integrated environmental education which builds the capacity of the people of NSW to be informed and active participants in moving society towards sustainability" (NSW OEH 2012). The NSW Government also funds a number of community education and awareness raising programs, such as the Sustainable Australia programs run by the Australian Conservation Foundation (NSW OEH 2008) which include "the development of publications to promote discussion about 
sustainability". The Government has produced a community engagement resource designed for "those who need to mobilise their public and stakeholders to participate in policy forums, planning processes or education programs" (NSW OEH 2011).

Local Government authorities produce a wide range of online and printed material on recycling, conserving water and energy and participating in community environmental programs. Examples of the latter are Lake Macquarie Adopt-a-SQID (Stormwater Quality Improvement Device) (LMCC 2011a) which provides community education and monitors waterways, and foreshore and estuary environments, and the Newcastle City Council 'Spring Water Bug Survey' which incorporates community assistance in assessing the health of 150 kilometres of natural waterways in the Newcastle area (NCC 2012c).

Lake Macquarie Council's Sustainable Neighbourhoods Program (LMCC 2011f) provides support to communities to reduce their ecological footprint, protect the natural environment, and increase community wellbeing and pride in their local area. These education programs target all sectors of the community, although some government programs at State level, especially in Victoria, have been directed specifically at renters, as noted in the review of resources for renters above.

\subsubsection{Guides for sustainability and adaptation in the home: matching advice with rental housing}

Sustainability education and guidelines for residents are focused variously on better risk management, community resilience and adaptation, and improved environmental outcomes through more educated, environmentally aware attitudes and behaviours on the part of citizens.

However Government programs and resources for householders wishing to make their homes more sustainable and adapt to climate change, are often directed specifically at landowners, homeowners and house buyers. They generally assume that sustainable design, renovation, or adaptive modifications will be enjoyed by the owner-occupier. Engaging with tenants' needs, capacities and interest in sustainability in these household guides has the potential to change landlords' and property managers' perceptions and expectations about the suitability of houses bought as rental investment properties.

The Commonwealth Government's LivingGreener site provides information on rebates and 'green' guides which are of use to both tenants and owner-occupiers (DCCEE 2012). However the NSW Government's 'Beat the heat' guide' (NSW Health undated) and the 'Welcome to Your Home' guide produced for public housing tenants by the NSW Department of Housing (Housing NSW 2012b) include recommendations which might involve resources unavailable to tenants. Examples from the NSW Health guide include: "if possible, have curtains with pale linings in rooms that get a lot of sunlight', 'avoid dark reflective curtain linings and metal Venetian blinds", "consider putting external blinds, shutters or some other shading on windows in rooms which face west". It makes a number of recommendations about insulation, cross-ventilation, air conditioners, and access to east or south-facing rooms Housing (NSW Health undated). The Housing NSW guide advises: "open windows but don't compromise your security", keep blinds/curtains closed, and adjust settings for air conditioning 
(Housing NSW 2012b). The NSW Government has also funded the Australian Conservation Foundation's GreenHome Guide (2007), which includes guidelines on behavioural change applicable to all householders, such as reducing water and energy consumption, recycling and re-using, but also includes advice on installing a rainwater tank, changing air-conditioner settings, installing solar hot water and solar power systems, composting, planting trees and organic gardening.

Constraints on alternative energy, food and water sources, cross-ventilation, security, quality of curtains and access to air conditioning or fans, will be significant factors in tenants' capacity to adapt to climate change.

AHURI's report on landlords' investment in sustainability (Gabriel et al. 2010a) noted that even landlords with strong views about the importance of sustainability who had made changes to their own homes, had not thought of making similar changes to the homes of their tenants. Informing tenants about the sustainability and adaptive capacity of their homes, and making explicit the application of design and 'green' guides to rental properties, may be one way of changing landlords' consciousness in this regard. This consciousness would be consistent with the principle of 'extended producer responsibility' (a version of the ESD principle of 'polluter pays') where the product provider (in this case the housing provider) takes responsibility for the environmental impact of their product throughout its lifecycle (Millar 2009). Resulting improvements in rental properties would also increase the value to tenants of government guides about 'beating the heat' or 'living greener', since houses would meet minimum standards of thermal and energy performance, and information could be made available to tenants about these aspects of their homes through mandatory disclosure schemes.

Landlord action on sustainability modifications to rental houses is however likely to lead to rent increases unless the works are subsidised by government, or through low cost loans such as the 'environmental upgrade agreements'. These agreements, between a building owner, the local council and a finance provider, enable a large capital investment in improving, for example, the energy efficiency of the building. They allow the building owner to repay a loan over an extended period through increased rates payments to Council. Tenants of the building pay an increased rent, but a smaller power bill. Victoria has Environmental Upgrade Agreements in place for commercial buildings (Robinson 2010).

The NSW Local Government Amendment (Environmental Upgrade Agreements) Act 2010 commenced on 18 February 2011, for upgrading or retrofitting non-residential or multi-residential buildings of more than 20 strata lots. The Act provides a way of funding works to improve the energy, water or environmental efficiency or environmental sustainability of those buildings (DEH 2012). In introducing the Bill to NSW Parliament, the Minister for Climate Change and Environment noted that the legislation would help to overcome the 'split incentive' where capital investments by landlords result in the most benefit for tenants, for example through energy savings. The Act also requires that no tenant can be required to pay more than they would if the agreement were not in place (Sartor 2010). 
However rent increases for upgraded houses to compensate the landlord may also be offset for the tenant by reduced utility costs. Further evaluation of costs and benefits for both landlord and tenant is needed in this area, applying at the least the ESD principles of both equity and 'polluter pays'.

\subsubsection{Participation by tenants in wider climate change responses}

Government 'education for sustainability' plans have the goals of capacity building and behaviour change in individuals and communities, to address "national sustainability objectives" (DEWHA 2009) and produce "informed and active participants in moving society towards sustainability" (NSW OEH 2012). Lake Macquarie's Sustainable Neighbourhoods program (LMCC 2011f) and organisations such as Transition Newcastle (2012) offer opportunities for involvement of tenants as well as homeowners to work as neighbours, engage in local projects, and learn sustainable practices through workshops and information sharing.

However just as 'consumer interests' can be extended beyond individual household energy security and costs to include reduction in greenhouse gas emissions (see the discussion on the National Electricity Market above), so too could capacity building in the community be extended beyond local actions to include capacity for engagement in wider regional and international equity and environmental issues (the "great moral challenge of our generation" (Rudd 2007)). The awareness raising, participatory and capacity building processes envisaged in the Commonwealth and State governments' education strategies could be utilised by those who wish to engage with regional or global networks, as well as offering support for changes to household practices and participation in community-based activities.

\subsubsection{Tenancy legislation and the capacity of tenants to adapt to climate change}

A number of amendments to NSW Residential Tenancies Act and Regulation (2010 (updated January 2012); 2010 (updated July 2011) respectively) were made in 2010, which have an impact on the capacity of tenants to engage in sustainable practices and adapt to climate change.

The 2010 Regulation requirement that landlords install water efficiency measures in residential rental properties was seen as not going far enough. The Public Interest Advocacy Centre (PIAC) argued that "the failure of the Regulation to oblige or encourage landlords to install dual flush toilets is a missed opportunity to promote water-efficiency and reduce the financial burden on tenants as utility prices rise" (Santow 2010). While the Regulatory Impact Statement had claimed this would be too costly for landlords, PIAC noted that a Queensland regulation to this effect had been in force since 2005 (Santow 2010).

The NSW Tenants Union (NTU 2012) expressed concern about other recent changes to the Act which apply when a landlord terminates a tenancy without grounds. The NTU argues that the new provisions of the Act require the Residential Tenancy Tribunal to terminate a tenancy if the tenant overstays, rather than considering the tenant's case before the tenancy is terminated. This change, according to the NTU, increases the power imbalance between tenant and landlord, and "ensures that tenants 
nearly always consider the prospect of exercising their legal rights with utmost caution, and is in direct contrast to the idea of achieving a genuine balance between landlords and tenants" (NTU 2012).

Also of concern to the Tenants' Union is that occupants of share housing are not covered by the Act, nor are they protected under any other laws:

Urgent reform of the marginal rental sector, including a regime for 'occupancy principles', such as is set out in the Residential Tenancies Amendment (Occupancy Agreements) Bill 2011, is needed to ensure these and many other occupants in marginal rental accommodation are not left out in the cold (NTU 2012).

The weakness of tenants' position when seeking improvements to their homes was noted in a 2010 review of tenancy legislation by the National Association of Tenant Organisations (NATO). It reported a continued lack of minimum housing standards for rental housing, and that "[e]ven in States such as South Australia and Tasmania where there is legislation covering housing standards... advocates report that the system still does not adequately protect tenants. They suspect that the underlying concern to tenants when pursuing repairs is retaliatory eviction" (National Association of Tenant Organisations et al. 2010: 34). While this comment was focused particularly on habitability and safety standards, it can be applied also to the lack of thermal and other environmental attributes of older rental housing in NSW. (The issue of building standards and performance disclosure was discussed above).

NATO's main concern is with the power imbalance in tenant-landlord relationships, in that tenants "cannot threaten to end the agreement without considerable financial and emotional cost to themselves" (National Association of Tenant Organisations et al. 2010: 15). They also suggest there is evidence that tenancy law more supportive of tenants would not be a disincentive for landlords to invest in rental housing (National Association of Tenant Organisations et al. 2010).

For the NSW Tenants Union (NTU 2012) the power balance between tenants and landlords is a factor limiting tenants' capacity to seek sustainability improvements to their houses, or to make their own adaptive modifications to houses. This is exacerbated by the current severe shortage of rental properties, especially in the regions under study in this project.

\subsubsection{Tenant modifications to houses and security of tenure}

The provisions of tenancy legislation, especially those requiring the tenant to reinstate on departure any changes made during the tenancy, are disincentives for tenants wishing to make a vegetable garden, to alter the fabric of the building to increase passive heating and cooling, or to install water and waste recycling systems. AHURI's comparative study on security of occupancy for tenants in Europe, northern America, the UK and Australia (Hulse et al. 2011) defined secure occupancy as including the ability of tenants to "[e]xercise a degree of control over their housing circumstances and be able to make a home, to the extent that they wish to do this" (Hulse et al. 2011: 3 ). AHURI noted that longer leases and more flexible contract conditions overseas are 
more supportive of tenants in 'making a home'. In the Netherlands for example, tenants on long leases can make alterations such as installing new floor coverings or curtains, or minor upgrades to kitchens and laundries. Moreover these modifications do not need to be reversed when the tenant vacates the property (Hulse et al. 2011: 156).

\subsubsection{Changing tenancy law}

NATO has drawn attention to difficulties in obtaining nationally consistent changes to Residential Tenancies Acts. There is no provision in the Australian Constitution for the Commonwealth Government to legislate with respect to tenancy, housing or aspects of consumer protection, which remain the responsibility of the States. NATO refers to the International Covenant on Economic, Social and Cultural Rights, but questions whether this can be used to manage all aspects of tenancy legislation, such as landlords' rights. It concludes that the Council of Australian Governments (COAG) may be the best forum to establish principles and timeframes for reform, or the Ministerial Council on Consumer Affairs which could work towards nationally consistent law reform (National Association of Tenant Organisations et al. 2010).

\subsubsection{Adaptation to climate change: tenant support services}

It is also likely that climate change will be a test of the adequacy of tenancy support and advocacy services, for example after natural disasters when tenants are potentially faced with eviction, temporary relocation, loss of their own property or subsequent rent increases to cover the costs of reconstruction and upgrading.

However there are concerns that tenancy advice and advocacy groups are substantially underfunded. TenantsNSW note that two independent reviews of the Tenancy Advice and Advocacy Program (TAAP) commissioned by the NSW Department of Fair Trading have recommended substantial increases in funding:

To date, Fair Trading has refused to implement the recommendations of the reviews. This is surprising given that funds are available - the [Rental Bond Board] had a \$10.42-million surplus at 30 June $2011 . .$. Increasing TAAP funding from the RBB's surplus would come at no cost to other services (TenantsNSW 2012).

In Queensland, tenant support services have been forced to close as a result of recent government budget cuts: '29 tenant advice services have been given 12 weeks' notice to close" (TUQ 2012). The Queensland Tenants' Union has argued that this will increase homelessness and demands for public housing. It will also, in the event of climate change impacts on tenants such as dislocation or reduced habitability of their homes, diminish the level of support and advice available to them.

\subsubsection{Rebates and incentives: potential for extending to tenants}

The tax rebates available to landlords, particularly for repairs and maintenance and for small capital works (up to $\$ 300$ which may be claimed immediately) (ATO 2012), could also be considered for tenants investing in the sustainability of their rental home. 
In the ACT, the Wood Heater Replacement Program offered an $\$ 800$ subsidy during 2012 for replacing an old wood heater with a new mains supplied gas heater.

Ratepayers are eligible for the subsidy, as well as owners of rental properties provided that the tenant and the property owner agree (ACT Environment and Sustainable Development Directorate 2012). However in the absence of any mandatory requirement on the landlord, such replacements will depend on the good will and environmental commitment of the landlord. There is no provision for the tenant to apply for the subsidy (and contribute to any shortfall in cost), even with the landlord's approval.

Small Technology Certificates (STCs) for small-scale energy systems are available for both tenants and landlords ${ }^{6}$. They are generally redeemed by assigning them to the installer, who in turn offers a discount on installation (Clean Energy Regulator 2012). Alternatives, such as leasing solar panels which are owned and managed by a supplier, may also be worth exploring (see for example SolarCity (California) 2012).

While the NSW Fridge Buyback scheme provides residents with free collection of old fridges by professional removalists and a $\$ 35$ rebate (Fridge Buyback 2006), and the Commonwealth offers up to $\$ 2,000$ towards the purchase of a new car fitted with LPG, there is currently no replacement scheme for low income earners wishing to replace an energy inefficient appliance with a five-star rated appliance. The closest option to replacement at present is Hunter Water's occasional showerhead replacement programs, and their No Interest Loan Scheme for purchasing water efficient washing machines or a dual flush toilet (HWC 2011b; HWC 2011a).

\subsubsection{Conclusions}

The primary issue emerging from an overview of government policy, legislation and programs relating to tenancy, sustainability and climate change, is the need for greater equity and inclusion of the rental sector. Addressing this issue requires all levels of government to make explicit in policies, legislation and programs the potential contributions and impacts arising in the rental sector. This should occur at least in the areas of transport, land use planning and housing provision, housing performance, utilities, disaster planning, education and incentives for change. It should also include a consideration of the resources required for equitable implementation. Making explicit both the contributions of, and impacts on, the rental sector is likely to lead also to a rethinking of tenancy law, so that it better supports tenants, landlords and property managers as social and economic agents of sustainability and climate change adaptation.

\subsection{Housing NSW}

One of the key findings of our research was the difference between the public rental housing sector and private rental housing in NSW. Of particular interest was the work being done by Housing NSW in improving the environmental sustainability and adaptability of housing stock in the public housing sector. Housing NSW is one of the largest providers of social housing in the world and currently houses 340,000 people,

\footnotetext{
${ }^{6}$ Email from Clean Energy Regulator dated 4 September 2012.
} 
thus making a substantial contribution to the rental sector overall (Housing NSW 2011). Housing NSW "aims to be a leader in reducing greenhouse gas emissions and adapting to climate change in a way that promotes social equity and financial responsibility for social housing in NSW" (Housing NSW 2012a). This section is a brief overview of the work undertaken by Housing NSW, particularly in developing their environmental strategy and Welcome to Your Home brochure (a sustainability guide for public housing tenants).

\subsubsection{Environmental Strategy}

One of the main differences between the private rental housing sector and Housing NSW is in focus and motivation for housing provision. Housing NSW, which is focused on tenants rather than landlord investment, is in a unique position in terms of its ability to enhance the adaptive capacity of the rental sector. In our interviews, a Housing NSW manager commented:

As an organisation I think we are moving forward with some of these initiatives. We are putting stuff in that benefits the clients. So we're a landlord-we're not a landlord to make money we're a landlord to provide housing and to provide housing solutions for clients. We're a client focussed landlord. People might argue with that but that's - inherently that's what we do. It's just that we can't keep everybody happy. But that's the difference between us and the private landlord. We don't worry about the investment of our asset [Public Housing Practitioner 3].

Housing NSW has established an Environmental Sustainability Unit that aims to be a sustainability leader in the housing sector. The unit released an Environmental Strategy in 2008 which is the first of its kind in Australia (Housing NSW 2011). The strategy aims to support Housing NSW improve the sustainability of public housing dwellings and the sustainability of the organisation more generally. It includes a list of actions, goals and key performance indicators to improve the sustainability of Housing NSW, both in terms of public housing tenants and dwelling, but also the offices and staff of Housing NSW. A number of programs have been developed for application across their housing stock including initiatives to install water saving shower heads, insulation and solar hot water (Housing NSW 2012a). Table 5 below provides an overview of the sustainability programs in which Housing NSW is engaged.

The organisation has tailored minimum building requirements to climatic zones across NSW:

Then what we've done is put specific climate zone requirements ... because we manage properties across the whole state. What you do in cold climate areas is a bit different to what you do [elsewhere]. So ... our internal architects use this [Public Housing Practitioner 2].

Other Housing NSW practices include environmental surveys, gathering information on energy and water performance, climate-proofing measures, incorporating sustainability principles into design requirements and maintenance contracts [interview with Public Housing Practitioner 2]. Whilst these activities have focused predominantly on the 
physical asset of the home, the organisation has also looked to the everyday practices of tenants:

So I guess we are focusing probably more on things that we can do inside $d$ wellings, to make them more energy and water efficient. If you think about it too, I think our tenants expect that we show leadership in that area. Rather than just expecting them to live more frugally [Public Housing Practitioner 2].

Table 5: Housing NSW Sustainability Programs

\begin{tabular}{|l|l|}
\hline Sustainability Program & Key Activities \\
\hline Home power savings & $\begin{array}{l}\text { Energy assessment and power savings kit program with } \\
\text { NSW government }\end{array}$ \\
\hline $\begin{array}{l}\text { Sustainability Action Values } \\
\text { Everyone }\end{array}$ & $\begin{array}{l}\text { Community gardens and environmental education } \\
\text { program in Sydney, Canterbury, Marrickville and } \\
\text { Randwick Local Government Areas supported by } \\
\text { Environmental Trust Grants }\end{array}$ \\
\hline Community Greening & $\begin{array}{l}\text { Community garden program jointly run with the Botanic } \\
\text { Gardens Trust }\end{array}$ \\
\hline Green Streets & $\begin{array}{l}\text { Tree planting program on streets, parks and gardens in } \\
\text { partnership with non-government organisations. }\end{array}$ \\
\hline Environmental Workshops & $\begin{array}{l}\text { Two councils work with Housing NSW to deliver Saving } \\
\text { Energy at Home and Sustainable Living workshops }\end{array}$ \\
\hline Staff engagement & $\begin{array}{l}\text { Online Green office survey at Housing NSW which } \\
\text { assists green office campaigns }\end{array}$ \\
\hline $\begin{array}{l}\text { Design Requirements and } \\
\text { Green Star Developments }\end{array}$ & $\begin{array}{l}\text { Environmental standards for new public housing } \\
\text { building developments }\end{array}$ \\
\hline Solar Hot Water Systems & $\begin{array}{l}\text { Program that replaces existing electric hot water units } \\
\text { with solar hot water units }\end{array}$ \\
\hline Solar photovoltaic systems & Program to install solar photovoltaic systems \\
\hline Water saving shower head & $\begin{array}{l}\text { Installation of water saving shower heads and tap } \\
\text { aerators on all properties }\end{array}$ \\
\hline Rainwater Tanks & $\begin{array}{l}\text { Program that ensures new residential dwellings receive } \\
\text { water tanks }\end{array}$ \\
\hline Recycling & $\begin{array}{l}\text { Recycling program for housing NSW offices and high } \\
\text { rise buildings }\end{array}$ \\
\hline Ceiling Insulation & Retrofit program for housing in cold climatic areas \\
\hline Efficiency & $\begin{array}{l}\text { Green power, energy efficient technologies and E10 } \\
\text { fuel program }\end{array}$ \\
\hline Source:
\end{tabular}

Source: (Housing NSW 2011)

This approach to tenant action is supported by our research finding that tenants are actors who are contributing to the environmental sustainability of their dwellings. 


\subsection{2 'Welcome to Your Home' brochure}

In June 2012, Housing NSW produced an information booklet for public housing tenants about how to save energy and water called Welcome to Your Home.

The guide provides a list of suggestions for reducing consumption of energy and water and saving money, in the following areas:

- energy use around the home

- heating and cooling

- family and kitchen

- laundry and bathroom

- waste and recycling

- outside the house

- shopping.

It includes explanations about why particular practices are important and how they assist tenants save water or money. For example, under 'Laundry' the guide suggests: "If you are buying a new washing machine buy the most water and energy efficient one you can afford. Front loaders are generally more efficient than top loaders" (Housing NSW 2012b: 8). Many of the suggested practices, rather than just saving energy and water, would improve more general sustainability outcomes and help tenants save money: for example the guide provides a "seasonal buying guide for fruit and vegetables", along with contact numbers and websites for potentially useful services and organisations.

This guide is comprehensive and has clearly been targeted to a group of low-income tenants who are positioned as actively contributing to the sustainability of their homes. One manager noted that the sustainability practices expected of public housing tenants were different from those of private housing tenants, and that the guide had been targeted accordingly:

... we don't necessarily expect our tenants to do some things that the private sector tenants would, I guess [Public Housing Practitioner 2].

However the provisioning of sustainable technologies and encouraging the reduction of greenhouse gas emissions with low-income groups is a complex task. One example of these complexities is the secure provision of hot water to public housing tenants while also meeting sustainability targets:

So when you have a look at our design requirements, with hot water systems the first preference is a split system... gas boosted basically. Then gas instantaneous is the next preference. Then split system with electric boosting ... one issue that we do have with gas though is if, technically if a tenant doesn't have a gas account currently. ... They actually might not be better off financially because the money that they're saving with their gas hot water system. ... they're actually having to pay an extra $\$ 200$ a year in service fees... But... pensioners ...only get the one-off utility discount. So if you look at the actual service component of their bills, it is actually quite high... It's an issue that we've got with low-income 
communities... But I guess we do have to balance up, as I said, the cost of things like solar versus gas and the ongoing maintenance [Public Housing Practitioner 2].

This highlights the complexity of providing services to tenants and achieving environmental outcomes at an institutional level at the same time as maintaining the affordability of utilities for low-income tenants.

\subsubsection{Conclusions}

The differences between the public and private rental sectors were particularly apparent in our discussions with Housing NSW managers, including the volume of dwellings managed by a single landlord, and the objective of social equity. This balancing of sustainability and equity objectives was also evident throughout the interviews with housing managers. Housing NSW however has the capacity to significantly shape sustainability outcomes and adaptive capacity in the rental sector through alterations made to the physical housing stock and influencing everyday tenant practices.

\subsection{Climate change adaptation and rental housing in Newcastle: analysis of interviews and focus groups}

\subsubsection{Introduction}

Just being ... concerned about what's happening beyond your own home, to the point that it affects what you do within your own home [Tenant 14: house/private manager]

As a result of low recruitment rates for tenants and private property managers in the Toronto (Lake Macquarie) area, the analysis below focuses on the broader issues raised by the primary data rather than the comparative analysis of Newcastle and Toronto envisaged in the original proposal.

Individual tenants and housing managers have been identified anonymously throughout the analysis below, as shown in Table 6:

Table 6: Interviewee identifiers

\begin{tabular}{|l|l|}
\hline Interviewee category & Identifier used in this report \\
\hline Tenants (public housing) & Tenant $\mathrm{X}$ : dwelling type/ Housing NSW \\
\hline Tenants (private housing) & $\begin{array}{l}\text { Tenant } \mathrm{X} \text { : dwelling type/ private landlord/ } \\
\text { private property manager }\end{array}$ \\
\hline Housing managers (social housing) & Public Housing Practitioner $\mathrm{X}$ \\
\hline Housing managers (private sector) & Private Property Manager $\mathrm{X}$ \\
\hline
\end{tabular}


The analysis in this section includes:

1. The assets of the rental sector in adapting to climate change, including existing everyday practices by tenants and property managers, existing capacities and commitments of individuals and organisations to sustainability and climate change adaptation

2. Barriers which limit the capacity of individuals and organisations to exercise these assets. These relate to the quality, availability and affordability of housing stock, attitudes of stakeholders to climate change adaptation and sustainability, lack of resources, public perceptions of tenancy, and economic and regulatory constraints which act as disincentives or obstacles to climate change adaptation in the sector

3. The analysis is set against the background provided above on the kind of public media attention paid to tenants and sustainability, the information resources already available on sustainable practices for renters and property managers, and the legislative and policy frameworks at all levels of government

4. Underlying both assets and barriers to climate change adaptation are the relationships between the stakeholders - tenants, landlords and property managers - and the ways in which these relationships construct, and are constructed by, the everyday practices of stakeholders.

\subsubsection{Summary of findings}

The tenants we interviewed were motivated by clearly articulated positions of concern about the impact of human activity on the environment, and exercised this concern through everyday sustainable household practices and sometimes through engagement with community or political organisations. They believed however that their capacity to act in the home was inhibited by a lack of care by landlords and property managers about the sustainability of tenants' homes.

Busyness and lack of resources was seen as a constraint on private property managers' capacity to advocate or arrange for sustainability modifications to the properties they managed. Mediating between landlord and tenant was seen as a major part of the property manager's role and left little time for promoting the sustainability of rental housing. There was also a greater range of views amongst the property managers about the importance or reality of climate change, from belief to some scepticism. Private property managers, while viewing legislative change as difficult to implement saw it as necessary to motivate landlords to make improvements to their properties. Nevertheless, they noted a range of attitudes of landlords in this regard.

Housing Managers in the public sector saw the public housing sector as policy leaders in sustainability and adaptation, but constrained by lack of resources (human and financial) and the busy reactive nature of their work. While there were many similarities in the everyday practices of housing managers in the private and public sectors in addressing climate change there were also some differences. Public housing managers recognised the role of public housing as providing a home for vulnerable people as critical to responses to climate change. They regarded the security of tenure enjoyed by many public housing tenants as enhancing their capacity to adapt their dwellings to be more sustainable, or in response to climate change. In addition public housing managers were more likely to mention the challenges posed by the physical 
condition of the housing stock they manage, reflecting the history of public housing building practices in NSW since the 1940s. Routine maintenance of dwellings is a major task of Housing NSW, at times leaving few resources for climate change adaptation. Finally, some Northern Region Housing NSW housing managers saw the difficulty of providing feedback to central office as a barrier to climate change adaptation. Moreover the split of Housing NSW between tenant and asset management may exacerbate this problem, providing another barrier to adaptation in the sector.

Tenants believed that negative social and political attitudes to renters are an obstacle to changing tenancy conditions and improving housing. However public housing managers were more likely to acknowledge that a tenant's house was their home, and the importance of a tenant's capacity to make changes to the house as part of 'homemaking'.

Both public and private sector managers suggested the provision of advice to tenants on energy or water efficiency needed to be done thoughtfully, and noted the potential for advice to be patronising or intrusive. This aspect of housing managers' role, along with their role in providing advice to landlords on maintenance, improvements, and responses to tenants' requests, positions housing managers as crucial 'knowledge brokers' in improving the adaptive capacity of the rental sector.

Some understanding of this role can be seen in private housing managers who expressed a strong need for more authoritative information and training in order to be able to advocate convincingly to landlords for sustainability improvements in rental properties.

Both tenants and housing managers acknowledged that the current shortage of rental housing in many areas, including the Newcastle area, was one of the most important constraints on tenants' ability to influence the market through preference for housing with better sustainability profiles. The lack of housing options was perceived by tenants as disempowering, and the possibility of a lease being terminated was a reason for not seeking improvements to properties to make them more adaptive or sustainable.

Tenants commented also that improvements to properties were likely to result in rent increases; housing managers noted that mandatory improvements were likely to force some 'marginal' landlords to sell their investment property and thus put greater pressure on the rental market.

Tenants expressed frustration about lease conditions which prevent or discourage them from making sustainability modifications to their homes, or from pressuring property managers/landlords to do so. Private housing managers also expressed frustration with changes to tenancy laws, such as recently introduced requirements for water-saving devices and smoke alarms, as cumbersome to implement and an example of the difficulties of engaging landlords with sustainability investments in their properties.

Public housing managers felt that the size and bureaucracy of the organisation made change difficult, especially if change were initiated in frontline offices. However in they 
strongly believed that the organisation's recent housing projects were exemplary in their sustainability standards.

Both property managers and tenants acknowledged the 'split incentive' arising when investment by landlords (for example in solar power or water-saving devices) results in savings by tenants. Both also, however, acknowledged that incentive schemes and short tenancy contracts discourage tenant's investment in a rental property because the tenant is not generally eligible to receive the subsidy or rebate, nor will they be occupying the house for long enough to receive a return on their investment over time; instead it is the landlord who will benefit in the long term.

Tenants felt however that property managers could be unhelpful in negotiating tenant requests for modifications to their homes, and noted that information about the environmental performance of a dwelling was not available to them.

Nevertheless, the interviews with tenants and property managers mapped out a strong asset base in the rental sector which could be used to adapt the sector to climate change. These included:

- for tenants, strong visions of the future and understandings of what would make a difference for the better

- for property managers an understanding of the tenant/landlord/property manager relationship, tenancy legislation and contracts, costing and procurement of maintenance and improvements to houses

- existing capacity on the part of both tenants and property managers to act on adaptation through everyday practice, despite structural, material or resource limitations

- extension of influence through networks. For tenants this included neighbourhood, community and political networks. For property managers this included organisational base, professional training and information networks, and their role as 'knowledge brokers' for both landlords and tenants

- specific ideas for change to improve the adaptive capacity and sustainability of the rental sector.

In the next section we turn to more specific details about of findings from interviews and focus groups with housing managers and tenants.

\subsubsection{Role of the property manager}

Property managers currently perceive their role as primarily one of 'juggling' the demands of tenants and landlords. Sustainability and climate change adaptation in the rental sector is not part of 'core business' or their everyday practice. Climate change and sustainability are not widely discussed in workplaces, and there is some climate change scepticism.

There is a shortage of authoritative information available to property managers on which to base advice to landlords about sustainability modifications to rental properties. Sustainability and climate change are not addressed in training courses for property managers, nor in programs and information delivered by the Real Estate Institute. 
Property managers have found legislation mandating improvements to housing, such as smoke alarms and water-saving devices, to be onerous and difficult to implement. There is a general perception that regulation is unnecessarily complex and has not taken account of issues 'on the ground' when designing legislative requirements.

Proposals for change which emerged from the research included a changed role for property managers as advocates and knowledge brokers for sustainability and adaptation in the rental sector. This should be supported by new training programs, professional development programs and information resources, through the REI or elsewhere, including regular professional or public seminars, or online courses. The content of these programs could include:

- advocacy and negotiation skills to support property managers in seeking adaptive improvements to housing from landlords and enhanced adaptive practices from tenants

- up to date technical knowledge to support property managers in facilitating costefficient compliance with building sustainability standards: for example through providing up to date information on regulations, incentives and rebates, costeffective sustainability improvements to dwellings, comparative costing processes for modifications, comparative information on green energy providers

- training of property managers to either conduct or commission building performance audits.

\subsubsection{Responsibilities of the landlord}

Landlords often do not perceive their responsibilities and interest in sustainability and climate change extending to their rental properties. Even legislative requirements, for example requiring water-saving devices to be installed in all rental properties, were often complied with only reluctantly.

A changed landlord culture could frame rental properties as 'ethical investments', which must provide opportunities for tenants to practice sustainability and adapt to climate change. Proposals to support such a change in culture include:

- education and awareness programs for landlords, provided by government or the REI, and disseminated through property managers or online

- increased government subsidies for modifications to houses such as solar panels, solar hot water and water tanks in rental properties

- enforcement of higher building standards for existing housing stock, or mandatory disclosure of building performance to prospective tenants

- incentive schemes for housing such as the current environmental upgrade agreements applicable to larger buildings

- demonstration projects which show how adaptation and sustainability can be integrated into rental properties, and associated costs and subsidies.

Such measures need to be designed carefully to ensure that landlords do not withdraw their investments in the rental sector. Developments that drive down investment in an already tight rental market are likely to create new barriers to adaptation. As a result 
key industry representatives, including tenant organisations, housing/ property managers and landlords should be active participants in the drafting of any new legislative requirements or policy frameworks

\subsubsection{Supporting tenants' adaptation to climate change}

Tenants see themselves as active agents in climate change adaptation and sustainability, but are aware of the structural and legislative barriers to living as sustainably as they wish. The tenants interviewed for the research project also generally identified their interests in sustainability and climate change adaptation with the interests of other more vulnerable groups, such as those in developing countries, the elderly, or future generations. Tenancy legislation limits tenants' capacity to make sustainability and adaptive changes to their homes. These legislative restrictions are exacerbated by a lack of advocacy by property managers in passing on requests from tenants to landlords to make such changes, even at the tenant's own cost.

These restrictions on tenant adaptive capacity are also exacerbated by short leases and by a landlord and housing management culture which does not see a tenant's house as a 'home', in contrast to longer more secure leases overseas and lease conditions which support 'home-making' by tenants. The exceptions to this culture were public housing managers whose organisational culture was based on a view that the tenant's house is their home.

Proposals emerging from the research which address these issues include:

- stronger communication protocols between tenant, housing manager and landlord facilitated by a property manager with appropriate training to promote the best outcomes

- changes to Tenancy Acts and lease contracts to enable, rather than inhibit, modifications by tenants such as gardens and water tanks, with a simplified approval process

- changes to Tenancy Acts and lease contracts to provide for longer leases (with necessary protections for both landlord and tenant in the case of changed circumstances or a breach of the lease conditions)

- development of modification contracts between tenants, landlords and suppliers (of solar panels, water tanks etc.) or enable a tenant to lease fixtures for the duration of the tenancy only, or to take the fixture with them to the next tenancy

- automatic provision of sustainability guides for tenants moving into a new home, with building performance information where possible

- development of guides for tenant advice and advocacy organisations to enable them to review programs and resources not specifically directed at the rental sector but which may offer useful tools for sustainability and climate change adaptation

- education and training resources for tenants to participate in community, regional and international initiatives to respond to climate change. 


\subsubsection{Housing affordability and availability}

The greatest constraint on tenants' capacity to seek sustainable, adaptive housing is the shortage of affordable housing in the rental market. The tight rental market has not improved despite a COAG agreement on housing affordability and a number of Commonwealth and State government funding initiatives over recent years.

Specific proposals to increase availability and affordability of rental housing which arose out of this research include:

- consideration by COAG of the Housing Supply Bonds proposal recently by AHURI (Lawson et al. 2012)

- changing planning legislation to enable multi-family housing which shares resources such as kitchens and bathrooms

- increases in government funding for public and community housing.

\subsubsection{Rental housing standards}

New housing is required to meet high standards of environmental performance in accordance with the National Building Code and State-mandated ratings schemes such as BASIX in New South Wales. However existing housing is far from meeting these standards, and represents the greatest proportion of rental housing. Poor building performance is both a disincentive and an obstacle to tenant adaptation to climate change, and more information about building performance is needed in order for tenants, landlords and property managers to take action on improving building standards in the rental sector.

The consequence of improved sustainability of rental housing however is likely to be rising rents and this is an issue which needs to be addressed the same time as building standards.

The rental housing sector is also likely to be disproportionately affected by disaster preparedness plans, which include raising houses, constructing flood refuges or relocating entire low-lying suburbs. These responses are likely to result in either evictions or rising rents because of mandatory modifications to houses.

Similarly, there may be other enforced modifications to homes in the future due to resource scarcities.

Proposals for change emerging from this research include:

- increased funding for housing maintenance by Housing NSW

- extending Environmental Upgrade Agreements to apply to all rental housing

- a review by COAG of rental housing standards and an assessment of priorities for regulation and incentives to landlords to retro-fit existing housing stock

- assessments by COAG or State governments of the implications of disaster management plans, including modifications or relocation of housing, on the rental sector 
- $\quad$ expedited introduction of the Commonwealth's proposed Residential Building Mandatory Disclosure scheme.

\subsubsection{Communication between tenants, landlords and housing managers}

The concerns by tenants that their requests for adaptive modifications were not passed on to landlords by housing managers, and the housing managers' perception that they are constantly 'juggling' demands from both landlords and tenants indicates a need for better communication systems between all three parties. This will become even more important if adaptive changes to housing are increasingly mandated by government, and during disaster responses.

Proposals emerging from this research include:

- more training for property managers in advocating and communicating to landlords the need for sustainability and adaptive changes to rental housing

- exploration of other avenues for enabling direct communication between landlord and tenant, especially about climate change adaptation and sustainability issues. This could possibly be undertaken by the REI, or through an online forum where issues could be discussed by tenants, landlords or property managers.

\subsubsection{Government responsibilities}

The concerns expressed in our interviews and focus groups, and our review of current legislative and policy documents suggest that addressing all of these issues requires greater recognition and inclusion of the rental sector in government policies and programs. Proposals reflecting this call for recognition and inclusion are:

- all levels of government should make explicit in policies, legislation and programs the potential contributions of, and impacts on, the rental sector. This should occur at least in the areas of transport, land use planning and housing provision, housing performance, utilities, disaster planning, education and incentives for change

- Federal, state, local government climate change adaptation strategies for boosting resilience to floods, bushfires, storms, heat stress, and other natural disasters should include specific strategies to engage tenants, landlords and property managers

- resourcing of policy implementation and programs should include a consideration of the resources required for equitable implementation across all sectors, including the rental sector

- a review of tenancy law in line with the other recommendations of this report, so that it better supports tenants, landlords and property managers as social and economic agents of sustainability and climate change adaptation.

Tenancy advice and advocacy groups have expressed concern about rising numbers of clients and reduced funding. The need for such services is likely to increase with the impacts of climate change on tenants, such as dislocation or reduced habitability of rental housing. This report proposes that funding of Tenancy Advice and Advocacy 
Programs should be reviewed to ensure capacity to address the impacts of climate change on the rental sector.

The following is a detailed analysis of the primary data which supports these findings.

\subsubsection{Assets: Tenants' understanding and commitment to sustainability and climate change adaptation}

\subsubsection{Definitions of sustainability}

Almost all of the tenants who participated in this project revealed some form of concern about the world which committed them to sustainable practices in their own households:

I'm conscious of that sort of intergenerational equity ... that I'm handing over the Earth to generations beyond me, hopefully in just as good a state as I inherited it or better [Tenant 20: house/private manager].

I don't want have a negative impact on the planet, which is almost impossible being alive, but I want to have a minimal [impact] [Tenant 6: house/private landlord].

I became less focused on thinking that we needed to conserve these wilderness areas because that was the only way that we're ever going to save Mother Nature and thought well, it's more about how do we live rightly and sustainably with nature in our everyday lives [Tenant 9: house/private landlord].

So it's probably more about just minimising your footprint on the earth... But also trying to share that with other people, like share that awareness [Tenant 3: house/private landlord].

The public housing tenants we interviewed expressed a range of motivations for acting sustainably, from economic to concern about the future of the planet:

Well, you want to keep your electricity bill as low as possible [laughs]. [Economic motivation?].

Yeah.

[Are you motivated to be sustainable in a kind of more general way?] Yes, as far as possible [Tenant 17: flat/Housing NSW].

Well, trying to make it survival - that we don't pollute our country. It's our planet. If we don't look after it, what is going to be there for our future siblings and what they're going to have to put up with from our mistakes? We have been making a lot of mistakes. Come on, look at all this land where we clear the land, took all the trees away [Tenant 22: townhouse/Housing NSW].

Literally to save the planet, because I don't think the planet's going to survive.... So the use of oil and the use of resources - rather, I should say, the primacy of all that means that - and we've used all this stuff so quickly, like in the blink of an 
eye - well, there's no other conclusion, because we've probably reached a tipping point... [Tenant 23: flat/Housing NSW].

To act in accordance with these definitions of sustainability, most of the tenants we interviewed undertook everyday household practices that conserved energy or water, reduced consumption of processed or packaged goods, recycled waste, and often produced their own food. In both interviews and focus groups, tenants pointed out the value of neighbourhood connections in sharing information and resources to assist tenants in these practices.

\subsubsection{Care for others and care for self}

There is a disjunct between the motivations ascribed to tenants in many sustainability guides, where saving money is at least an equal objective with helping the environment (see the document review section above), and the motivations expressed in the overwhelming majority of our interviews which were more focused on caring about the environment and caring about others.

When asked about 'the main impact on self' of poor quality housing, lack of incentives to invest in sustainable modifications, or poor quality infrastructure, a number of tenants discussed their inability to reduce living expenses, particularly energy, or to use public transport or bicycles (see 'Limits on Tenants' Capacity to Act' below).

The comments made by tenants about their reasons for acting sustainably or responding to climate change reflected views about the need for deep change in ways of living, and world views which considered sustainability and adaptation much more broadly than tenants' own lives. Almost all of the tenants we interviewed felt that the impact of climate change on themselves was less significant than its impact on future generations or on those who were disadvantaged, for example those in developing countries, the elderly or the poor.

This accorded with the views they held about why sustainability matters, and in particular the view that sustainability is about protecting future generations, the developing world, and other species:

[In Kiribati] - they're looking for land to purchase to relocate their people. ... if you're kind of well off and if you're all right financially, it almost isn't going to impact you. It's going to be the people at home that don't - can't afford heating, or cooling, or are vulnerable in the community like older people that are going to be dying in extreme weather events [Tenant 14: house/private manager].

[I]n terms of just living here, I don't know how affected it will be, because we are quite a privileged society. Unfortunately like it's - a lot of the developing nations are just suffering at the moment, with the extreme weather conditions and the rising sea levels, and access to food and clean water [Tenant 3: house/private landlord].

Yes, catastrophic. It will affect mostly people that live - well, not mostly, but a lot of people that live near the sea, which is where the main population centres are 
located, especially in the tropics and, well, around the tropics and between the two tropics of Capricorn, which is where the big boom of population is happening. So it could be, I mean, like very, very catastrophic [Tenant 4: flat/private manager].

These motivations are examples of Milligan and Wiles' (2010) combined 'caring for' the environment and 'caring about' the environment. Caring for the environment was most evident in everyday sustainability activities such as conserving water and energy or gardening, and caring about the environment was evident in participation in community movements, or green activism. However Milligan and Wiles (2010) argue that both everyday activities and participation in groups concerned with 'distant others' are examples of actively caring for and emotionally caring about the environment.

For some tenants, 'caring about' also produced stress and sometimes a sense of despair about the future.

\subsubsection{Stress about the future}

Almost all of the tenants in fact felt that there would be very little impact of climate change on themselves during the foreseeable future. Nevertheless, several tenants expressed stress, or distress, about the future or about what was already occurring elsewhere:

So environmental refugees and people [will be] suffering because of their mental health, psychological wellbeing... [Tenant 3: house/private landlord].

It's depressing. That's the other reason why we don't like to think about climate change. It depresses us...I think you've got a bit of blinkers on to not actually want to do something about. But I know it's scary and I know that fear is definitely a motivator for avoiding the topic [Tenant 7: townhouse/private manager].

Another tenant predicted that "we're going to have wars on water and food scarcity and yeah we probably have to all move to Tasmania or something" [Tenant 12 : flat/private landlord], while another told us: "I feel humankind is doomed, that's my background. There's no solution to that" [Tenant 23: flat/Housing NSW].

This stress related both to the fate of others, and to their own incapacity to change things. On the other hand, some made the point that exercising agency and acting for sustainability could only occur if one was not 'overwhelmed', or too stressed to act:

... I do notice sometimes, I just can't bear to watch say documentaries. I just find it overwhelming. I do feel sometimes quite powerless ...I've been quite despairing about it at times. But the way I keep going with it is I just do what I can [Tenant 10: flat/private manager].

Oh I'm just a bit worn out. You spend years being all enthusiastic and fighting for the cause and c'mon guys, let's do this. We have to act now and then you just go you know what - humans are stuffed [Tenant 12: flat/private landlord]. 
Well, not being effective enough. I always had to work full time, kind of thing and you need a bit of time to do those things. ... just that whole thing of the way there's power between the police and what you're doing. That whole thing used to just depress me too much... [Tenant 16: house/private landlord].

These comments reflect the sometimes counter-motivational impact of some apparently overwhelming issues, as Barnett and Land (2007: 1068) claim:

It is just as likely for someone to conclude that their contribution is so highly mediated that not only are they not able to do much about it, but that this does not really count as being responsible in any reasonable sense at all....

... on its own, the mere fact of being bound into relationships with distant others does not actually provide any compelling reason that could account for or motivate relationships of care, concern, or obligation.

Despite these expressions of despair, almost all of the tenants we interviewed believe that their contribution to sustainability through everyday practices and community engagement was worthwhile.

So I suppose it's on a personal level, it's just I feel I do what I can and I know that there's always a lot more that I can do. I think I've started to get over feeling guilty because I can't do all the things that l'd like to do. So I think rather than just say people should do that and people should do this I feel like it's important that I do as much as I can [Tenant 15: house/private manager].

My mother and my father both gave me their anxiety and care for the world, which puts me in a place where I see the world and desperately hopeless it all seems and I sort of feel powerless to do anything. I basically came to the point where I gathered I only have so much power as an individual and the best I can do is to set a good example, educate others and just talk to as many people as possible and be as passionate as I can about it. So that's the go [Tenant 19: house/private manager].

\subsubsection{Assets: Property managers' understanding and commitment to sustainability and climate change adaptation}

Housing NSW managers varied in their views on sustainability, although several commented that they had an important role to play in advising and supporting tenants in sustainable practices, generally using the approach that it would save the tenant money. They varied considerably in their understanding of, or belief in, climate change:

To me it's no hotter now than what it was when I was a kid... So I don't know. The thing for me around climate change is there's a lot of scepticism and there are a lot of people making money out of it which increases the scepticism. There's a lot of disputed science over it so I guess if you like, I'm getting splinters from sitting on the fence [Public Housing Practitioner 7].

I individually I am because I suppose I've always thought about it, right from the 1970s. I can remember back then even being - it was topical even then. As a 
young adult, energy and fuel and everything that runs the planet was discussed and debated... I've always had a bit of an awareness about it. It's just the escalation now. To me it's more than just what we do in our homes. We've got China pumping out \$2 shop stuff that our tenants and others buy. Gadgets and belongings and material items are easily, readily available and they're cheap [Public Housing Practitioner 6].

... the weather now is what we're getting about 25 years ago. We are going to get a normal August and pretty normal summer, that we had 20 years ago or 25 years ago. So I just see it a bit cyclic too, as well as the other change bit, as well [Public Housing Practitioner 5].

Other comments which reflected ambivalence about climate change included: "I think 'oh I'm right up on the top of a rise it won't impact on me', but what about those down there, you know" [Public Housing Practitioner 4], and ."...people are bombarded with information these days and it gets hard to source, I suppose, something that you can really rely on [Public Housing Practitioner 1].

Private housing managers also expressed a range of views, which included a combination of support for sustainability but scepticism about climate change:

I think in most people I think there's a form of it that we all do our own little bit even - I would love to have chickens in the back yard and grow my own veggies, I just don't have time and I don't have the space for it. But if I definitely had the space for it l'd definitely be doing all that sort of stuff.

... I'm really not one way or the other [about climate change]... I just believe that we just basically have this universal thing, it just means that we're at the 30 year or the 40 year and things are meant to be like they are at the moment and they'll change - you know. I don't believe all this climate change myself [Private Property Manager 6].

... stuff that I put on my blog once. Look I don't know if this climate change is true or not. Then I put in a little cartoon. It's funny it's like - oh so we cleaned up the whole world for nothing... I mean it's a good thing to me to clean up anyhow. Yeah I've just done things because I believe in it. There have been benefits from getting the house green. Solar panels, insulation, I've got a water tank [Private Property Manager 3].

Another suggested: "I'm not a sceptic on it but I'm not a 100 per cent convinced either" [Private Property Manager 5].

\subsubsection{Assets: Action by tenants on climate change and sustainability}

The actions taken by the tenants we interviewed reflected a strong sense of agency despite the constraints they perceived in terms of the fabric of their house and tenancy contracts. 
Tenants exercise considerable agency in sustainability through everyday household practices, modelling sustainable living, informal and organised advocacy, and engagement with their communities.

\subsubsection{Individual household practices:}

Individual household practices undertaken by tenants included buying green power, reducing energy use, growing food and buying second hand:

[I buy] 100 per cent wind power from Origin [Tenant 12: flat/private landlord].

I mostly don't use that [heater] actually, unless I have visitors. When I'm at home, and if I'm sitting down and not doing much and I get cold, I'll often actually throw my dressing gown on... If I'm lying down having a rest or watching telly and it's cold, I'll put the rug over me [Tenant 10: flat/private manager].

We've got the garden, so growing our own food. We've got the chooks - eggs. The water tank. We have a lot of people living together, so we save power that way. We can afford to buy bulk food as well and organic, which is more sustainable [Tenant 3: house/private landlord].

Other things, generally clothes, I buy second hand...Yeah, cars and stuff like that, but useful little things around the place too you now, all sorts of stuff... [T]he local church runs an op shop just down in the shopping centre... [Tenant 2: flat/private manager].

\subsubsection{Modelling sustainable living}

Tenants modelled sustainable living through encouraging others to be conscious of lighting and electricity use:

... the girl that was living here at the time I always thought was quite wasteful, like she'd just leave lights on in multiple rooms.... I tried to put a stop to that so I tried to encourage people living in the house that, you know, this is costing us too much money [Tenant 9: house/private landlord].

I guess we're really, really big with the kids with turning lights off. So we - that's something we do quite a lot [Tenant 8: house/private manager].

\subsubsection{Advocacy}

A number of tenants engaged in conversations with family and friends in order to discuss climate change; which they did as a form of advocacy:

[M]y nephew is studying science at uni. He's doing physics. He went to stay with my older sister in Sydney and they were talking about climate change or something. It turns out he's a bit of a climate change sceptic. It's only his first semester at uni and it was like, okay well we'll let him study science for a bit longer and talk to him again later [Tenant 15: house/private manager]. 
Yeah oh look, my family down in Victoria, I think they do believe [in the importance of sustainability] now but they didn't for a long time and I've been talking about it since 1978 or something like that [Tenant 16: house/private landlord].

I've got a couple of family members completely - don't even do anything right with the garbage section. I look at it and I go - and they get there and it's all full. I said well, actually, you can fit all that into that garbage. What do you mean, Aunty ...? So I tipped the whole recycle bin out, squashed all the PVC bottles and everything else, put it all back in, and I said there. There's about that much more room, now. How the hell did you do that? It's called squashing. It's called packing. Opening up the boxes [Tenant 22: townhouse/Housing NSW].

\subsubsection{Political activism}

Some tenants engaged in formal forms of advocacy through their involvement with environmental groups and organisations:

[This house is] an intentional community. So people are living here because they have shared values around the environment and social justice. So - and that's the idea, that those people come together and work on those projects together. Form a community, and try and be sustainable as well, ourselves.

I'm a member of the Climate Action Newcastle Group so I support them and just do a bit of environmental activism ... or actually giving some money to some groups or going along to whatever is going on if I can at the time [Tenant 12: flat/private landlord].

I see my involvement with the Newcastle Greens as really advocating for a more sustainable future. Getting involved politically, I think is really important to actually stand up and try and change some of the policies that currently exist. Whether it's at a local level, in things like waste management systems - things like that. Whether it's state or federal, it's all valid. It's all necessary [Tenant 8: house/private manager].

\subsubsection{Community engagement}

Tenants were active in their local community through participating in various community gardens, transition towns groups and alternative forms of economies such as food cooperatives and local energy trading schemes (LETS):

[W]e need to be getting onto - our governments aren't moving quick enough really - to be getting onto doing local scale stuff and taking responsibility ourselves and setting stuff up for that [Tenant 2: flat/private manager].

We don't want to set up a community garden. We want it to ... affect the economy, have a local food economy. So we want to have a market garden growing food for outlets such as farmers' markets, a couple of cafes, our own subscribers - so we want to set up and we have done it [Tenant 20: house/private manager]. 
We're currently participating in the Transition Newcastle Street Challenge... The first month was about looking at water usage. So we're looking at trying to reduce water consumption - strategies for that. This month is about energy consumption [Tenant 4: flat/private manager].

I belong to Beanstalk Food Coop. So I get a lot of my fruit and veggies from there so we often juice stuff ourselves [Tenant 15: house/private manager].

I like trading - I don't really like money very much... so I'm a member of Hunter LETS (Local Energy Trading System) [Tenant 19: house/private manager].

\subsubsection{Assets: Action on climate change and sustainability by property managers}

\subsubsection{The role of property managers in sustainability and adaptation}

Everyday practices of housing managers can work to enhance or limit the adaptive capacity of the rental sector. At a broader level, the property management sector itself operates in a number of ways which can be perceived as either assets or limitations on adaptation.

Elements of the rental sector - for instance, housing management styles, and processes of information exchange, such as formal training - can be considered as assets to be potentially enrolled in efforts to adapt the rental sector. Housing managers recognise that the rental sector at present contains only limited instances/ examples of sustainability, and the structures that support the professional development of property managers, such as conferences, currently fail to support them in enabling adaptation. However these structures can be recognised as assets with the capacity to be harnessed and built upon.

Housing managers in both the public and private sector acknowledged that they had a role in sustainability and climate change adaptation:

I think we've grown with the growth in the community. Certainly the change of government in 2007 promoted awareness, I guess, around the environment to a larger degree [Public Housing Practitioner 7].

Yeah, I believe so. I mean, so long as you're aware of what's happening, and where you can improve a property, I guess one, for the environment - two, for the - well, one for the environment and one for the landlords and the tenants who are living in the property. So I think if you're aware of different things happening and I guess you recommend these things to the landlords, it's going to help out everywhere [Private Property Manager 8].

They saw that as - and that's another thing with landlords; most landlords are busy people. Most landlords are business people, and they're very time poor, and that's why they want their property managed. So with energy efficiency, this is probably something - if there is a minor cost involved, as long as the property 
manager takes control of it, there's a way of bringing that in [Private Property Manager 1].

One private property manager suggested that property managers need to be "more involved at the grass roots" of policy change: "they should actually speak to people that manage rental property and find out what the story is and what they need to be doing" [Private Property Manager 2].

The public and community housing practitioners we interviewed saw their organisations as leaders in sustainability. Housing NSW has recently released its sustainability strategy (DFS 2011) including a guide for public housing tenants on sustainable practices ('Welcome to Your Home' (Housing NSW 2012b)). The guide is subtitled "Information to help you save energy and water", and it focuses on saving money as a primary reason for reducing energy and water consumption, recycling, and buying second-hand clothing, for example:

I think we're leaders in that way. I don't think the private sector comes anywhere near us... I think we're often very well above the bottom line. Not in size of dwelling but in what you get in the dwelling.

So we don't provide massive homes but we provide smaller homes with a higher standard of environmental focus [Public Housing Practitioner 6].

So I guess just in terms of size and magnitude and management, we're - or hope to think that we're leading the way in terms of sustainable [housing]. [Public Housing Practitioner 2].

The Community Housing organisation supports community sustainability projects and competitions as part of its community liaison program. The Community Housing practitioner suggested their organisation may exceed Housing NSW in this area:

We believe that we were ahead of Housing NSW anyway in relation to our - and I believe we're ahead of other community housing organisations with our community sustainability programs anyway. We believe that we've led the way a little bit there, which has been good. But I don't know much about what Housing are doing at the moment, no [Community Housing Practitioner].

While public and private housing managers were generally pessimistic about the extent to which sustainability and climate change have been incorporated into the rental sector, they also offered examples where positive environmental changes had taken place in their rental stock. These examples are rarely straightforward; they demonstrate the complexity of enacting incentive and regulatory led changes, and range from instances of individual landlords carrying out small scale retrofits to an individual dwelling, to new housing projects with environmental features built by Housing NSW. While not all examples offered by Property Managers are climate change adaptation specific, they are nevertheless helpful for developing 'best practice' in managing environmental efficiencies in the rental sector, and by extension, specific recommendations for managing adaptation.

Adaptation occurs through property maintenance; regulatory led changes; incentive led changes; systemic programs to update properties; other examples of retrofitting; and new housing. 


\subsubsection{Adaptation through maintenance}

Public housing practitioners in particular noted that there is an increasing trend for more efficient technologies to be fitted to dwellings as part of both responsive maintenance and scheduled maintenance and property upgrades. This includes measures such as replacing broken electric hot water systems with solar and providing gas connections to specific estates.

It's not a program as such but certainly if an existing showerhead fails, it's replaced with a water-saving device [Public Housing Practitioner 7].

We've just upgraded a couple of buildings out at Hamilton South. We've just put them onto gas [for hot water].

They've got apartment blocks and they're three storey and there are common area laundries out the back. So we are closing them down slowly and putting redesigning the kitchens into putting the frontload washer...

That's just happened to two buildings out there.

So there's the whole program that will happen through the estate out there [Public Housing Practitioner 5].

[M]ore recently when we have water - hot water systems that break down if the orientation of the house is suitable we try and replace it with a solar hot water system maintenance [Public Housing Practitioner 3].

But, certainly climate change I think it's changing the way we approach our building, changing the way we approach our maintenance [Public Housing Practitioner 3].

\subsubsection{Legislative and regulatory led changes}

Water efficiency legislation was discussed as the most common (and indeed, the only) widespread instance where retrofitting (of water efficient showerheads) on rental properties was carried out, and where environmental legislation specific to the rental sector exists. It can be considered as a 'case study' for the challenges of legislative led changes, offering insights into the different ways housing managers implemented the legislation, and an indication of some of the experience and systems which housing managers bring as assets in climate change adaptation.

Strategies that private property managers used for implementing the legislation included:

- the provision of detailed and specific information to landlords about the legislation and why they would benefit from it including an estimation of cost

- case by case pricing for individual dwellings

- negotiating a fixed cost with plumbers carrying out the work

- organising the work for each property to minimise the work required of landlords

- setting a deadline for landlords to agree to the work. 
Housing managers also noted that some landlords elected to pay the water themselves and raise the rent to recoup the cost of water.

Housing NSW also now charges tenants for water. One housing manager stated that Housing NSW commenced charging for water in 2005, prior to the water efficiency legislation. Public housing practitioners were more attuned to the behavioural impact on the tenants of charging for water and generally discussed water-saving retrofits in these terms:

We did supply water-saving showerheads... Across the state. Not everybody handled them well and a lot couldn't see the difference necessarily but we did definitely have a program for that [Public Housing Practitioner 7].

A lot of literature was sent out and many human hours were spent managing the tenants to understand the reasons behind it and why it needed to happen.

Because prior to tenants paying for their water usage, public housing tenants used exponentially much, much more water than a private - than another resident would have.

Yes [water consumption has reduced]. People are very conscientious about it now [Public Housing Practitioner 6].

Mind you, clients don't like them much so they decide to take them out [Public Housing Practitioner 3].

In contrast with this focus on tenant behavioural change, private housing managers saw negotiating with landlords to implement the legislative changes as the key challenge (see 'Limits on housing managers' capacity to act' below).

\subsubsection{Other legislation}

Other legislative changes which will have an impact on public and private housing adaptation over coming years include the replacement of old hot water services with more efficient systems:

There's issues coming up now where electric hot water systems as a tank can't be replaced with the same. They've got to do something more energy-efficient. So the laws themselves are going to force landlords into that decision-making as well. So they're looking at those heat pump hot water systems, they tend to be a bit cheaper...

... In theory, probably within 10 to 12 years, the actual cylinder electric things will all be gone [Private Property Manager 5].

\subsubsection{Incentive led changes}

Examples of incentive led changes reveal the different ways that housing managers, landlords, and tenants are able, or not able, to engage with government initiated schemes that provide rebates and financial incentives for the installation of energy efficient materials such as solar panels and insulation. 
The Commonwealth Government's home insulation scheme, perceived as being at no/low cost to the landlord, and to the benefit of both the tenant and the landlord, was considered by housing managers to be reasonably successful in encouraging the retrofit of rental stock by private landlords. The experience was soured however by the controversies that eventually ended the scheme in 2010, after a report to Government on alleged fraud and health and safety issues relating to installation (Combet 2010).

Housing managers demonstrated a spectrum of different attitudes and practices in terms of their willingness to facilitate the installation of insulation. This ranged from wariness about the scheme, where landlords would only be referred to a provider when they initiated inquiries about the scheme, to proactively approaching landlords in order to promote the scheme.

While examples of solar panel installation were rare, this is unsurprising given the constraints that housing managers noted about installation in rental properties (see 'Limits on housing managers' capacity to act' below). The examples given by housing managers below suggest a variety of ways in which housing managers, tenants, and landlords can together develop innovative strategies to overcome some of these issues, such as including electricity in the rent:

Now, there's one property in particular - I think probably about 16 solar panels. They never have to pay electricity. I think owners like to keep it in their name, because when they first install them, they get a rebate, but as soon as you take it out of your name and put it into somebody else's, it drops dramatically.

So we've got quite a few owners go don't worry - I'm getting a pretty good return. I'm not paying for it because I'm generating all this electricity. Their electricity is part of the rent [Private Property Manager 8].

When there was the government deal on having [insulation] batts put in the roof, a lot of landlords took that on because it was a great opportunity. It improves the value of their property. It certainly helps the tenant when they use their heating and cooling to not have to use it as much. So in that sense it makes it a bit more energy-efficient as well in homes. There were a lot of people who took that on [Private Property Manager 5].

... when the whole government incentive thing was happening...with the insulation and this is when we were finding that all of a sudden every company could do insulation for you. So our roofer contacted us and said look for every insulation job you do for us we'll give you 50 bucks. Of course, right, bang let's get into this because we've got - you know at that time we had an enormous portfolio.

So I guess we kind of saw the value in it for our owners offering them a service and to better the property as well. So there was a huge trend when that came in, the government brought that incentive out, and it wasn't going to cost the owners any money they all just jumped at it [Private Property Manager 4].

With the batts, I must admit, that was flagged to me as an issue from the outset. For me, it was basically left to me and I saw it as a problem and I did nothing to encourage owners to become involved in it and when we did have owners that 
rang and thought they might consider it, we referred them to established companies that I knew were good companies in Newcastle to be involved. Like, insulation industries, as example, for one [Private Property Manager 2].

We've had a lot of owners have solar panels put in. We've had a lot of owners put water tanks in to cut cost, and that's the thing; being the business manager, I think you've got to be proactive in it. [I]f you see something that the water usage is coming in and it's like \$600-700, I mean the owners have got to pay that, because you can't charge the students, because it's a share accommodation. I'd recommend that - okay, Mr Smith, just realised that your water usage is becoming higher and higher - have you ever considered putting in water tanks it's good for the environment, and it's going to be good for your pocket as well [Private Property Manager 8].

\subsubsection{Influencing tenant behaviour}

Both public and private housing managers commented that there are individualised ways that property managers seek to influence tenant understanding of sustainability (and hence tenants' everyday practices), as well as approaches adopted by housing management in a particular office (private agency or Housing NSW).

Property managers recognised that encouraging sustainability and facilitating adaptation was valuable, and could enhance residents' experiences of their dwellings. On the other hand, both private and public housing managers recognise that attempts to do so may involve an impost on residents and what they do with their homes. As noted in the literature review above, there has been a trend, especially in social housing management, for housing managers to take a paternalistic attitude to tenants through attempting to influence behaviours. Implicit in the statements of some housing managers is an awareness of this as an issue:

[Do you [give tenants] messages about saving energy, saving water?] I think our people get sick of us being at their door, really. It's just my staff knocking on the door to do a property inspection. Throughout the year we'll have - we service the smoke alarm every 12 months so our contractor is there whether the client has an issue or not because they're going in to service the smoke alarm. If there's a maintenance issue our contractor's there and invariably our technical officer could be there. So for a minor maintenance item, our annual inspection, the smoke alarm inspection - all of a sudden they've got us four times in the year for that. Not a great reason [Public Housing Practitioner 7].

I think if I circulated something like that to some of my tenants they'd say 'I'm paying the bills, it's my house... Get out' [Private Property Manager 6].

Other housing managers suggested that "[i]f they don't get it from us, they're probably not going to get it" [Public Housing Practitioner 6], and that providing sustainability information to tenants meant that the property manager was "not just seen as the faceless agent that they pay rent to" [Private Property Manager 9]. 
Housing managers also made observations about the degree to which they believe sustainability is embedded in tenants' everyday practices:

The ladies there were very focused on water-saving devices to the point where we had people in their 80s carrying buckets of grey water from their first-floor unit downstairs. So some residents were very switched on to it but others, again, it's take it or leave it [Public Housing Practitioner 7].

Yeah I would say in a small majority. Tenants do - when we find - when we're showing them properties they do look to see if there's any - like some of them now have got solar system hot water systems without the panels. So people look at that. The option of whether they can have gas heating. Some of them even like it that they can actually have a little garden out the back so they can grow veggies [Private Property Manager 6].

I did have one tenant that I noticed has put a sign on the front, "no junk mail, wastes earth's resources". That's probably the only environmentally conscious statement I've actually seen [Private Property Manager 3].

Both public and private housing managers note the difficulties of generalising about tenant practices:

I think it still comes down to if they want to, they will. You go to some places where it's all working quite well. Some people want to recycle and some don't [Public Housing Practitioner 5].

I guess yes and no. I mean you've got so many different tenants out there, and from different cultures and nationalities, and business people to students, to just normal families [Private Property Manager 8].

Some public housing managers suggest low resource use practices of tenants are generated through economic necessity rather than a concern for sustainability:

Yes and they aim to keep their bills low because they usually living on statutory incomes such as Centrelink. A lot of our tenants probably have a much smaller footprint. They don't have dishwashers necessarily [Public Housing Practitioner $6]$.

There are - you often do hear tenants talking lots about saving energy with heating especially. You can go to a tenant's house or a unit now and they're rugged up, just sitting there with no heating on... They can't afford it [Public Housing Practitioner 5].

This reflects similar findings on the adoption of sustainability practices found by Gibson et al 2011.

Strategies for influencing behaviour included: providing advice to tenants to assist in bill reduction, using reports on water and energy use to directly approach tenants with an unusually high usage to ascertain if there are structural problems with the house causing this use (e.g. leaky taps), promoting sustainable features to prospective 
tenants, recommending insulation to landlords, pointing out potential economic savings of retrofitting energy efficient technologies to landlords, and providing checklists to landlords that include assessing the sustainable features of a dwelling when the landlord signs with a housing manager. These practices are already embedded in housing managers' daily routines.

As expected, the key difference between public and private housing managers is the spheres of influence in which they operate: the practices of private managers influence both tenants and landlords, while the public housing managers focus on their capacity to influence tenants. As noted elsewhere in this report (see 'Limits on housing managers' capacity to act') some public housing managers speak about their perceived inability to influence the broader policy directions of the organisation, which suggests that they do at times attempt to influence their organisation in addressing sustainability.

The following comments suggest that personal commitment to the environment can also be an influence on their practices:

It's not something that I think the department's openly touted to us as managers or staff. When a program comes onboard, everyone gets onboard and supports it. But as far as everyday living, the day to day things that sit outside projects and programs. It really depends on an individual. So if you've got individuals that are personally committed to energy savings and are worried about climate change or even concerned about the way human beings live, they will talk to the tenants about ways you can cut your bills down.

Now, we all do that. We do that very actively in our teams. We're often talking to our tenants about ways they can make their lives run smoother by reducing bills or we refer them to places where they can get advice and assistance over that and other topics [Public Housing Practitioner 6].

[If you were taking tenants around, would you point to the fact that it's got insulation or it's got LED lights? Is that something you'd draw to their attention?] Interviewee: Yeah. I would do. Some people sort of shrug that off and other people go, well that's very good. But how that plays then in their decision-making process, I don't get to really know, unfortunately [Private Property Manager 9].

There are organisational processes which are assets in supporting tenants' everyday practices of climate change adaptation:

We get a report too, on water usage. Often, if there is a spike in someone's water usage, it will send an alert to us. So we then send a staff member out to investigate the whole water spike. So we'll say have you got - we'll get the water meter tested or pressure tested. They can get their - we'll check for leaks in their cistern and things like that. If there is no leaks well, obviously, the washing or the hosing - and then we can say to them well, it's got nothing to do with the maintenance of the home [Public Housing Practitioner 5].

I mentioned some tenants a couple of weeks ago about how much their electricity was. They nearly fell over. So it's just being mindful in the future just to not leave any things on. We've got some lists that we laminate and put in different 
properties, about remember to recycle, don't leave fans on, keep the common areas clean and tidy. So we've got that in all of our student accommodation and basically the days that the garbage is due, because people don't know. So we try to - with especially the students - to try and help them out as much you can [Private Property Manager 8].

The importance of this role of housing managers in influencing tenants (and landlords) has been under explored in research on the private rental sector. This is certainly something that warrants further research.

\subsubsection{Influencing landlords}

The examples below suggest willingness by landlords to invest in sustainability in their properties when housing managers present them information showing the potential for a financial return. The perception of housing managers as knowledge brokers is connected to the issue perceived by housing managers of a lack of training and knowledge about sustainability and climate change, discussed later in this report:

There's a database of around 500 landlords there who - they will spend money and if they can get it from their property manager who they've already got a relationship with saying how about you look at this company. Then it gives a little bit more clout, so we're really careful not to say okay you said that's the way then let's do it when people like that come in [Private Property Manager 5].

You know, if something's broken they'll go ahead and fix it but they're not really looking at taking the next step to insulation and water compliance and those sorts of things on their own without a push from me. So I guess the more I get to know this portfolio the more I get to know the owners, the more I can get them to do [Private Property Manager 4].

When I meet a new owner, and I meet them all the time. We go - I've got a special checklist that I go through, and all that - is it solar panel, is it gas, electricity - sorry, gas or electric hot water system, and these are some check lists that we ask the owner to do, and we'd ensure that yes, it's got your water efficiency and the shower, and yes in the laundry and things like that. So, the majority have gone with it [Private Property Manager 8].

What I tend to find is that when a landlord does re-do a roof or a roof cavity, they do tend to insulate it. We recommend that they put insulation in, and a lot of the time they do [Private Property Manager 1].

Private housing managers consistently referred to themselves as 'juggling' the relationship between the landlord and the tenant. They referred to the complexity and multiple dimensions involved in managing landlord-tenant relationships, including positive and negative housing manager-tenant relationships, and the importance of the relationship between the housing manager and landlord, which is sometimes fraught with tension. They identified reluctance from some landlords to take on board advice offered by housing managers: 
It's surprising to me the number of initiatives we've done with our landlords for their benefit but they've then turned around and said hang on, you guys are trying to make some money. You're going to make some money out of this. What's in it for you? [Private Property Manager 9].

This is reflected in the discussion below on implementing water-saving legislation in rental properties (under 'Limits on housing managers' capacity to act').

It was also suggested that tenants were undervalued in the landlord-tenant relationship, a view supported by the comments of tenants about tenants' rights (see 'Limits on tenants' capacity to act' below).

But, no, it seems like the owners kind of get everything sometimes and the tenants get nothing and we really need to sort of put our tenants up there on the same pedestal because ultimately they live there, they pay the rent, they look after the house [Private Property Manager 4].

\subsubsection{Limits on tenants' capacity to act}

\subsubsection{Tenant motivation versus restrictions of tenancy}

As noted above, tenants' concerns were 'bigger than the house'; the environmental failings of the house brought their way of living into at least partial conflict with a commitment to sustainability and care about the future:

I want to be as efficient as possible, but I just - it's really restricting in this house ...So just those [everyday] things - that's where I feel like I have the most control at the moment. But everything else, it's just reactive to what this house is [Tenant 14: house/private manager].

[W]e're not allowed to have gardens, we're not allowed to have like even plant boxes out the front....

[G]ardening and growing your own food and things like that is I guess a means of independence.... Not having to rely to corporations and kind of taking charge of your own health because you can control to an extent what chemicals go on those foods and all that sort of stuff. I think finance does play a small role in it but yeah, I guess for me it's really just - I really like nature and I don't like what's happening [Tenant 13: flat/private manager].

It's just been pushing it uphill from day one unfortunately. At the end of the day we can do other things to make our contribution rather than having the hassle of speaking to [the property manager] and being rejected [Tenant 4: flat/private manager].

I'm passionate about permaculture which ... about sustainable systems, like creating, designing and then maintaining sustainable systems, whether that's on a household scale, a community scale or a neighbourhood scale... Yeah, I'll pay the rent and I'll maintain the house and do those things but don't tell me not to put things in my driveway or to grow a garden [Tenant 20: house/private manager]. 
It was noted earlier that there is a tension between tenants' often bleak and stressful view of the future, and a strong ethical motivation to act for the benefit of others and the future. In the midst of this tension, the material and structural barriers to sustainability are the more frustrating. These barriers are not seen as issues for the tenant's own adaptation to climate change, but as barriers to ethical behaviour consistent with the beliefs of the tenant and which they believe has implications for the future and for others in the world.

\subsubsection{Housing shortages}

One of the most important constraints on tenants' capacity to influence the sustainability of their dwellings is the current shortage of rental housing in Australia (a $1.3 \%$ vacancy rate in Newcastle as at February 2012 (REINSW 2012)). The market pressure tenants can apply to landlords for sustainability changes to dwellings is limited by this severe supply-side constraint and Government moves to improve affordability and supply have not yet had any significant effect (COAG Reform Council 2012):

I was starting to get desperate. I was starting to get really scared. Like I moved in on the Friday and started work on the Monday. That was how close it was. So environmental stuff was the least of my worries at that point [Tenant 10: flat/private manager].

Although I suppose [mandatory disclosure of sustainability performance] wouldn't have made any difference if in a tight rental market like here because you just take what you can get don't you [Tenant 12: flat/private landlord].

Yeah, the problem is the rental market's so tight, even I've heard that they're thinking about doing this mandatory disclosure scheme, where houses have to have what their star rating is, or something like that... But in somewhere like Newcastle, you could have a one star, and if it means you can get a house... [Tenant 14: house/private manager].

...it's very, very hard in the rental market in Newcastle. Extremely hard. So I don't want to jeopardise my situation. It works for me at the moment [Tenant 21: flat/private landlord].

Housing managers suggested that legislation requiring improvements to rental housing also has the potential to act as a barrier to the provision of sufficient affordable housing:

Landlords - and I'm sure there are certain things that discourage landlords from investing or potential landlords because they think there are all these costs and the tenant gets it all their own way. If you put more barriers in place, there's already a shortage of housing and housing is costing a lot of money. I just think you got to be careful that if you put more barriers up, either landlords that exist are just going to go it's all too hard, I'm selling, and they'll get out of the market, which again, there's not too many new investors coming in. So you've got to be careful if you are putting in these - and as much as they're a good thing, they're 
also a barrier to someone wanting to take on an investment property. So you need to balance the two up [Private Property Manager 5].

\subsubsection{Infrastructure constraints on tenant response to climate change}

A shortage of rental housing results in limited housing options for tenants, and these options are often accompanied by limited transport and shopping options which are in conflict with tenants commitment to sustainability.

Renters are over-represented in low income households, so that, more than homeowners, their sustainability choices are also reliant on public transport, sustainable and affordable housing and consumption choices, and low-cost renewable energy choices. The availability of public transport interacts with sustainability of food choices when transport and local shopping options are limited:

I think maybe the fact that there's no sort of stores around that sell stuff that's not packaged in a tonne of plastic. So like basically the two options are Coles and Woolworths or drive to somewhere that has organic and sustainably produced food. So that I guess is a bit difficult ...More bike paths, that would be nice, I hate riding on the road.

Most of where I live doesn't even have footpaths so people tend to walk on the road and there's a lot of people with just hotted up cars who go flying around everywhere and it's just not really safe. ...So I think yeah, that would be Council I guess, just better development for areas so people can get around and better transport and that sort of stuff [Tenant 13: flat/private manager].

I even thought of writing to the Council. There aren't footpaths... So I walk in the gutter sort of thing. The streets are fairly wide but - yeah, it's not great... Yeah. They haven't planned for that around here...

I also have a bike, which I've got here, but I've only used it once here.... had to buy a car to live in Newcastle because to get to work from here - seven minutes by car, but it was an hour by bus [Tenant 10: flat/private manager].

\subsubsection{Short leases, insecure leases}

Another constraint on tenants' influence over the sustainability of their housing is the short term of most residential leases in Australia (6-12 months). Short leases are not only an inhibiting factor in the connection that tenants develop with the place where they live, their sense of security and home, but have several significant impacts on the sustainability of housing, including disincentives for tenants to make investments in their houses, and a reduced ability to pressure landlords for improvements, for fear of eviction.

One advantage for public housing tenants is their longer leases. The public housing tenants interviewed for this study had lived in their homes for 10, 20 and 30 years respectively. Public housing managers are also more likely to be aware of the ways that tenants value their dwellings and recognise in their management practices the need to allow tenants to feel 'at home' in their dwellings. Private housing managers did 
not discuss the connections that tenants feel for their dwellings, nor how connections to their dwelling may potentially be enrolled in the adaptive practices of tenants.

Comments by public/community sector practitioners' included:

It strives to I guess create a love, if you like, for where you're living. You know, it's not Dodge City because it's a housing estate. There are benefits, you know [Public Housing Practitioner 7].

I think as far as landlords go, we're a lot more generous and flexible than our private landlord counterparts might be because there's an old philosophy that tenants need to feel this is their home. They need to be able to make a home out of it and they need to feel secure in it and have a buy in. If they feel it's temporary and they're not allowed to do anything. Well, it's a disincentive ([Public Housing Practitioner 6].

Well he treats his house like his own. He obviously doesn't own but it's his home. He treats it that way and he wanted everything to be perfect and stuff like that, which you can understand [Community Housing Practitioner].

The main issues for climate change adaptation arising from the short-term leases are (i) that they act as a disincentive for tenants to invest in adaptive modifications their own homes and (ii) the prospect of possible eviction reduces tenants' ability to pressure landlords for adaptive improvements to their housing. These issues are discussed below.

(i) Disincentives for tenant investment in their homes.

Short lease periods are a disincentive for tenants themselves to invest in significant modifications with long-term cost recovery. This is the 'split incentive' in reverse: the landlord would benefit from tenant investment in water tanks, window-seals, insulation or ceiling fans, but the tenant is unlikely to recover their investment in the term of the lease:

If I knew I was going to be living here for a while, then I might talk to the landlord about paying for a system myself because I guess us as renters would be the ones saving on electricity and things [Tenant 18: townhouse/private manager].

Because if we could do things I would be happy to renew the place, like and say, okay, I'm going to live here 10 years. I'm going to paint the walls and make it better. I can't do anything... [Tenant 4: flat/private manager].

One tenant noted that putting in water tanks "wouldn't make sense" if the tenant moved on after even five years [Tenant 14: house/private manager].

Another pointed out the difference between Australia and other countries where 20 year leases are normal: "So you would do things like that, you would insulate the house and you would plant fruit trees [Tenant 15: house/private manager]. Another noted that they would have bought better quality curtains if they had had a longer lease [Tenant 11: house/private manager]. 
(ii) Reduced ability to pressure landlords

Along with the tight rental market, short-term leases also reduce tenants' capacity to pressure landlords for sustainability changes to their homes:

We've just signed a new lease ... but they're not saying it's a six or 12 month lease or anything...

Like if I upset them, like I could be out of a home and in Newcastle, like it's so hard to get a rental here that it's a risk [Tenant 9: house/private landlord].

... if you want things you have to run it past the agent and the owner and it's just that whole - I guess that's constraining in a sense. Like it can be selfconstraining I suppose. I probably wouldn't push as far because I don't want to the lease only goes for a year and I think that's pretty standard [Tenant 2: flat/private manager].

I mean I could push the landlord and ask for an awning and see how he goes. But like I said, I'm also trying to manage that not being a demanding - trying not to be a demanding renter so that he doesn't go hang on, I'm hearing from him too much. What ... could I be getting for rent from that place? Oh, I could be getting this for my rent [Tenant 20: house/private manager].

\subsubsection{Lease conditions concerning modifications}

The lease conditions themselves often inhibit tenant modifications such as tree planting, vegetable gardens, installation of water tanks or insulation, by requiring all changes to be 'unmade' on vacating the premises, or by prohibiting specific practices or modifications:

Because I used to have, as a married house owner... we did all those composting things and had worm farms ...Know all about it, I just can't quite do it to somebody else's house [Tenant 5: house/private landlord].

I focused on [bigger trees] down there but they might end up deciding to cut all that down. The things like the pawpaw and the bananas they're fine because they grow so quickly and if they cut them down then that's not the end of the world...

We're not supposed to have pets so I don't think chickens are pets [Tenant 15: house/private manager].

...the sense was that your garden has to be returned to its original state which was grass and nothing and bare - bareness - because that's easier for real estate [Tenant 20: house/private manager].

Not being able to compost is a really big thing for me [Tenant 21: flat/private landlord]. 


\subsubsection{Access to subsidies and rebates}

At present, most financial incentives for sustainability upgrading of dwellings (e.g. rebates, tax benefits or rebates for solar panels, solar hot water, insulation) are aimed at home-owners and owner-occupiers, rather than tenants. The application of these taxation incentives or rebates by landlords to upgrade rental properties is patchy at best:

My impression is that if they're not willing to spend maybe $\$ 1,000$ on putting in some new carpet then insulation's probably out of the question [Tenant 9: house/private landlord].

Where subsidies were available to tenants, they involved administratively cumbersome processes:

... Hunter Water has a program where you can take your old shower heads like the ones that we have and you can go and replace for free or pay $\$ 40$ to get this really nice fandangled water saving showerhead, but you have to be the owner of the home. You have to be the ratepayer, so if I wanted to do that I could but then I have to like ring the owner and organise with them to come with me so that they can prove that they're the - you know and so on and so forth. That, to me sometimes I'm just like oh, I can't be bothered doing that. ...in the to and fro of every day it's just like one little impediment and I just think oh, well I'll just try and have shorter showers [Tenant 9: house/private landlord].

Neither public housing organisations nor their tenants are able to access rebates and incentives for sustainability modifications to houses. However public housing managers noted a small number of tenants had expressed interest in accessing these rebates so that their homes could be improved.

One public housing manager commented that he had received inquiries from tenants about participating in Government rebate schemes to upgrade their home:

We get a one-off query every so often. When the Federal Government was promoting its solar water scheme, we had residents seeking for us to put them up. Now we weren't entitled to the credit base so...

...so our clients weren't exposed to the incentive, if you like.

[But] they were definitely interested.

[What about when the insulation rebate was on?]

Same thing. They were definitely interested. Again, the rebate doesn't apply to us as a government body [Public Housing Practitioner 7].

This willingness of tenants, both public and private, to adapt their individual dwellings can be regarded as an asset, and raises the need for greater inclusion of the rental sector in legislation and policy development discussed in an earlier section of this report (see the document review of legislation and policy in Section 4.2.3). 


\subsubsection{Disclosure of building performance}

Landlords are responsible for the fixed features of dwellings which have an impact on sustainability, such as insulation, water-saving devices, natural light and electrical lighting, cross ventilation and availability of gas supply. These features vary greatly between properties. However no disclosure to prospective tenants of a dwelling's energy efficiency or thermal performance is currently required, although a proposal for Residential Building Mandatory Disclosure is under consideration by the Commonwealth Government (Australian Department of Climate Change and Energy Efficiency 2012) (see the document review of legislation and policy in Section 4.2.3).

In interviews, tenants made a number of comments about the need for environmental audits and performance disclosure:

It would be great to have some information about the house and what - I mean it would be - I was thinking when I saw, about like a rating system... You know where you went through the $[B A S I X]$... that would be awesome to have something like that for renting so you knew. You might pay a little bit extra if you know that you've got insulation, quality curtains...

Well maybe compost bins should be standard as well [Tenant 11: house/private manager].

... also maybe to, as part of renting a place, saying these are the environmentally friendly features of this house. So then someone - you might actually be able to make the informed decision. When someone says, do you have insulation? You go, yes I do. Or then you can say to the landlord, we don't have insulation. There was a government rebate on it. Why didn't you take it up? You can get solar panels. Why haven't you done that?... Having like a public transport guide built-in so that immediately looking at it, going that's near public transport without even having to look into it [Tenant 7: townhouse/private manager].

... even if there was a green accreditation for rental places. I think that would be just a lovely thing [Tenant 21: flat/private landlord].

\subsubsection{Relationship with landlords}

Although lease contracts are now a 'consumer contract' and no longer an 'interest in land' (Bradbrook 1998), the rental sector consists of buildings not occupied by their owners, and which are viewed (often from a considerable geographical distance) principally as investments rather than providing a service to a consumer (unlike hotels or serviced apartments for example). The tenant can be viewed in purely financial terms, joined with the dwelling to provide a 'rate of return' which covers the landlord's mortgage or increases their income. As Hulse et al. (2011: 154) note:

[T]he ideology of home ownership is ... embedded in the legislative context ... such that the claims of landlords for possession of properties ('recover their asset') take precedence over the claims of households to continue to occupy their housing ('keep their home'). 
There was a wide spectrum of tenant-landlord relationships, including a small number where landlords and tenants were equally committed to making the rental property sustainable and adaptive to climate change:

... the landlord is - says she's happy for us to make changes. Yeah, when we have an idea - solar panels. We go to - we say, look, is this okay? She says yep, that's fine. Go for it.

Yeah, not so much about - we just know that the landlord is supportive of making it as sustainable as possible. It's just things - like modifications to the house we need to be careful with. So if we were - that water tank is pretty big. So it's like you check - we checked with her about the water tank [Tenant 3: house/private landlord].

Tenants' perception generally however is that the homes they live in are an investment only, and that, often understandably, there is no interest on the part of the landlord or the housing manager in providing a dwelling which provides more than basic habitability, rather than also enabling sustainable or adaptive practices (saving water, reducing energy consumption in lighting, heating/cooling or cooking and refrigeration, or growing their own vegetables):

Oh yeah, there's not really any - it's quite cemented around here and I asked to use the garden outside and I couldn't get an answer back from them. It'd just be too hard to have a compost bin or worms so yeah I don't do that... I'd like to but it's yeah, I don't do that [Tenant 12: flat/private landlord].

...there's a new board, like a new floorboard put in there [after 3 years] because the old one had a big split, like essentially it had a big hole that we stared into the ground. So you know, all the cold air just got up [Tenant 9: house/private landlord].

I don't think there's any insulation at all in the back of the house because it's bloody cold [Tenant 11: house/private manager].

I think it's just little things like just replacing the seals on the windows because they don't seal properly and let some cold air in [Tenant 13: flat/private manager].

I'd say it's a lack of insulation. The roof's not ventilated. It seems like it's got ventilation points, but as far as I can tell, there's no whirlybird or anything on the roof... [Tenant 14: house/private manager].

We changed over the lights from halogens to compact fluoros when we moved in so we've kept all the halogens [Tenant 12: flat/private landlord].

Some tenants did note that they were able to make modifications to their home, for example by constructing a vegetable garden, because their landlord had a laisser-faire or indifferent attitude to the tenancy:

It's more of a not caring thing than a caring thing. They're Western Australian, they live in Western Australia and it's sort of an investment property for them. How I see it is I have rapidly increased the investment since I got here. I look 
after the house as if it's my own. There's so much maintenance stuff that the real estate just do not do because they're lazy as hell. I take it upon myself to do bits and pieces [Tenant 19: house/private manager].

Moreover while landlords and housing managers may care about sustainability and climate change in other aspects of their lives (e.g. their own homes, their office, the future of their families), in the view of the vast majority of the private sector tenants we interviewed, the rental properties these landlords or property managers own or manage often do not appear to be included in this caring.

In the current market for rental housing, there are fewer of the normal competitive market pressures to 'please' the consumer. AHURI's report on landlords' investment in sustainability noted that landlords with strong views about the importance of sustainability had made changes to their own homes but not those of their tenants. Some of the landlords' comments reported by AHURI included:

'It didn't even enter my head. I think about it heaps in my own home. Like, heaps. But not at all in the rentals'.

'I hadn't even thought about them for the rentals but maybe I should'.

'I think maybe if you don't live in a place you don't think about it as much as you would if you actually did live in it' (Gabriel et al. 2010a: 56).

One of the public housing managers interviewed for this study also raised this distinction:

Well, it's true because I'm - I will do - my wife's all into looking now at grey water harvesting and all that sort of stuff. Putting a... tank underneath the deck and pumping it back into the laundry and all that sort of stuff. Great ideas. Would I do it in our rental property? No, I wouldn't because I wouldn't get a return on it [Public Housing Practitioner 3].

However some housing managers made the point that landlords can have attachments to their rental properties that exceed a concern with return on investment:

... when you get a house where the owner's quite attached to it, they'll want it fixed to match existing, ... whereas if it's an investment property, you'll tend to see if there's a window leaking or something like that, and the guy goes look I can rebuild the window as such but it's going to take me longer, it's going to cost you more money than sticking an aluminium one in. If it's just a pure investment property, the owner is going to go put the aluminium one in [Private Property Manager 5].

I find the ones that are actually more built for sustainability are the ones where they've been previously owner occupied and they might have the water tank in the back yard, they've got the veggie patch down the side. They've got the solar panels on the roof, they've done it all because they've actually lived there and benefited from it themselves. Then that's been worthwhile to the tenants that have moved in there [Private Property Manager 6]. 


\subsubsection{Relationship with housing managers}

Housing managers are a critical link between tenants' wishes or needs, and landlords' investment in properties, but, almost all of the tenants we interviewed, do not appear to have taken a proactive or advocacy role in this regard - in fact sometimes the reverse:

I said can we at least - if we can't get a couple of solar panels, can we at least get [solar] hot water because that's most of our energy usage. They're like hmm, no, don't care.

[Do you think they asked the landlord?]

I don't even know if they bothered. I don't even know even if they tried, if the landlord would care because it's an investment property and they're on the other side of the country just going whatever.

[Do you think your landlord or real estate agent is motivated to make your house more sustainable?]

No, to put it simply [Tenant 19: house/private manager].

[Have you asked [Tenant of the property manager] to do anything to make it more sustainable?]

I haven't...I probably could do that, yeah....I don't know what - I mean they would have to run it past the owner I think, that's usually the answer [Tenant 2:

flat/private manager].

So I've ...logged ...that [issue]....with the agents but they didn't actually get back to me [Tenant 11: house/private manager].

...we've called the real estate and asked them [about a garden] and they've said they were going to speak to the landlord but we've had a few instances where they said they were going to speak to the landlord and they didn't. We inquired about getting insulation and they said they were going to speak to the landlord and they didn't [Tenant 13: flat/private manager].

A more proactive and advocacy approach by housing managers may be useful in encouraging landlord participation in incentive schemes, and in such schemes as Environmental Upgrade Agreements, and Residential Building Mandatory Disclosure (described elsewhere in this report - see document review of legislation and policy in Section 4.2.3).

\subsubsection{Social and political attitudes to tenancy}

The importance and prevalence of home-ownership in Australia has produced negative constructions of renting and of tenants. This is reflected in tenants' comments on the generally uncaring attitude of housing managers or landlords (wider than the issue of caring about sustainability), and on calls for more tenants' rights:

So that's just how it is renting, isn't it? You're down the pecking order [Tenant 11: house/private manager]. 
Look I like renting. I choose to rent. I've never wanted to own. It gives me a freedom to move around. But sometimes l'd like to be recognised for that.

...Given a bit of respect and not have a 20 year old come in and check that you haven't trashed the place [Tenant 21: flat/private landlord].

I [I]t's becoming more ridiculous for ordinary people to own their own places. So really there's more and more and more of us that are going to be living in rental accommodation, so it needs to be taken more seriously [Tenant 2: flat/private manager].

Other tenants talked about tenants' rights, suggesting that if the tenant is paying off the landlord's mortgage, the tenant "should have at least equal rights to be there" [Tenant 6: house/private landlord]. Another suggested that the Residential Tenancies Act should be changed "to give the tenant rights to request things" [Tenant 12: flat/private landlord].

It was evident from the document review of media articles earlier in this report, that the rental sector is often framed as a series of 'problems', and tenants as passive victims or beneficiaries of government policies (see for example the discussions in the document review on the Commonwealth Government's 'carbon tax').

However more recent media coverage, such as the ABC radio series 'This Rental Life', and some of the sustainability guides recently developed for renters, position tenants as active contributors to sustainability, and the rental sector as an area of interesting sustainability activity.

\subsubsection{Limits on housing managers' and landlords' capacity to act}

\subsubsection{Lack of leadership in private rental sector}

Housing managers, both private and public, commented on the structural and organisational barriers to change. Lack of leadership in the private sector was seen as a significant issue, unlike in the public sector where lack of resources to implement policy, and the large quantity of old housing stock, were seen as the most important issues. Some private housing managers wanted to see greater leadership in sustainability and climate change adaptation from the Real Estate Institute:

But you know that would take some courage by some people I think up the top. I think it would be good but you know you couldn't do it on a local agency level like this. It would have to be - this is what I think anyhow - there'd have to be some kind of initiative from the top. Small agencies like this we're too busy trying to stay in business [Private Property Manager 3].

I think they've got to embrace the whole thing for a start. I don't think they have actually. As I mentioned, New South Wales hasn't - as I said, they don't even mention it in their journals. Not a peep ever unless l've missed some little article they might have had. But there's nothing.

Even start to talk about it in their journals and seminars and conferences and 
things. Even have a little something going on, there's nothing [Private Property Manager 2].

Well, they're the same type of governing agency. I think they should have a responsibility to provide the information [Private Property Manager 4].

A representative of the Real Estate Institute commented that sustainability and climate change adaptation were areas which needed to be addressed by the Institute at board level:

... from a state point of view, the Real Estate Institute of New South Wales is there to educate and provide services for real estate members. We're there for them. But we also see that very much what we do is assist consumers as well, and we're finding ourselves more to be property advocates out there for consumers. I think probably what we can do is we can recommend to our national body that these are areas that need to be looked at and a policy needs to be formed. Once policy is formed on a board level, then you tend to find that there is an action plan put in place for it [Private Property Manager 1].

\subsubsection{General lack of interest in sustainability: Housing managers' perceptions}

Some housing managers discussed the challenges of pursuing a sustainability agenda in a generally unengaged or uninformed market, and appeared to view all actors in the rental market (including property managers) as generally unengaged, uninformed, or even sceptical about climate change and the need to act on it:

It doesn't come up as a big topic of discussion between us and our landlords. When you look at solar panels, insulation, lighting and all those different options available and even where we have properties that are being renovated by us they're doing new kitchens and those sorts of things - sustainability is not a huge issue for them. They're not really thinking about it [Private Property Manager 9].

No, and you know look we were out with friends on Saturday night and you know it sort of just was a passing thing in conversation and they said, that's if there is anything in it, you know. So I think people are really unsure what it is about, a bit like the KY2 [Y2K] bug or whatever, you know we spent millions on making sure it didn't happen but then it didn't happen anyway [Public Housing Practitioner 4].

Yeah, awareness, motivation. I think a lot of people just - they read about it and hear about it but when you live day-to-day I guess it's not evident I suppose necessarily unless you go looking for statistics and figures [Public Housing Practitioner 1].

Another noted that it was hard "to sort of engage [contractors] on that sort of thing" [Public Housing Practitioner 3]. Owners, it was noted, "might care or they might say they care. But they don't do anything about it" [Private Property Manager 7]. This lack of interest was expressed in terms of a need for a "change of mentality and a change of attitude from tenants to landlords" [Private Property Manager 3]. 


\subsubsection{Organisational structure in public rental sector}

Public housing practitioners noted that they had to negotiate the complex bureaucracy intrinsic to working in a large organisation:

But one person can have an idea but until you've got half a dozen people thinking the same idea, nothing much comes of it. You can tell your good idea to someone and then they resign.

That's one of the frustrations of working in a big organisation. If you owned your own homes, you could implement your good ideas. But when you're working in a big organisation, individuals can have really great ideas but from where we are, I don't see us as being in the driver's seat of innovative ideas [Public Housing Practitioner 6].

Staff turnover in Housing NSW was also noted by one public housing tenant:

They change all the time.

[Like once every six months, once every year?]

Yeah, something like that. We got a new one now since when-maybe this year some time. Usually, they're acting, you see. They're acting client service officer. It does make it difficult. Oh yes. Usually the new ones, when they come in,... some of them introduce themselves by a letter. I'm your new client service officer and so on. But they seldom show their faces [Tenant 17: flat/Housing NSW].

Another Housing NSW tenant commented on the bureaucratic structure of the organisation, and the lack of resources:

I've got all the way up that chain going from the [client service officer] to the team leader to the senior team leader, those three I mentioned... but the realpolitik, if I trust that I've established a rapport with these guys at that level, what they're telling me is they don't have the resources, so the organisation has been gutted in terms of their budget, which I get - because of whatever [Tenant 23: flat/Housing NSW].

Organisational size and established processes also govern how maintenance contracts are carried out, and may limit the ways that sustainability concerns are incorporated into them:

One of the challenges for us around innovation around solar hot water for argument's sake is that it needs some buy-in into our maintenance contract in that we've got a five-year contract for people to service gas and electric hot water systems. But I'm not sure how that will transcend into solar heating or solar hot water services, whether it's an extension of the contract somehow and therefore becomes unsustainable financially, whether it will need to become part of future long-term maintenance contracts or not [Public Housing Practitioner 7]. 


\subsubsection{Resource constraints in the public rental sector}

One of the greatest barriers to adaptation and improved sustainability of housing in the public rental sector was a shortage of resources and a large stock of ageing houses:

I think the sheer cost. If you look at the 125,000 properties, to insulate that number is cost-prohibitive. Private enterprise and public enterprise don't have the financial capacity to take that on [Public Housing Practitioner 7].

It's sort of - at the moment, budgets are tight. It's really hard to - like certainly if we got additional funding, I would support it. But I think if you look at what's core business in terms of housing, at the moment we are focusing more on things that we have to provide anyway such as the type of hot water system. How can we make that the most energy efficient hot water system? [Public Housing Practitioner 2].

Seriously it is - it's money. We're very limited in relation to what we do with our maintenance, especially financially we are. We only get limited funding through governments. We get a certain amount of money when we do manage different properties. So we managed AAH properties, aboriginal housing properties or we manage old housing stock. We only get a certain amount of money per resident to use. So very much we're limited by money. So in asset we just try and do it the best was we can [Community Housing Practitioner].

This is compounded by the ageing housing stock in the public sector, which includes large numbers of older, in some cases run down, dwellings, built before contemporary environmental standards for housing were legislated, and, in some cases, located in areas where the quality of the housing is eroded due to weather and geography. The scale of such properties in Housing NSW's portfolio, including within Newcastle and Lake Macquarie, is recognised as a barrier:

Well I think in the main our properties have the environmental controls of the era that they were built. A lot of those homes that were built in say the '50s, '60s and '70s - a lot of those would be the asbestos fibrous cement sheets and they'll be either in gyprock or a fibrous plaster internal wall with no filling in the cavity. So they're quite cool. A lot of air moves through the cavity. Invariably they're on foundations which means they're circulating under the home and clients may have increased power bills trying to heat those units.... Cold in winter, hot in summer, yep [Public Housing Practitioner 7].

I think some of the older type stock - and predominantly a lot of our older type stock their sustainability features are extremely limited [Public Housing Practitioner 3].

This is also compounded by the 'split incentive', discussed below. 


\subsubsection{Costs and the 'split incentive' in the private rental sector}

In the private rental sector, whereas tenants commented on a reluctance on the part of landlords to make sustainability improvements to their properties, housing managers commented on cost as a significant barrier:

It is more expensive to do. That's the problem. There's one property at the moment that I'm aware of where just the lighting alone to make it - use LED lighting as opposed to the standard fittings - it's nearly three times the cost [Private Property Manager 9].

Because most of them it is just really - it's - I can understand where they're coming from, it's their retirement fund, their long service or they leave it to their kids when they die. They don't really want to - a lot of owners don't want to really spend any more money on it than they have to. They just want to keep it nice and just tick over with the rent coming in. They don't really want to spend a lot of money [Private Property Manager 6].

One of the factors in the lack of landlord investment in Australia is that tenants are generally responsible for utility bills, including electricity and gas. Since early 2012, they have also been required to pay for water usage, provided that the dwelling has been fitted with water-saving devices in sinks and showers. Thus there is a 'split incentive' for making the rental sector sustainable, where a landlord's capital investment in solar energy systems or water tanks, for example, has economic returns for the tenant rather than the landlord.

However, there is also a disincentive for tenants: any capital improvements to the property by tenants will not bring economic returns within short lease periods, and are likely to require dismantling when the tenancy ends (see 'Lease conditions concerning modifications' below).

Emphasising these different ways in which incentives are 'split' helps to reconceptualise tenants as equally active participants in the rental sector, and hence as stakeholders in legislative and policy decisions intended to encourage adaptive change:

The solar scheme came out and was of interest to some of our landlords but none of them proceeded with it because they couldn't see how they could get any advantage out of it themselves because they are not the electricity account holder at the end of the day. So they said, well we can invest this money doing the solar but there's no return on our investment for us. So they elected not to do that. That was only a very small number of owners who even inquired about it [Private Property Manager 9].

But the tenant might save the electricity but there's nothing there for the owner. There's no incentive for the owner to do it in the first place and they don't want to [Private Property Manager 2]. 
If a landlord and a consumer can see that there is a return on their money, other than their just being good citizens, then they'll do something about it [Private Property Manager 1].

Apart from the issue of the split incentive, the Australian Housing and Urban Research Institute (AHURI) has drawn attention to another risk of shifting utility costs to tenants: the potential for low-income households to be unable to afford basic thermal comfort, referred to as 'fuel poverty'. They note that in some jurisdictions overseas, financial assistance for heating and cooling is provided to low income households:

For example, since 2009, German heating costs are subsidised within the housing allowance scheme. In New Jersey, the Home Energy Assistance Program helps very low-income residents with their heating and cooling bills and makes provisions for emergency heating system services and emergency fuel assistance (Hulse et al. 2011: 152).

In a climate change future, and with increasing utility costs, heating and cooling is likely to become a bigger burden for low income tenants over and above their rent payments.

As noted above, Housing NSW was unable to access some of the Commonwealth Government incentives for retrofitting houses, because of its status as a government body. This was attributed to Commonwealth-State divisions over responsibilities for funding:

So I think it's actually a ...... between a rock and a hard place I could say, in that the Federal Government doesn't like funding environmental programs in statebased housing, because they think the states should. But then again the state often doesn't have the funding.

Look I guess we just try and do what we can with what we have, and look for opportunities [Public Housing Practitioner 2].

\subsubsection{Complexity and implementation of legislation}

Housing managers viewed legislation as both an obstacle to action and as the kind of 'top down' initiative required to drive change. It acted as an obstacle when there appeared to be inconsistencies in legislation:

We had a bit of a problem there where, if you'd have the insulation done, you didn't qualify for a rebate on the hot water service [Private Property Manager 7].

Another issue was changing legislation, or legislation which was later repealed:

But then you know sometimes they'll put in the legislation and then they'll back off.

Well let's see, I mean for a start the scheme for the hot water system - if they're going to make scheme and make a do about it stick to it. Don't let it quietly drop by the wayside when it's too hard, starts getting unpopular or whatever [Private Property Manager 3]. 
Housing managers also saw government as not supportive or consistent in promoting sustainability:

I think probably energy efficiency drills down to planning legislation. There's so many levels that need to work together, and unfortunately when you come to government, we tend to find that various levels of government departments don't find it very easy to work together. Once again that is the red tape we're talking about in seeing energy efficiency in more housing built out there [Private Property Manager 1].

Regulatory changes which were seen as necessary to drive change in everyday practice, included changes to standard contract provisions and changes to building standards:

But that all goes back into how we tender our contract, whether we ask for - it's all part of the specifications of our contract. We have an agreed schedule of rights. As I said, it's predominantly based on - with maintenance it's a like for like replacement. It's very difficult then to, at the right price, to do a repair with recycled materials or something like this, and to enforce that when it's a like. I think it's something that potentially needs to go back to the policy - the technical policy makers [Public Housing Practitioner 3].

The role of housing managers in negotiating relationships with both landlords and tenants was particularly evident in their comments on implementation of the recent water efficiency legislation in NSW. These comments demonstrated the complexities of implementing legislative changes in practice:

Getting through all the bureaucracy and the forms to fill out to try and get the subsidy to do whatever you want to do that's an environmentally friendly initiative. Maybe the Government needs to look at that to make it more streamlined and easier if they're going to offer incentives [Private Property Manager 3].

Almost all of the private property managers discussed the struggle to have the landlords install water saving devices, and the different strategies they employed to do so. The stories reflected tensions in the landlord-property manager relationship more broadly. Implementation was also complicated by tenants' issues with using the new technology and efforts by some to restore original flow rates in showers.

A range of stories is provided below because water saving legislation is one of the few recent examples of legislated sustainability improvements in the rental sector, and therefore is an interesting precedent for any future retrofitting requirements to rental housing. It illuminates the relationships between property managers, landlords and tenants, the potential impact that implementation processes can have on the capacity of the sector to adapt to climate change:

That's been a nightmare. It's been difficult because a lot of our landlords have resented the fact that that imposition was put on them. It's a pretty discriminatory piece of legislation because the Residential Tenancy Act says okay, this is what you have to do to your rental property if you want to recover water usage - and 
that's fine. Unfortunately there's a cost associated with doing that.

A lot of tenants actually didn't want it done. Particularly one of the regulations was with the shower heads and they had to have a maximum flow rate of nine litres per minute. That's fine but often those shower heads are like showering under a tropical mist. People say, when I wash my hair it takes me twice as long. We've subsequently found a lot of tenants have tampered with the devices that are installed and actually removed the restrictive valve so that they can have what they say is a decent shower.

So the problem then for us moving forward is, if we make the premises waterefficient, tenant's there for 12 months, 18 months, two years and has tampered with it - as a property manager or a landlord, you don't know that it's been tampered with unless you do the test on the premises again and then you've got to make the premises water-efficient again. So a lot of landlords said, all too hard. Not going to spend the money, not going to have the hassle. We'll just increase our rents by $X$ amount of dollars to cover the water usage that I can no longer charge as a separate thing [Private Property Manager 9].

Like we actually contacted our owners probably three times saying this is the paperwork, here it is, just fill it out, we'll do the rest. It wasn't until they sent in their first - because we don't get all water invoices sent directly to us, some owners like to get them themselves. Then they send it to us, please get the water usage back of the tenant. I would write back nice and say I would love to but your property is not certified for water usage. Then it's like oh, quick, outcome the paperwork, quick let's get a water audit done. It changes it very quickly [Private Property Manager 6].

Well we had the best plumber on board and he gave us a pretty accurate figure for the old and the new properties. So we were able to give the owners an estimation of price. So that was able to sway them to make a decision... ... at least I was able to say to them, well it's $\$ 150$ for the certificate plus labour and they'd go, well if I'm looking at a minimum of that, the water bill - the last water bill is $\$ 169$ so therefore I've already got my money back within the next quarter. So they were able to rattle around the figures in their mind and then decide that it probably was a good way to go [Private Property Manager 4].

They didn't want to - I got a set fee from a plumber to make it easy. To try and get a quote for each and every one individually would have been a nightmare. So I just negotiated a set fee with the plumber and we took it from there [Private Property Manager 3].

... we said that when it comes to legislation, we are obliged to virtually force the landlords. So what we did was we didn't ask the landlord to comply; we told them that we were going to make good their taps and that, and if they didn't do it themselves, we would have it done on or before a certain day [Private Property Manager 1]. 


\subsubsection{Busyness and lack of time}

Both private and public housing managers saw themselves as already at full capacity in responding ('reacting') to demands from tenants and landlords (or in the case of public managers a range of competing Housing NSW organisational requirements). The 'juggling' of these demands as their primary focus left little time for advocating or facilitating sustainability changes to rental housing. This was especially the case when it was anticipated that their audience would be unreceptive to change:

Well, the only barrier would be the numbers of the 10 client service offices to 4000 properties and how you have to prioritise what is important today. So in an ideal world, if we could do a lot more in that regard, if we had more human resources, more people on the ground. We could do a lot more. We do our own little projects, if you like [Public Housing Practitioner 6].

We don't have - if you look at our frontline staff, like our client service offices, they don't have the time, the capability or the capacity to actually rollout environmental programs [Public Housing Practitioner 2].

Property managers have a huge workload and that's a nice optional extra to think that they will do but at the end of the day, I think that they will all be feeling too overwhelmed with their current tasks so they go, I don't have time for this. This doesn't benefit with me. I'm belting my head up against a brick wall with a landlord who doesn't want to spend the money anyway, so I'm just going to let sleeping dogs lie [Private Property Manager 9].

So it's four hours out of my day to get two hours' worth of learning of stuff that I could maybe read in a book or something. Which are they going to do it? No because they're too busy [Private Property Manager 5]

Public housing managers in particular note competing priorities for example between seeking to house a changing client base, and pursue organisational environmental objectives:

We're trying to do things in areas where we think it's going to be most impacted, but how do you do it equitably across the portfolio? It's difficult to know. We can't just - every time a tenant writes in to say, I want this, we can't suddenly drop everything. We have to try and structure a program and roll it out so it's fair and equitable, across the state as well, but considering different housing needs and housing types [Public Housing Practitioner 2].

Many competing priorities. As I was saying, we're very reactive and the welfare of our clients kind of gets in the way of thinking about those sorts of things [Public Housing Practitioner 1].

Because public housing, our target group is people with high needs, so very often it is the long term unemployed or people coming out of jail. People who have homelessness which is often the root cause, maybe alcohol and drug use. They're difficult. You can't really start educating them about the environment 
when they're battling to deal with their other issues [Public Housing Practitioner $6]$.

\subsubsection{Lack of training and knowledge}

A very strong theme to emerge from interviews with housing managers is the absence of information about climate change being circulated through various formal real estate networks. Several property managers discussed a lack of training and information about climate change and sustainability delivered through the industry body, REI (such as in training programs and journals), as well as in processes that take place in their individual offices (for example, team meetings, conversations with colleagues) (see discussion later on relationships and networks in Section 4.4.9.2):

I guess for me I don't really understand solar panels, I don't understand the whole start from finish process. So someone would need to explain that to me for me to be able to then explain it to someone else [Private Property Manager 4].

So therefore if they had a course or something property managers could go - and again it would have to be right across the board - to learn how to convince landlords to be more environmentally friendly even if it cost them a few dollars. That might make a bit of training, how would you have those skills? Because at the moment it's not priority for them [Private Property Manager 3].

Even in the journals - I get the real estate journal every month - and there's a lot of things in them but nothing along those lines at all [Private Property Manager 2].

I've done quite a bit of training this year... and l've just renewed my licences and that and I did not have anything like that said to me [Private Property Manager 6].

Some public housing managers also seemed unaware of aspects of the sustainability initiatives taken by their organisation. This is not unexpected given other comments made about communications and feedback across a large organisation (see 'Limits on housing managers' capacity to act' above). In Housing NSW, communication issues have been exacerbated by the recent split of functions across two government departments:

I'm not a hundred per cent sure. I think most of new hot water systems that go in are more environmentally friendly. I couldn't tell you exactly the details of that. There is some consideration around those things but I couldn't give you that. ... I've read it [the Sustainability Strategy] but I'm not overly familiar with it. I'm not sure to be honest [Public Housing Practitioner 1].

[The Sustainability Strategy] is not something that I think the Department's openly touted to us as managers or staff. [Public Housing Practitioner 6].

I haven't had much to do with it [the Sustainability Strategy], no. See it would be more Assets that would do that. We've been divided up, we don't, while we look after the tenants and the houses, assets have now gone over to finance. So that 
makes a difference to us having much to do with that sort of thing [Public Housing Practitioner 4].

\subsection{9 'Unmaking unsustainability' in the rental sector: the roles of tenants, landlords, housing managers and government}

Despite the barriers identified above, the vast majority of the tenants we interviewed believed they could act on sustainability to a significant extent. Some of their comments drew attention to the importance of individual actions, and 'being part of the solution rather than part of the problem':

I find most of that comes down, particularly in an old house like this and particularly in rentals where they don't really want - people aren't that inclined to spend a lot of money, it comes down to I think like the individual practices of the people in the house [Tenant 9: house/private landlord].

It's a concern about the environment... So I think, well if I didn't change what I was doing that I'm just contributing to the problem, rather than contributing to a solution... I think - of course, it's going to take a lot more than just these purchases - daily purchases, but I think if everyone started doing that, then it would be a lot better than not [Tenant 14: house/private manager].

For other tenants, it was simply a matter of acting consistently with a consciousness (a 'mentality' or awareness) of their impact on environment:

... I think it's a matter of being able to do what you can do, have that awareness and just be conscious of what sort of impacts you have. It's like being socially aware [Tenant 4: flat/private manager].

So yeah, I think it's probably something that's viewed as this really enormous thing that's really hard to deal with but it's actually really simple to change your life and change the way you live to stop it happening [Tenant 13: flat/private manager].

I am aware that just tiny things, they might not actually make a big impact in the grand scheme of things. But it's the mentality that you take from the tiny changes of building them into your daily life that also inform other decisions [Tenant 9: house/private landlord].

Tenants' commitment to household sustainability practices and their engagement with community groups suggest a belief that responsibility for the 'unmaking of unsustainability' is distributed, and requires not only changes to regulatory and economic structures underpinning lease conditions and building standards, but radical changes to ways of living and community life. Elizabeth Shove describes such changes as the "processes of social and infrastructural destabilization, collapse and repair" necessary to support lower-carbon ways of life (Shove 2010: 282). 


\subsubsection{Optimising tenants' assets}

While housing managers focused on building fabric and tenant behaviour as the factors most important in climate change adaptation, other assets such as tenant commitment to sustainability and adaptation, their care about the environment, and engagement with wider sustainability networks, are also important assets of the rental sector.

Tenants' own views on ways of increasing their capacity to act sustainably and adaptively were expressed both in interviews and focus groups. The most important of these concerned relationships between tenants, housing managers and landlords, housing affordability and choice, and areas of regulation such as lease conditions, housing standards and performance disclosure, and financial incentives for both landlords and tenants.

\subsubsection{Strengthening landlord-tenant relationships}

Some of the frustration expressed by tenants during interviews, and in focus groups, concerned the 'gate-keeper' role of the housing manager, and the inability of tenants to discuss the sustainability of their homes directly with the landlord. Some tenants had circumvented the housing manager and established direct contact with the landlord, who sometimes proved to be more responsive to the tenant's requests:

I got the landlord to put ceiling insulation in... They were responsive to my request, yeah. I mean I had to work for that. I've had to get the landlord's details. I'm lucky that he is a very approachable landlord, someone who doesn't palm me off to the real estate to deal with [Tenant 20: house/private manager].

The landlord, because we have got a water bill, it has their address on it. They only live up the road... So I have thought about leaving them a letter saying how hopeless the real estate is [Tenant 14: house/private manager].

AHURI's study of secure occupancy suggested that new approaches were needed to build constructive relationships between tenants and landlords, including "information and education programs for both parties and through promoting best practice standards of rental management" (Hulse et al. 2011: 178). In our focus group discussions it was suggested that communication between tenants and landlords could occur through online discussion forums.

As discussed above, these relationships needed to be situated in a wider acceptance of tenants' right to "secure, affordable and decent housing'" (Hulse et al. 2011: 9), which is also sustainable. The focus groups in our study called for changed attitudes to renters and the rental sector, as a diverse group with valuable knowledge, commitment and networks, who also play a significant role in the economy.

\subsubsection{Housing affordability and infrastructure}

One of the greatest barriers to improving the adaptability and sustainability of rental housing was seen by tenants and housing managers as the shortage of rental housing, which reflects a more general shortage of affordable housing. 
AHURI has developed a detailed proposal for housing supply bonds to fund affordable rental housing, for consideration by the Commonwealth Government. The model is based on a successful scheme in Austria. AHURI noted that:

the 5-yearly renegotiation of the national housing policy framework, the NAHA [National Affordable Housing Agreement], represents a critical window of opportunity to establish an enhanced, more comprehensive and long-term national policy framework for achieving public and private investment in affordable housing supply at sufficient scale to address current and predicted housing needs (Lawson et al. 2012: 21).

The NSW Government has recently announced a program of asset sales to increase available funding for social housing, although this is also likely to involve displacement of existing social housing tenants (Allen and Morton 2012; Allen 2012).

Changes to improve the sustainability of housing, infrastructure or consumer products, is to some extent already occurring. Environmental standards for new housing, (some) improvements in public transport, bicycle paths and pedestrian networks (NSW Government 2012a; NSW Department of Transport 2012), more organic or 'sustainably harvested' food and local markets reflect policy and market responses to community pressures for sustainability.

One focus group in our study also proposed Council collection and processing of foodwaste where composting in individual households (e.g. units) is difficult.

\subsubsection{Building standards and performance disclosure}

... right now to be a landlord, to rent out your property, you have to have certain responsibilities. Maybe those responsibilities could include the way the house is the energy-efficiency of that house [Tenant 20: house/private manager].

Shove and others have discussed the material and structural contexts in which decisions about sustainability or adaptation are made (Shove 2010; Marres 2011). Constraints on decision-making were reflected in tenants' suggestions about improving the sustainability of rental housing, and providing access to information about the environmental performance of their dwellings.

Recommendations from the focus groups included a proposal that sustainability upgrades of dwellings should be factored into change-overs between tenancies, or negotiated with existing tenants.

The focus groups in our study suggested that the concept of a 'sustainability return on investment' needs to be more widely promoted. Environmental Upgrade Agreements, in which the landlord repays a long-term loan through the Council rates system, commenced in NSW in February 2011, but currently apply only to commercial buildings and multi-residential buildings of 20 or more units.

Focus Groups also noted the more fundamental issue of sustainable design of buildings, and the potential for new housing to be constructed using different models, 
either smaller or with more communal spaces, to save energy and resources. This goes beyond the environmental standards which are now part of the National Construction Code (ABCB 2011) or the development by the Local Government and Planning Ministers Council of a standard layout for residential subdivisions to optimise passive solar design (Council of Australian Governments (COAG) 2010).

The Commonwealth Government's proposed scheme for Residential Building Mandatory Disclosure, when finalised, will focus attention on the ways in which building performance information is presented and disseminated to tenants. It has been noted that while landlords express interest in environmental assessments of their rental homes, they do not want a mandatory disclosure scheme (Gabriel et al. 2010a: 77, 79).

In New Jersey, landlords are legally required to provide a Truth in Renting booklet to tenants, which includes information about lease conditions, rent settings, habitability, and health and safety (Hulse et al. 2011: 173):

While all jurisdictions provide some information of this kind, the New Jersey approach can be considered to exemplify best practice because of features such as its statutory foundation, scope, regular updating and accessibility to residents.

The Netherlands has taken mandatory disclosure a step further and established a 'Complaint Point for Energy Waste':

Tenants can report poorly insulated dwellings let by landlords, with the aim of developing a plan to improve the responsiveness of landlords to these issues. A related website identifies the worst offending landlords and there is an annual election for the best and worst landlord in the Netherlands. On this site, both tenants and landlords can also access information concerning insulation techniques (Hulse et al. 2011: 177).

Despite the 'sellers' market, and the importance to tenants of factors such as location in selecting a rental dwelling, AHURl's recent study noted the potential for tenant preferences to shift 'in an environment of higher energy and water costs and where tenants are able to access clear information about the sustainable performance of properties and therefore make informed choices in the marketplace (Gabriel et al. 2010a: 84). A regulatory impact statement on the proposed Australian Residential Building Mandatory Disclosure legislation noted that the impact of such information is still an unknown quantity (The Allen Consulting Group 2011).

\subsubsection{Changing the role of the housing manager}

Tenants made a number of suggestions for changing the role of housing managers to include sustainability audits of houses and to act as advocates for sustainability to landlords:

So when you're doing the - going to sign up on the house, the property manager can take you through and do a bit of a sustainability audit - make suggestions. See what role they could play in making things work better and a place more sustainable. Whether that's identifying light bulbs that need to be changed or 
showerheads or opportunities for composting, or other things like that [Tenant 8: house/private manager].

I never see it happening but it's an interesting thought if you give the real estate agents more responsibility to make sure that these things are occurring. So maybe make it part of their job - maybe they get a little bit of compensation off the Government or something, but make it part of their job to push for these things to say it's not going to cause your house any damage, it's only going to increase the value to the property owner. Why not solar hot water? That'd make a massive difference. If we just have the real estate agents behind us as the tenants, then I'm sure we could do a lot more. We would be much less restricted. I think the main restriction at the moment is the attitude of them [Tenant 19: house/private manager].

Such a role would extend the existing role of housing managers as knowledge brokers, particularly in their relationship with landlords. Support for such an expanded role would require improvements in the training and information currently provided to property managers on sustainability and climate change adaptation.

\subsubsection{Building knowledge and networks for housing managers}

As noted above (under 'Limits to housing managers' capacity to act'), housing managers are already strongly aware of the absence of training and information to support them in advocating for change to landlords. However strong networks and training mechanisms are already available which have the potential to deliver specific information and training on climate change and sustainability. Some of these networks were discussed by property managers, albeit generally in terms of their failure to provide this kind of training. However they offer pathways to greater support for property managers' role in climate change adaptation:

I remember LJ Hooker - they haven't had this year - but each year leading up to now, they've had a property management conference that goes for three days. I was there. They had a round-table session where you could go to different tables and talk to them about - people spoke about different topics like dealing with the media, dealing with this, dealing with - and one of them was dealing with natural disasters [Private Property Manager 5].

I guess other companies that I've worked for have put together seminars and say okay, well there's a change in the legislation with regards to water usage or there's a change in legislation regarding smoke alarms and then you would get 80, 90 property managers in a room together all trying to nut out ways of how we can best get all of our properties made compliant and how we can go about doing it and what are the best ways that we can present it to an owner but currently, no there's not been anything like that [Private Property Manager 4].

Yeah, we have lots of internal training but we have a team meeting once a month and we get other agencies in to talk about their services and do the same [Public Housing Practitioner 1]. 
What that [training] was all about was in relation to us becoming a consultant in relation to changing people's ways and views on how they live. A lot of it came down to us being financially for us. The whole project was in relation to us being more aware of climate change. How it impacts and how little we can do that makes a big impact type thing. [The organisation] did it - well for me it was mainly to assist our tenants financially in relation to that. ...

They're just going to look at you and say 'well does that save my money?' [Community Housing Practitioner].

AHURI's report on investment in sustainable rental housing also suggested the value of greater education of landlords, including authoritative information about government initiatives which was practical and clearly presented (Gabriel et al. 2010a: 72, 75). Other options canvassed in the report included the establishment of a central body to provide independent and detailed product performance information on energy and water saving technologies (Gabriel et al. 2010a: 73).

\subsubsection{Accreditation of 'green' property managers}

The focus groups in our study proposed accreditation of 'green' property managers, possibly with a 'green rentals' website.

AHURI's recent study of rental housing investors concluded that the investors would like to see property managers more actively involved in raising landlord awareness about the sustainability of their properties, providing information about options, and facilitating the installation of large items such as solar panels or solar hot water systems:

Some respondents noted that having real estate agents play a central role in facilitating sustainable improvements to rental properties would be a significant turnaround from the existing situation whereby their agent undertakes a minimal property management role (Gabriel et al. 2010a: 76).

\subsubsection{Lease conditions to support adaptation in the rental sector}

The focus groups in our study suggested changes to lease conditions to allow modifications to remain in place across tenancies, and that property managers promote tenancy-to-tenancy continuity of gardens and other sustainability initiatives, for example by using routine inspections to monitor and keep initiatives on track or maintained. Tenants also expressed support for this kind of change in their interviews:

But I think that it would be great to have more security for renters, more like in Europe where basically if you have paid the mortgage off for someone, you should have at least equal rights to be there. .... [In Australia] they don't even let you change things like the garden, even if you're putting the labour in. So I think renters should have more rights [Tenant 6: house/private landlord].

I think changes to the tenancy act or the leases so that tenants have a bit more freedom. .... group of my friends ... had this really great vegetable garden and the landlord chucked an absolute tantrum because they wanted it to be all 
grass.... think yeah, also more flexibility in how you can use the property that you have. So being able to install your own kind of blinds or stuff like that [Tenant 13: flat/private manager].

I think that's the difference between Australia and a lot of other countries where people have 20 year leases ... people rent for most of their lives and I think that's changing in a lot of countries but I have lived in a lot of places where it's just normal to rent. So you would do things like that, you would insulate the house and you would plant fruit trees [Tenant 15: house/private manager].

AHURI's comparative study on security of occupancy for tenants in Europe, northern America, the UK and Australia defined secure occupancy as including the ability of tenants to "[e]xercise a degree of control over their housing circumstances and be able to make a home, to the extent that they wish to do this" (Hulse et al. 2011: 3).

The report noted that longer leases and more flexible contract conditions overseas are more supportive of tenants in 'making a home'. For example in Germany:

... if there is a garden, the tenant is entitled to use this and the tenancy agreement will specify responsibilities for maintaining the garden. Further, the lease may also contain provisions for compensation for improvements made by the tenant... a modernisation agreement with the landlord is required to enable them to recoup (depreciated) investments when moving out (Hulse et al. 2011: 155).

Elsewhere, for example in the Netherlands, tenants on long leases can make alterations such as installing new floor coverings or curtains, or minor upgrades to kitchens and laundries. Moreover these modifications do not need to be reversed when the tenant vacates the property (Hulse et al. 2011: 156).

\subsubsection{Incentives}

Housing managers viewed cost as the major barrier to landlords' making sustainability improvements to their rental properties. Both property managers and tenants commented on the need for more incentives to encourage landlord investment in their properties. This need is connected to the potential for such investments to result in a rent increases unless the cost is subsidised or undertaken through loan schemes such as Environmental Upgrade Agreements (discussed in Section 4.2.3 ). One suggestion emerging from the interviews was an award scheme for green property managers or landlords:

There's also this increase in corporate social responsibility ... they need to be seen to be doing the right thing... At the end of the day, there's got to be an incentive behind it to do it.... They have awards in sustainability design... You've got the Green Building Design Awards. You've got the Green-Building Council... So all of these peak bodies have become involved in pushing their sustainability agenda. If there's nothing in it for people they won't do it. There's got to be a trade-off or a cost benefit somewhere along the way [Tenant 4: flat/private manager]. 
Some tenants suggested a leasing arrangement so that tenants were able to install alternative energy systems at low cost:

Well I think there has to be some way to overcome that split incentive between the landlord not wanting to put in those big items ... because the tenant gets the bill benefits. So I think the Government really needs to focus on that. How there might be some kind of scheme, or work with providers to - because I know, like for instance in the U.S., they have solar panel leasing.... So you can lease solar panels on your roof. You don't own them; the company owns them. You pay electricity - the bill to them. Then after 10 years or something, you can own them [Tenant 14: house/private manager].

Extending landlords' sustainability investments beyond their own homes, property managers' role beyond the activities of rent collection and ensuring basic habitability of dwellings, would enhance the resources available to renters and increase their choices and influence over the ways in which they can live their lives sustainably and adaptively.

\subsection{Outputs}

An essential component of the research project was its engagement with not only academic and policy discourses on climate change adaptation, but more directly with the rental sector, by providing ongoing support for change towards sustainability and climate change adaptation. Analysis of the transcripts of interviews and focus groups has been used to develop recommendations and resources which could inform ongoing action elsewhere in Australia, including the development of a community implementation plan.

This report contains a set of recommendations for government, the property management sector and tenant networks about ways of potentially enhancing climate change adaption in the rental sector. These recommendations will be circulated to government authorities, leaders in the property management industry, and to community groups working with tenants. The project Steering Committee includes representatives of government and industry have provided advice on pathways for disseminating the recommendations of this report.

The outputs of the project will be widely disseminated via linkages to the website of the Centre for Urban and Regional Studies at the University of Newcastle.

The outputs thus fall into four categories: community (and in particular tenants), the property industry, government and academic.

\subsubsection{Outputs for community use}

The website, Facebook page and YouTube clips provide information and case studies on the kinds of adaptive and sustainable practices already occurring in the rental sector. These are intended to enhance tenant, property manager and landlord capacity to respond to climate change by increasing expectations of what is possible in rental housing. 


\subsubsection{Project website}

The project website is part of the University of Newcastle website hosted by the Centre for Urban and Regional Studies. It provides information about the project, the research team and project outputs. It is regularly updated when papers or other outputs such as YouTube clips become available: <http://www.newcastle.edu.au/researchcentre/urban-and-regional-studies/transforming-cities-city-lives-city-natures-citypolitics/climate-change-and-urban-transitions/climate-change-adaptation-in-the-rentalsector/>.

\subsubsection{Facebook page}

The Facebook page is more regularly updated than the website, and offers an opportunity for comment by interested members of the public:

$<$ https://www.facebook.com/SustainingRentalLife>

\subsubsection{Briefing Papers}

Thirteen Briefing Papers have been developed over the course of the project, and are accessible on the project website, and from the project Facebook page. They are working documents that contribute to debate on theoretical, methodological and practical issues related to climate change adaption in rental housing. Posting them on the website and Facebook page provides an opportunity for comment from readers, researchers, renters and housing managers.

\subsubsection{4 'Resources for renters' pamphlet}

A pamphlet 'Resources for renters' was developed for distribution at community events and at the public information sessions about the project. This resource can be accessed on the project website:

$<$ http://www.newcastle.edu.au/research-centre/urban-and-regionalstudies/transforming-cities-city-lives-city-natures-city-politics/climate-change-andurban-transitions/climate-change-adaptation-in-the-rental-sector/>.

\subsubsection{YouTube clips}

Eleven YouTube clips have been approved and publicly released on YouTube. Each video features a tenant (or tenants) describing the ways in which they practice sustainable living or a property manager discussing an aspect of sustainability or climate change adaptation in rental housing. Links to these video clips are posted on the project website and the Facebook page:

Episode One: Children and sustainability (Fee) http://www.youtube.com/watch?v=MAsYQJhom6I

Episode Two: Keeping warm sustainably in a rental house (Liza) http://www.youtube.com/watch?v=o-VyhScQBm8 
Episode Three: Permaculture gardening: Possibilities in a rental house (Lachlan) http://www.youtube.com/watch?v=4YTgAkvwwSg

Episode Four: Second Hand Goods and sustainability (Anne) http://www.youtube.com/watch?v=YDPvh0KCkb4

Episode Five: Housemates and sustainability (Ryan) http://www.youtube.com/watch?v=vFa7t8oilBc

Episode Six: Renting with chickens (Liza and Lachlan) http://www. youtube.com/watch?v=6619y9vOvW4

Episode Seven: Getting connected: practising sustainability with your community (EI Cortado and Liza)

http://www.youtube.com/watch?v=SAm0CowqDfA

Episode Eight: Rental agreements overseas: sustaining rental life (Valeria) http://www.youtube.com/watch?v=2tL3zJMy6sA

Episode Nine: Planning for sustainability (El Cortado) http://www.youtube.com/watch?v=7aE2rsxboRA

Episode Ten: The Real Estate Institute and sustainability (Wayne) http://www.youtube.com/watch?v=gS6zohTpyGc

Episode Eleven: Rental Property Managers and sustainability (Susan) http://www.youtube.com/watch?v=veg3yANSaWw

\subsubsection{Best Practice information guide}

5. The project team, in consultation with its Steering Committee, has developed a set of information sheets, as part of a community implementation plan, that contain a series of sustainability checklists for tenants, housing managers and landlords. The guide contains sustainability checklists for property managers, landlords and tenants; and overview of resources for renters; listing of our YouTube clips; a checklist fact sheet on gardening and chickens in rental housing; and a project overview. As part of our community implementation plan, it is intended that this guide be distributed to landlords and tenants via property managers as part of the leasing process in order to enhance the adaptive capacity of the rental sector through encouraging retro fitting from below. This guide will be available on the CURS website and be distributed to community groups.

\subsubsection{Outputs for government}

The project outputs most relevant to government are the recommendations of this report which will be disseminated through NCCARF's role in the Commonwealth Government's national climate change response strategy.

Local Government representatives on the Project Steering Committee will also receive copies of the report and its recommendations. A twelve page key findings document 
which highlights the recommendations coming out of the research will be developed. This key findings document will be available to download.

\subsubsection{Outputs for industry}

The best practice information guide for property managers is aimed at providing pathways for wider adoption by landlords of retro-fitting practices to make rental dwellings better adapted to climate change. In addition, a workshop for property managers will be held in Newcastle, NSW, to disseminate the best-practice information guides, overview the key findings of the project and provide an opportunity to enhance the role of property managers as sustainability 'knowledge brokers' by creating an knowledge-sharing environment for property managers. It enhances landlord and housing manager capacity to respond to climate change by advising on ways to encourage landlord investment in adaptive modifications to housing

\subsubsection{Academic publications}

Three conference papers have been presented:

Palmer, J., Instone, L., Mee, K., Williams, M., and Vaughan, N. (2012) Mobilising the contribution of the rental sector to adaptive and resilient suburbs: an asset-based approach, Institute of Australian Geographers Annual Conference, Macquarie University, July 2012

Palmer, J., Instone, L., Mee, K., Williams, M., and Vaughan, N. (2012) Why an assetbased approach to climate change adaptation in the rental sector? National Climate Change Adaptation Research Facility Annual Conference, Melbourne, June 2012

Palmer, J., Instone, L., Mee, K., Williams, M., and Vaughan, N. (2012) Challenges in an asset-based approach to climate change adaptation in the rental sector. National Climate Change Adaptation Research Facility Annual Conference, Melbourne, June 2012. 


\section{RECOMMENDATIONS}

On the basis of the findings summarised in 4.4.2 above, we recommend:

1. An enhanced role for housing managers as advocates and knowledge brokers for sustainability and climate change adaptation in the rental sector. This should be supported by new training programs, professional development programs and information resources, including regular professional or public seminars, or online courses. The content of these programs could include:

- advocacy and negotiation skills to support housing managers in seeking adaptive improvements to housing from landlords and enhanced adaptive practices from tenants

- up to date technical knowledge to support property managers in facilitating costefficient compliance with building sustainability standards: for example through providing up to date information on regulations, incentives and rebates, costeffective sustainability improvements to dwellings, comparative costing processes for modifications, comparative information on green energy providers

- training of property managers to either conduct or commission building performance audits.

(Refer Findings at 4.4.2.1)

2. Nurturing a new culture of renting and investing for landlords so that investment properties are increasingly understood as 'ethical investments' which provide opportunities for tenants to practice sustainability and adapt to climate change. Opening up the rental market could potentially provide another source of investment in affordable rental housing and therefore address a key barrier to adaptation in the section. This could be led by:

- education and awareness programs for landlords, provided by government or the REI, and disseminated through housing managers

- increased government subsidies for modifications to houses such as solar panels, solar hot water, water tanks

- enforcement of higher building standards to existing housing stock, and mandatory disclosure of building performance to prospective tenants

- an extension of the availability of environmental upgrade agreements to all rental properties

- demonstration projects which show how adaptation and sustainability can be integrated into rental properties, and associated costs and subsidies.

(Refer Findings at 4.4.2.2)

3. Providing longer leases in private rental to increase adaptive capacity in the rental sector. Note: Longer leases may be seen as a risk by landlords concerned about being locked into leases with tenants who do not pay their rent or appropriately maintain the property. One suggestion would be to have a longer lease with a probation period of a shorter lease (say 6 months). If the tenant has proved a good 
risk for the landlord in this period of time they could automatically qualify for a longer lease period if they choose.

(Refer Findings at 4.4.2.3)

4. Changed responsibilities and opportunities for tenants, to enable investments of time and money in a secure 'home'. This would require:

- availability of lease contracts for items such as solar panels or water tanks, either short-term or creating a 'legacy' commitment for the next tenant

- effective communication pathways between tenant and landlord, potentially facilitated by a housing manager with appropriate training

- automatic provision of sustainability guides for tenants moving into a new home, with building performance information where possible

- development of guides for tenant advice and advocacy organisations to enable them to review programs and resources not specifically directed at the rental sector, but which may offer useful tools for sustainability and climate change adaptation

- education and training resources for tenants to participate in community, regional and international initiatives to respond to climate change.

(Refer Findings at 4.4.2.3)

5. Changes to lease conditions which enable, rather than inhibit, modifications by tenants such as gardens, water tanks. This would require:

- a simplified approval process for tenant-initiated modifications, as part of tenancy contracts

- consideration on a case-by-case basis of conditions requiring tenants to leave a property in the same condition as they found it, especially cases where tenants have established viable food gardens.

(Refer Findings at 4.4.2.3)

6. A garden rental bond, similar to the pet rental bond should be provided as an option for tenants who wish to develop a vegetable garden. The cost of this bond could be equivalent to the cost of employing a garden service to ensure a vegetable garden is an asset for the property, rather than returning a garden to lawn or original condition.(Almost every tenant we interviewed suggested that a vegetable garden, or the potential of a vegetable garden was one important adaptive feature of a house, and it could enhance the value of a rental property for the landlord).

(Refer Findings at 4.4.2.3) 
7. Government action on regulatory change to support the above changes, including:

- incorporation of standard modification provisions into tenancy law, with the potential for contracts with suppliers of solar panels, water tanks etc. to be novated ${ }^{7}$ to future tenancies

- changes to tenancy law to enable a tenant to install major fixtures for the duration of the tenancy only, or to take the fixture with them to the next tenancy.

(Refer Findings at 4.4.2.3 and 4.4.2.7)

8. Government action on affordable and adaptive rental housing including:

- consideration by the Commonwealth Government of the Housing Supply Bonds proposal recently released by AHURI (Lawson et al. 2012)

- Changing planning legislation at State level to enable multi-family housing which shares resources such as kitchens and bathrooms.

(Refer Findings at 4.4.2.4 and 4.4.2.7)

9. An overall increase in funding for newly built public housing to increase the climate change adaptive capacity of the rental sector as a whole. Newly built public housing is designed with the higher sustainability requirements of the contemporary era. In addition given that a chronic shortage of affordable rental housing is a major barrier to climate change adaptation and that public housing has long waiting lists, an increase in the supply of newly built public housing would directly address climate change adaptation. The longer leases in public housing also mean that tenants may have a greater capacity for climate change mitigation and adaptation measures in public housing.

(Refer Findings at 4.4.2.4 and 4.4.2.7)

10. An increase in the supply of community housing to address climate change adaptation, for the same reasons noted under the previous recommendation about public housing. Community housing providers should see providing adaptable housing as part of their core business. Sustainability criteria should be part of funding of community housing.

(Refer Findings at 4.4.2.4 and 4.4.2.7)

11. An overall increase in the maintenance budget of Housing NSW, that will allow appropriate maintenance of stock as well as increasing the performance of the dwellings would aid climate change adaptation.

There are many problems with the physical quality of much of the current Housing NSW stock that was built in the 40s, 50 s and 60s.

While Housing NSW is focused on increasing the performance of its dwellings

\footnotetext{
${ }^{7}$ Novation is the substitution of a new contract for an old one. The new agreement extinguishes the rights and obligations that were in effect under the old agreement. In the case of a novation, the original debtor is totally released from the obligation, which is transferred to someone else ((Farlex 2012).
} 
within current financial constraints, the quality of older housing stock is a barrier to climate change adaptation in the sector at present.

(Refer Findings at 4.4.2.5 and 4.4.2.7)

12. Government review of rental building sustainability standards:

- to review the potential for adaptive retro-fitting of older rental housing, in close consultation with the property management and landlord sectors

- to review the potential to extend Environmental Upgrade Agreements to apply to all rental housing.

(Refer Findings at 4.4.2.5 and 4.4.2.7)

13. Government at all levels making explicit in policy and legislation development the potential contributions and impacts arising in the rental sector, including:

- policy and legislation in the areas of transport, land use planning and housing provision, housing performance, utilities, disaster planning, education and incentives for change

- a consideration of the resources required to support equitable implementation of policies across all sectors, including the rental sector.

(Refer Findings at 4.4.2.7)

14. Federal, state, local government climate change adaptation strategies for boosting resilience to floods, bushfires, storms, heat stress, and other natural disasters should include specific strategies to engage tenants, landlords and property managers.

(Refer Findings at 4.4.2.7) 


\section{GAPS AND FUTURE RESEARCH DIRECTIONS}

\subsection{Gaps in existing research}

Housing managers emerged from our research as potentially key 'knowledge brokers' in climate change adaptation within the rental sector, with a role in advocating to landlords and influencing tenant behaviour. This role is underexplored in existing research on the rental sector.

Similarly, while work has been done on improving the sustainability of rental housing (by AHURI for example (Gabriel et al. 2010a)), the diversity of landlords, and the ways in which they might participate in adapting the rental sector to climate change has not yet been explored.

Analysing the impacts of climate change on low income households formed a part of our study, but we were not able to focus on the community housing sector. This is an important and expanding area of the rental sector and its response to climate change warrants further research.

While rental housing shortages were revealed in our study as a critically important factor in the lack of adaptive housing and lack of tenant influence over the quality of their housing, the interaction of structural factors with climate change adaptation in the rental sector needs further exploration.

This study was based in the Newcastle area of NSW, and it would be worthwhile to conduct other studies which engage landlords, tenants and property managers in other locations, with different climate challenges and different regulatory frameworks.

\subsection{Future research directions}

Areas which therefore warrant further research in the near future include:

- the role of housing managers in influencing tenants and landlords and facilitating climate change adaptation in the rental sector

- the role of landlords in climate change adaptation in the rental sector, including existing best practice by some landlords and education of landlords

- climate change adaptation in the community housing sector

- education and training of property managers to address barriers to climate change adaptation

- similar studies in areas with different climatic conditions and different regulatory frameworks

- the impact of broad structural issues such as the current housing market on the adaptive capacity of the rental sector. 


\section{REFERENCES}

AAP (2012) 'MPs Petition against Pension Rent Gouge', AAP News Australia, 20 April 2012

ABC (2012a). 'Action Urged on Hunter's Chronic Housing Crisis'. Online News Article $<$ http://www.abc.net.au/news/2012-06-08/action-urged-on-hunter27s-chronichousing-crisis/4059842> accessed 8 June

ABC (2012b). 'Hunter Experiencing Chronic Public Housing Shortage'. Australian Broadcasting Association <http://www.abc.net.au/news/2012-05-14/hunterexperiencing-chronic-public-housing-shortage/4009056> accessed 9 July 2012

ABC Radio National (2012a). 'This Rental Life'. Life Matters.

$<$ http://www.abc.net.au/radionational/features/this-rental-life/> accessed 9 July 2012

ABC Radio National (2012b). 'This Rental Life (Part 1): The Portable Oasis: Renters Are Gardeners Too!'. Life Matters.

<http://www.abc.net.au/radionational/programs/lifematters/this-rental-

life/4053658> accessed 9 July 2012

ABCB (2011). 'Energy Efficiency'. Australian Building Codes Board

$<$ http://www.abcb.gov.au/major-initiatives/energy-efficiency> accessed 14 September 2012

ACOSS (2012). Submission to the Select Committee on Energy Prices. ACOSS Paper 193, Australian Council of Social Service, Sydney.

<http://acoss.org.au/images/uploads/Senate Inquiry Electricity Prices Sept 2

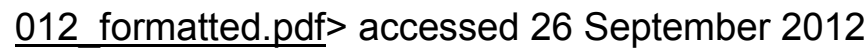

ACT Environment and Sustainable Development Directorate (2012). Web page.

'Actsmart: Wood Heater Replacement Program'. ACT Government

$<$ http://www.actsmart.act.gov.au/your household/wood heater replacement pr ogram> accessed 16 November 2012

Adger, W. N., S. Dessai, M. Goulden, M. Hulme, I. Lorenzoni, D. R. Nelson, L. O. Naess, J. Wolf and A. Wreford (2009). Are There Social Limits to Adaptation to Climate Change? Climatic Change 93(3-4): 335-354.

Adger, W. N., J. Paavola, S. Huq and M. J. Mace, Eds. (2006). Fairness in Adaptation to Climate Change. The MIT Press, Cambridge, MA and London.

Albanese, A. (2011). Media release. 'Australia's First Urban Design 'Protocol". Minister for Infrastructure and Transport $<$ http://www.minister.infrastructure.gov.au/aa/releases/2011/November/AA227 2011.aspx> accessed 27 November 2012

Allen, L. (2012) 'State Libs' Assets Sale Ramped Up', The Australian, Sydney, News Limited, 25 October 
Allen, L. and R. Morton (2012) 'Libs Eye Riches in Social Housing', The Australian, Sydney, News Limited, 25 October

Allon, F. and Z. Sofoulis (2006). Everyday Water: Cultures in Transition. Australian Geographer 37( 1): 45-55.

Alternative Technology Association (2009). 'Renters Guide to Sustainable Living'. $<$ http://www.ata.org.au/wpcontent/sustainability/ata renters guide sustainability.pdf> accessed 4 April

Anderson, A. (2009). Media, Politics and Climate Change: Towards a New Research Agenda. Sociology Compass 3(2): 166-182.

Anderson, S. (2012) 'Canberra's Rental Crisis 'Worst' of Any City in the Country', The Sydney Morning Herald, Sydney, Australia, Fairfax, 1 May 2012

ATO (2012). Rental Properties 2012: Guide for Rental Property Owners. ATO, Australian Taxation Office, Commonwealth of Australia, Canberra <http://www.ato.gov.au/content/downloads/ind00313554n17290612.pdf> accessed 11 September 2012

Australian Associated Press (2012) 'WA Backflips on Carbon Tax Compensation', AAP News Australia, 21 April 2012

Australian Bicycle Council (2011). Web page. 'Australian Local Government Bicycle Account 2011'. Austroads $<$ http://www.austroads.com.au/abc/images/pdf/australian\%20local\%20governm ent\%20bicycle\%20account\%202011 web.pdf> accessed 22 November 2012

Australian Bureau of Statistics (2008). Report. '2006 Census Community Profile Series: Carrington (Newcastle) (State Suburb)'. Commonwealth of Australia $<$ http://www.censusdata.abs.gov.au/ABSNavigation/prenav/ViewData?\&action= 404\&documentproductno=SSC14106\&documenttype=Details\&tabname=Detail s\&areacode $=S S C 14106 \&$ issue $=2006 \&$ producttype $=$ Community $\% 20$ Profiles $\& \& p$ roducttype $=$ Community \%20Profiles\&javascript=true\&textversion=false\&navmap displayed=true\&breadcrumb=PLD\&\&collection=Census\&period=2006\&productt ype=Community\%20Profiles\&\#Basic\%20Community\%20Profile $>$ accessed 6 December 2012

Australian Conservation Foundation (2007). The Greenhome Guide: New South Wales Edition. ACF, Melbourne.

$<$ http://www.livingthing.net.au/RC/pp/acfgreenhomeNSW.pdf> accessed 7 December 2012

Australian Department of Climate Change and Energy Efficiency (2012). Web page. 'Residential Building Disclosure'. Australian Government <http://www.climatechange.gov.au/government/initiatives/rbd.aspx> accessed 11 September 2012 
Australian Energy Market Commission (2012). Power of Choice Review - Giving Consumers Options in the Way They Use Electricity: Final Report, AEMC, C. Government, Sydney. <http://www.aemc.gov.au/media/docs/Final-report1b158644-c634-48bf-bb3a-e3f204beda30-0.pdf> accessed 5 December 2012

Australian Energy Regulator (2012). Power of Choice Review of Demand-Side Participation in the Nem: AER Submission to the AEMC Draft Report, AEM, C. Government, Melbourne.

<http://www.aer.gov.au/sites/default/files/AER\%20submission\%20to\%20AEMC \%20draft\%20report-\%20Power\%20of\%20Choice\%20review\%20\%200ctober\%202012.pdf> accessed 5 December 2012

Australian Government (2011a). Securing a Clean Energy Future: The Australian Government's Climate Change Plan. Department of Climate Change and Energy Efficiency, Australian Government, Canberra $<$ http://www.cleanenergyfuture.gov.au/wpcontent/uploads/2011/07/Consolidated-Final.pdf> accessed 14 November 2012

Australian Government (2011b). Securing a Clean Energy Future: The Australian Government's Climate Change Plan in Summary. Australian Government, Canberra < $<$ http://www.cleanenergyfuture.gov.au/wpcontent/uploads/2011/07/securing-a-clean-energy-future-summary.pdf> accessed 18 October 2012

Australians for Affordable Housing (undated). Housing Costs through the Roof: Australia's Housing Stress, HousingStressed.org.au. $<$ http://housingstressed.org.au/wp-content/uploads/2011/10/Housing-coststhrough-the-roof-Final-Report.pdf> accessed 19 September 2012

Bankoff, G. (2001). Rendering the World Unsafe: 'Vulnerability' as Western Discourse. Disasters 25(1): 19-25.

Bankoff, G. (2010) No Such Thing as Natural Disasters. Harvard International Review August 2010, Harvard College <http://hir.harvard.edu/no-such-thing-as-naturaldisasters?page $=0,0>$ accessed 16 March 2012

Barnett, C. and D. Land (2007). Geographies of Generosity: Beyond the' Moral Turn'. Geoforum 38(6): 1065-1075.

Barr, S. (2011). Climate Forums: Virtual Discourses on Climate Change and the Sustainable Lifestyle. Area 43(1): 14-22.

Bebbington, A. (1999). Capitals and Capabilities: A Framework for Analyzing Peasant Viability, Rural Livelihoods and Poverty. World development 27(12): 2021-2044.

Beder, S. (2000). Costing the Earth: Equity, Sustainable Development and Environmental Economics. New Zealand Journal of Environmental Law 4: 227243. 
Bengtsson, J. (2008). Fact sheet. 'Your Development: Adaptation to Climate Change Heat and Fire'. CSIRO Sustainable Ecosystems and Australian Department of the Environment, Water, Heritage, and the Arts $<$ http://yourdevelopment.org/factsheet/view/id/64> accessed 14 November 2012

Bierre, S., P. Howden-Chapman and L. Signal (2010). 'Ma and Pa' Landlords and the 'Risky' Tenant: Discourses in the New Zealand Private Rental Sector. Housing Studies 25(1): 21 - 38.

Biscoe, P. (2007). Ecologically Sustainable Development in New South Wales. Paper presented to the 5th Worldwide Colloquium of the IUCN Academy of Environmental Law, Paraty, Brazil, June.

BMT WBM (2012). Newcastle City-Wide Floodplain Risk Management Study and Plan: Draft Report, The City of Newcastle. $<$ http://www.newcastle.nsw.gov.au/ data/assets/pdf file/0003/189570/draft N ewcastle City-wide Floodplain Risk Management Study and Plan Exhibition Copy - March 2012 .pdf> accessed 12 July 2012

Bottrill, C. (2007). Internet-Based Tools for Behaviour Change. Paper presented to the European Council for Energy Efficient Economies (ECEEE) Summer Study. Dynamics of Consumption Session 9, paper 211.

Bradbrook, A. J. (1998). Residential Tenancies Law - the Second Stage of Reforms. Sydney Law Review 20(3): 402-434.

Brakey, A. (2012). Retail Markets and Consumer Participation. Paper presented to the AEMC Strategic Priorities for Energy Market Development Public Forum, 29 August, Sydney.

Brown, T. and M. Bhatti (2003). Whatever Happened to 'Housing and the Environment'? Housing Studies 18(4): 505 - 515.

Caldwell, A. and K. Helbig (2012) 'Battlers' Carbon Payments under Rent Hike Threat', The Courier Mail, Brisbane, Australia, 9 July 2012

Cameron, J. (2005). Focussing on the Focus Group. In Qualitative Research Methods in Human Geography. I. Hay, Ed. Oxford University Press, Melbourne: 116-132.

Cameron, J. and K. Gibson (2005). Alternative Pathways to Community and Economic Development: The Latrobe Valley Community Partnering Project. Geographical Research 43(3): 274-285.

CARE International (2009). Climate Change Vulnerability and Capacity Analysis Handbook, <http://www.careclimatechange.org/cvca/CARE CVCAHandbook.pdf> accessed 24 January 2012. 
Carvalho, A. (2007). Ideological Cultures and Media Discourses on Scientific Knowledge: Re-Reading News on Climate Change. Public Understanding of Science 16: 223-243.

Carvalho, A. (2010). Media(Ted) Discourses and Climate Change: A Focus on Political Subjectivity and (Dis)Engagement. WIREs Climate Change 1(March/April): 172179.

Christudason, A. (2002). Legislating for Environmental Practices within Residential Property Management in Singapore. Property Management 20(4): 252 - 263.

Clapham, D., B. Franklin and L. Saugeres (2000). Housing Management: The Social Construction of an Occupational Role. Housing, Theory, and Society 17(2): 68 82.

Clean Energy Regulator (2012). 'Assigning STCs'. Australian Government $<$ http://ret.cleanenergyregulator.gov.au/Certificates/Small-scale-TechnologyCertificates/assigning-stcs> accessed 12 September 2012

Clement, J. (2012) 'O'farrell's Grab for Cash - Carbon Tax Supplement Wiped out by Rental Increases', Canterbury-Bankstown Express, Sydney, Australia, 26 June 2012

COAG (2010). National Strategy on Energy Efficiency. Council of Australian Governments, Commonwealth of Australia, Canberra <http://www.coag.gov.au/sites/default/files/nsee update july 2010.pdf> accessed 11 September 2012

COAG Reform Council (2011). Review of Capital City Strategic Planning Systems. COAG, Australian Government, Canberra <http://www.coagreformcouncil.gov.au/reports/docs/capital cities/review of ca pital city strategic planning systems.pdf> accessed 5 September 2012

COAG Reform Council (2012). Affordable Housing 2010-11: Comparing Performance across Australia. COAG, Australian Government, Canberra $<$ http://www.coagreformcouncil.gov.au/reports/docs/ah comparing 10 11/Hous ing full\%20report 10-11.pdf> accessed 10 September 2012

Combet, G. (2010, 22 April 2010). Web page. 'Doorstop: Home Insulation Program'. Australian Government <http://www.climatechange.gov.au/minister/previous/combet/2010/transcripts/A pril/tr20100422.aspx> accessed 12 September 2012

Coorey, P. and D. Wroe (2012) 'O'Farrell Accused of Carbon Tax Compo Raid', The Sydney Morning Herald, Sydney, Australia, 20t June 2012

Council of Australian Governments (COAG) (2010). National Strategy on Energy Efficiency. Australian Government, Canberra <http://www.coag.gov.au/sites/default/files/nsee update july 2010.pdf> accessed 11 September 2012 
Crang, M. and I. Cook (2007). Doing Ethnographies. Sage Publications Ltd, London.

CSIRO and DEWHA (2008). Web page. 'Your Development'. CSIRO Sustainable Ecosystems and Australian Department of the Environment, Water, Heritage, and the Arts < http://yourdevelopment.org/casestudy/all/> accessed 6 November 2012

Cullen, S. (2012, 29th June). 'Governments Failing on Housing Affordability'. $<$ http://www.abc.net.au/news/2012-06-29/governments-failing-to-curb-rentalstress-report/4099176> accessed 9 July

DCC (2010). Adapting to Climate Change in Australia: An Australian Government Position Paper. Department of Climate Change, Commonwealth Government, Canberra <http://www.climatechange.gov.au/ /media/publications/adaptation/gov-adaptclimate-change-position-paper.pdf> accessed 17 July 2012

DCCEE (2012). 'Livinggreener: Information, How-To's and Rebates for Sustainable Living: Rebates and Assistance NSW'. Department of Climate Change and Energy Efficiency, Commonwealth of Australia $<\underline{\text { http://livinggreener.gov.au/rebates- }}$ assistance?queries state query=NSW\&submit=Search> accessed 12 July 2012

DECCW (2010). Flood Risk Management Guide: Incorporating Sea Level Rise Benchmarks in Flood Risk Assessments. Department of Environment,, Climate Change and Water, NSW Government, Sydney $<$ http://www.environment.nsw.gov.au/resources/water/coasts/10759FloodRiskM anGde.pdf> accessed 20 September 2012

DEH (2011). Floodplain Development Manual: The Management of Flood Liable Land. NSW Department of Environment and Heritage, NSW Government, Sydney $<$ http://www.environment.nsw.gov.au/resources/floodplains/2 flood manual.pdf $>$ accessed 20 September 2012

DEH (2012, 19 March 2012). Web page. 'NSW Environmental Upgrade Agreement Legislation'. NSW Department of Environment and Heritage, NSW Government $<$ http://www.environment.nsw.gov.au/sustainbus/eualegislation.htm> accessed 17 July 2012

DEWHA (2009). Living Sustainably: The Australian Government's National Action Plan for Education for Sustainability. Department of Environment, Water, Heritage and the Arts, Commonwealth of Australia $<$ http://www.environment.gov.au/education/publications/pubs/national-actionplan.pdf> accessed 7 November 2012 
DFS (2011). Environmental Sustainablity Strategy Update 2011/12 - 2013/14. NSW Department of Finance and Services, NSW Land and Housing Corporation, Sydney <http://www.housing.nsw.gov.au/NR/rdonlyres/75664B7D-3C8C-4175AA78-1941AE7F1BC0/0/EnvironmentalSustainabilityStrategyupdate.PDF> accessed 19 September 2012

Dickson, L. (2011) 'Fresh Take on the Tenancy Act Alters Slightly the Tenant-Landlord Balance', Manly Daily Sydney, Australia, 22nd January 2011

DIT (2012). Creating Places for People: An Urban Design Protocol for Australian Cities. Department of Transport and Infrastructure, Commonwealth of Australia, Canberra <http://www.urbandesign.gov.au/downloads/files/INFRA1219 MCU R SQUAR E URBAN PROTOCOLS 1111 WEB FA2.pdf> accessed 4 October 2012

Dolan, K. (2011a) 'Help Wanted to Keep Things Fair - Rental', The Age, Melbourne, Australia, 23 July 2011

Dolan, K. (2011b) 'Light-Bulb Moment for Landlords', The Age, Melbourne, Australia, 10th September 2011

Dolan, K. (2011c) 'Tenants Left in a Financial Fix', The Age, Melbourne, Fairfax, 17 December 2011

Dolan, K. (2011d) 'Three's a Crowd', The Age, Melbourne, Australia, 3 December 2011

Dolan, K. (2012a) 'From Mean Streets to Green Streets', The Age, Melbourne, Australia, 21 April 2012

Dolan, K. (2012b) 'Life on the Great Dividing Range', The Age, Melbourne, Fairfax, $<$ http://theage.domain.com.au/real-estate-news/life-on-the-great-dividing-range$\underline{\text { 20120210-1s5ub.html> }}$

Dolan, K. (2012c) 'Lights Out: It's Time for Bright Ideas', The Age, Melbourne, Australia, 24th March 2012

Dolan, K. (2012d) 'Take Control of Your Power Bills', The Age, Melbourne, Fairfax, 6 August 2011

DoP (2006). Lower Hunter Regional Strategy 2006-31. NSW Department of Planning, NSW Department of Planning, NSW Government, Sydney $<$ http://www.planning.nsw.gov.au/regional/pdf/lowerhunter regionalstrategy.pdf $>$ accessed 2 October 2012

DoP (2010). NSW Coastal Planning Guideline: Adapting to Sea Level Rise. NSW Department of Planning, NSW Government <http://www.planning.nsw.gov.au/LinkClick.aspx?fileticket=VYjmQirQIAk\%3d\&t abid=177\&language=en-US $>$ accessed 12 July 2012 
DoP (2012). A New Planning System for NSW: Green Paper. NSW Department of Planning, State of NSW, Sydney

$<$ http://www.planning.nsw.gov.au/LinkClick.aspx?fileticket=fUggrUzDe3A\%3d\&t abid=68\&language=en-US > accessed 16 July 2012

DoPI (2011). Fact sheet. 'Amendments to State Environmental Planning Policy (Affordable Rental Housing) 2009'. NSW Department of Planning and Infrastructure, NSW Government $<$ http://www.planning.nsw.gov.au/LinkClick.aspx?fileticket=drMAlh9x 4\%3d\&tabid=313\&language=en-AU> accessed 4 October 2012

DoTRMS (2012). Web page. 'Pedestrians'. NSW Department of Transport, Roads and Maritime Services, NSW Government $<$ http://www.rta.nsw.gov.au/doingbusinesswithus/lgr/downloads/programs/pede strians.html> accessed 24 September 2012

DPC (2011). NSW 2021. Department of Premier and Cabinet, NSW Government, Sydney $<$ http://www.2021.nsw.gov.au/sites/default/files/NSW2021 WEB\%20VERSION. pdf> accessed 12 July 2012

Drape, J. and A. Bennett (2012) 'Public Housing Rents up under Carbon Tax', Nine MSN News, Nine MSN, 14 June 2012

DSEWPC (1992). National Strategy for Ecologically Sustainable Development. Department of Sustainability, Environment, Water, Population and Communities, Commonwealth of Australia, Canberra <http://www.environment.gov.au/about/esd/publications/strategy/intro.html\#WIE SD> accessed 13 November 2012

DSEWPC (2010). Web page. 'Intergovernmental Agreement on the Environment'. Department of Sustainability, Environment, Water, Population and Communities, Commonwealth of Australia $<$ http://www.environment.gov.au/about/esd/publications/igae/index.html> accessed 8 November 2012

EDO (2009). Submission to the NSW Office of Fair Trading on Draft Residential Tenancies Bill 2009, Environmental Defender's Office New South Wales. $<$ www.edo.org.au/edonsw/site/.../091217residential tenancies act.pdf>

Ennis, G. and D. West (2010). Exploring the Potential of Social Network Analysis in Asset-Based Community Development Practice and Research. Australian Social Work 63(4): 404-417.

Environment Victoria (2012). 'Things You Can Do Right Now (No Need to Speak to Your Landlord First)'. <http://environmentvictoria.org.au/content/things-youcan-do-right-now-without-speaking-your-landlord-first> accessed 20th March 
Environment Victoria and Tenants Union of Victoria Ltd (2010). The Victorian Green Renters' Guide Sustainable Living Tips for Renters.

$<$ http://environmentvictoria.org.au/sites/default/files/Renters $\% 27 \% 20$ guide $\% 20 \mathrm{e}$ dition $\% 202 \% 20$ web\%20version.pdf>

Evans, D. (2011). Consuming Conventions: Sustainable Consumption, Ecological Citizenship and the Worlds of Worth. Journal of Rural Studies 27: 109 - 115.

FaHCSIA (2012). Web page. 'National Rental Affordability Scheme'. Department of Families, Housing, Community Services and Indigenous Affairs, Commonwealth of Australia <http://www.fahcsia.gov.au/ourresponsibilities/housing-support/programs-services/national-rental-affordabilityscheme> accessed 12 September 2012

Farlex (2012). 'The Free Dictionary'. Farlex Inc. <http://legaldictionary.thefreedictionary.com/novation> accessed 17 December 2012

Femenías, P. and A. van Hal (2009). Pathways for Sustainable Housing Transformations: An International Comparison of Retrofitting Strategies for (Social) Housing. Paper presented to the 3rd CIB International Conference on Smart and Sustainable Built Environment (SASBE2009), Delft, The Netherlands, June.

Flint, J. (2004). Reconfiguring Agency and Responsibility in Social Housing Governance in Scotland. Urban Studies 41(1): 151-172.

Folke, C. (2006). Resilience: The Emergence of a Perspective for Social-Ecological Systems Analyses. Global Environmental Change 16(3): 253-267.

Franklin, B. J. (2000). Demands, Expectations and Responses: The Shaping of Housing Management. Housing Studies 15(6): 907-927.

Franz, J. and E. Papyrakis (2011). Online Calculators of Ecological Footprint: Do They Promote or Dissuade Sustainable Behaviour? Sustainable Development 19(6): 391-401.

Fridge Buyback (2006). 'Fridge Buyback - Home Page'. <http://www.fridgebuyback.com.au/> accessed 12 July 2012

Gabriel, M., P. Watson, R. Ong, G. Wood and M. Wulff (2010a). The Environmental Sustainability of Australia's Private Rental Housing Stock. AHURI Final Report No.159, Australian Housing and Urban Research Institute, Melbourne.

Gabriel, M., P. Watson, R. Ong, G. Wood and M. Wulff (2010b). The Environmental Sustainability of Australia's Private Rental Housing Stock, AHURI Positioning Paper No. 125 January 2010, Australian Housing and Urban Research Institute, Melbourne.

Gibson-Graham, J. K. (2006). A Postcapitalist Politics. University Of Minnesota Press, Minneapolis. 
Gibson, C., L. Head, N. Gill and G. Waitt (2011). Climate Change and Household Dynamics: Beyond Consumption, Unbounding Sustainability. Transactions of the Institute of British Geographers 36(1): 3-8.

Goss, J. and T. R. Leinbach (1996). Focus Groups as Alternative Research Practice: Experience with Transmigrants in Indonesia. Area 28(2): 115-123.

Grayson, J. (1997). Campaigning Tenants: A Pre-History of Tenant Involvement to 1979. In Housing Community and Conflict: Understanding Resident Involvement. C. Cooper and M. Hawtin, Eds. Arena, Aldershot.

Green Renters (2012). 'Green Renters'. <http://www.greenrenters.org/> accessed 29 May

Grineski, S. E. and A. A. Hernández (2010). Landlords, Fear, and Children's Respiratory Health: An Untold Story of Environmental Injustice in the Central City. Local Environment: The International Journal of Justice and Sustainability 15(3): 199-216.

Gurran, N., E. Hamin and B. Norman (2008). Planning for Climate Change: Leading Practice Principles and Models for Sea Change Communities in Coastal Australia, Prepared for the National Sea Change Task Force, July 2008, University of Sydney.

Haines, A. and G. P. Green (2012). Asset Building \& Community Development. Sage Publications, Inc, Thousand Oaks.

Harrison, D. (2012) 'State May Take Cut of Carbon Tax Pension Rise', The Sydney Morning Herald Sydney, Australia, 3 April 2012

Heltberg, R., P. B. Siegel and S. L. Jorgensen (2009). Addressing Human Vulnerability to Climate Change: Toward a 'No-Regrets' Approach. Global Environmental Change 19(1): 89-99.

Hill, A. (2008). Book Review: W. Neil Adger, Jouni Paavola, Saleemul Huq, and M.J. Mace (Eds.) Fairness in Adaptation to Climate Change, the Mit Press (Cambridge, Ma and London), 2006. Development in Practice 18(1): 141-143.

Hobson, K. and S. Niemeyer (2011). Public Responses to Climate Change: The Role of Deliberation in Building Capacity for Adaptive Action. Global Environmental Change 21(3): 957-971.

Horne, R., C. Maller and R. Lane (2011). Remaking Home: The Reuse of Goods and Materials in Australian Households, in Material Geographies of Household Sustainability. In Material Geographies of Household Sustainability. R. Lane and A. Gorman-Murray, Eds. Ashgate, Farnham Surrey England: 89-111. 
Housing NSW (2011). Environmental Sustainability in Housing NSW 2011/12- 2013/14, NSW Government, Ashfield.

<http://www.housing.nsw.gov.au/NR/rdonlyres/75664B7D-3C8C-4175-AA781941AE7F1BC0/0/EnvironmentalSustainabilityStrategyupdate.PDF> accessed 22 February 2012

Housing NSW (2012a). 'Environmental Sustainability at Home Overview '. $<$ http://www.housing.nsw.gov.au/Living+in+Public+Housing/Environmental+Sus tainability+at+Home/> accessed 17 December 2012

Housing NSW (2012b). 'Welcome to Your Home, Information to Help You Save Energy and Water'. FACS


31 July 2012

Howitt, R., O. Havnen and S. Veland (2010). Natural and Unnatural Disasters: Responding with Respect for Indigenous Rights and Knowledges. Paper presented to the Conference on Indigenous Reconstruction and Autonomy after Disaster, Taipei, 11-13 November.

Hulse, K., V. Milligan and H. Easthope (2011). Secure Occupancy in Rental Housing: Conceptual Foundations and Comparative Perspectives. AHURI Final Report No.170, Australian Housing and Urban Research Institute, Melbourne.

HWC (2011a). Web page. 'Hunter Region No Interest Loan Scheme'. Hunter Water Corporation <http://www.hunterwater.com.au/Save-Water/Save-WaterInitiatives/No-Interest-Loan-Scheme.aspx> accessed 4 October 2012

HWC (2011b). Web page. 'Showerhead Exchange'. Hunter Water Corporation $<$ http://www.hunterwater.com.au/Save-Water/Save-WaterInitiatives/Showerhead-Exchange.aspx> accessed 4 October 2012

Hyder Consulting (2011). Role and Performance of Local Government: Waste and Recycling Related Data and Information. Department of Sustainability, Environment, Water, Population and Communities, Commonwealth of Australia, Canberra <http://www.environment.gov.au/wastepolicy/publications/pubs/localgovernment.pdf> accessed 24 September 2012

Ison, N., J. Usher, R. Cantley-Smith, S. Harris and C. Dunstan (2011). The Nem Report Card: How Well Does the National Electricity Market Serve Australia?, A report prepared by the Institute for Sustainable Futures and the Monash University Faculty of Law for the Total Environment Centre, Total Environment Centre Inc, Sydney. <http://www.isf.uts.edu.au/publications//sonetal2011nem.pdf> accessed 6 November 2012

Just Change (2012, 2008). 'About Just Change'. <http://www.justchangeaustralia.org/aboutjustchange.html> accessed 29 May 2012 
Kates, R. W. and T. J. Wilbanks (2003). Making the Global Local: Responding to Climate Change Concerns from the Ground. Environment 45(3): 13-23.

Kelly, M. (2011) 'Landlords Splash out for Water Efficiency', The Newcastle Herald Newcastle, Australia, 8 February 2011

Kelly, M. (2012) 'Building Approvals Slump Amid Hunter Housing Shortage', Newcastle Herald, Newcastle, Fairfax, 20 November 2012 $<$ http://www.theherald.com.au/story/1132190/building-approvals-slump-amidhunter-house-shortage/?cs=391> accessed 20 November 2012

Kretzmann, J. and J. P. McKnight (1996). Assets-Based Community Development. National Civic Review 85(4): 23-29.

Kretzmann, J. P. and J. L. McKnight (1993). Building Communities from the inside Out: A Path toward Finding and Mobilizing a Community's Assets. Center for Urban Affairs and Policy Research, Northwestern University, Evanston.

Kyrö, R., J. Heinonen and A. Säynäjoki (2011). Occupants Have Little Influence on the Overall Energy Consumption in District Heated Apartment Buildings. Energy and Buildings 43: 3484 - 3490.

Kyrö, R. K., J. Heinonen and S. Junnila (2012). Housing Managers Key to Reducing the Greenhouse Gas Emissions of Multi-Family Housing Companies? A Mixed Method Approach. Building and Environment 56: 203 - 210.

Lacey, S. (2012) 'A New Lease of Eco Life', Sydney Morning Herald, Sydney, Fairfax, 16 June 2012 <http://www.smh.com.au/environment/energy-smart/a-new-leaseof-eco-life-20120614-20b1c.html>

Lake Macquarie City Council (2010, 6 April 2010). 'Ecological Footprint'. Lake Macquarie City Council $<$ http://www.lakemac.com.au/page.aspx?pid=1013\&vid=14> accessed 12 June 2012

Lake Macquarie City Council (2012a). Web page. 'Be Prepared for Extreme Heat'. LMCC <http://www.lakemac.com.au/page.aspx?vid=14\&pid=1401> accessed 18 February 2013

Lake Macquarie City Council (2012b). Web page. 'Emergency Ready Lake Macquarie'. LMCC < http://www.lakemac.com.au/emergency-ready> accessed 18 February 2013

Lake Macquarie City Council (2012c). Web page. 'Natural Disaster'. LMCC $<$ http://www.lakemac.com.au/environment/natural-disaster> accessed 18 February 2013

Lake Macquarie City Council (2012d). 'Sustainable Living'. <http://www.lakemac.com.au/environment/sustainable-living > accessed 29 May 
Lake Macquarie City Council (2012e). 'Workshops'.

<http://www.lakemac.com.au/environment/workshops> accessed 24 July

Lane, R. and A. Gorman-Murray (2011). Material Geographies of Household Sustainability. Ashgate Publishing.

Lawson, J., V. Milligan and J. Yates (2012). Housing Supply Bonds - a Suitable Instrument to Channel Investment Towards Affordable Housing in Australia?: Ahuri Final Report No.188, Australian Housing and Urban Research Institute, Melbourne.

Levina, E. and D. Tirpak (2006). Key Adaptation Concepts and Terms, OECD/IEA, Paris. <http://www.oecd.org/environment/cc/36278739.pdf> accessed 25 February 2013

LGSA (undated). Web page. 'Ecologically Sustainable Development'. Local Government and Shires Association <http://www.lgsa.org.au/policy/ecologicallysustainable-development> accessed 26 November 2012

Lister, D. (2004). Young People's Strategies for Managing Tenancy Relationships in the Private Rented Sector. Journal of Youth Studies 7(3): 315-330.

Lister, D. (2005). Controlling Letting Arrangements? Landlords and Surveillance in the Private Rented Sector. Surveillance \& Society 2(5): 513-528.

LJ Hooker (2012a). 'Liveability'. LJ Hooker < http://www.liveability.com.au/> accessed 29t May

LJ Hooker (2012b). 'Rent Smart'. LJ Hooker <http://www.liveability.com.au/wpcontent/uploads/2012/09/Renters-Guide Final3.pdf> accessed 9 October 2012

LJ Hooker (Queensland) (unpublished). Disaster Management Best Practise Guide. LJ Hooker, Brisbane.

LMCC (2011a). Web page. 'Adopt-a-Sqid'. Lake Macquarie City Council <http://www.lakemac.com.au/natural-environment/waterways/adopt-a-sqid> accessed 22 November 2012

LMCC (2011b). Web page. 'Draft Lake Macquarie Waterway Flood Study and Flood Risk Management Plan: Summary of Findings and Recommendations'. <http://www.lakemac.com.au/downloads/Flood\%20Study\%20and\%20Plan\%20 Summary.pdf> accessed 13 November 2012

LMCC (2011c). Environmental Sustainability Action Plan 2011-2018, City of Lake Macquarie.

<http://www.lakemac.com.au/downloads/City\%20of\%20Lake\%20Macquarie $\% 2$ 0Environmental\%20Sustainability\%20Action\%20Plan\%202011-2018.pdf> accessed 12 July 2012 
LMCC (2011d). Lake Macquarie Local Disaster Plan (Displan) 2011, City of Lake Macquarie.

<http://www.lakemac.com.au/downloads/D02179220\%20\%20DISPLAN\%20201

$1 \% 20$ public .pdf> accessed 19 February 2013

LMCC (2011e). Factsheet. 'Sea Level Rise Policy'. Lake Macquarie City Council $<$ http://www.lakemac.com.au/page.aspx?pid=109\&fid=1176\&ftype=File\&vid=1\& $\underline{\text { dlp}}=$ True $>$ accessed 19 February 2013

LMCC (2011f). Web page. 'Sustainable Neighbourhoods: About the Program'. Lake Macquarie City Council <http://www.lakemac.com.au/environment/sustainableneighbourhoods/program> accessed 4 October 2012

LMCC (2012). Community Plan 2008-2018, City of Lake Macquarie. $<$ http://www.lakemac.com.au/about-council/corporate-planning-andperformance/community-plan-2008-2018> accessed 20 September 2012

Maller, C., R. Horne and T. Dalton (2012). Green Renovations: Intersections of Daily Routines, Housing Aspirations and Narratives of Environmental Sustainability. Housing, Theory and Society 29(3): 255-275.

Maller, C. J. and R. E. Horne (2011). Living Lightly: How Does Climate Change Feature in Residential Home Improvements and What Are the Implications for Policy? Urban Policy and Research 29(1): 59-72.

Manzi, T. and B. Smith Bowers (2004). So Many Managers, So Little Vision: Registered Social Landlords and Consortium Schemes in the Uk. International Journal of Housing Policy 4(1): 57-75.

Marres, N. (2011). The Making of Climate Publics: Eco-Homes as Material Devices of Publicity. Distinktion: Scandinavian Journal of Social Theory 9(1): 27-45.

Martins, B. (2012) 'Carbon Tax Offset Taken by Rent Rise', Fairfield City Champion, Australia, 3 July 2012

McCann, J. (2010). 'Green Living for Renters'. Issue \#26, May/June 2010. G-Magazine <http://www.gmagazine.com.au/features/2185/green-living-renters> accessed 20th March 2012

McKay, D. and R. Rauscher (2005). Esd Strategies at the Local Government Level: Case Study of the City of Newcastle. Proceedings of the State of Australian Cities Conference, Griffith University, Brisbane.

$<$ http://www.griffith.edu.au/ data/assets/pdf file/0020/81380/environmentalcity-21-mckay.pdf> accessed 13 July 2012

Mee, K. (2004). Necessary Welfare Measure of Policy Failure: Media Reports of Public Housing in Sydney in the 1990s. In Social Constructionism in Housing Research. K. Jacobs, J. Kemeny and T. Manzi, Eds. Ashgate, Aldershot: 117141. 
Mee, K. (2009). A Space to Care, a Space of Care: Public Housing, Belonging, and Care in Inner Newcastle, Australia. Environment and Planning A 41(4): 842858.

Mee, K. and N. Vaughan (2012). Experiencing Home. In International Encyclopedia of Housing and Home. Susan J. Smith, Marja Elsinga, L. F. O'Mahonyet al, Eds. Elsevier, Oxford. 2: 146-151

Melbourne Times Weekly (2012) 'Green up, Renters Told', Melbourne Times Weekly, Melbourne, Fairfax, 12 June 2012

Miles, K., J. Byrnes and K. Bannon (2010). Review of Regional Water Quality and Security: Review and Reform Strategy I. Australia, AECOM Australia Pty Ltd, Sydney <http://www.infrastructureaustralia.gov.au/publications/files/Review of Regiona IWaterQuality and Security Volume1 251010.pdf> accessed 26 September 2012

Millar, I. (2009). The Environmental Law Framework for Sustainable Development Principles of Sustainable Development in International, National and Local Laws. Paper presented to the Sustainable Future Project, Workshop Six: Economics and Administration for Sustainability, Canberra.

Millennium Ecosystem Assessment (2003). Analytical Approaches. In Ecosystems and Human Well-Being: A Framework for Assessment. J. Alcamo and E. M. Bennett, Eds. Island Press, Washington.

Milligan, C. and J. Wiles (2010). Landscapes of Care. Progress in Human Geography 34(6): 736-754.

Moloney, S., R. E. Horne and J. Fien (2010). Transitioning to Low Carbon Communities-from Behaviour Change to Systemic Change: Lessons from Australia. Energy Policy 38(12): 7614-7623.

Morioka, K. (2012). A Climate for Change: Understanding Women's Vulnerabilty and Adaptive Capacity to Climate Change from Actionaid's Rights-Based Approach - Case Studies from Papua New Guinea and Solomon Islands. ActionAid Australia, Sydney.

Moser, C. (2011). Climate Change Adaptation: Finding the Right Response. In Adaptation Knowledge Platform (Akp). AIT-UNEP RRC.AP, Bangkok.

Moser, C., A. Norton, A. Stein and S. Georgieva (2010). Pro-Poor Adaptation to Climate Change in Urban Centers: Case Studies of Vulnerability and Resilience in Kenya and Nicaragu. 54947-GLB, The World Bank, Sustainable Development Network, Social Development Department, Washington. 
Moser, C. and D. Satterthwaite (2008). Towards Pro-Poor Adaptation to Climate Change in the Urban Centres of Low- and Middle-Income Countries, Human Settlements Discussion Paper Series: Climate Change and Cities, International Institute for Environment and Development, IIED, London.

<http://pubs.iied.org/pdfs/10564IIED.pdf> accessed 12 March 2012

National Association of Tenant Organisations, P. Carr and M. Tennant (2010) A Better Lease on Life - Improving Australian Tenancy Law. National Shelter Inc $<$ http://www.shelter.org.au/index.php?option=com docman\&task=doc downloa d\&gid=14\&ltemid $=127>$ accessed 12 July 2012

NCC (2010). Web page. 'Bushfire Assessment'. Newcastle City Council $<$ http://www.newcastle.nsw.gov.au/environment/bushland and fire/bushfire as sessment> accessed 19 February 2013

NCC (2011a). Web page. 'Neigbhourhood Safer Places'. Newcastle City Council $<$ http://www.newcastle.nsw.gov.au/environment/bushland and fire/neighbourh ood safer places> accessed 19 February 2013

NCC (2011b). Newcastle 2030. Our Vision for a Smart, Liveable and Sustainable City. The City of Newcastle Future City group $<$ http://www.newcastle.nsw.gov.au/ data/assets/pdf file/0007/146554/Newcas tle 2030 Publication final web.pdf>

NCC (2011c). Web page. 'Storm Safety'. Newcastle City Council $<$ http://www.newcastle.nsw.gov.au/environment/storm safety> accessed 19 February 2013

NCC (2012a). Web page. 'Flood Contacts'. Newcastle City Council <http://www.newcastle.nsw.gov.au/environment/flooding and waterways/flood contacts $>$ accessed 19 February 2013

NCC (2012b). Newcastle Displan: Local Disaster Plan 2012, Newcastle City Council. <http://www.newcastle.nsw.gov.au/ data/assets/pdf file/0016/14272/01 Final Displan 2012 Private.pdf> accessed 19 February 2013

NCC (2012c). Media release. 'Spring Water Bug Survey'. City of Newcastle <http://www.newcastle.nsw.gov.au/about newcastle/news and events/media $r$ eleases/media releases/spring water bug survey> accessed 4 October 2012

NCC (2012d). Web page. 'Sustainable Building Advisory Service'. The City of Newcastle

$<$ http://www.newcastle.nsw.gov.au/building and planning/sustainable building advisory service> accessed 20 September 2012

NCC NSW (2012). 'NSW Sustainable Renting Guide'. Nature Conservation Council NSW, $<$ http://nccnsw.org.au/sites/default/files/NSW\%20Sustainable\%20Renting\%20G uide\%20w\%20NRMA\%20logo.pdf> accessed 4 April 2012 
NCOSS (2012). Blog. 'Government Changes Position on Social Housing Rents'. Council of Social Service of NSW <http://www.ncoss.org.au/content/view/6822/100/> accessed 19 September 2012

Nicastri, D. (2011) 'Act Gives Renters the Edge -- Landlords Claim New Tenancy Laws Put Them on an 'Uneven' Playing Field', Manly Daily Sydney, Australia, 19 January 2011

NPHP (2002). The Role of Local Government in Public Health Regulation. National Public Health Partnership, NPHP, Melbourne $<$ http://www.nphp.gov.au/publications/legislation/localgov.pdf> accessed 25 September 2012

NPHP (2010). Web page. 'The National Public Health Partnership (NPHP)'. NPHP <http://www.nphp.gov.au/> accessed 25 September 2012

NSW Department of Fair Trading (2011a). Natural Disasters: Information for Tenants. State of NSW, Parramatta.

<http://www.fairtrading.nsw.gov.au/Tenants and home owners/Renting a ho me/During a tenancy/Natural disasters.html> accessed 12 July 2012

NSW Department of Fair Trading (2011b). Starting a Tenancy: Information for Tenants. State of NSW, Parramatta.

$<$ http://www.fairtrading.nsw.gov.au/pdfs/Tenants and home owners/Starting a tenancy information for tenants.pdf> accessed 12 July 2012

NSW Department of Fair Trading (2012a). Renting a Home: During a Tenancy. State of NSW, Parramatta.

$<$ http://www.fairtrading.nsw.gov.au/Tenants and home owners/Renting a ho me/During a tenancy.html> accessed 12 July 2012

NSW Department of Fair Trading (2012b). Renting a Home: Ending a Tenancy. State of NSW, Parramatta.

<http://www.fairtrading.nsw.gov.au/Tenants and home owners/Renting a ho me/Ending a tenancy.html> accessed 12 July 2012

NSW Department of Family and Community Services (2012). 'Welcome to Your Home, Information to Help You Save Energy and Water'. Housing NSW

<www.housing.nsw.gov.au/NR/.../Welcometoyourhomebooklet.pdf $>$ accessed 31st July 2012

NSW Department of Transport, Roads and Maritime Services (2012). Web page.

'Pedestrians'. NSW Government

$<$ http://www.rta.nsw.gov.au/doingbusinesswithus/lgr/downloads/programs/pede strians.html> accessed 24 September 2012 
NSW EDO (2008). Coastal Councils and Planning for Climate Change: An Assessment of Australian and NSW Legislation and Government Policy Provisions Relating to Climate Change Relevant to Regional and Metropolitan Councils, prepared by the NSW Environmental Defenders Office for the Sydney Coastal Councils Group, Sydney Coastal Councils Group and NSW Environmental Defenders Office, Sydney.

<http://www.sydneycoastalcouncils.com.au/sites/default/files/coastalcouncilspla nningforclimatechange.pdf $>$ accessed 7 November 2012

NSW Environmental Trust (2010). Annual Report 2009-10, NSW Government, Sydney. <http://www.environment.nsw.gov.au/resources/grants/10899EnviroTrustAR201 $\underline{0 . p d f}>$ accessed 26 November 2012

NSW Government (2012a). Draft NSW Long Term Transport Master Plan. NSW Government, Sydney <http://haveyoursay.nsw.gov.au/document/index/21> accessed 21 September 2012

NSW Government (2012b). Draft NSW Renewable Energy Action Plan. NSW Department of Resources and Energy, NSW Government, Sydney $<$ http://haveyoursay.nsw.gov.au/document/show/475> accessed 12 September 2012

NSW Health (undated). Web page. 'How to Prepare for a Heat Wave'. State of NSW $<$ http://www0.health.nsw.gov.au/campaigns/beattheheat/prepare for heat wav e.asp> accessed 9 November 2012

NSW OEH (2008). 'Our Environment It's a Living Thing: New Projects'. NSW Office of Environment and Heritage <http://www.livingthing.net.au/PP Proj n.htm> accessed 7 November 2012

NSW OEH (2011). Web page. 'A Guide for Engaging Communities in Environmental Planning and Decision Making'. NSW Office of Environment and Heritage <http://www.environment.nsw.gov.au/community/ComEngagement.htm> accessed 14 November 2012

NSW OEH (2012). Web page. 'NSW Council on Environmental Education'. NSW Office of Environment and Heritage $<$ http://www.environment.nsw.gov.au/cee/index.htm> accessed 7 November 2012

NTU (2012) Residential Tenancies Act 2010: Report. Tenants' Union of New South Wales < http://www.tenantsunion.org.au/index.php/publications/paperssubmissions/85-rta-2010-report> accessed 26 June 2012

O'Dwyer, E. (2011) 'Greener at the Grassroots - Sustainable Sydney Special ReportSustainable Homes ', The Sydney Morning Herald, Sydney, Australia, 12 October 2011

Pike, B. (2011) 'Cover Story - Home Truths for Investors', The Daily Telegraph, Sydney, Australia, 9 July 2011 
Pillora, S. (2010). Australian Local Government and Climate Change: Working Paper No.1, prepared by the UTS Centre for Local Government for the Australian Centre of Excellence for Local Government, ACELG, Sydney. $<$ http://www.acelg.org.au/upload/program1/1296541034 Climate Change Pap er WEB1.pdf $>$ accessed 7 November 2012

Priemus, H. (2005). How to Make Housing Sustainable? The Dutch Experience. Environment and Planning B: Planning and Design 32: 5 - 19.

Priemus, H., F. Dieleman and D. Clapham (1999). Current Developments in Social Housing Management. Journal of Housing and the Build Environment 14(3): 211-223.

Prowse, M. and L. Scott (2008). Assets and Adaptation: An Emerging Debate. IDS Bulletin 39(4): 42-52.

Raimondo, E. (2012) 'Victorian Rental Vacancies Tighten', The Sydney Morning Herald, Sydney, Fairfax, 14 April 2012

Rasila, H. (2010). Customer Relationship Quality in Landlord-Tenant Relationship. Property Management 28(2): 80-92.

Ravetz, A. (2001). Council Housing and Culture. Routledge, London; New York.

Real Estate Excellence Academy (2013). 'Natural Disasters and Rental Property Best Practice Guide'. Stacey Holt Real Estate Excellence $<$ http://staceyholtrealestateexcellence.blogspot.com.au/2013/01/naturaldisasters-and-rental-property.html> accessed 19 February 2013

Reardon, C., G. Milne, C. McGee and P. Downton (2010a). Web page. 'Your Home Renovator's Guide: Assessing Your Home'. Commonwealth of Australia <http://www.yourhome.gov.au./renovatorsguide/assessing.html> accessed 14 November 2012

Reardon, C., G. Milne, C. McGee and P. Downton (2010b). Your Home: Technical Manual (4th Ed). Australian Government <http://www.yourhome.gov.au/technical/index.html> accessed 17 September 2012

Reduce your footprint (2012). 'About'. <http://reduceyourfootprint.com.au/pages/about/> accessed 31 July 2012

Reid, L., P. Sutton and C. Hunter (2010). Theorizing the Meso Level: The Household as a Crucible of Pro-Environmental Behaviour. Progress in Human Geography 34(3): 309-327.

REINSW (2012). 'Rental Vacancy Rates Lose Ground in Sydney and Newcastle'. Real Estate Institute of NSW <http://www.reinsw.com.au/Rental-vacancy-rates-loseground-in-Sydney-and-Newcastle/default.aspx> accessed 24 October 2012 
REIQ (2011). Fact Sheet. 'Dealing with a Natural Disaster - Flood and Storm'. Real Estate Institute of Queensland <www.reiq.com.au>

Residential Tenancies Authority (Qld) (2011). Fact Sheet. 'Natural Disasters'.

Queensland Government <http://www.rta.qld.gov.au/Renting/During-atenancy/Serious-problems-during-a-tenancy/Natural-disasters> accessed 13 November 2012

Ribot, J. (2010). Vulnerability Does Not Fall from the Sky: Toward Multiscale, Pro-Poor Climate Policy. Social Dimensions of Climate Change: Equity and Vulnerability in a Warming World. R. Mearns and A. Norton. World Bank, Washington: 47-74. <http://issuu.com/world.bank.publications/docs/9780821378878/2?mode=a p> accessed 9 March 2012

Robinson, S. (2010) Green Landlords: New Incentives for Green Retrofits to Existing Buildings. Mason Sier Turnbull Lawyers <http://www.mst.com.au/news/greenlandlords-new-incentives-for-green-retrofits-to-existing-buildings $>$ accessed 5 June 2012

Roelvink, G. and J. K. Gibson-Graham (2009). A Postcapitalist Politics of Dwelling: Ecological Humanities and Community Economies in Conversation. Australian Humanities Review 46: 145-158.

Rose, D. B. (2004). Reports from a Wild Country: Ethics for Decolonisation. UNSW Press, Sydney.

RTA (2009). Council Projects Funded by the RTA: Memorandum of Understanding. NSW Roads and Traffic Authority, NSW Government, Sydney <http://www.rta.nsw.gov.au/trafficinformation/downloads/mou 0609.pdf> accessed 24 September 2012

Rudd, K. (2007). Climate Change: The Great Moral Challenge of Our Generation. Australian Labor. YouTube. <http://www.youtube.com/watch?v=CqZvpRjGtGM>

Santow, E. (2010). Residential Tenancies Regulation 2010: Submission to the Department of Fair Trading NSW, Public Interest Advocacy Centre, Sydney. $<$ http://www.piac.asn.au/sites/default/files/publications/extras/10.10.13 Letter $r$ e Residential Tenancies Regulation.pdf> accessed 12 July 2012

Sartor, F. (2010). Legislative Assembly 'Agreement in Principle' Speech: Local Government Amendment (Environmental Upgrade Agreements) Bill 2010. State of NSW, Sydney < http://www.parliament.nsw.gov.au/Prod/parlment/nswbills.nsf/0/1bf9d822d9dd 2288ca2577d7001779e6/\$FILE/LA\%2011010.pdf> accessed 12 July 2012

Saugeres, L. (1999). The Social Construction of Housing Management Discourse: Objectivity, Rationality and Everyday Practice. Housing, Theory and Society 16(3): 93-105. 
Saugeres, L. (2000). Of Tidy Gardens and Clean Houses: Housing Officers as Agents of Social Control. Geoforum 31: 587-599.

Saugeres, L. and D. Clapham (1999). Themes and Contradictions in Housing Management: An Analysis of Bureaucratic Discourse. Netherlands Journal of Housing and the Built Environment 14(3): 257-276.

Shove, E. (2010). Social Theory and Climate Change: Questions Often, Sometimes and Not yet Asked. Theory, Culture \& Society 27(2-3): 277-288.

Slocum, R. (2004). Polar Bears and Energy-Efficient Lightbulbs: Strategies to Bring Climate Change Home. Environment and Planning D: Society and Space 22: 413-438.

Smid, J.-W. and N. Nieboer (2008). Energy-Efficient Asset Management for Professional Landlords. International Journal of Strategic Property Management 12: 19-34.

Smithson, J. (2000). Using and Analysing Focus Groups: Limitations and Possibilities. International Journal of Social Research Methodology 3(2): 103-119.

Smithson, J. (2008). Focus Groups. In The Sage Handbook of Social Research Methods. P. Alasuutari, L. Bickman and J. Brannen, Eds. SAGE Publications Inc, London: 357-370.

SolarCity (California) (2012). Web page. 'Solarlease'. $<$ http://www.solarcity.com/residential/solar-lease.aspx> accessed 27 November 2012

SOPAR (undated). Asset-Based Community Development as a Methodology. In Abcd Methodology Manual. SOPAR (Society for Partnership), Gatineau, Québec: 2760.

Stanley, J. (2009). Promoting Social Inlcusion in Adaptation to Climate Change, Monash Sustainability Institute Melbourne.

Stenberg, J., L. Thuvander and P. Femenías (2009). Linking Social and Environmental Aspects: A Multidimensional Evaluation of Refurbishment Projects. Local Environment: The International Journal of Justice and Sustainability 14(6): 541556.

Strengers, Y. and C. Maller (2011). Integrating Health, Housing and Energy Policies: Social Practices of Cooling. Building Research \& Information 39(2): 154-168.

Sullivan, D. (2007). Climate Change: Addressing the Needs of Low-Income Households in the Private Rental Market: Background Paper, Brotherhood of St Laurence.

Tarala, K. (2011) 'New Laws Address Key Tenancy Issues', The Newcastle Herald, Newcastle, Australia, Fairfax, 2nd February 2011 
TenantsNSW (2012). Web page. 'Increase Tenants' Advice Funding Now!'.

TenantsNSW <http://www.tenants.org.au/tenants-advice-funding > accessed 18 September 2012

TenantsNSW (2013a). Web page. 'Factsheet 16: Ending Tenancy Early'. Tenants' Union of NSW < http://www.tenants.org.au/factsheet-16-ending-tenancy-early> accessed 18 February 2013

TenantsNSW (2013b). Web page. 'Factsheet 22: Storm Damage'. Tenants' Union of NSW <http://www.tenants.org.au/factsheet-22-storm-damage> accessed 18 February 2013

The Allen Consulting Group (2011). Mandatory Disclosure of Residential Building Energy, Greenhouse and Water Performance: Consultation Regulation Impact Statement, for the National Framework for Energy Effficiency Building Implementation Committee. <http://ris.finance.gov.au/files/2011/08/03Mandatory-Disclosure-RIS.pdf> accessed 12 July 2012

The City of Newcastle (2011). Newcastle 2030. Our Vision for a Smart, Liveable and Sustainable City. The City of Newcastle Future City group $<\underline{\text { http://www.newcastle.nsw.gov.au/ data/assets/pdf file/0007/146554/Newcas }}$ tle 2030 Publication final web.pdf>

The City of Newcastle (2012). 'Climate Cam: Residential Sector'. $<$ http://www.newcastle.nsw.gov.au/environment/climate cam/residential sector $>$ accessed 24 July

The Daily Examiner (2012) 'Renters 'Betrayed by O'Farrell Govt", The Daily Examiner, Grafton, New South Wales, 2 June 2012

The Standard (2012) 'Free Tips on How to Easily Cut Household Energy Costs', The Standard, Warrnambool, Australia, 17 May 2012

Toohey, S. and J. Fritze (2009). A Future Focussed Housing Standard: The Case for Rental Housing Standards to Help Vulnerable Households Adapt to Climate Change, VCOSS, Melbourne.

Tovey, J. (2012) 'O'Farrell Accused of 'Grab' at Pensioner Carbon Rebate', The Sydney Morning Herald, Sydney, Australia, 15 June 2012

Transition Newcastle (2012). 'Transition Streets Challenge'. Transition Newcastle <http://www.transitionnewcastle.org.au/project/transition-streets-challenge> accessed 19 November 2012

TUQ (2012). Web page. 'Call to Reinstate Tenant Advice Services'. Tenants' Union of Queensland <http://tuq.org.au/wp/?p=917> accessed 18 September 2012 
UN Conference on Environment and Development (1992). The Rio Declaration on Environment and Development. UNEP

$<$ http://www.unep.org/Documents.Multilingual/Default.asp?documentid=78\&arti cleid=1163> accessed 21 November 2012

Vanderheiden, S. (2009). Distinguishing Mitigation and Adaptation. Ethics, Place and Environment 12(3): 283-286.

Wade, M. and J. Irvine (2012). 'Incomes Rising but Families Caught in Housing Squeeze'. The Sydney Morning Herald $<$ http://www.smh.com.au/national/incomes-rising-but-families-caught-inhousing-squeeze-20120621-20r1v.html> accessed 27 June

Waitt, G., P. Caputi, C. Gibson, C. Farbotko, L. Head, N. Gill and E. Staynes (2012). Sustainable Household Capability: Which Households Are Doing the Work of Environmental Sustainability? Australian Geographer 43(1): 51 - 74.

Watson, M. and R. Lane (2011). Mapping Geographies of Reuse in Sheffield and Melbourne. In Material Geographies of Household Sustainability. R. Lane and A. Gorman-Murray, Eds. Ashgate, Farnham Surrey England: 133-155.

Whitmarsh, L., G. Seyfang and S. O'Neill (2011). Public Engagement with Carbon and Climate Change: To What Extent Is the Public 'Carbon Capable'? Global Environmental Change 21(1): 56-65.

Wilkenfeld, G., C. Hamilton and H. Saddler (1995). Australia's Greenhouse Strategy: Can the Future Be Rescued: Discussion Paper Number 3, The Australia Institute, Canberra.

<https://www.tai.org.au/file.php?file=discussion papers/DP3.pdf> accessed 22 November 2012

Winston, N. (2009). Urban Regeneration for Sustainable Development: The Role of Sustainable Housing? European Planning Studies 17(12): 1781-1796.

WMAwater (2011a). Lake Macquarie Waterway Flood Risk Management Study and Plan: Public Exhibition Copy, Lake Macquarie City Council. <http://www.lakemac.com.au/downloads/Exhibition\%20LakeMacFloodRisk\%20\%20low\%20res.pdf> accessed 12 July 2012

WMAwater (2011b). Lake Macquarie Waterway Flood Study: Public Exhibition Copy, Lake Macquarie City Council. <http://www.lakemac.com.au/downloads/Lake\%20Macquarie\%20Flood\%20Stu dy\%20-\%20Part\%201.pdf > accessed 21 September 2012

Wood, A. (2012) 'Carbon Tax Payments Taken in Rent Grab', The Daily Telegraph, Sydney, Australia, 15 June 2012 


\section{APPENDIX 1: LIST OF TENANT RESOURCE DOCUMENTS ANALYSED}

Alternative Technology Association (2009). 'Renters Guide to Sustainable Living'. $<$ http://www.ata.org.au/wp-content/sustainability/ata_renters_guide_sustainabili ty.pdf > accessed 4th April

Environment Victoria (2012). 'Things you can do right now (no need to speak to your landlord first)'. <http://environmentvictoria.org.au/content/things-you-can-do-right-nowwithout-speaking-your-landlord-first> accessed 20th March 2012

Environment Victoria and Tenants Union of Victoria Ltd (2010). The Victorian Green Renters' Guide Sustainable living tips for renters. <http://environmentvictoria. org.au/sites/default/files/Renters $\% 27 \% 20$ guide $\% 20$ edition $\% 202 \% 20$ web\%20version.p $\mathrm{df}>$

Green Renters (2012). 'Green Renters'. <http://www.greenrenters.org/> accessed 29th May

Just Change (2012, 2008). 'About Just Change'. <http://www.justchangeaustrali a.org/aboutjustchange.html> accessed 29th May 2012

Lake Macquarie City Council (2010, 6th April 2010). 'Ecological Footprint'. Lake Macquarie City Council <http://www.lakemac.com.au/page.aspx?pid=10 13\&vid=14> accessed 12th June

Lake Macquarie City Council (2012a). 'Sustainable Living'.

<http://www.lakemac.com.au/environment/sustainable-living> accessed 29th May 2012

Lake Macquarie City Council (2012b). 'Workshops'.

<http://www.lakemac.com.au/environment/workshops> accessed 24th July 2012

LJ Hooker (2012a). 'Liveability'. LJ Hooker <http://www.liveability.com.au/> accessed 29th May 2012

LJ Hooker (2012b). 'Rent Smart'. LJ Hooker <http://www.liveability.com.au/wpcontent/uploads/2012/09/Renters-Guide_Final3.pdf> accessed 9th October 2012

McCann, J. (2010). 'Green living for renters'. Issue \#26, May/June 2010. G-Magazine <http://www.gmagazine.com.au/features/2185/green-living-renters> accessed 20th March 2012

Nature Conservation Council NSW (2012). 'NSW Sustainable Renting Guide'. Nature Conservation Council NSW, <http://nccnsw.org.au/sites/default/files/NSW\%20Sustainable\%20Renting\%20Guide\%2 Ow\%20NRMA\%20logo.pdf> accessed 4th April 2012 
NSW Department of Fair Trading (2011). Starting a Tenancy: Information for Tenants. State of NSW, Parramatta.

$<$ http://www.fairtrading.nsw.gov.au/pdfs/Tenants_and_home_owners/Starting_a_tenan cy_information_for_tenants.pdf> accessed 12 July 2012.

NSW Department of Fair Trading (2012a). Renting a Home: During a Tenancy. State of NSW, Parramatta.

<http://www.fairtrading.nsw.gov.au/Tenants_and_home_owners/Renting_a_home/Duri ng_a_tenancy.html> accessed 12 July 2012

NSW Department of Fair Trading (2012b). Renting a Home: Ending a Tenancy. State of NSW, Parramatta.

<http://www.fairtrading.nsw.gov.au/Tenants_and_home_owners/Renting_a_home/Endi ng_a_tenancy.html> accessed 12 July 2012

NSW Department of Family and Community Services (2012). 'Welcome to your home, information to help you save energy and water'. Housing NSW

$<$ www.housing.nsw.gov.au/NR/.../Welcometoyourhomebooklet.pdf> accessed 31st July

Reduce your footprint (2012). 'About'.

<http://reduceyourfootprint.com.au/pages/about/> accessed 31st July 2012

The City of Newcastle (2011). Newcastle 2030. Our Vision for a Smart, Liveable and Sustainable City. The City of Newcastle Future City group

<http://www.newcastle.nsw.gov.au/_data/assets/pdf_file/0007/146554/Newcastle_203

0_Publication_final_web.pdf>

The City of Newcastle (2012). 'Climate Cam: Residential Sector'.

<http://www.newcastle.nsw.gov.au/environment/climate_cam/residential_sector> accessed 24th July 2012 


\section{APPENDIX 2: LIST OF MEDIA DOCUMENTS ANALYSED}

AAP (2012) 'NSW public housing rent to rise, slightly', AAP News, Australia, 14 June 2012

AAP (2012) 'WA backflips on carbon tax compensation', AAP News Australia, 21 April 2012

AAP (2012) 'MPs petition against pension rent gouge', AAP News Australia, 20 April 2012

ABC (2012). 'Action urged on Hunter's chronic housing crisis'. Online News Article $<$ http://www.abc.net.au/news/2012-06-08/action-urged-on-hunter27s-chronic-housingcrisis/4059842> accessed 8 June 2012

ABC (2012). 'Hunter experiencing chronic public housing shortage'. Australian Broadcasting Association <http://www.abc.net.au/news/2012-05-14/hunterexperiencing-chronic-public-housing-shortage/4009056> accessed 9 July 2012

ABC Radio National (2012a). 'This Rental Life'. Life Matters.

<http://www.abc.net.au/radionational/features/this-rental-life/> accessed 9 July 2012

ABC Radio National (2012b). 'This Rental Life (Part 1): the portable oasis: renters are gardeners too!'. Life Matters.

<http://www.abc.net.au/radionational/programs/lifematters/this-rental-life/4053658>

accessed 9 July 2012

Anderson, S. (2012) 'Canberra's rental crisis 'worst' of any city in the country', The Sydney Morning Herald, Sydney, Australia, Fairfax, 1 May 2012

Australian Associated Press (2012) 'WA backflips on carbon tax compensation', AAP News Australia, 21st April 2012

Bartok, D. (2012) 'Pensioner angry at rent rise', Parramatta Advertiser Sydney, Australia, 4 July 2012

Bulletin Wire (2012) 'O'Farrell defends NSW rent hike', Bulletin Wire, Australia, 15 June 2012

Caldwell, A. and K. Helbig (2012) 'Battlers' carbon payments under rent hike threat', The Courier Mail, Brisbane, Australia, 9 July 2012

Canberra Times (2011) ' Greens push for sustainable rentals', Canberra Times, Canberra, Australia, 12 April 2012

Clement, J. (2012) 'O'Farrell's grab for cash - carbon tax supplement wiped out by rental increases', Canterbury-Bankstown Express, Sydney, Australia, 26 June 2012

Coorey, P. and D. Wroe (2012) 'O'Farrell accused of carbon tax compo raid', The Sydney Morning Herald, Sydney, Australia, 20 June 2012 
Cullen, S. (2012, 29th June). 'Governments failing on housing affordability'.

$<$ http://www.abc.net.au/news/2012-06-29/governments-failing-to-curb-rental-stressreport/4099176> accessed 9 July 2012

Dickson, L. (2011) 'Fresh take on the Tenancy Act alters slightly the tenant-landlord balance', Manly Daily Sydney, Australia, 22 January 2011

Dolan, K. (2011) 'Help wanted to keep things fair - RENTAL', The Age, Melbourne, Australia, 23 July 2011

Dolan, K. (2011) 'Light-bulb moment for landlords', The Age, Melbourne, Australia, 10 September 2011

Dolan, K. (2012) 'Life on the great dividing range', The Age, Melbourne, Australia, Fairfax, 10 July 2012

Dolan, K. (2011) 'Tenants left in a financial fix', The Age, Melbourne, Australia, Fairfax, 17 December 2011

Dolan, K. (2011) 'Renters caught in a fix over repairs', The Age, Melbourne, Australia, Fairfax, 12 November 2011

Dolan, K. (2011) 'Three's a crowd', The Age, Melbourne, Australia, 3 December 2011

Dolan, K. (2012) 'From mean streets to green streets', The Age, Melbourne, Australia, 21 April 2012

Dolan, K. (2012) 'Lights out: it's time for bright ideas', The Age, Melbourne, Australia, 24 March 2012

Dolan, K. (2012) 'Take control of your power bills', The Age, Melbourne, Fairfax, 6 August 2011

Drape, J. and A. Bennett (2012) 'Public housing rents up under carbon tax', Nine MSN News, Nine MSN, 14 June 2012

Gurran, N., E. Hamin and B. Norman (2008). Planning for climate change: Leading practice principles and models for sea change communities in coastal Australia, Prepared for the National Sea Change Task Force, July 2008, University of Sydney Hare, J. (2012) 'Eco issue 'not high on the agenda", The Australian, Australia, 30 April 2012

Harrison, D. (2012) 'State may take cut of carbon tax pension rise', The Sydney Morning Herald Sydney, Australia, 3 April 2012

Johanson, S. (2012) 'More renters, fewer outright owners', Sydney Morning Herald, Sydney, Fairfax, 22 June 2012

Kelly, M. (2011) 'Landlords splash out for water efficiency', The Newcastle Herald Newcastle, Australia, 8 February 2011 
Kelly, M. (2012a) 'Higher bond could cover tenants with pets', The Newcastle Herald, Newcastle, Australia, Fairfax, 16 June 2012

Kelly, M. (2012b) 'Streets ahead ', The Newcastle Herald Newcastle, Australia, 26 May 2012

Lacey, S. (2012) 'A new lease of eco life', Sydney Morning Herald, Sydney, Fairfax, 16 June 2012 <http://www.smh.com.au/environment/energy-smart/a-new-lease-of-ecolife-20120614-20b1c.html>

Martins, B. (2012) 'Carbon tax offset taken by rent rise', Fairfield City Champion, Australia, 3 July 2012

McClellan, B. (2012) 'Rent rise a 'cash grab' - pensioners fear increase will wipe out carbon compo ', Blacktown Advocate, Sydney, Australia, 20 June 2012

Melbourne Times Weekly (2012) 'Green up, renters told', Melbourne Times Weekly, Melbourne, Fairfax, 12 June 2012

Nicastri, D. (2011) 'Act gives renters the edge -- Landlords claim new tenancy laws put them on an 'uneven' playing field', Manly Daily Sydney, Australia, 19 January 2011

O'Dwyer, E. (2011) 'Greener at the grassroots - sustainable Sydney special reportsustainable homes ', The Sydney Morning Herald, Sydney, Australia, 12 October 2011

O'Dwyer, E. (2011) 'Overcoming the carbon question - sustainable Sydney special report', The Sydney Morning Herald, Sydney, Australia, Fairfax, 12 October 2011

The Penrith Press (2011) 'See how others live a green life', The Penrith Press Sydney, Australia, 9 September 2011

Pike, B. (2011) 'Cover Story - Home truths for investors', The Daily Telegraph, Sydney, Australia, 9 July 2011

Raimondo, E. (2012) 'Victorian rental vacancies tighten', The Sydney Morning Herald, Sydney, Fairfax, 14 April 2012

Tarala, K. (2011) 'New laws address key tenancy issues', The Newcastle Herald, Newcastle, Australia, Fairfax, 2 February 2011

The Daily Examiner (2012) 'Renters 'betrayed by O'Farrell Govt", The Daily Examiner, Grafton, New South Wales, 2 June 2012

The Standard (2012) 'Free tips on how to easily cut household energy costs', The Standard, Warrnambool, Australia, 17 May 2012

Toohey, S. and J. Fritze (2009). A future focussed housing standard: the case for rental housing standards to help vulnerable households adapt to climate change, VCOSS, Melbourne 
Tovey, J. (2012) 'O'Farrell accused of 'grab' at pensioner carbon rebate', The Sydney Morning Herald, Sydney, Australia, 15 June 2012

Wade, M. and J. Irvine (2012). 'Incomes rising but families caught in housing squeeze'. The Sydney Morning Herald <http://www.smh.com.au/national/incomes-rising-butfamilies-caught-in-housing-squeeze-20120621-20r1v.html> accessed 27 June

Wood, A. (2012) 'Carbon tax payments taken in rent grab', The Daily Telegraph, Sydney, Australia, 15 June 2012 


\title{
APPENDIX 3: LIST OF LEGISLATIVE AND POLICY DOCUMENTS ANALYSED
}

\begin{abstract}
Environmental Planning and Assessment Act 1979 No 203 (see also Environmental Planning and Assessment Amendment Act 2008 No 36), State of NSW, <http://www.legislation.nsw.gov.au/scanview/inforce/s/1/?TITLE=\%22Environmental\%2 OPlanning \%20and $\% 20$ Assessment $\% 20$ Act $\% 201979 \% 20$ No\%20203\%22\&nohits=y> accessed 17 July 2012
\end{abstract}

Protection of the Environment Administration Act No 60, State of NSW, <http://www.austlii.edu.au/au/legis/nsw/consol_act/poteaa1991485/> accessed 20 November 2012

NSW Local Government Act 1993 No 30,

<http://www.legislation.nsw.gov.au/fullhtml/inforce/act+30+1993+CD+0+N\#dict.1> accessed 26 November 2012

Electricity Supply Act 1995 No 94 (amended June 2012), State of NSW, <http://www.legislation.nsw.gov.au/fragview/inforce/act+94+1995+pt.3-div.1sec. $15 a+0+N$ ?tocnav=y> accessed 18 September 2012

Housing Act 2001 No 52, State of NSW, <http://www.legislation.nsw.gov.au/sessionalview/sessional/act/2001-52.pdf> accessed 12 July 2012

Newcastle Local Environmental Plan 2003 No 536, State of NSW, <http://www.legislation.nsw.gov.au/sessionalview/sessional/epi/2003-536.pdf> accessed 12 July 2012

Lake Macquarie Local Environmental Plan 2004 No 116 State of NSW, <http://www.legislation.nsw.gov.au/sessionalview/sessional/epi/2004-116.pdf> accessed 12 July 2012

Newcastle City Centre Local Environmental Plan 2008 No 24, State of NSW, $<$ http://www.legislation.nsw.gov.au/sessionalview/sessional/epi/2008-24.pdf > accessed 12 July 2012

Housing Regulation 2009 No 148, State of NSW,

<http://www.legislation.nsw.gov.au/sessionalview/sessional/sr/2009-148.pdf> accessed 12 July 2012

Residential Tenancies Act 2010 No 42, State of NSW, <http://www.legislation.nsw.gov.au/maintop/view/inforce/act+42+2010+cd+0+N> accessed 12 July 2012

Clean Energy Act 2011 No 131, <http://www.comlaw.gov.au/Details/C2011A00131/Html/Text\#_Toc308513395> accessed 18 July 2012

ABCB (2011). 'Energy Efficiency'. Australian Building Codes Board $<$ http://www.abcb.gov.au/major-initiatives/energy-efficiency> accessed 14 September 2012

AGO (undated). Web page (City of Darebin). 'Tax deductions for energy efficiency improvements in rental properties'. Australian Greenhouse Office, Commonwealth of 


\section{Australia}

<https://www.darebin.vic.gov.au/Files/Tax_Deductions_for_Energy_Efficiency_Improve ments_in_Rental_Properties.pdf> accessed 17 July 2012

Albanese, A. (2011). Media release. 'Australia's First Urban Design 'Protocol". Minister for Infrastructure and Transport

<http://www.minister.infrastructure.gov.au/aa/releases/2011/November/AA227_2011.a spx> accessed 27 November 2012

ALGA (2006). Local Government Roads and Transport Strategy 2006-2016, A. L. G. Association, Canberra.

<http://alga.asn.au/site/misc/alga/downloads/transport/ALGA_TransportStrategy_200616.pdf> accessed 24 September 2012

ALGA (2010). Web page. 'Roads and Transport Strategy 2006-2016'. Australian Local Government Association <http://alga.asn.au/?ID=240> accessed 24 September 2012

ALGA (2012). Web page. 'About ALGA'. Australian Local Government Association <http://alga.asn.au/?ID=42\&Menu=41,81> accessed 24 September 2012

ATA (2012). 'Federal - Renewable electricity STCs'. Alternative Technology Association <http://www.ata.org.au/rebates/federal-recs-renewable-electricity/> accessed 5 June 2012

ATO (2012a). Web page. 'National rental affordability scheme - refundable tax offset and other taxation issues'. Australian Taxation Office, Commonwealth of Australia <http://www.ato.gov.au/businesses/content.aspx?doc=content/00179876.htm> accessed 12 September 2012

ATO (2012b). Rental Properties 2012: guide for rental property owners. ATO, Australian Taxation Office, Commonwealth of Australia, Canberra <http://www.ato.gov.au/content/downloads/ind00313554n17290612.pdf> accessed 11 September 2012

Ausgrid (2012a). Web page. 'Environmental policy'. Ausgrid $<$ http://www.ausgrid.com.au/Common/Aboutus/ /media/Files/Environment\%20and\%20Community/Corporate\%20Responsibility/En viroPolicy2011.pdf> accessed 25 September 2012

Ausgrid (2012b). Web page. 'Network regulation'. Ausgrid <http://www.ausgrid.com.au/Common/Our-network/Network-regulation-andreports/Network-regulation.aspx> accessed 25 September 2012

Ausgrid (2012c). 'Smart Grid Smart City: What will be tested during the program'. Ausgrid <http://www.smartgridsmartcity.com.au/About-Smart-Grid-Smart-City/Whatwill-be-tested-during-the-program.aspx\#pig> accessed 4 October 2012

Australian Bicycle Council (2011a). Web page. 'Australian Local Government Bicycle Account 2011'. Austroads <http://www.austroads.com.au/abc/images/pdf/australian\%20local\%20government\%20 bicycle\%20account\%202011_web.pdf> accessed 22 November 2012

Australian Bicycle Council (2011b). Web page. 'National Cycling Strategy'. Austroads <http://www.austroads.com.au/abc/national-cycling-strategy> accessed 22 November 2012 
Australian Government (2011a). Securing a Clean Energy Future: The Australian Government's Climate Change Plan. Department of Climate Change and Energy Efficiency, Australian Government, Canberra <http://www.cleanenergyfuture.gov.au/wp-content/uploads/2011/07/ConsolidatedFinal.pdf> accessed 14 November 2012

Australian Government (2011b). Securing a Clean Energy Future: The Australian Government's Climate Change Plan in Summary. Australian Government, Canberra $<$ http://www.cleanenergyfuture.gov.au/wp-content/uploads/2011/07/securing-a-cleanenergy-future-summary.pdf> accessed 18 October 2012

Australian Government, State and Territory Governments and Australian Local Government Association (2006). Inter-Governmental Agreement establishing Principles guiding Inter-Governmental Relations on Local Government Matters. Australian Government, Canberra <http://www.dpac.tas.gov.au/_data/assets/pdf_file/0006/46392/Intergovernmental_rel ations_on_local_government_matters.pdf> accessed 24 September 2012

Biscoe, P. (2007). Ecologically Sustainable Development in New South Wales. Paper presented to the 5th Worldwide Colloquium of the IUCN Academy of Environmental Law, Paraty, Brazil, June

Blacktown City Council (2011). Annual Report. B. C. Council, Blacktown City Council, Blacktown

<http://www.blacktown.nsw.gov.au/shadomx/apps/fms/fmsdownload.cfm?file_uuid=F29 D5AAC-5056-991A-C17A-9C4D716FCE37\&siteName=blacktown> accessed 28

September 2012

BMT WBM (2012). Newcastle City-Wide Floodplain Risk Management Study and Plan: Draft Report, The City of Newcastle.

<http://www.newcastle.nsw.gov.au/_data/assets/pdf_file/0003/189570/draft_Newcastl e_City-wide_Floodplain_Risk_Management_Study_and_Plan_-_Exhibition_Copy__March_2012_.pdf> accessed 12 July 2012

BP Alternative Energy (2012). Web page. 'Solar power'. BP

$<$ http://www.bp.com/sectiongenericarticle.do?categoryld=9025019\&contentld=7046515 $>$ accessed 28 September 2012

BP Global (2012). Web page. 'Statistical Review of World Energy: Solar Capacity'. BP <http://www.bp.com/extendedsectiongenericarticle.do?categoryld=9041560\&contentld $=7075261>$ accessed 28 September 2012

Clean Energy Future (2012). Web page. 'Financing clean technologies'. Australian Government <http://www.cleanenergyfuture.gov.au/clean-energy-future/our-plan/cleanenergy-australia/financing-clean-technologies/> accessed 12 September 2012

Clean Energy Regulator (2012). 'Assigning STCs'. Australian Government $<$ http://ret.cleanenergyregulator.gov.au/Certificates/Small-scale-TechnologyCertificates/assigning-stcs> accessed 12 September 2012

COAG (2009). Web page. 'National Partnership Agreement on Social Housing (expired)'. Council of Australian Governments <http://www.coag.gov.au/node/357> accessed 27 September 2012 
COAG (2010). National Strategy on Energy Efficiency. Council of Australian Governments, Commonwealth of Australia, Canberra

<http://www.coag.gov.au/sites/default/files/nsee_update_july_2010.pdf> accessed 11 September 2012

COAG (2012a). Response to the COAG Reform Council's report: Review of Capital City Strategic Planning Systems. COAG Standing Committee on Transport and Infrastructure, Commonwealth of Australia, Canberra <http://www.scoti.gov.au/publications/files/SCOTI_response_to_the_CRC_report.pdf> accessed 5 September 2012

COAG (2012b). Responses to the COAG Reform Council Reports on National Agreements and National Partnerships: Attachment A. Council of Australian Governments, Commonwealth of Australia, Canberra

<http://www.coag.gov.au/sites/default/files/Responses\%20to\%20COAG\%20Reform\%2 0Council\%20Reports.pdf> accessed 10 September 2012

COAG Reform Council (2011). Review of Capital City Strategic Planning Systems. COAG, Australian Government, Canberra

<http://www.coagreformcouncil.gov.au/reports/docs/capital_cities/review_of_capital_cit y_strategic_planning_systems.pdf> accessed 5 September 2012

COAG Reform Council (2012). Affordable Housing 2010-11: Comparing performance across Australia. COAG, Australian Government, Canberra $<$ http://www.coagreformcouncil.gov.au/reports/docs/ah_comparing_10_11/Housing_full \%20report_10-11.pdf> accessed 10 September 2012

Collins, T. (2012) 'Gosford Council's backflip on sea level notifications', Express Advocate, Gosford, 5 July 2012 <http://express-advocategosford.whereilive.com.au/news/story/gosford-councils-backflip-on-sea-levelnotifications/> accessed 18 July 2012

Combet, G. (2010, 22 April 2010). Web page. 'Doorstop: Home Insulation Program'. Australian Government

<http://www.climatechange.gov.au/minister/previous/combet/2010/transcripts/April/tr20 100422.aspx> accessed 12 September 2012

Combet, G. and M. Dreyfus (2010). Press release. 'Cancellation of Green Start program'. <http://climatechange.gov.au/minister/greg-combet/2010/mediareleases/December/mr20101221.aspx> accessed 17 July 2010

ComfortDelgroCabcharge (2012a). Web page. 'ComfortDelGro Cabcharge Environmental Charter'. ComfortDelgroCabcharge <http://www.cdcbus.com.au/IgnitionSuite/uploads/docs/Environmental\%20Plan\%20201 1\%5B1\%5D.pdf> accessed 2 October 2012

ComfortDelgroCabcharge (2012b). Web page. 'Company profile'. ComfortDelgroCabcharge <http://www.cdcbus.com.au/Company-Profile.html> accessed 2 October 2012

Commonwealth Parliament (2011). Clean Energy (Household Assistance Amendments) Bill 2011: Explanatory Memorandum. H. Families, Community Services and Indigenous Affairs, APH, Canberra <http://parlinfo.aph.gov.au/parllnfo/search/display/display.w3p;query=ld\%3A\%22legisla 
tion\%2Fems\%2Fr4662_ems_9787e52d-0307-49c2-a24e-91f3d1b304dd\%22> accessed 18 July 2012

Compass Housing Services (2012). Web page. 'Welcome to Compass Housing'. Compass Housing Services

<http://www.compasshousing.org/site/index.cfm?display=247886> accessed 3 October 2012

Cullen, S. (2012, 29th June). 'Governments failing on housing affordability'. <http://www.abc.net.au/news/2012-06-29/governments-failing-to-curb-rental-stressreport/4099176> accessed 9th July

DCC (2010). Adapting to Climate Change in Australia: An Australian Government Position Paper. Department of Climate Change, Commonwealth Government, Canberra <http://www.climatechange.gov.au/ /media/publications/adaptation/govadapt-climate-change-position-paper.pdf> accessed 17 July 2012

DCCEE (2011). Barriers to Effective Climate Change Adaptation: A Submission to the Productivity Commission. Australian Department of Climate Change and Energy Efficiency, Commonwealth Government, Canberra <http://www.climatechange.gov.au/government/adapt/ /media/government/barriers_to_ adaptation.pdf> accessed 12 July 2012

DCCEE (2012a). Web page. 'Clean energy legislation'. Department of Climate Change and Energy Efficiency, Commonwealth of Australia

<http://www.climatechange.gov.au/government/clean-energy-future/legislation.aspx> accessed 18 July 2012

DCCEE (2012b). 'Coastal adaptation decison pathways projects'. Department of Climate Change and Energy Efficiency, Commonwealth of Australia

<http://www.climatechange.gov.au/government/initiatives/coastal-adaptation-decisionpathways.aspx> accessed 7 November 2012

DCCEE (2012c). 'LivingGreener: Information, how-to's and rebates for sustainable living: Rebates and assistance NSW: Energy and water efficient product information'. Department of Climate Change and Energy Efficiency, Commonwealth of Australia <http://livinggreener.gov.au/rebates-assistance/nsw/energy-water-efficient-appliances> accessed 17 July 2012

DCCEE (2012d). 'LivingGreener: Information, how-to's and rebates for sustainable living: Rebates and assistance NSW: Home Energy Assessment'. Department of Climate Change and Energy Efficiency, Commonwealth of Australia <http://livinggreener.gov.au/rebates-assistance/nsw/home-energy-assessment> accessed 12 July 2012

DCCEE (2012e). 'LivingGreener: Information, how-to's and rebates for sustainable living: Rebates and assistance NSW: LPG Gas Vehicle Conversion'. Department of Climate Change and Energy Efficiency, Commonwealth of Australia $<$ http://livinggreener.gov.au/rebates-assistance/aus/lpg-gas-conversion> accessed 12 July 2012

DCCEE (2012f). Web page. 'National Greenhouse and Energy Reporting'. Department of Climate Change and Energy Efficiency, Commonwealth of Australia <http://www.climatechange.gov.au/reporting> accessed 14 September 2012 
DCCEE (2012g). Web page. 'Residential Building Disclosure'. Department of Climate Change and Energy Efficiency, Commonwealth of Australia

<http://www.climatechange.gov.au/government/initiatives/rbd.aspx> accessed 11 September 2012

DCCEE (2012h). 'What the government is doing'. Department of Climate Change and Energy Efficiency, Commonwealth of Australia

<http://www.climatechange.gov.au/government.aspx> accessed 7 November 2012

De Sousa, D., N. Sommer and J. Thwaites (2010). Planning policy and practice: The right mechanism to tackle climate change? Update September 2010, Maddocks, Melbourne. <http://www.maddocks.com.au/reading-room/a/planning-policy-andpractice-the-right-mechanism-to-tackle-climate-change-update-september-2010> accessed 7 November 2012

DECCW (2009). Lower Hunter Regional Conservation Plan. NSW Department of Environment Climate Change and Water, NSW Government, Sydney <http://www.environment.nsw.gov.au/resources/protectedareas/09812LHRCP.pdf> accessed 17 July 2012

DECCW (2010). Flood Risk Management Guide: Incorporating sea level rise benchmarks in flood risk assessments. Department of Environment,, Climate Change and Water, NSW Government, Sydney

<http://www.environment.nsw.gov.au/resources/water/coasts/10759FloodRiskManGde. pdf $>$ accessed 20 September 2012

DEH (2011a). Floodplain Development Manual: the management of flood liable land. NSW Department of Environment and Heritage, NSW Government, Sydney <http://www.environment.nsw.gov.au/resources/floodplains/2_flood_manual.pdf> accessed 20 September 2012

DEH (2011b, 27 February 2011). Web page. 'New national parks and reserves for the Lower Hunter'. Department of Environment and Heritage, NSW Government $<$ http://www.environment.nsw.gov.au/newparks/hunterdraft.htm> accessed 17 July 2012

DEH (2012, 19 March 2012). Web page. 'NSW Environmental Upgrade Agreement legislation'. NSW Department of Environment and Heritage, NSW Government <http://www.environment.nsw.gov.au/sustainbus/eualegislation.htm> accessed 17 July 2012

Department of Sustainability and Environment, Victoria (2012). Web page. 'Understanding Climate Change: Future Coasts Program'. State Government of Victoria <http://www.climatechange.vic.gov.au/adapting-to-climate-change/futurecoasts> accessed 7 November 2012

DEWHA (2009). Living Sustainably: The Australian Government's National Action Plan for Education for Sustainability. Department of Environment, Water, Heritage and the Arts, Commonwealth of Australia <http://www.environment.gov.au/education/publications/pubs/national-action-plan.pdf> accessed 7 November 2012

DEWHA and DECC (NSW) (2009). ESD Operations Guide for Owners, Managers and Tenants. Department of the Environment Water Heritage and the Arts (Commonwealth of Australia) and Department of Environment and Climate Change NSW, Canberra 
<http://www.environment.gov.au/sustainability/government/publications/pubs/esdoperations-guide.pdf> accessed 12 July 2012

DFS (2011). Environmental Sustainablity Strategy update 2011/12 - 2013/14. NSW Department of Finance and Services, NSW Land and Housing Corporation, Sydney <http://www.housing.nsw.gov.au/NR/rdonlyres/75664B7D-3C8C-4175-AA781941AE7F1BC0/0/EnvironmentalSustainabilityStrategyupdate.PDF> accessed 19 September 2012

DIT (2010). Our Cities - building a productive, sustainable and liveable future. Department of Infrastructure and Transport, Commonwealth of Australia, Canberra $<$ http://www.infrastructure.gov.au/infrastructure/mcu/files/OurCities-Discussion_PaperComplete.pdf> accessed 5 September 2012

DIT (2011). Our Cities, Our Future: A national urban policy for a productive, sustainable and liveable future. Department of Infrastructure and Transport, Commonwealth of Australia, Canberra

<http://www.infrastructure.gov.au/infrastructure/mcu/files/Our_Cities_National_Urban_ Policy_Paper_2011.pdf> accessed 5 September 2012

DIT (2012a). Web page. 'Background - Organisation of Australia's Railways'.

Department of Infrastructure and Transport, Commonwealth of Australia

$<$ http://www.infrastructure.gov.au/rail/trains/background/index.aspx> accessed 4 October 2012

DIT (2012b). Creating places for people: An urban design protocol for Australian cities. Department of Transport and Infrastructure, Commonwealth of Australia, Canberra <http://www.urbandesign.gov.au/downloads/files/INFRA1219_MCU_R_SQUARE_URB AN_PROTOCOLS_1111_WEB_FA2.pdf > accessed 4 October $201 \overline{2}$

DIT (2012c). Web page. 'Roads to Recovery NSW Funding Allocations'. Department of Infrastructure and Transport, Commonwealth of Australia

$<$ http://www.nationbuildingprogram.gov.au/funding/r2r/r2r_nsw_funding_allocations.asp x> accessed 4 October 2012

DLG (undated). Fact sheet. 'Your Council: A Local Government Fact Sheet'.

Department of Local Government, NSW Government

<http://www.dlg.nsw.gov.au/dlg/dlghome/documents/Information/your\%20council\%20fa ctsheet.pdf> accessed 21 September 2012

DoP (2006). Lower Hunter Regional Strategy 2006-31. NSW Department of Planning, NSW Department of Planning, NSW Government, Sydney

<http://www.planning.nsw.gov.au/regional/pdf/lowerhunter_regionalstrategy.pdf> accessed 2 October 2012

DoP (2006b). 'New smoke alarm requirements: Owners of houses, residential flats and units '. NSW Department of Planning, NSW Government

<http://www.planning.nsw.gov.au/smokealarms/pdf/smoke_alarms_owners_factsheet1. pdf> accessed 17 July 2012

DoP (2010a). Newcastle-Lake Macquarie Western Corridor Planning Strategy. NSW

Department of Planning, NSW Government, Sydney

<http://www.planning.nsw.gov.au/regional/pdf/lowerhunter_regionalstrategy.pdf> accessed 18 September 2012 
DoP (2010b). NSW Coastal Planning Guideline: Adapting to sea level rise. NSW Department of Planning, NSW Government

<http://www.planning.nsw.gov.au/LinkClick.aspx?fileticket=VYjmQirQIAk\%3d\&tabid=17 7\&language=en-US $>$ accessed 12 July 2012

DoP (2011). BASIX: Five Year Outcomes Summary. NSW Department of Planning, NSW Government, Sydney

<https://www.basix.nsw.gov.au/docs/monitoring/BASIX_Five_Year_Outcomes_Summa ry.pdf> accessed 17 September 2012

DoP (2012a). 'Enews 9 July 2012: Housing initiatives receive financial boost'. NSW Department of Planning, NSW Government <https://promo-manager.serversecure.com/em/message/email/view.php?id=674945\&u=2204> accessed 16 July 2012

DoP (2012b). 'A new planning system for New South Wales: Frequently asked questions'. NSW Department of Planning, NSW Government

<http://www.planning.nsw.gov.au/LinkClick.aspx?fileticket=mUCmiR8mDr8\%3d\&tabid= 68\&language=en-US> accessed 16 July 2012

DoP (2012c). A New Planning System for NSW: Green Paper. NSW Department of Planning, State of NSW, Sydney

<http://www.planning.nsw.gov.au/LinkClick.aspx?fileticket=fUggrUzDe3A\%3d\&tabid=6 8\&language=en-US> accessed 16 July 2012

DoPI (2009). Information statement. 'Outer Metropolitan Sydney Bus Contract Regions 1, 2, 3 and 4: Lower Hunter/Lake Macquarie Region. Information about people, facilities, services and travel patterns to support the process of consultation with stakeholders'. NSW Department of Transport and Infrastructure, NSW Government $<$ http://www.transport.nsw.gov.au/sites/default/file/abouttrans/Outer-Metro-Regions-12-3-4.pdf> accessed 2 October 2012

DoPI (2011a). Fact sheet. 'Amendments to State Environmental Planning Policy (Affordable Rental Housing) 2009'. NSW Department of Planning and Infrastructure, NSW Government <http://www.planning.nsw.gov.au/LinkClick.aspx?fileticket=drMAlh9x_4\%3d\&tabid=313\&language=en-AU> accessed 4 October 2012

DoPI (2011b). Web page. 'Planning Reform Fund'. NSW Department of Planning and Infrastructure, NSW Government <http://www.planning.nsw.gov.au/planning-reformfund $>$ accessed 20 September 2012

DoPI (2011c). Web page. 'Regional Strategies: Hunter Region: Lower Hunter Regional Strategy'. NSW Department of Planning and Infrastructure, NSW Government <http://www.planning.nsw.gov.au/hunter-region> accessed 17 July 2012

DoPI (2012). Web page. 'Legislation and planning instruments'. NSW Department of Planning and Infrastructure, NSW Government

<http://www.planning.nsw.gov.au/legislation-and-planning-instruments> accessed 20 September 2012

DoT (2012). Web page. 'State Transit Authority of New South Wales'. NSW Department of Transport, NSW Government <http://www.statetransit.info/> accessed 21 September 2012

DoTRMS (2012). Web page. 'Pedestrians'. NSW Department of Transport, Roads and Maritime Services, NSW Government 
<http://www.rta.nsw.gov.au/doingbusinesswithus/lgr/downloads/programs/pedestrians. html> accessed 24 September 2012

DPC (2011). NSW 2021. Department of Premier and Cabinet, NSW Government, Sydney

<http://www.2021.nsw.gov.au/sites/default/files/NSW2021_WEB\%20VERSION.pdf> accessed 12 July 2012

DPC (2012). Web page. 'NSW Local Infrastructure Renewal Scheme'. NSW

Department of Premier and Cabinet, NSW Government

$<$ http://www.dlg.nsw.gov.au/dlg/dlghome/dlg_generalindex.asp?sectionid=1\&mi=6\&ml= 22\&Arealndex=LIRS> accessed 26 September 2012

Dreyfus, M. (2012, 28 February 2012). Web page. 'Renewable Energy Bonus Scheme: Joint Media Release'. Australian Government

<http://www.climatechange.gov.au/en/minister/mark-dreyfus/2012/media-

releases/February/mr20120228.aspx> accessed 12 September 2012

DSEWPC (1992). National Strategy for Ecologically Sustainable Development.

Department of Sustainability, Environment, Water, Population and Communities,

Commonwealth of Australia, Canberra

<http://www.environment.gov.au/about/esd/publications/strategy/intro.html\#WIESD> accessed 13 November 2012

DSEWPC (2010). Web page. 'Intergovernmental Agreement on the Environment'. Department of Sustainability, Environment, Water, Population and Communities, Commonwealth of Australia

<http://www.environment.gov.au/about/esd/publications/igae/index.html> accessed 8 November 2012

DSEWPC (2012). Assistance to Local Government Authorities for Regional Sustainability Planning: Guidelines. Department of Sustainability, Environment, Water, Population and Communities, Commonwealth of Australia, Canberra

<http://www.environment.gov.au/sustainability/regional-development/pubs/rspprogram-guidelines.pdf> accessed 12 September 2012

Energy Efficiency Working Group of the Select Council on Climate Change (2012).

National Building Energy Standard-Setting, Assessment and Rating Framework: Draft Framework for Consultation. Department of Climate Change and Energy Efficiency, Australian Government, Canberra

$<$ http://www.climatechange.gov.au/government/submissions/closedconsultations/ /media/government/submissions/nbf/draft-national-building-energystandard-setting-assessment-rating-framework-pdf.pdf> accessed 28 September 2012

Equipment Energy Efficiency Program (E3) (2012). Proof of Concept Residential Energy Monitoring Program: Final Report. Australian Government, Canberra $<$ http://www.energyrating.gov.au/wpcontent/uploads/Energy_Rating_Documents/Library/General/Residential_Energy_Moni toring_Program/Proof-of-Concept-REMP-Final-Report-March-20121.pdf $>$ accessed 11 September 2012

Ernst and Young (2012). Strong foundations for sustainable local infrastructure: Connecting communities, projects, finance and funds. L. G. Department of Regional Australia, Arts and Sport, Australian Government, Melbourne 
<http://www.regional.gov.au/local//gifr/files/20120622-strong-foundations.pdf> accessed 21 September 2012

FACS, N. (2012). 2012-13 Budget. NSW Department of Family and Community Services, NSW Government, Sydney

<http://www.facs.nsw.gov.au/_data/assets/pdf_file/0016/257002/1255_FACSBudget_12-13_LARGEPRINT_WEB.pdf> accessed 26 September $201 \overline{2}$

FACS: Housing NSW (2012a). Web page. 'Aboriginal and Torres Strait Islander: Housing Overview'. NSW Department of Family and Community Services, NSW Government <http://www.housing.nsw.gov.au/Aboriginal+and+Torres+Strait+Islander/Housing/> accessed 26 September 2012

FACS: Housing NSW (2012b). Web page. 'Community Housing Asset Ownership'. NSW Department of Family and Community Services, NSW Government <http://www.housing.nsw.gov.au/Community+Housing+Division/Community+Housing+ Providers/Community+Housing+Asset+Ownership.htm> accessed 26 September 2012

FACS: Housing NSW (2012c). Web page. 'Corporate Structure and Executive Team'. NSW Department of Family and Community Services, NSW Government <http://www.housing.nsw.gov.au/About+Us/Reports+Plans+and+Papers/Annual+Repor ts/2006-2007/Corporate+Structure+and+Executive+Team.htm> accessed 26 September 2012

FaHCSIA (2008). Housing Affordability Fund: The Guidelines. Department of Families, Housing, Community Services and Indigenous Affairs, Commonwealth of Australia, Canberra <http://www.fahcsia.gov.au/sites/default/files/files/housing-support/haf/r1-hafguidelines\%5B1\%5D.pdf> accessed 17 September 2012

FaHCSIA (2012a). Changes to Social Housing in States and Territories. Department of Families, Housing, Community Services and Indigenous Affairs, Commonwealth of Australia, Canberra <http://www.fahcsia.gov.au/our-responsibilities/housingsupport/programs-services/social-housing-initiative/changes-to-social-housing-instates-and-territories> accessed 12 September 2012

FaHCSIA (2012b). Web page. 'Home Energy Saver Scheme'. Department of Families, Housing, Community Services and Indigenous Affairs Commowealth of Australia $<$ http://www.fahcsia.gov.au/our-responsibilities/communities-and-vulnerablepeople/programs-services/financial-management-program/home-energy-saverscheme> accessed 18 October 2012

FAHCSIA (2012c). Web page. 'The Household Assistance Package'. Commonwealth of Australia <http://www.fahcsia.gov.au/household-assistance-package> accessed 18 July 2012

FaHCSIA (2012d). Web page. 'Housing Affordability Fund - Questions and Answers'. Commonwealth of Australia <http://www.fahcsia.gov.au/our-responsibilities/housingsupport/programs-services/housing-affordability-fund/housing-affordability-fundquestions-and-answers> accessed 17 September 2012

FaHCSIA (2012e). Web page. 'Housing Affordability Fund: Background'. Department of Families, Housing, Community Services and Indigenous Affairs, Commonwealth of Australia <http://www.fahcsia.gov.au/our-responsibilities/housing-support/programsservices/housing-affordability-fund\#Link2> accessed 28 September 2012 
FaHCSIA (2012f). Web page. 'National Rental Affordability Scheme'. Department of Families, Housing, Community Services and Indigenous Affairs, Commonwealth of Australia <http://www.fahcsia.gov.au/our-responsibilities/housing-support/programsservices/national-rental-affordability-scheme> accessed 12 September 2012

Farrow, L. (2012) 'Planning laws to end local wars: NSW govt', Herald Sun, Melbourne, 14 July 2012 <http://www.heraldsun.com.au/news/breaking-news/nsw-planning-to-bedepoliticised/story-e6frf7kf-1226425882584> accessed 16 July 2012.

Fridge Buyback (2006). 'Fridge Buyback - Home Page'.

<http://www.fridgebuyback.com.au/> accessed 12 July 2012

Goward, P. (2012). Media release. 'Impact of the Carbon Tax - Social Housing Rents'. NSW Government <http://www.housing.nsw.gov.au/NR/rdonlyres/DEFB53C5-727E458B-A2ED-

3D9806963616/0/IMPACTOFTHECARBONTAXSOCIALHOUSINGRENTS.pdf> accessed 19 September 2012

GreenMoney (2012). Web page. 'Get rewards for recycling'. GreenMoney <http://www.greenmoney.com.au/> accessed 3 October 2012

Grierson, S. (2010). Media release. 'More Affordable Housing for Newcastle'. <http://www.sharongrierson.com/SharonGrierson/Resources/100802\%20compass_hou sing.pdf> accessed 27 September 2012

Harrington, L. and J. Brown (2010). Lessons learnt from the pilot homes (proof of concept). Paper presented to the REMP Workshop, Melbourne, 4 June.

Hepworth, A. (2012) 'Energy rift grows as electricity use wanes', The Australian, Sydney, News Limited, 17 September.

Higgins, E. (2012) 'Councils can jettison UN sea-rise rules', The Weekend Australian, Sydney, News Limited, 8-9 September.

HWC (2011a). Web page. 'About Hunter Water'. Hunter Water Corporation <http://www.hunterwater.com.au/About-Us/FAQs/About-Hunter-Water.aspx> accessed 24 September 2012

HWC (2011b). Web page. 'Hunter Region No Interest Loan Scheme'. Hunter Water Corporation <http://www.hunterwater.com.au/Save-Water/Save-Water-Initiatives/NoInterest-Loan-Scheme.aspx> accessed 4 October 2012

HWC (2011c). Web page. 'IPART and Pricing'. Hunter Water Corporation $<$ http://www.hunterwater.com.au/About-Us/Our-Organisation/Governance/IPART-Pricing.aspx> accessed 24 September 2012

HWC (2011d). Web page. 'Showerhead Exchange'. Hunter Water Corporation <http://www.hunterwater.com.au/Save-Water/Save-Water-Initiatives/ShowerheadExchange.aspx> accessed 4 October 2012

HWC (2011e). Web page. 'Stormwater'. Hunter Water Corporation <http://www.hunterwater.com.au/Water-and-Sewer/Stormwater/> accessed 24 September 2012

Hyder Consulting (2011). Role and Performance of Local Government: Waste and recycling related data and information. Department of Sustainability, Environment, 
Water, Population and Communities, Commonwealth of Australia, Canberra <http://www.environment.gov.au/wastepolicy/publications/pubs/local-government.pdf> accessed 24 September 2012

IEEE (2007). A Brief History of the Sydney County Council Engineering Manual: Volume 1, IEEE, IEEE, Sydney.

<http://www.ewh.ieee.org/r10/nsw/subpages/history/history_electricity_syd_county_cou ncil.pdf> accessed 24 September 2012

IPART. 'Energy Savings Scheme: For householders'. NSW Independent Pricing and Regulatory Tribunal, NSW Government

<http://www.ess.nsw.gov.au/Overview_of_the_scheme/For_householders> accessed 12 July 2012

IPART (2012). 'Newsletter Issue 24, June'. NSW Independent Pricing and Regulatory Tribunal, NSW Government

<http://www.greenhousegas.nsw.gov.au/Documents/Newsletter_Issue\%2024_June201 2.pdf> accessed 12 July 2012

IPART (undated). 'Greenhouse Gas Reduction Scheme'. NSW Independent Pricing and Regulatory Tribunal, NSW Government <http://www.greenhousegas.nsw.gov.au> accessed 12 July 2012

Johnston, C. (2012). Shelter NSW Update: State budget 2012-13, Shelter NSW, Sydney. <www.shelternsw.org.au/> accessed 26 September 2012

Karvelas, P. (2012a) 'ALP fails to deliver on rental housing', The Australian, Sydney, News Limited, 12 September 2012

Karvelas, P. (2012b) 'Crean offloads councils promise', The Australian, Sydney, News Limited, 16 October 2012

Lawson, J., V. Milligan and J. Yates (2012). Housing Supply Bonds - a suitable instrument to channel investment towards affordable housing in Australia?: AHURI Final Report No.188, Australian Housing and Urban Research Institute, Melbourne

LGPMA (2011). Web page. 'Attachment A to BRCWG Report Card on progress of deregulation priorities: Local Government and Planning Ministers' Council - First National Report on Development Assessment Performance 2008/9'. Commonwealth of Australia <http://www.coag.gov.au/node/82> accessed 14 September 2012

LGSA (undated-a). Web page. 'Ecologically Sustainable Development'. Local Government and Shires Association <http://www.lgsa.org.au/policy/ecologicallysustainable-development> accessed 26 November 2012

LGSA (undated-b). Web site. 'Planning for Climate Change: Workshop Package'. Local Government and Shires Association <http://www.lgsa.org.au/policy/planning-forclimate-change> accessed 6 November 2012

Livable Housing Australia (2012). 'Launch of Livable Housing Australia and the Livable Housing Design Quality Mark'. Livable Housing Australia <http://www.livablehousingaustralia.org.au/> accessed 4 October 2012

LMCC (2010). eShorance: Estuarine Shoreline Response to Sea Level Rise, City of Lake Macquarie. <http://www.lakemac.com.au/eshoreance/> accessed 12 July 2012 
LMCC (2011a). Web page. 'Adopt-A-SQID'. Lake Macquarie City Council <http://www.lakemac.com.au/natural-environment/waterways/adopt-a-sqid> accessed 22 November 2012

LMCC (2011b). Environmental Sustainability Action Plan 2011-2018, City of Lake Macquarie.

<http://www.lakemac.com.au/downloads/City\%20of\%20Lake\%20Macquarie\%20Enviro nmental\%20Sustainability\%20Action\%20Plan\%202011-2018.pdf> accessed 12 July 2012

LMCC (2011c). Factsheet. 'Sea Level Rise Policy'. Lake Macquarie City Council $<$ http://www.lakemac.com.au/page.aspx?pid=109\&fid=1176\&ftype=File\&vid=1\&dlp=Tru e> accessed 12 July 2012

LMCC (2011d). Web page. 'Sustainable Neighbourhoods: About the program'. Lake Macquarie City Council <http://www.lakemac.com.au/environment/sustainableneighbourhoods/program> accessed 4 October 2012

LMCC (2012a). Community Plan 2008-2018, City of Lake Macquarie. $<$ http://www.lakemac.com.au/about-council/corporate-planning-andperformance/community-plan-2008-2018> accessed 20 September 2012

LMCC (2012b). Web page. 'Review of lake flooding including sea level rise'. <http://www.lakemac.com.au/page.aspx?pid=1303\&vid=14> accessed 16 July 2012

Maher, S. and A. Hepworth (2012) 'RET falters as splits in energy sector mount', The Australian, Sydney, News Limited, 18 September 2012

McKay, D. and R. Rauscher (2005). ESD Strategies at the Local Government Level: Case Study of the City of Newcastle. Proceedings of the State of Australian Cities Conference, Griffith University Brisbane.

<http://www.griffith.edu.au/_data/assets/pdf_file/0020/81380/environmental-city-21mckay.pdf> accessed 13 July 2012

Miles, K., J. Byrnes and K. Bannon (2010). Review of Regional Water Quality and Security: Review and Reform Strategy I. Australia, AECOM Australia Pty Ltd, Sydney <http://www.infrastructureaustralia.gov.au/publications/files/Review_of_RegionalWater Quality_and_Security_Volume1_251010.pdf> accessed 26 September 2012

National Association of Tenant Organisations, P. Carr and M. Tennant (2010) A Better Lease on Life - Improving Australian Tenancy Law. National Shelter Inc $<$ http://www.shelter.org.au/index.php?option=com_docman\&task=doc_download\&gid= 14\&Itemid=127> accessed 12 July 2012

National Housing Supply Council (2012). Web page. 'Terms of Reference'.

Commonwealth of Australia <http://www.nhsc.org.au/content/reference.html> accessed 3 September 2012

National Transport Secretariat (2003). National Charter of Integrated Land Use and Transport Planning. Commonwealth of Australia, Canberra <http://www.atcouncil.gov.au/documents/files/National_Charter_ATC_MAY_03.pdf> accessed 23 November 2012 
NCC (2003). Newcastle Environment Management Plan. The City of Newcastle <http://www.newcastle.nsw.gov.au/_data/assets/pdf_file/0020/5528/newcastle_enviro nment_manag_plan.pdf $>$ accessed 12 July 2012

NCC (2005). Affordable Housing Strategy. The City of Newcastle, Newcastle <http://www.newcastle.nsw.gov.au/_data/assets/pdf_file/0005/5567/AFFORDABLE_H OUSING_POLICY.pdf> accessed 4 October 2012

NCC (2006). Newcastle Biodiversity Strategy. The City of Newcastle $<$ http://www.newcastle.nsw.gov.au/_data/assets/pdf_file/0015/20823/Newcastle_Biodi versity_Strategy.pdf> accessed 12 July 2012

NCC (2011a). Newcastle 2020: Carbon and Water Management Action Plan. The City of Newcastle

<http://www.newcastle.nsw.gov.au/_data/assets/pdf_file/0006/173364/FINAL_Carbon _Water_MAP_for_Web_secure.pdf> accessed 12 July 2012

NCC (2011b). Newcastle 2030. Our Vision for a Smart, Liveable and Sustainable City. The City of Newcastle Future City group

<http://www.newcastle.nsw.gov.au/_data/assets/pdf_file/0007/146554/Newcastle_203 0_Publication_final_web.pdf> accessed 12 July 2012

NCC (2012a). Web page. 'S149 Planning certificates'. The City of Newcastle <http://www.newcastle.nsw.gov.au/building_and_planning/building_and_development_ advice/s149_planning_certificates> accessed 21 September 2012

NCC (2012b). Media release. 'Spring Water Bug Survey'. City of Newcastle <http://www.newcastle.nsw.gov.au/about_newcastle/news_and_events/media_release s/media_releases/spring_water_bug_survey> accessed 4 October 2012

NCC (2012c). Web page. 'Sustainable Building Advisory Service'. The City of Newcastle <http://www.newcastle.nsw.gov.au/building_and_planning/sustainable_building_adviso ry_service> accessed 20 September 2012

NCCARF (undated). Web page. 'Lake Macquarie City Council, NSW: Response to Sea Level Rise'. National Climate Change Adaptation Research Facility <http://www.nccarf.edu.au/content/lake-macquarie-city-council-nsw> accessed 22 November 2012

NCEE (2006). Learning for Sustainability: NSW Environmental Education Plan 20072010. NSW Council on Environmental Education, Sydney <http://www.environment.nsw.gov.au/resources/cee/2006347_Ifsenvedplan20072010.p df $>$ accessed 14 November 2012

NPHP (2002). The Role of Local Government in Public Health Regulation. National Public Health Partnership, NPHP, Melbourne $<$ http://www.nphp.gov.au/publications/legislation/localgov.pdf> accessed 25 September 2012

NSW DEC (2006). A Guide for Engaging Communities in Environmental Planning and Decision Making. NSW Department of Environment and Conservation, Sydney 
<http://www.environment.nsw.gov.au/resources/warr/2006288_engagingcommunities.p df> accessed 14 November 2012

NSW Department of Fair Trading (2011a). Ending a Tenancy: Information for Landlords. State of NSW, Parramatta.

<http://www.fairtrading.nsw.gov.au/pdfs/Tenants_and_home_owners/Ending_a_tenanc y_information_for_landlords.pdf $>$ accessed 12 July 2012

NSW Department of Fair Trading (2011b). Starting a Tenancy: Information for Landlords. State of NSW, Parramatta.

<http://www.fairtrading.nsw.gov.au/pdfs/Tenants_and_home_owners/Starting_a_tenan cy_information_for_landlords.pdf> accessed 12 July 2012

NSW Department of Fair Trading (2011c). Starting a Tenancy: Information for Tenants. State of NSW, Parramatta.

<http://www.fairtrading.nsw.gov.au/pdfs/Tenants_and_home_owners/Starting_a_tenan cy_information_for_tenants.pdf $>$ accessed 12 July 2012

NSW Department of Fair Trading (2012a). During a Tenancy: Information for Landlords. State of NSW, Parramatta.

<http://www.fairtrading.nsw.gov.au/pdfs/Tenants_and_home_owners/During_a_tenanc y_information_for_landlords.pdf> accessed 12 July 2012

NSW Department of Fair Trading (2012b). Web page. 'National Rental Affordability Scheme'. NSW Government

<http://www.housing.nsw.gov.au/Centre+For+Affordable+Housing/NRAS/> accessed 18 September 2012

NSW Department of Fair Trading (2012c). Renting a Home: During a Tenancy. State of NSW, Parramatta.

<http://www.fairtrading.nsw.gov.au/Tenants_and_home_owners/Renting_a_home/Duri ng_a_tenancy.html> accessed 12 July 2012

NSW Department of Fair Trading (2012d). Renting a Home: Ending a Tenancy. State of NSW, Parramatta.

<http://www.fairtrading.nsw.gov.au/Tenants_and_home_owners/Renting_a_home/Endi ng_a_tenancy.html> accessed 12 July 2012

NSW Department of Fair Trading (2012e). 'Tenants Advice and Advocacy Program'. NSW Government <http://www.fairtrading.nsw.gov.au/About us/Our_services/Grants/Tenants advice an d_advocacy_program.html> accessed 18 September 2012

NSW EDO (2008). Coastal Councils and Planning for Climate Change: An assessment of Australian and NSW legislation and government policy provisions relating to climate change relevant to regional and metropolitan councils, prepared by the NSW

Environmental Defenders Office for the Sydney Coastal Councils Group, Sydney

Coastal Councils Group and NSW Environmental Defenders Office, Sydney.

$<$ http://www.sydneycoastalcouncils.com.au/sites/default/files/coastalcouncilsplanningfo rclimatechange.pdf $>$ accessed 7 November 2012

NSW EDO (2012). 'LEPs and SEPPs'. NSW Environmental Defender's Office <http://www.edo.org.au/edonsw/site/factsh/fs02_1_3.php> accessed 2 October 2012 
NSW Environmental Trust (2010). Annual Report 2009-10, NSW Government, Sydney. <http://www.environment.nsw.gov.au/resources/grants/10899EnviroTrustAR2010.pdf> accessed 26 November 2012

NSW EPA (2012). 'EPA Organisation'. NSW Government <http://www.environment.nsw.gov.au/whoweare/epa.htm> accessed 24 September 2012

NSW Government. Web page. 'Q \& A on BASIX'. NSW Government $<$ https://www.basix.nsw.gov.au/information/q_a_basix.jsp> accessed 17 September 2012

NSW Government (2012a). Draft NSW Long Term Transport Master Plan. NSW Government, Sydney <http://haveyoursay.nsw.gov.au/document/index/21> accessed 21 September 2012

NSW Government (2012). Draft NSW Renewable Energy Action Plan. NSW Department of Resources and Energy, NSW Government, Sydney <http://haveyoursay.nsw.gov.au/document/show/475> accessed 12 September 2012

NSW Health (undated). Web page. 'How to Prepare for a Heat Wave'. State of NSW <http://www0.health.nsw.gov.au/campaigns/beattheheat/prepare_for_heat_wave.asp> accessed 9 November 2012

NSW Ministry for Police and Emergency Services (2008). Web page. 'NSW State Disaster Plan: Supporting Plans'. NSW Government <http://emergency.nsw.gov.au/content.php/479.html> accessed 12 November 2012

NSW Ministry for Police and Emergency Services (2011). Web page. 'NSW State Disaster Plan: Sub Plans'. NSW Government <http://emergency.nsw.gov.au/content.php/534.html> accessed 12 November 2012

NSW OEH. Web page. 'NABERS'. NSW Office of Environment and Heritage, NSW Government <http://www.nabers.gov.au/public/WebPages/Home.aspx> accessed 28 September 2012

NSW OEH (2008). 'Our Environment it's a Living Thing: New Projects'. NSW Office of Environment and Heritage <http://www.livingthing.net.au/PP_Proj_n.htm> accessed 7 November 2012

NSW OEH (2011). Web page. 'A Guide for Engaging Communities in Environmental Planning and Decision Making'. NSW Office of Environment and Heritage <http://www.environment.nsw.gov.au/community/ComEngagement.htm> accessed 14 November 2012

NSW OEH (2012a). Web page. 'Adapting to Climate Change'. Office of Environment and Heritage, NSW Government <http://www.environment.nsw.gov.au/climatechange/adaptation.htm> accessed 6 November 2012

NSW OEH (2012b). 'Environmental Trust'. NSW Office of Environment and Heritage <http://www.environment.nsw.gov.au/grants/envtrust.htm/> accessed 7 November 2012 
NSW OEH (2012c). Web page. 'NSW Council on Environmental Education'. NSW Office of Environment and Heritage

<http://www.environment.nsw.gov.au/cee/index.htm> accessed 7 November 2012

NSW OEH (2012d). Web page. 'Working with other Governments'. Office of Environment and Heritage, NSW Government

<http://www.environment.nsw.gov.au/climatechange/nationalaction.htm> accessed 6 November 2012

NSW Office of Water (2012a). Web page. 'About us'. NSW Government <http://www.water.nsw.gov.au/About-Us/default.aspx> accessed 24 September 2012

NSW Office of Water (2012b). Web page. 'Law and Policy'. NSW Government <http://www.water.nsw.gov.au/Water-management/Law-and-Policy/default.aspx> accessed 24 September 2012

NTU (2008). Factsheet. 'Tenants Rights Factsheets'. Tenants' Union of New South Wales <http://www.tenants.org.au/publish/factsheets/index.php> accessed 19 September 2012

NWC (2011). Web page. 'National Water Initiative'. National Water Commission, Commonwealth of Australia <http://www.nwc.gov.au/reform/nwi> accessed 24 September 2012

O'Connor, B. (2012). Media release. 'Delivering Essential Social Housing for New South Wales'. Australian Government

<http://www.brendanoconnor.fahcsia.gov.au/node/69> accessed 27 September 2012

Parnell, T. and R. Pope (2008). Evaluation of the RTA's Pedestrian Access \& Mobility Plan (PAMP) and Bike Plan Programs (South West Region of NSW), The Centre for Inland Health, Charles Sturt University, Albury/Wodonga.

http://www.csu.edu.au/_data/assets/pdf_file/0004/153967/RTA-PAMP-and-Bike-PlanT-Parnell-Sumary-edited.pdf accessed 1 August 2012

Pillora, S. (2010). Australian Local Government and Climate Change: Working Paper No.1, prepared by the UTS Centre for Local Government for the Australian Centre of Excellence for Local Government, ACELG, Sydney.

<http://www.acelg.org.au/upload/program1/1296541034_Climate_Change_Paper_WE B1.pdf $>$ accessed 7 November 2012

Productivity Commission (2011a). 'Benchmarking Planning, Zoning and Development Assessments: Media release'. Commonwealth of Australia

<http://www.pc.gov.au/projects/study/regulationbenchmarking/planning/report/mediarelease> accessed 12 September 2012

Productivity Commission (2011b). Performance Benchmarking of Australian Business Regulation: Planning, Zoning and Development Assessments. Commomnwealth of Australia, Canberra

http://www.pc.gov.au/projects/study/regulationbenchmarking/planning/report accessed 18 October 2012

Productivity Commission (2012). Electricity Network Regulatory Frameworks: Draft Report. Commonwealth of Australia, Canberra

<http://www.pc.gov.au/projects/inquiry/electricity/draft> accessed 18 October 2012 
Randwick City Council (2012). Web page. 'Waste management'. Randwick City Council $<$ http://www.randwick.nsw.gov.au/Looking_after_our_environment/Waste_managemen t/index.aspx> accessed 3 October 2012

RDA (undated). 'NSW RDA Committees'. Regional Development Australia, Commonwealth of Australia <http://rda.gov.au/my-rda/nsw> accessed 17 September 2012

RDA Hunter (undated). Regional Plan 2010-2020. Regional Development Australia, RDA Hunter, Newcastle

<http://www.rdahunter.org.au/SiteFiles/rdahunterorgau/RDA_Hunter_Regional_Plan_2 010___2020.pdf> accessed 12 September 2012

Reardon, C., G. Milne, C. McGee and P. Downton (2010). Your Home: Technical Manual (4th ed). Australian Government

<http://www.yourhome.gov.au/technical/index.html> accessed 17 September 2012

Robinson, S. (2010) Green landlords: new incentives for green retrofits to existing buildings. Mason Sier Turnbull Lawyers <http://www.mst.com.au/news/green-landlordsnew-incentives-for-green-retrofits-to-existing-buildings> accessed 5 June 2012

RTA (2002). How to Prepare a Pedestrian Access and Mobility Plan: An easy three stage guide. NSW Roads and Traffic Authority, NSW Government, Sydney

<http://www.rta.nsw.gov.au/doingbusinesswithus/downloads/technicalmanuals/mobilityplan_how-to.pdf> accessed 24 September 2012

RTA (2009). Council Projects funded by the RTA: Memorandum of Understanding. NSW Roads and Traffic Authority, NSW Government, Sydney <http://www.rta.nsw.gov.au/trafficinformation/downloads/mou_0609.pdf> accessed 24 September 2012

Sartor, F. (2010). Legislative Assembly 'Agreement in Principle' Speech: Local Government Amendment (Environmental Upgrade Agreements) Bill 2010. State of NSW, Sydney <http://www.parliament.nsw.gov.au/Prod/parlment/nswbills.nsf/0/1bf9d822d9dd2288ca 2577d7001779e6/\$FILE/LA\%2011010.pdf> accessed 12 July 2012

Senior Officials Group on Energy Efficiency (2010). National Partnership Agreement on Energy Efficiency: Annual Report to COAG 2010-11. COAG, Australian Government, Canberra <http://www.coag.gov.au/sites/default/files/npa ee annual report to coag 201011.pdf> accessed 11 September 2012

Sky News (2012, 14 July 2012). 'Business Welcomes NSW Planning Changes'. State of NSW <http://www.skynews.com.au/finance/article.aspx?id=771682> accessed 16 July 2012

TenantsNSW (2012a). Web page. 'About us'. TenantsNSW <http://www.tenants.org.au/publish/about-us/index.php> accessed 18 September 2012

TenantsNSW (2012b). Web page. 'Increase Tenants' Advice Funding Now!'. TenantsNSW <http://www.tenants.org.au/publish/about-us/increase-tenants-advicefunding-now.php> accessed 18 September 2012 
The Allen Consulting Group (2011). Mandatory disclosure of residential building energy, greenhouse and water performance: Consultation Regulation Impact Statement, for the National Framework for Energy Effficiency Building Implementation Committee. <http://ris.finance.gov.au/files/2011/08/03-Mandatory-Disclosure-RIS.pdf> accessed 12 July 2012

The Treasury (2001). Commonwealth National Competition Policy Annual Report 200001. Chapter 7: COAG related reforms (electricity, gas, water, road transport). T. Treasury, Australian Government, Canberra <http://archive.treasury.gov.au/documents/177/PDF/ch7.pdf> accessed 25 September 2012

Transport for NSW (2012). Web page. 'Country Rail Contracts'. NSW Government <http://www.transport.nsw.gov.au/Content/country-rail-contracts> accessed 22 November 2012

TUV (2012). Web page. 'Our history'. Tenants' Union of Victoria <http://www.tuv.org.au/about+us/our+history> accessed 18 September 2012

UN Conference on Environment and Development (1992). The Rio Declaration on Environment and Development. UNEP

$<$ http://www.unep.org/Documents.Multilingual/Default.asp?documentid=78\&articleid=1 163> accessed 21 November 2012

WELS Regulator (2012). Web page. 'What is WELS?'. Australian Government <http://www.waterrating.gov.au/about/index.html> accessed 28 September 2012

Wilkenfeld, G., C. Hamilton and H. Saddler (1995). Australia's Greenhouse Strategy: Can the Future be Rescued: Discussion Paper Number 3, The Australia Institute, Canberra. <https://www.tai.org.au/file.php?file=discussion_papers/DP3.pdf > accessed 22 November 2012

WMAwater (2011a). Lake Macquarie Waterway Flood Risk Management Study and Plan: Public Exhibition Copy, Lake Macquarie City Council.

<http://www.lakemac.com.au/downloads/Exhibition\%20LakeMacFloodRisk\%20\%20low\%20res.pdf> accessed 12 July 2012

WMAwater (2011b). Lake Macquarie Waterway Flood Study: Public Exhibition Copy, Lake Macquarie City Council.

<http://www.lakemac.com.au/downloads/Lake\%20Macquarie\%20Flood\%20Study\%20\%20Part\%201.pdf> accessed 21 September 2012

Wyld Group (2011). Mid-term review of the Solar Cities program. Australian Department of Climate Change and Energy Efficiency, Australian Government, Canberra <http://www.climatechange.gov.au/government/initiatives/solarcities/publications-resources/mid-term-review-solar-cities.aspx> accessed 17 July 2012 


\title{
APPENDIX 4: PRIVATE HOUSING MANAGER INTERVIEW SCHEDULES
}

\author{
INTRODUCTION
}

Before we start, remember that if you feel uncomfortable at any point, you may choose to withdraw from the interview at any time.

Can you tell us how many properties you own/manage in the inner Newcastle/Toronto area?

What sort of properties are in your portfolio? I.e. detached housing, flats, apartments, etc.

How long have you been managing these properties/working as a property manager in this company/previously?

\section{SUSTAINABILITY PRACTICES AND INFRASTRUCTURE ASSETS}

Over that time, have you seen any shifts towards making rental housing more energy and water efficient, or some other changes towards more sustainable housing? If yes, please describe these changes.

Over your time as a housing manager have you noticed any changes in tenant behaviours towards more environmentally-friendly habits in their homes? Are prospective tenants asking for information about energy efficiency, insulation, etc.?

The Residential Tenancies Act 2010 provides incentives to landlords to promote water efficiency. In your experience, have these measures been taken up in the housing you manage? Do you think the amendments have had a positive effect? What are the key barriers to these changes?

Do you think that green lease schedules, as per the commercial sector, could be useful for encouraging environmental change in residential tenancies?

How easy or hard is it to engage landlords with making environmentally-positive changes to their rental properties? Over your time as a housing manager, have you noticed a change in landlords' approach to sustainability?

Does the possibility of climate change affect your work as a rental housing manager? If yes, can you describe what is being done in response to the possible impacts of climate change [flood, extreme weather events, hotter days]

\section{MAINTAINING ASSETS}

Can you talk about property maintenance and whether sustainability principles are built into maintenance contracts and practices?

Can you describe the extent (if any) of retrofitting of rental housing to enhance its sustainability? e.g. energy efficiency, insulation, solar power, flow-reduction taps and showerheads, water tanks, etc. How are decisions made regarding retrofitting properties to make them more sustainable? Who initiates action?

INFORMATION ASSETS AND NETWORKS 
Can you talk about how the policies or legislation /regulation (if any) regarding sustainability and/or climate change impact on the work you do and the housing you manage?

Is there any information on sustainability or climate change in your real estate training, or in materials circulated from bodies such as the REIA?

What sorts of issues, if any, are discussed in real estate circles about sustainability and climate change? Can you describe these and the sort of opinions that are presented?

Can you tell us what are your main sources of information about climatic change?

Do you have conversations with colleagues, in your workplace, or in other agencies, about climate change? If yes, who is involved in these conversations, and what sorts of issues and actions are discussed?

Do private landlords and real estate agents provide any information or help for tenants that will help them live more sustainably? If yes, please describe what is provided and whether you think it has made a difference. If not, do you think this would be useful?

[Depending on outcome of earlier question regarding changes in tenants' behaviour/requests] Have you noticed any changes in what tenants want in a rental property, are they asking about energy and water efficiency or requesting permission for changes? If yes, please describe? [plus other specific changes such as fixing doors or windows]. When did you notice these changes occurring? In a particular sector of the rental market? Or particular group of tenants?

\section{BARRIERS AND OPPORTUNITIES FOR CHANGE}

What do you see as the major constraints on improving the sustainability of rental housing?

The split incentive between tenants and landlords is often cited as a key barrier to change in the sector. Do you think this is the case? How does it manifest? What could be done to overcome these issues?

Have you experienced difficulties in motivating a) landlords and b) tenants to change practices towards better sustainability in the rental sector?

What do you think are the opportunities for real estate agents/housing managers to help to improve adaptation to climate change in the future?

\section{FUTURE POSSIBILITIES}

What would motivate or inspire you to promote action to adapt to potential climate change impacts in your business?

Do you think there is scope for improving the environmental initiatives of the REIA? What would this involve?

What training would you find useful (if any) in building the capacity of you as a professional, and your organisation, to respond to climate change?

What do you think are the three most important changes that could be made to make the private rental sector more sustainable and more prepared for climate change impacts? Who should be involved in making these changes? 


\title{
APPENDIX 5: PUBLIC HOUSING MANAGER INTERVIEW SCHEDULES
}

\author{
INTRODUCTION
}

Before we start, remember that if you feel uncomfortable at any point, you may choose to withdraw from the interview at any time.

Can you tell us what your position is within Housing NSW and what your main duties are?

How long have you been working in this position/Housing NSW?

Can you describe the sorts of properties you manage and how many?

Can you describe the sustainability or environmentally-friendly features (if any) of the properties that you manage.

\section{SUSTAINABILITY PRACTICES AND INFRASTRUCTURE ASSETS}

Housing NSW has commenced a sustainability program [name of program] - can you tell us what you know about how that program got started and what has happened since it began?

Have you had a role in this program, and/or has your job as a housing manager changed because of the program?

What would you say are the most successful features of the program?

What changes, if any, do you think need to be made to make the sustainability program more effective?

Across your years with Housing NSW, have you noticed a change in the organisation's approach to sustainability?

[for housing officers who deal with tenants] In your opinion, are tenants satisfied with the sustainability features of their homes? Can you describe what sorts of things they say to you/changes they want? How do they let you know/How do you find out?

In your experience, do tenants generally undertake some level of environmentallyfriendly/sustainability activities in their homes? Can you describe the sorts of things that tenants do? Have these activities changed over time? Are more or less people doing these activities now than when you stated your job with Housing NSW?

What do you think climate change means for Housing NSW and its tenants?

\section{MAINTAINING ASSETS}

Can you describe what is being done in response to the possible impacts of climate change for new and existing housing? [e.g. to respond to flood, extreme weather events, hotter days]

What impact do you think the split between asset and tenancy management will have on these responses to climate change? 
[For asset managers] Can you talk about property maintenance and whether sustainability principles are built into maintenance contracts and practices?

[For tenancy managers] What are your views about property maintenance and whether sustainability principles are built into maintenance contracts and practices?

Can you describe the extent (if any) of retrofitting of Housing NSW housing stock to enhance its sustainability? e.g. energy efficiency, insulation, solar power, flowreduction taps and showerheads, water tanks, etc. How are decisions made in regards to retrofitting properties to make them more sustainable?

Is any use made of schemes such as Green Stars for buildings, or Green Lease Schedules, in maintaining or building Housing NSW assets?

\section{INFORMATION ASSETS AND NETWORKS}

Can you talk about how the policies or legislation /regulation (if any) regarding sustainability and/or climate change impact on the work you do and the housing stock of Housing NSW.

Do you have conversations with colleagues, in your workplace, or in other agencies, about climate change? If yes, who is involved in these conversations and what sorts of issues and actions are discussed?

Can you tell us what are your main sources of information about climate change?

Does Housing NSW provide any information or help for tenants that will help them live more sustainably? If yes, please describe what is provided and whether you think it has made a difference.

\section{BARRIERS TO CHANGE}

What do you think are the major barriers to change in preparing Housing NSW housing stock for the potential impacts of climate change? [e.g. floods, hotter days, extreme weather events]

What are the major opportunities in this regard?

What do you think are the major barriers to change in preparing Housing NSW housing staff and work practices for the potential impacts of climate change?

What are the opportunities in this regard?

\section{FUTURE POSSIBILITIES}

Do you think there is scope for improving the environmental performance of Housing NSW? What would this involve?

What training would you find useful (if any) in building the capacity of you as a professional, and the organisation, to respond to climate change?

What do you think are the three most important changes that could be made to make the rental sector in general more sustainable and more prepared for climate change impacts? Who should be involved in making these changes? 


\section{APPENDIX 6: TENANT INTERVIEW SCHEDULES}

\section{INTRODUCTION}

Before we start, remember that if you feel uncomfortable at any point, you may choose to withdraw from the interview at any time.

Can you tell us how long you've lived in this house/flat/apartment?

Apart from yourself, who else lives here? (i.e. friends, children, spouse, etc.)

Do you rent this house from a private landlord, or through a real estate agent, or from Housing NSW?

Can you describe your house/flat/apartment for us ... (prompt ... whatever comes to mind)

Tell us about the features

- about this house do you like most and ...

- $\quad$ which features do you like least?

- (prompts: inside/outside/community/location)

\section{SUSTAINABILITY PRACTICES AND INFRASTRUCTURE ASSETS}

Can you show us ...

... any physical aspects of the house/flat/apartment that you'd describe as being environmental (and/or un-environmental) or that help you behave in an environmentally-friendly or sustainable way at home. For instance solar power, water reduction showerhead?

Inside/outside/location

... any practices you do on a daily or regular basis that help conserve energy, water, reduce waste or help the environment in some way? Inside, outside, wider community. If yes, can you describe what you do and how often you do these things. Do these habits and practise vary seasonally? Can you show us what you do in different seasons?

... any features about your dwelling or location that make it hard for you to be environmentally-friendly or sustainable in your daily practices? ... inside/outside/wider community

When you first rented this dwelling, did you look for or consider its environmental qualities? For example, did you look for energy efficiency, water-reduction showerheads, or other features (such as location e.g. close to transport, comfortable climate)? Can you show us what was already here?

Since you moved here, has your real estate agent or landlord made any adjustments to the house/flat/apartment to make it more sustainable? If so can you show us what these are - did you request them - how are they working from your point of view? 


\section{MOTIVATION TO ACT}

Can you talk about what inspires or motivates you to make the changes you've talked about/ undertake these practices / take these actions?

Is sustainable living, or being environmentally-friendly important to you? If yes, can you tell us what you think it means to live sustainably?

Does the possibility of climate change motivate you to become more sustainable? If yes, can you tell us what you know about climate change and how you think it might affect you. Do you think it poses any issues for your home?

Does the possibility of climate change affect how you behave in your daily life / in your home / or where you live? If yes, can you describe what you do in response to the possible impacts of climate change [flooding, hot days, extreme weather events].

\section{INFORMATION ASSETS AND NETWORKS}

Can you tell us what are your main sources of information about climate change?

Have you received any information from your housing manager/officer or landlord about sustainability or climate change? If not, would you like to?

Do you talk with other tenants about making your homes more sustainable?

Do you have conversations with friends / family / others about climate change. If yes, what sorts of issues and actions are discussed?

Thinking about the environmentally-friendly actions that you take around your home, can you tell us where or from whom you got the idea or information on what to do.

\section{BARRIERS AND OPPORTUNITIES FOR CHANGE}

As a renter, do you feel constrained in any way as to the sorts of environmental-friendly practices or changes you can make?

Do you think your landlord or real estate agent is motivated to make your dwelling more environmentally-friendly?

Do you talk to your housing officer/housing manager/landlord?

Have you asked your housing officer/housing manager/landlord for anything to be changed to make your home more sustainable? Why?/why not? What happened as a result?

Has your housing manager/housing officer/landlord changed since you've lived here?

Are there specific changes you would like your landlord to make to your home?

Do the conditions of your lease and bond or the Residential Tenancies Act -help or hinder your environmentally-friendly behaviour?

[for Housing NSW tenants] Do you feel more able to make sustainability changes to your house than if you were in a private rental? 
Do you think there are actions that housing officers/housing managers/or landlords could do towards enhancing the sustainability of rental properties? If yes, what are these?

\section{FUTURE POSSIBILITIES}

[If not already answered] What would motivate or inspire you to take action to adapt to potential climate change impacts? [more time, energy, knowledge?]

Is there anything that you haven't mentioned which you would like to tell us?

What do you think are the three most important changes that could be made to make the rental sector more sustainable and more prepared for climate change impacts? Who should be involved in making these changes? 


\section{APPENDIX 7: FOCUS GROUP SCHEDULES}

\section{Preamble}

Everybody has a contribution they bring towards improving sustainability in the rental housing sector. This focus group is inspired by the concept that we all have important assets - personal, organisational, financial, knowledge, ideas, skills, talents, physical that can contribute in different ways towards improving the world and how we can live in it in the face of climate change. This type of approach - called an asset-based approach - believes that by bringing these skills, ideas and other assets together, we can work collectively to achieve positive change.

Rental housing is sometimes considered as a sector with deficiencies and needs. In this focus group we'll be thinking about the sector as an arena full of skills, talents and possibilities. Today, we'll be doing a number of activities such as brainstorming, mapping, discussing and planning. Some of these activities will be in small groups and others will involve the whole group. We'll be sharing ideas and working towards coming up with some recommendations for the future.

\section{Privacy}

Before we start, remember that if you feel uncomfortable at any point, you may choose to withdraw from the group at any time.

We also encourage everyone to respect each other's privacy and to make sure that individuals are not mentioned by name in discussion about the issues afterwards.

Focus group activities:

Mapping personal assets (pairs then to butchers paper for whole group to see)

Assets: Gifts, talents, dream, hopes, fears

Mapping the sector assets (pairs then to butchers paper)

Assets: Physical, associations, economy, institutions, individuals

\section{Uncovering assets (small groups 3-4 then butchers paper)}

What have you done that has been successful in your home, business or workplace that you would like to share with others?

What motivates you to do these activities?

Watch best practice videos. Discuss and add ideas to butchers paper.

What would a sustainable rental housing sector look like?

Identifying areas for building capacity (whole group - scribe writes responses to butchers paper)

Looking around the room at the various assets (on butchers paper) what do you think are the most important assets for making the rental housing sector more sustainable? 
What are the other building blocks that need to be in place for the rental sector to prepare for climate change?

Who needs to be involved?

\section{Building better worlds (whole group discussion)}

What motivates you to make changes? And how can we motivate others?

How can we use the assets we've identified today to more effectively work towards sustainable living and dwellings?

How can we work together better, for everyone's benefit? How might this happen?

Recommendations (small groups (3-4) write recommendations and report back to whole group)

What do you think are the most inspiring and practical ideas from today's discussion?

Who needs to be informed about these proposals?

What should happen next? 


\section{APPENDIX 8: LIST OF COMMUNITY GROUPS CONTACTED TO RECRUIT TENANTS}

(reason for selection as part of tenant recruitment process is shown in brackets)

Fig Tree Community Garden (sustainability)

Australian Youth Climate Coalition Newcastle (climate change)

Beanstalk Organic Food Cooperative (sustainability)

Carrington Community garden (sustainability)

Climate Action Newcastle (climate change)

Compass Housing (housing)

Hunter Regional Landcare Network (environment)

Hunter Tenants Advice Service (housing)

Islington Community Group (potential tenant membership)

Lake Macquarie Climate Action (climate change)

Lake Macquarie Landcare Resource Centre (environment)

March Street Community Gardens (sustainability)

McAuley Community Housing (housing)

Newcastle Sunrise Rotary (potential tenant membership)

Newcastle University Environment Collective (environment)

Pacfic Link (housing)

Permaculture Hunter (sustainability)

Newcastle Probus (potential tenant membership)

Probus Club of Toronto (potential tenant membership)

Rising Tide (climate change)

Sandhills Community Garden (sustainability)

Tear Australia Newcastle Group (sustainability)

The Wilderness Society Newcastle (environment)

Tighes Hill Community Garden (sustainability)

Tighes Hill Community Group (potential tenant membership)

Toronto and Districts Garden Club Inc. (potential tenant membership)

Toronto Macquarie Ladies Probus (potential tenant membership)

Toronto Sustainable Neighbourhood Group (sustainability)

Transition Newcastle (sustainability)

United Residents Groups for the Environment of Lake Macquarie (URGE)

(environment)

Wesley Mission (potential tenant membership) 



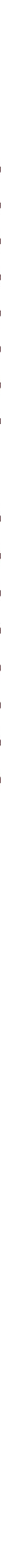

